Florida International University

FIU Digital Commons

FIU Electronic Theses and Dissertations

University Graduate School

$11-4-2020$

\title{
Organic-Inorganic Halide Perovskite Nanocrystals and Solar Cells
}

Rui Guo

rguo003@fiu.edu

Follow this and additional works at: https://digitalcommons.fiu.edu/etd

Part of the Condensed Matter Physics Commons, Materials Chemistry Commons, and the Semiconductor and Optical Materials Commons

\section{Recommended Citation}

Guo, Rui, "Organic-Inorganic Halide Perovskite Nanocrystals and Solar Cells" (2020). FIU Electronic Theses and Dissertations. 4582.

https://digitalcommons.fiu.edu/etd/4582

This work is brought to you for free and open access by the University Graduate School at FIU Digital Commons. It has been accepted for inclusion in FIU Electronic Theses and Dissertations by an authorized administrator of FIU Digital Commons. For more information, please contact dcc@fiu.edu. 


\section{FLORIDA INTERNATIONAL UNIVERSITY \\ Miami, Florida}

ORGANIC-INORGANIC HALIDE PEROVSKITE NANOCRYSTALS AND SOLAR

\section{CELLS}

A dissertation submitted in partial fulfillment of

the requirements for the degree of

DOCTOR OF PHILOSOPHY

in

PHYSICS

by

Rui Guo

2020 
To: Dean Michael R. Heithaus

College of Arts, Sciences and Education

This dissertation, written by Rui Guo, and entitled Organic-Inorganic Halide Perovskite Nanocrystals and Solar Cells, having been approved in respect to style and intellectual content, is referred to you for judgment.

We have read this dissertation and recommend that it be approved.

Yesim Darici

Kevin O'Shea

Nezih Pala

Xuewen Wang

Wenzhi Li, Major Professor

Date of Defense: November 4, 2020

The dissertation of Rui Guo is approved.

Dean Michael R. Heithaus

College of Arts, Sciences and Education

Andrés G. Gil

Vice President for Research and Economic Development and Dean of the University Graduate School

Florida International University, 2020 
(C) Copyright 2020 by Rui Guo

All rights reserved. 


\section{DEDICATION}

I am dedicating this dissertation to my parents and my wife for their endless love, support, and encouragement. 


\section{ACKNOWLEDGMENTS}

It has been a joyful time in my life to conduct my Ph.D. studies at Florida International University. I would like to thank the following people, without whom my research would not have been possible.

First of all, I would like to express my deepest gratitude to my supervisor Prof. Wenzhi Li, for his consistent support, patience, and encouragement. His valuable guidance always kept me on the right path during my whole Ph.D. study at FIU. I particularly thank him for encouraging me to publish my research!

I would like to extend my sincere thanks to my committee members, Prof. Yesim Darici, Prof. Kevin O’Shea, Prof. Nezih Pala, and Prof. Xuewen Wang, for their insightful suggestions, extensive knowledge, constructive criticism, and patience.

I would also like to thank Prof. Yan Yao in UH and Dr. Yaoguang Rong in HUST, China, for their generous share of knowledge and ideas; Prof. Jin He for providing access to his oxygen plasma cleaner; Prof. Chunlei Wang for providing access to her glovebox for chemical weighing; Prof. Nezih Pala for his help on solar simulator and quantum efficiency measurement setup; Prof. Kevin O’Shea for providing access to the rotary evaporator and vacuum oven in his lab; and Jonathan Comparan in AMERI, FIU for his help on XRD measurements. I would also like to express my gratitude to Dr. Zhuan Zhu, Prof. Jiming Bao from UH, Dr. Abdelaziz Boulesbaa, Dr. Alexander Puretzky, and Dr. Kai Xiao from ORNL for the fruitful collaborations.

I would like to thank my parents for their support, patience, and encouragement. Last but not least, I would like to give my very special thanks to my wife, Jing Guo, who always supported me to go through the hard times! 


\begin{abstract}
OF THE DISSERTATION
ORGANIC-INORGANIC HALIDE PEROVSKITE NANOCRYSTALS AND SOLAR
\end{abstract}

CELLS

by

Rui Guo

Florida International University, 2020

Miami, Florida

Professor Wenzhi Li, Major Professor

A great challenge facing humanity is finding inexhaustible and inexpensive energy sources to power the planet. Renewable energies are the best solutions because of their abundance, diversity, and pollution-free emission. Solar energy is the cleanest and most abundant renewable energy source available. In the continuing quest for efficient and low-cost solar cells, perovskite solar cells (PSCs) have emerged as a potential replacement for silicon solar cells. Since 2009, the efficiencies of PSCs have been skyrocketing from $3.8 \%$ to $25.2 \%$ and are now approaching the theoretical limit. Along with the perovskite thin films used for photovoltaics, perovskite nanocrystals (NCs) also attracted significant attention because of their remarkable optoelectronic properties for application in lasing and light-emitting devices.

Perovskite NCs have demonstrated interesting and distinctive properties that could be exploited in new technologies. However, their practical applications have been held back by materials synthesis and characterization roadblocks. In this dissertation, two-dimensional (2D) $\left(\mathrm{C}_{6} \mathrm{H}_{5} \mathrm{C}_{2} \mathrm{H}_{4} \mathrm{NH}_{3}\right)_{2} \mathrm{PbBr}_{4}(\mathrm{PEPB})$ nanocrystals were synthesized, and their optical properties were studied. Compare to its bulk counterpart, the 2D PEPB 
nanocrystals exhibited a larger bandgap due to the quantum confinement effect and lattice relaxation. The study on its exciton dynamics showed an exciton induced absorption peak with a lifetime of $16.7 \mathrm{ps}$.

Furthermore, the structure and crystallinity of the perovskite thin film play critical roles in determining the performance of PSCs. Though different synthesis methods have been developed so far to prepare perovskite thin film for PSCs, there is still a serious lack of understanding of the relation between the perovskite thin film crystal structure and PSC performance. In this dissertation, perovskite thin films were prepared using methylamine (MA)-gas-mediated $\mathrm{MAPbI}_{3}$ precursor solution. Compared to the conventional one-step spin coating method, the MA-gas-mediated method yielded perovskite films with larger crystal grains, smoother surface morphology, and a preferred crystal orientation. PSCs using the MA-gas-mediated precursor exhibited superior performance to the devices using the conventional one-step spin-coating method. In summary, the study on the growth parameters and the optical properties of PEPB NCs offer valuable insight for developing light-emitting devices based on perovskite nanocrystals. The successful fabrication of PSC devices in air using the MAgas-mediated precursor suggests that this method for preparing perovskite precursor solution has great potentials in delivering commercial perovskite solar cells. 


\section{TABLE OF CONTENTS}

CHAPTER

PAGE

CHAPTER 1. Energy, Global Warming, and Renewable Energy Sources ............................... 1

1.1. World energy consumption and global warming ............................................. 1

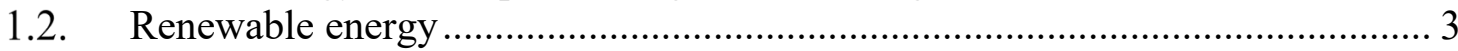

1.3. Solar energy and solar PV ................................................................... 5

1.4. Dissertation research motivation and outline..................................................... 8

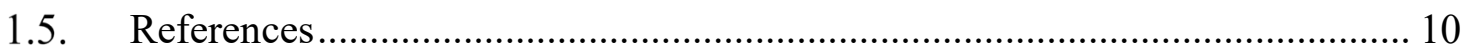

CHAPTER 2. Device Physics of Solar Cells...................................................................... 14

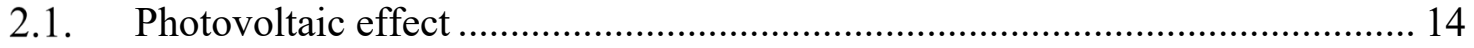

2.2. Band structure of semiconducting materials................................................ 15

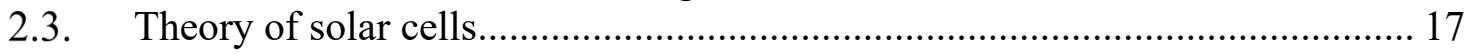

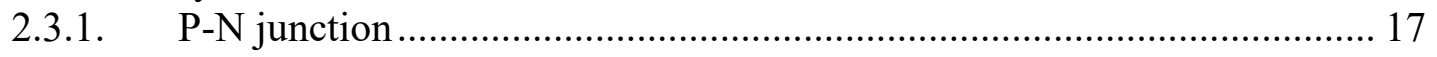

2.3.2. Photogeneration of charge carriers ……………...................................... 22

2.3.3. Charge separation and photocurrent …………...................................... 23

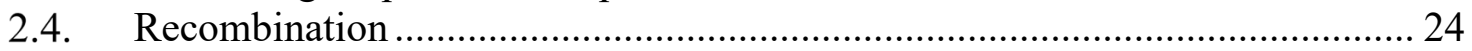

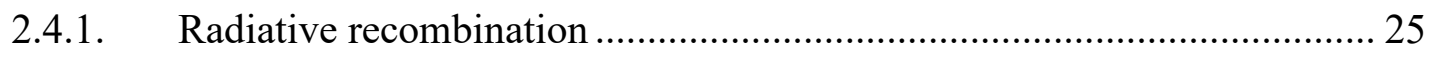

2.4.2. Shockley-Read-Hall recombination..................................................... 26

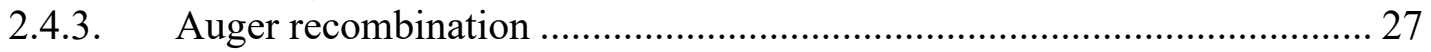

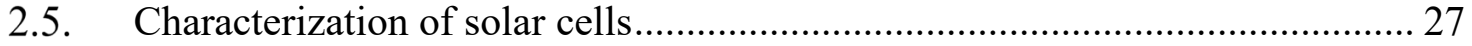

2.5.1. The solar spectrum ......................................................................... 28

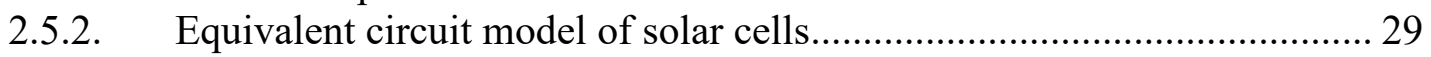

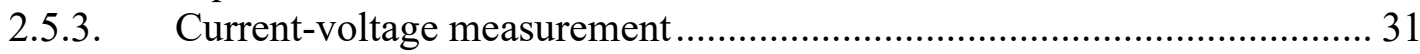

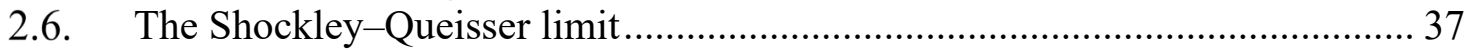

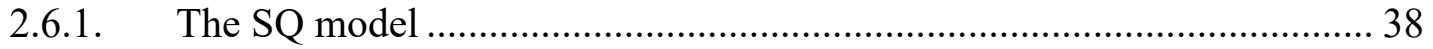

2.6.2. Energy loss beyond the SQ model......................................................... 40

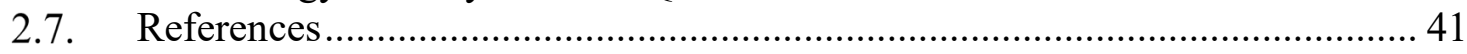

CHAPTER 3. Organic-Inorganic Perovskite Materials and Perovskite Solar Cells ............... 43

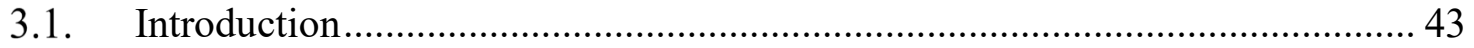

3.2. Crystal Structures for Perovskite Compounds .................................................... 43

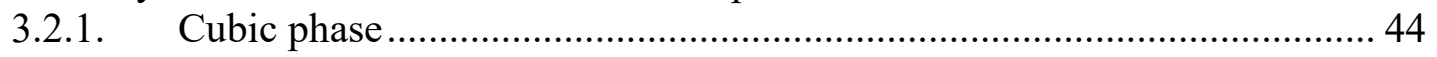

3.2.2. Hexagonal and tetragonal phase ………………................................... 45

3.2.3. Orthorhombic phase ............................................................................ 47

3.2.4. Rhombohedral phase ........................................................................ 48

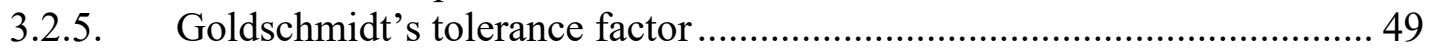

3.3. Organic-inorganic halide perovskites …………............................................. 51

3.3.1. Methylammonium lead iodide .............................................................. 51

3.3.2. Formamidinium lead iodide .................................................................. 52

3.4. Properties of organic-inorganic halide perovskites......................................... 53

3.4.1. High absorption coefficient and small Urbach energy .............................. 53

3.4.2. Long charge carrier diffusion length.......................................................... 55 


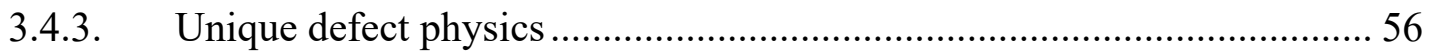

3.4.4. Electronic band structure and direct bandgap ........................................... 56

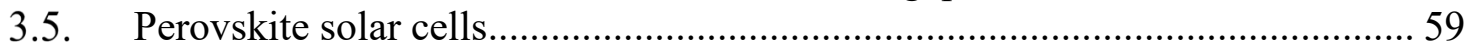

3.5.1. Architecture evolution of perovskite solar cells ...................................... 60

3.6. Versatile fabrication strategies for depositing perovskite thin films ................ 62

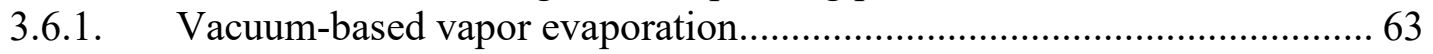

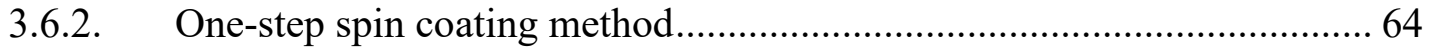

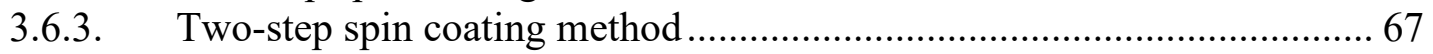

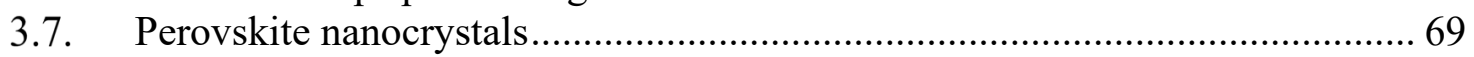

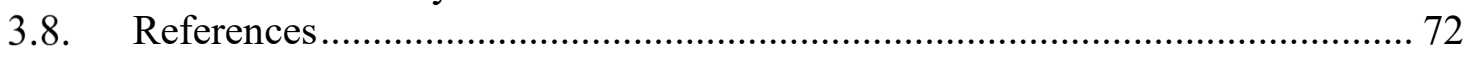

CHAPTER 4. Two-dimensional Phenethylammonium Lead Bromide (PEPB) Perovskite NCs: Synthesis and Photoluminescence Properties ................................................................. 84

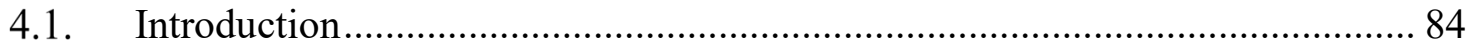

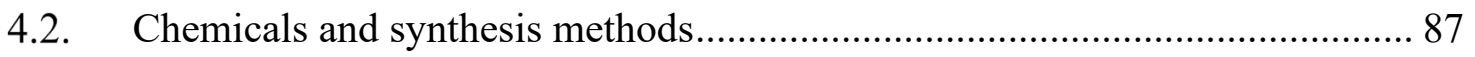

4.2.1. Synthesis of phenethylammonium bromide............................................. 87

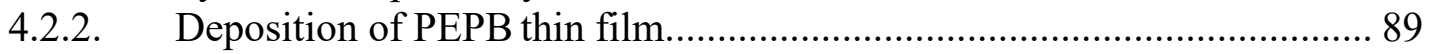

4.2.3. Growth method for PEPB single crystal ................................................ 90

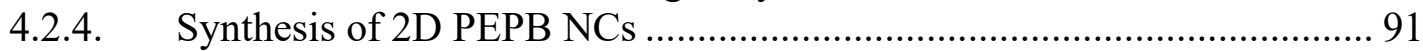

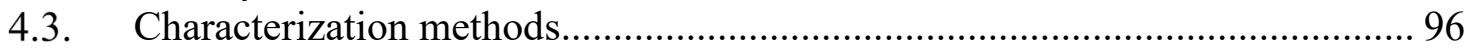

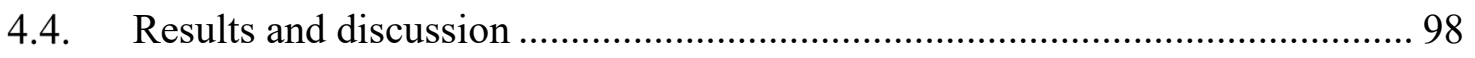

4.4.1. Crystal structure of PEPB thin films ..................................................... 98

4.4.2. Optical absorption spectrum of PEPB thin films .................................... 101

4.4.3. PL properties of PEPB thin films...................................................... 102

4.4.4. Crystal structure of PEPB bulk single crystals ..................................... 104

4.4.5. Optical absorption spectrum of PEPB bulk single crystals .................... 106

4.4.6. Surface morphology of 2D PEPB NCs................................................. 107

4.4.7. PL properties of PEPB NCs ............................................................... 109

4.4.8. Time-resolved reflectance spectroscopy of PEPB NCs............................ 111

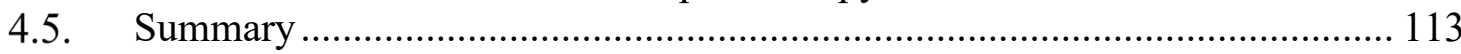

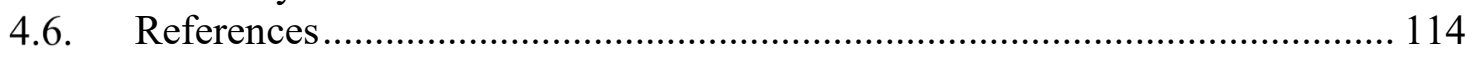

CHAPTER 5. MA-gas-assisted Deposition of $\mathrm{MAPbI}_{3}$ Thin Film for Highly Efficient

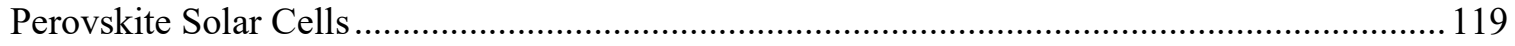

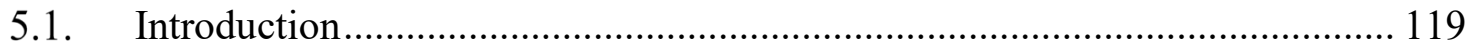

5.2. Fabrication of perovskite solar cells ............................................................ 121

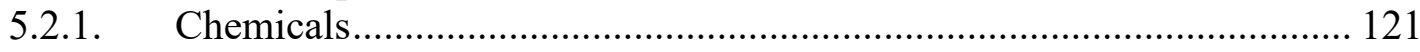

5.2.2. Deposition of $\mathrm{MAPbI}_{3}$ thin films by spin coating ……......................... 122

5.2.3. Fabrication procedures for perovskite solar cells ................................... 124

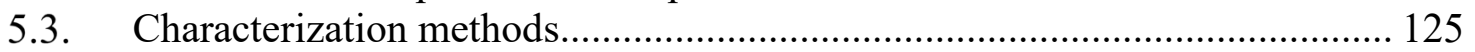

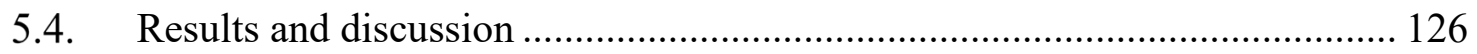

5.4.1. Surface morphology and optical absorption of $\mathrm{MAPbI}_{3}$ thin films ........ 128

5.4.2. Crystal structures of $\mathrm{MAPbI}_{3}$ thin films ………................................. 130

5.4.3. Performances of the perovskite solar cells............................................ 132

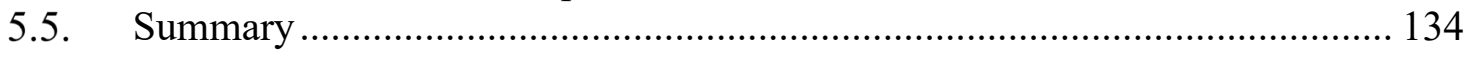




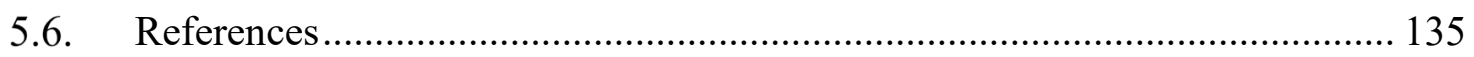

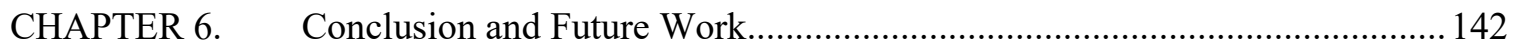

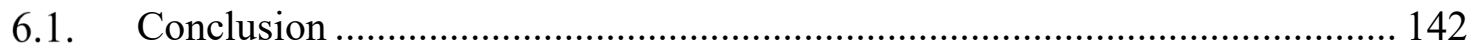

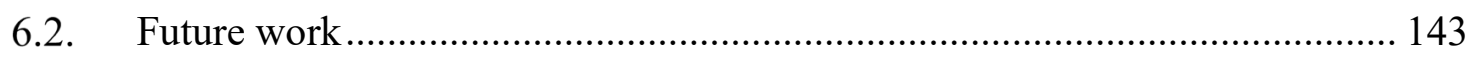

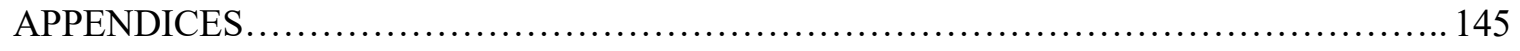

VITA....................................................................... 154 


\section{LIST OF TABLES}

TABLE

Table 3-1 The Wyckoff positions and the atomic coordinates of the Group Pm3m for cubic perovskite structure ${ }^{[22]}$

Table 3-2 The Wyckoff positions and the atomic coordinates of the Group $\mathrm{P}_{3} \mathrm{~cm}$ for hexagonal perovskite structure ${ }^{[24,25]}$.

Table 3-3 The Wyckoff positions and the atomic coordinates of the Group $14 / \mathrm{mcm}$ for tetragonal perovskite structure ${ }^{[26]}$

Table 3-4 The Wyckoff positions and the atomic coordinates of the Pnma space group for the orthorhombic perovskite structure ${ }^{[22]}$

Table 3-5 The Wyckoff positions and the atomistic positions in $R \overline{3} c$ rhombohedral perovskite structure ${ }^{[21]}$.

Table 3-6 Ionic radii of A cations, $\mathrm{B}$ cations, and $\mathrm{X}$ anions in perovskites for $\mathrm{PV}$ applications.

Table 3-7 Bandgap $\left(E_{g}\right)$, exciton binding energy $\left(R^{*}\right)$, reduced effective mass $(\mu)$, effective dielectric constant $\left(\varepsilon_{\text {eff }}\right)$ for $\mathrm{MAPbI}_{3}$ and $\mathrm{FAPbI}_{3}$. Reproduced from reference ${ }^{[57]}$ with permission from the Royal Society of Chemistry.

Table 4-1 Thickness of spin-coated PEPB film on ultra-flat quartz coated glass substrate.

Table 4-2 Concentrations and solvent volume ratios of the final precursor solutions for the synthesis of $2 \mathrm{D}$ PEPB nanocrystals on $\mathrm{SiO}_{2} / \mathrm{Si}$ and quartz substrates.

Table 4-3 Miller notation and the positions $(2 \theta)$ of peaks in the XRD spectra of PEPB thin film.

Table $4-4 \sin \theta$ and $n \lambda / 2 \AA ̊$ of XRD spectra of PEPB thin films. 101

Table $4-5 \sin \theta$ and $n \lambda / 2 \AA$ of XRD spectra of PEPB single crystals 105

Table 4-6 Parameters returned by the converged fit to the decay of the excited state induced absorption signal shown in Figure 4-13 (B). $\mathrm{A}_{\mathrm{i}}(\%)$ and $\mathrm{T}_{\mathrm{i}}(\mathrm{ps})$ are the amplitude and the time constant of the exponential decay component $i$. The amplitude-weighted lifetime $\tau$ is calculated as $\tau=$ $\sum_{i} A_{i} T_{i} / \sum_{i} A_{i}$ 
Table 5-1 Details of chemicals used in the fabrication of perovskite solar cells......... 122 


\section{LIST OF FIGURES}

FIGURE

Figure 1-1 Global primary energy consumption, measured in terawatt-hours per year $^{[1,2]}$....... 2

Figure 1-2 Annual carbon dioxide $\left(\mathrm{CO}_{2}\right)$ emissions from different fuel types ${ }^{[6,12]}$....... 3

Figure 1-3 Annual additions of renewable power capacity, by source, and total........... 4

Figure 1-4 Estimated Renewable Energy Share of Global Electricity Production in $2018^{[14]}$ 5

Figure 1-5 Solar irradiance spectrum above atmosphere and at sea level. 6

Figure 1-6 Cumulative solar PV capacity, by country, $2010-2018^{[1]}$. 7

Figure 2-1 Diagram of the evolution of the atomic $s$ and $p$ orbitals into valence and conduction bands at zone center within the tight-binding approximation for a semiconductor

Figure 2-2 Band filling diagrams for metal, semimetal, semiconductor, and insulator.

Figure 2-3 Energy band diagram of two different types (p-type and n-type) of silicon before the junction is formed. The solid and hollow circles represent the free electrons and free holes, respectively

Figure 2-4 A p-n junction in thermal equilibrium with no external electric field.lue and red lines represent the electron and hole concentrations, respectively. The area between dashed lines is the depletion region or the space charge region. The red and blue circles represent the positively charged donor ions and the negatively charged acceptor ions, respectively. The red and blue shaded areas represent the positively charged and the negatively charged region, respectively.

Figure 2-5 Abrupt p-n junction in thermal equilibrium adapted from reference ${ }^{[6]}$. (A) Space charge distribution. The red and blue circles represent the positively charged donor ions and the negatively charged acceptor ions, respectively. $\mathrm{W}_{\mathrm{Dp}}$ and $\mathrm{W}_{\text {Dn }}$ represent the width of the depletion region in the p-type side and the n-type side, respectively. (B) Electric field distribution. (C) Electric potential distribution. $\psi_{b i}$ is the build-in potential. The red and blue shaded areas represent the positively charged and the negatively charged depletion region, respectively. (D) Energy band diagram. The solid and hollow circles represent the free electrons and holes, respectively. 
Figure 2-6 Diagram of the three stages of PV power conversion: (A) absorption of a photon and generation of an electron-hole pair, (B) thermalization of charge carriers, and (C) selective extraction of electrons and holes at two terminals.

Figure 2-7 Schematic diagrams of (A) radiative, (B) Shockley-Read-Hall, and (C) Auger recombination. 25

Figure 2-8 Spectral irradiance received outside the Earth's atmosphere (AM0), and on the surface of Earth at mid-latitudes, passing through 1.5 atmosphere thickness (AM1.5G and AM1.5D). Reproduced from data accessed from NREL ${ }^{[11]}$.

Figure 2-9 Equivalent circuit of a single-junction solar cell. 30

Figure 2-10 A generic J-V curve and power density output of a solar cell under sun illumination. The intercepts of the $\mathrm{J}-\mathrm{V}$ curve (black) on the $x$-axis and the $y$-axis are the $V_{O C}$ and $J_{S C}$, respectively. The maximum power point is located at the peak of the power density curve (purple). The blue rectangle is defined by the $x$-axis, $y$-axis, $V_{O C}$, and $J_{S C}$. The orange rectangle is defined by the $x$-axis, $y$-axis, and the maximum power point. The ratio of the orange area divided by the blue area is the fill factor.

Figure 2-11 Effect of shunt resistance on the J-V curve of a solar cell.......................... 36

Figure 2-12 Effect of series resistance on the $\mathrm{J}-\mathrm{V}$ curve of a solar cell.......................... 37

Figure 2-13 Fundamental solar cell efficiency limits and records up to April 2016. (A) AM1.5 solar spectrum with distinct dips due to molecular absorption in Earth's atmosphere. Photons with energy below the bandgap ( $E_{g}$, dashed black line corresponds to $\mathrm{Si}$ ) are not absorbed. Photons with more energy than bandgap are fully converted to free charge carriers due to thermalization. The maximum power generated is limited by voltage loss relative to the bandgap voltage. (B) Theoretical Shockley-Queisser detailed balance limit as a function of bandgap (black line) and $75 \%$ and $50 \%$ of the limit (gray lines). The record efficiencies for different materials are plotted for the corresponding bang gaps. From reference ${ }^{[14]}$. Reprinted with AAAS permission.

Figure 3-1 Categorization of perovskite compound.

Figure 3-2 Cubic perovskite crystal structure for the $\mathrm{ABX}_{3}$ compound.......................... 45

Figure 3-3 $\mathrm{P}_{3} \mathrm{~cm}$ hexagonal perovskite unit cell. ...................................................... 46

Figure 3-4 I4/mcm tetragonal perovskite unit cell. 47 
Figure 3-5 Orthorhombic Pnma perovskite structure unit cell. Note that the octahedron formed by one $\mathrm{B}$ cation and six $\mathrm{X}$ anions at the center of the unit cell is tilted.

Figure 3-6 $R \overline{3} c$ rhombohedral perovskite structure unit cell.

Figure 3-7 (A) Ball-stick model for close-packed cubic perovskite structure. For clarity, the radii of these spheres are smaller than the ionic radii of $\mathrm{A}, \mathrm{B}$, and $\mathrm{X}$. (B) and (C): Cross-sectional view of (100) plane including B cations and $\mathrm{X}$ anions and $(1 / 2,0,0)$ plane including $\mathrm{A}$ cation and $\mathrm{X}$ anions, respectively. The blue, gold, and red spheres represent the $\mathrm{A}$ cation, $\mathrm{B}$ cations, and $\mathrm{X}$ anions, respectively.

Figure 3-8 The crystal structures of the (a) orthorhombic, (b) tetragonal, and (c) cubic phases of $\mathrm{CH}_{3} \mathrm{NH}_{3} \mathrm{PbI}_{3}{ }^{[31]}$. The upper and lower panels are oriented through $<100>$ and $<001>$, respectively. The $\mathrm{PbI}_{6}$ octahedra are shaded gray. Reproduced with permission from reference ${ }^{[31]}$.

Figure 3-9 Absorption coefficients of $\mathrm{MAPbI}_{3}$ and $\mathrm{MAPbI}_{3-\mathrm{x}} \mathrm{Cl}_{\mathrm{x}}$. (A) Compilation of room-temperature absorption coefficient data for $\mathrm{MAPbI}_{3}$ and $\mathrm{MAPbI}_{3-\mathrm{x}} \mathrm{Cl}_{\mathrm{x}}$. Reproduced with permission from reference [50]. Copyright 2015 American Chemical Society. (B) Comparison of absorption coefficients, $\alpha(\lambda)$, of four photovoltaic materials. Reproduced with permission from reference ${ }^{[46]}$. Copyright 2015 Optical Society of America.

Figure 3-10 Electronic band structure of $\mathrm{MAPbI}_{3}$.(a) Real-space 3D view of the cubic crystal structure of $\mathrm{AMX}_{3}\left(\mathrm{~A}=\mathrm{Cs}, \mathrm{CH}_{3} \mathrm{NH}_{3}, \mathrm{M}=\mathrm{Pb}, \mathrm{Sn}\right.$, and $\mathrm{X}$ $=\mathrm{I}, \mathrm{Br}, \mathrm{Cl}$ ) with the $\mathrm{Pm} 3 m$ space group. $\mathrm{CH}_{3} \mathrm{NH}_{3}{ }^{+}$cation (red ball) is located at the center of the cube. (b) Reciprocal-space 3D view showing the first Brillouin zone (BZ) of the Pm3m space group. Points of high symmetry in the cubic BZ: $\Gamma$ denotes the origin of the BZ; $\mathrm{X}$ is the center of a square face at the BZ boundary; $\mathrm{M}$ is a center of a cube edge, and Rs are vertices of the cube. (c) Electronic band structure for the hightemperature cubic $\mathrm{Pm} 3 \mathrm{~m}$ phase of $\mathrm{MAPbI}_{3}$ with spin-orbit coupling (SOC) at the local density approximation (LDA) level of theory. An upward energy shift of $1.4 \mathrm{eV}$ has been applied to match the experimental bandgap value at R. Irreducible representations obtained from a $P m 3 m$ double group analysis are given at $\mathrm{R}$ and $\mathrm{M}$ points for the electronic states close to the bandgap. Vertical arrows show various possible optical transitions close to the bandgap energy. Optical transitions along the line between the $\mathrm{M}$ and $\mathrm{R}$ points generate carriers that easily relax toward the $\mathrm{R}$ point. Reprinted with permission from reference $^{[56]}$. Copyright 2015 American Chemical Society. 
Figure 3-11 Improvement of the power conversion efficiencies of PSCs over time. The figure is drawn based on the data in Solar Cell Efficiency Tables (Version 33 to Version 53) of Wiley ${ }^{[59]}$ and the latest NREL best research-cell efficiencies chart ${ }^{[60]}$.

Figure 3-12 Device configuration of (A) mesoporous, planar (B) n-i-p, and (C) pi-n structured perovskite solar cells.

Figure 3-13 Perovskite thin film deposited by vapor evaporation. (A) Schematic illustration of a dual-source thermal evaporation system. MAI was the organic source, and $\mathrm{PbI}_{2}$ was the inorganic source. SEM top views of (B) a vapor-deposited $\mathrm{MAPbI}_{3}$ thin film and (C) a solution-processed $\mathrm{MAPbI}_{3}$ thin film. Cross-sectional SEM images of under high magnification of complete solar cells constructed from (D) a vapordeposited $\mathrm{MAPbI}_{3}$ thin film and (E) a solution-processed $\mathrm{MAPbI}_{3}$ thin film. Reproduced with permission from reference ${ }^{[9]}$, Springer Nature Limited.

Figure 3-14 (a) Device architecture of the bilayered perovskite solar cell (glass/ $\mathrm{FTO} / \mathrm{bl}_{-} \mathrm{TiO}_{2} / \mathrm{mp}-\mathrm{TiO}_{2}$-perovskite nanocomposite layer/perovskite upper layer/PTAA/Au). (b) XRD pattern of the annealed perovskite coating on fused silica substrate. The inset shows a SEM image of a surface consisting of a glass/FTO/bl- $\mathrm{TiO}_{2} / \mathrm{mp}-\mathrm{TiO}_{2}$-perovskite nanocomposite layer/perovskite upper layer. (c) Solvent engineering procedure for preparing the uniform and dense perovskite film. Reprinted with permission from reference ${ }^{[64]}$, Springer Nature Limited...... 64

Figure 3-15 (A) Illustration of the key steps in the Lewis acid-base adduct method in which an adduct film is formed by dripping on diethyl ether. (B) Cross-sectional scanning electron microscopy image of a perovskite solar cell containing a $\mathrm{MAPbI}_{3}$ film formed using the Lewis acid-base adduct approach. (C) Comparison of the interaction energy of an adduct formed between FAI (where $\mathrm{FA}^{+}$is formamidinium), $\mathrm{PbI}_{2}$ and dimethyl sulfoxide (DMSO) as the Lewis base and that of the related adduct formed with N-methyl-2-pyrrolidone (NMP) as the Lewis base. Reprinted with permission from reference ${ }^{[7]}$, Springer Nature Limited...... 66

Figure 3-16 SEM images of thermally annealed (TA) perovskite films with thicknesses of $250 \mathrm{~nm}(\mathrm{a}), 430 \mathrm{~nm}(\mathrm{~d})$, and $1015 \mathrm{~nm}(\mathrm{~g})$, and solventannealed (SA) perovskite films with thicknesses of $250 \mathrm{~nm}$ (b), $430 \mathrm{~nm}$ (e), and $1015 \mathrm{~nm}(\mathrm{~h})$; the scale bars are $2 \mu \mathrm{m}$. c,f,i) Grain-size distributions of the SEM images to the left. Reprinted with permission from reference ${ }^{[76]}$.

Figure 3-17 (A) Schematics of $\mathrm{FAPbI}_{3}$ perovskite crystallization involving the direct intramolecular exchange of DMSO molecules intercalated in $\mathrm{PbI}_{2}$ 
with formamidinium iodide (FAI). The DMSO molecules are intercalated between edge-sharing $\left[\mathrm{PbI}_{6}\right]$ octahedral layers. (B) XRD patterns of (a) as-prepared $\mathrm{PbI}_{2}(\mathrm{DMSO})_{2}$ powders, (b) vacuumannealed $\mathrm{PbI}_{2}$ (DMSO) powders, and (c) as-deposited film on fused quartz substrate using $\mathrm{PbI}_{2}$ (DMSO) complex solution. Reprinted with permission from reference ${ }^{[12]}$

Figure 3-18 Schematic illustration showing the LARP and hot injection methods for colloidal synthesis of perovskite NCs. The schematic drawing for LARP is reproduced with permission from reference ${ }^{[96]}$. Copyright (2015) American Chemical Society. The diagram for hot injection is reproduced with permission from reference ${ }^{[104]}$.

Figure 4-1 ${ }^{1} \mathrm{H}$ NMR spectroscopy of $\mathrm{C}_{6} \mathrm{H}_{5} \mathrm{C}_{2} \mathrm{H}_{4} \mathrm{NH}_{3} \mathrm{Br}(\mathrm{PEBr})$ in $\mathrm{CDCl}_{3}$ and DMSO-d 6 . 88

Figure 4-2 (A) UV-Vis absorption and (B) PL spectra of the precursor solutions for the synthesis of 2D PEPB nanocrystals. (B) inset is the light emission of the precursor solutions under UV illumination (from left to right: Solution 1, co-solvent of DMF and CB, Solution 2, co-solvent of CB and $\mathrm{ACN}$, the final precursor solution).

Figure 4-3 A series of optical microscopy images (magnification: 50X) of the 2D PEPB nanocrystals synthesized by solutions with $\mathrm{Pb}^{2+}$ concentrations and solvent volume ratios in Table 4-2.

Figure 4-4 Optical microscopy images of 2D PEPB nanocrystals synthesized on (A) conductive $\mathrm{Si}$ and (B) quartz substrates.

Figure 4-5 (A) XRD spectra of 60-, 70-, 80-, and 110-nm-thick spin-coated PEPB thin films on ultra-flat quartz coated glass substrates. (B) Ball-and-stick model of the crystal structure of $\left(\mathrm{C}_{6} \mathrm{H}_{5} \mathrm{C}_{2} \mathrm{H}_{4} \mathrm{NH}_{3}\right)_{2} \mathrm{PbBr}_{4}$ showing the interplanar distance, $d$. Only non-hydrogen atoms are presented in the schematic illustration.

Figure 4-6 (A) Optical absorption spectra of 60-, 70-, 80-, and 110-nm-thick spincoated PEPB thin films on ultra-flat quartz coated glass substrates. (B) Optical absorption spectra of 70-nm-thick spin-coated PEPB thin films on ultra-flat quartz coated glass (UFG) and quartz substrates 102

Figure 4-7 Steady PL and time-resolved PL spectra of PEPB thin films. (A) and (B): UV-Vis absorption (red lines) and steady PL spectra (green lines) of PEPB thin films on the UFG substrate and the quartz substrate, respectively. The PL spectra were smoothed by Savitzky-Golay method (blue lines). (C): Time-resolved PL spectrum of PEPB thin film on quartz substrate. The inset is the blue light emitted from PEPB film on 
the quartz substrate under a compact handheld UV lamp. (D) Timeresolved PL spectrum (circle) was well fitted by a double-exponential function (red line), with the fitting result displayed in the inset. 103

Figure 4-8 Powder XRD spectrum of PEPB single crystals 104

Figure 4-9 UV-Vis absorption spectrum of $\left(\mathrm{C}_{6} \mathrm{H}_{5} \mathrm{C}_{2} \mathrm{H}_{4} \mathrm{NH}_{3}\right)_{2} \mathrm{PbBr}_{4}$ single crystal. 106

Figure 4-10 (A) Structural illustration of a single layer $\left(\mathrm{C}_{6} \mathrm{H}_{5} \mathrm{C}_{2} \mathrm{H}_{4} \mathrm{NH}_{3}\right)_{2} \mathrm{PbBr}_{4}$ (PEPB) (black balls: lead atoms; gold balls: bromine atoms; grey balls: carbon atoms; light blue balls: nitrogen atoms; $\mathrm{H}$ atoms were removed for clarity). (B) Bright-field optical images of the 2D PEPB nanocrystals on $\mathrm{SiO}_{2} / \mathrm{Si}$ substrate. (C) Height profile of a $2 \mathrm{D}$ PEPB nanocrystal. The inset shows the AFM image with a scale bar of $3 \mu \mathrm{m}$. (D) AFM image of a pyramid formed on top of a PEPB nanocrystal. (E) Height profile of the pyramid. A magnified image of the pyramid is shown in the inset. Scale bar in the inset: $2 \mu \mathrm{m}$. (F) Thickness distribution statistics of 2D PEPB nanocrystals synthesized on $\mathrm{SiO}_{2} / \mathrm{Si}$ substrates.

Figure 4-11 PL properties of the $2 \mathrm{D}\left(\mathrm{C}_{6} \mathrm{H}_{5} \mathrm{C}_{2} \mathrm{H}_{4} \mathrm{NH}_{3}\right)_{2} \mathrm{PbBr}_{4}$ nanocrystals. (A) Steady-state PL spectrum of a piece of bulk crystal and three 2D $\left(\mathrm{C}_{6} \mathrm{H}_{5} \mathrm{C}_{2} \mathrm{H}_{4} \mathrm{NH}_{3}\right)_{2} \mathrm{PbBr}_{4}$ nanocrystals measured using a UV-LED source. (B) PL peaks of three 2D nanocrystals located at $480 \mathrm{~nm}$ and $525 \mathrm{~nm}$, obtained using a $405 \mathrm{~nm}$ laser as excitation and a $410 \mathrm{~nm}$ long-pass filter. 110

Figure 4-12 Time-resolved reflectance contrast of four 2D PEPB nanocrystals.

Figure 4-13 (A) Time-resolved reflection contrast change up to 100 ps time-delay. (B) Dynamics of the induced absorption signal averaged around the peak at $600 \mathrm{~nm}$ (symbols). The experimental data were fitted to a biexponential decay function (solid line)

Figure 5-1 Diagrams of the front (A) and back (B) side of the FTO substrates for PSCs. Only half of the front side, i.e., the blue area, of the substrate is covered with FTO. Notice that the label on the back of the substrate is flipped when observed from the front side.

Figure 5-2 (A) Schematic illustration of the experimental setup to prepare the $\mathrm{MAPbI}_{3} \cdot \mathrm{MA}_{\mathrm{x}}$ precursor solution. (B) and (C): images of the $\mathrm{MAPb}_{3} \cdot \mathrm{MA}_{\mathrm{x}}$ solutions prepared with and without moisture, respectively. (D) and (E): diagrams of the deposition procedures using the $\mathrm{MAPbI}_{3} \cdot \mathrm{DMSO}$ and the $\mathrm{MAPbI}_{3} \cdot \mathrm{MA}_{\mathrm{x}}$ precursor solutions, respectively 
Figure 5-3 SEM images of $\mathrm{MAPbI}_{3}$ by Lewis adduct (A) and $\mathrm{MAPbI}_{3}$ by $\mathrm{MAPbI}_{3} \cdot \mathrm{MA}_{\mathrm{x}}(\mathrm{B})$. AFM topography images of $\mathrm{MAPbI}_{3}$ by Lewis adduct $(\mathrm{C})$ and $\mathrm{MAPbI}_{3}$ by $\mathrm{MAPbI}_{3} \cdot \mathrm{MA}_{\mathrm{x}}(\mathrm{D})$ and the corresponding $3 \mathrm{~d}$ views in $(\mathrm{E})$ and $(\mathrm{F})$. Diameter distribution of crystal grains measured in the SEM images of $\mathrm{MAPbI}_{3}$ by Lewis adduct $(\mathrm{G})$ and $\mathrm{MAPbI}_{3}$ by $\mathrm{MAPbI}_{3} \cdot \mathrm{MA}_{\mathrm{x}}(\mathrm{H})$. (I) Optical absorption spectra of $\mathrm{MAPbI}_{3}$ by Lewis adduct and $\mathrm{MAPbI}_{3}$ by $\mathrm{MAPbI}_{3} \cdot \mathrm{MA}_{x}$

Figure 5-4 XRD spectra of (A) $\mathrm{MAPbI}_{3}$ by Lewis adduct, (B) as-spun $\mathrm{MAPbI}_{3}$ thin film by $\mathrm{MAPbI}_{3} \cdot \mathrm{MA}_{\mathrm{x}}$, (C) $\mathrm{MAPbI}_{3}$ by $\mathrm{MAPbI}_{3} \cdot \mathrm{MA}_{\mathrm{x}}$ baked in Arenriched environment, and (D) $\mathrm{MAPbI}_{3}$ by $\mathrm{MAPbI}_{3} \cdot \mathrm{MA}_{\mathrm{x}}$ baked in MAgas-enriched environment. (E) full widths at half maximum (FWHMs) of (110) peak (solid red line) and (220) peak (solid black line), and the ratio of integrated peak intensity of (110) vs. (220) peak (blue dash line) of XRD spectra in (A) to (D). (F) spectra of the $\mathrm{MAPbI}_{3}$ thin film deposited by filtered and unfiltered $\mathrm{MAPbI}_{3} \cdot \mathrm{MA}_{\mathrm{x}}$ precursor solutions.

Figure 5-5 (A) Cross-section SEM and schematic illustration of the device structure. $\mathrm{Au}$, spiro-OMeTAD, and $\mathrm{MAPbI}_{3}$ layers were labeled by gold, green and red colors, respectively. The small inset on the bottom right corner is the original SEM image. (B) Forward- and reversescanned $\mathrm{J}-\mathrm{V}$ curves of PSC by the Lewis adduct precursor and the $\mathrm{MAPbI}_{3} \cdot \mathrm{MA}_{\mathrm{x}}$ precursor. (C) and (D): histograms and distribution curves of the PCEs of devices by the Lewis adduct precursor and the $\mathrm{MAPbI}_{3} \cdot \mathrm{MA}_{\mathrm{x}}$ precursor. (E) histogram of PCEs of 320 devices by the $\mathrm{MAPbI}_{3} \cdot \mathrm{MA}_{x}$ precursor 


\section{ABBREVIATIONS AND ACRONYMS}

\begin{tabular}{|c|c|}
\hline $\mathrm{ACN}$ & Acetonitrile \\
\hline $\mathrm{BCP}$ & Bathocuproine \\
\hline $\mathrm{CB}$ & Chlorobenzene \\
\hline DMF & Dimethylformamide \\
\hline DMSO & Dimethyl sulfoxide \\
\hline FF & Fill factor \\
\hline FTO & Fluorine-doped tin oxide \\
\hline GBL & $\gamma$-Butyrolactone \\
\hline ITO & Indium tin oxide \\
\hline Li-TFSI & Bis(trifluoromethane)sulfonimide lithium salt \\
\hline MA & Methylamine \\
\hline MAI & Methylammonium iodide \\
\hline PCE & Power conversion efficiency \\
\hline PL & Photoluminescence \\
\hline PV & Photovoltaic \\
\hline Spiro-OMeTAD & $\begin{array}{l}2,2^{\prime}, 7,7^{\prime} \text {-Tetrakis }\left(N, N \text {-di- } p \text {-methoxyphenylamine)-9, } 9^{\prime} \text { - }\right. \\
\text { spirobifluorene }\end{array}$ \\
\hline TBP & 4-tert-butylpyridine \\
\hline TTDIP & Titanium diisopropoxide bis(acetylacetonate) \\
\hline
\end{tabular}




\section{CHAPTER 1. Energy, Global Warming, and Renewable Energy Sources}

\subsection{World energy consumption and global warming}

In our world today, energy is the foundation for personal well-being, poverty eradication, and economic development. Global primary energy consumption (Figure 1-1), together with the world population, has been increasing nearly exponentially since the Industrial Revolution. According to BP Statistical Review of World Energy (2019), global primary energy consumption hit another historic high in 2018, reaching 13,864 million tonnes oil equivalent (Mtoe), and increasing at a rate of $2.9 \%$, the fastest increase since $2010^{[1,2]}$. When measured in terawatt-hours, global primary energy consumption of 2018 reached $157,064 \mathrm{TWh}^{1}, 2.4 \%$ higher than that of $2017^{[1]}$. In the United States, the primary energy consumption increased by $4 \%$ from 2017 , which is also the most massive increase since 2010 in both absolute and percentage terms ${ }^{[1]}$. However, despite the accrescent worldwide energy consumption, 940 million people (13\% of the world population) still do not have access to electricity ${ }^{[3]}$.

Further, climate change is a threat to human civilization that cannot be undermined. Scientific research has revealed incontrovertible evidence of global temperature rise of $1^{\circ} \mathrm{C}$ above preindustrial ${ }^{[4]}$. The global average atmospheric concentrations of carbon dioxide $\left(\mathrm{CO}_{2}\right)$ have reached over 400ppm (parts per million), the highest levels in over 800,000 years $^{[5]}$. Energy production and consumption account for $2 / 3$ of global greenhouse gas (GHG) emissions attributed to human activity ${ }^{[6]}$. Moreover, burning fossil fuels (mostly

\footnotetext{
${ }^{1} 13,864$ Mtoe is greater than 157,064 TWh. When measured in TWh, the electricity generated from nuclear, hydropower, wind, solar, and other renewable energies are used in calculation rather than the energy of these renewable sources, thus the statistical discrepancy.
} 
coal, oil, and natural gas) is the largest contributor to global warming and account for over $3 / 4$ of global GHG emissions and nearly $90 \%$ of all $\mathrm{CO}_{2}$ emissions $^{[6,7]}$, as shown in Figure 1-2. Worldwide consumption of fossil fuels reached 11,743 Mtoe in 2018, releasing 33.7 billion tonnes of $\mathrm{CO}_{2}{ }^{[1,6,8]}$.In the United States, $\mathrm{CO}_{2}$ from fossil fuel has accounted for approximately $76 \%$ of GHG emissions for the entire time series since $1990^{[9]}$.

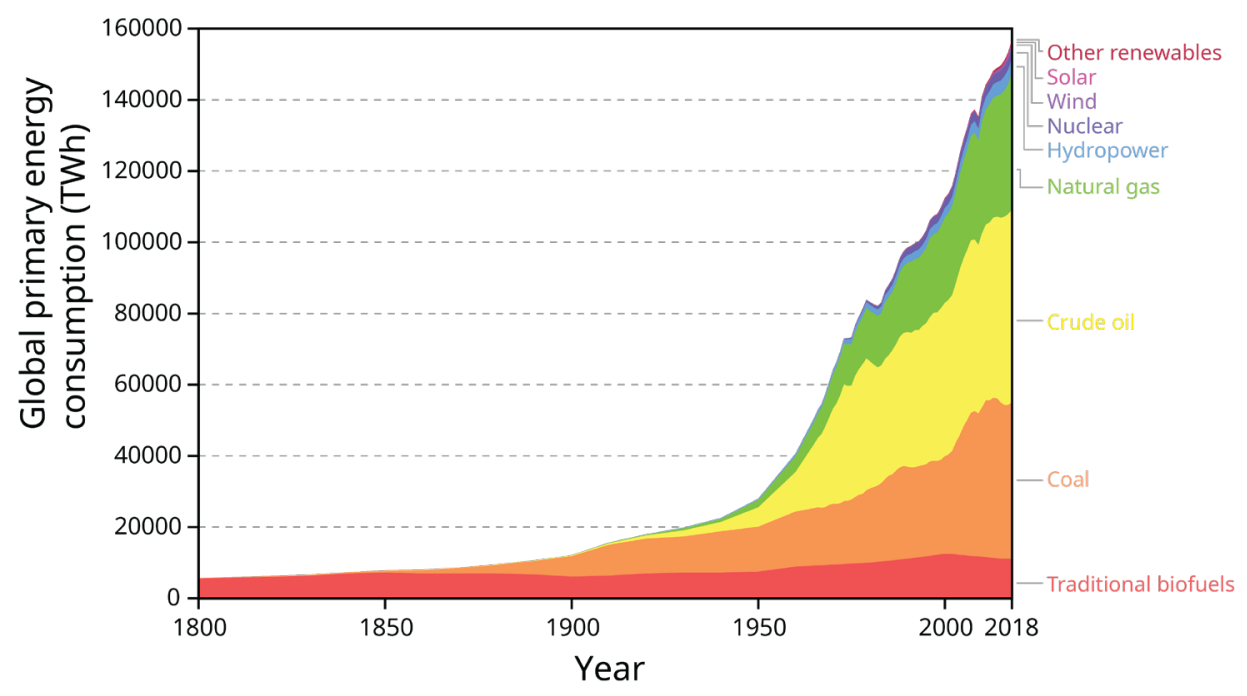

Figure 1-1 Global primary energy consumption, measured in terawatt-hours per year ${ }^{[1,2]}$.

If we are to meet the Paris Agreement's ${ }^{[10]} 1.5-2^{\circ} \mathrm{C}$ temperature rise limits and mitigate dangerous climate change effects, the world needs a rapid, concerted, and fundamental transition in energy sources to reduce the consumption of fossil fuels. However, governments' plans for fossil fuels production by 2030 will lead to the emission of 39 billion tonnes of $\mathrm{CO}_{2}, 53 \%$ more than would be consistent with a $2^{\circ} \mathrm{C}$ pathway and $120 \%$ more than would be consistent with a $1.5^{\circ} \mathrm{C}$ pathway ${ }^{[7,11]}$. The worldwide energy market is faced with an immediate division between the expectations of fast, renewablesdriven energy transitions and the reality of today's energy systems in which reliance on fossil fuels remains stubbornly high. 


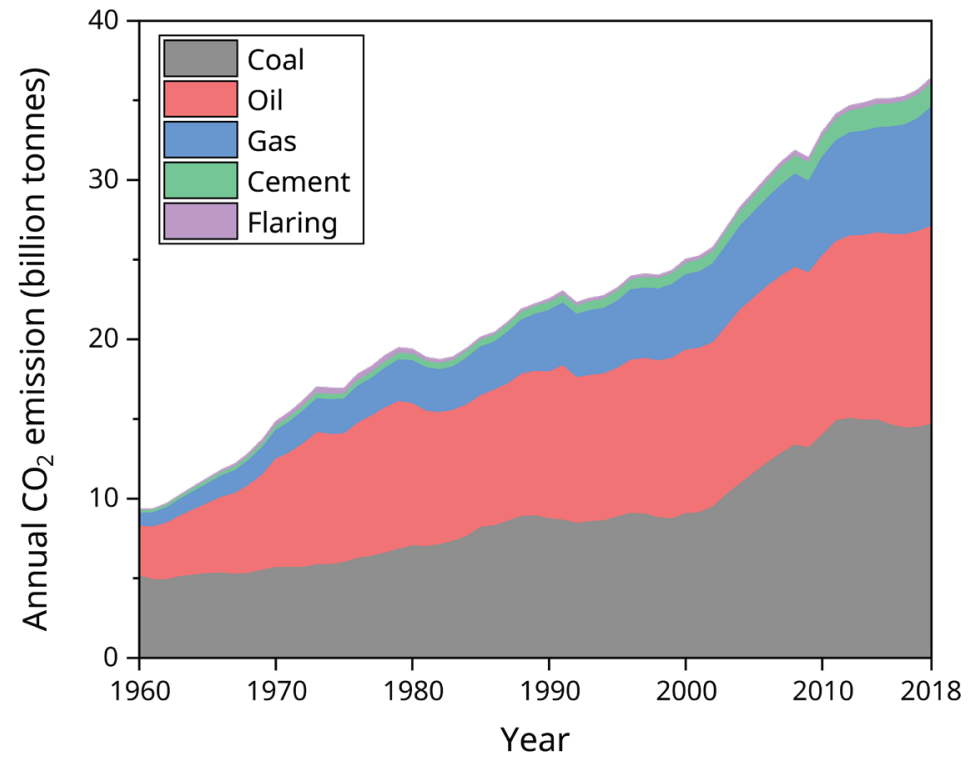

Figure 1-2 Annual carbon dioxide $\left(\mathrm{CO}_{2}\right)$ emissions from different fuel types ${ }^{[6,12]}$.

\subsection{Renewable energy}

Renewable energy is energy that is harnessed from sources that are naturally replenished on a human timescale ${ }^{[13]}$. Among multiple options for reducing GHG emissions while still satisfying the increasing demand for global energy consumption, renewable energies can provide more comprehensive benefits as well as having a substantial potential to mitigate climate change. If implemented correctly, renewable energies will assist with social and economic development, expand energy access worldwide, provide a secure energy supply, and improve public health measures.

Historically, humankind has been using renewable energy since people began burning wood for cooking and keeping warm. Nowadays, modern renewable energy resources, such as hydropower, wind energy, geothermal energy, and solar energy, have already been successfully integrated into the global energy market. From 2010 to 2018, additional renewable power capacity has been added to the worldwide power grid each 
year, as displayed in Figure 1-3. In 2018, 181 gigawatts (GW) of renewable power capacity was added to the grid, expanding the global renewable power capacity to $2,378 \mathrm{GW}^{[14]}$, which is equivalent to over $33 \%$ of global electricity capacity. Although the expansion of renewable power capacity slowed slightly in 2019 , from $181 \mathrm{GW}$ to $176 \mathrm{GW}$ and growth rate from $7.9 \%$ to $7.4 \%{ }^{[14]}$, renewable power has been the largest contributor to the global power capacity expansion since 2012 , holding $72 \%^{[15]}$ of the net capacity expansion in 2019.

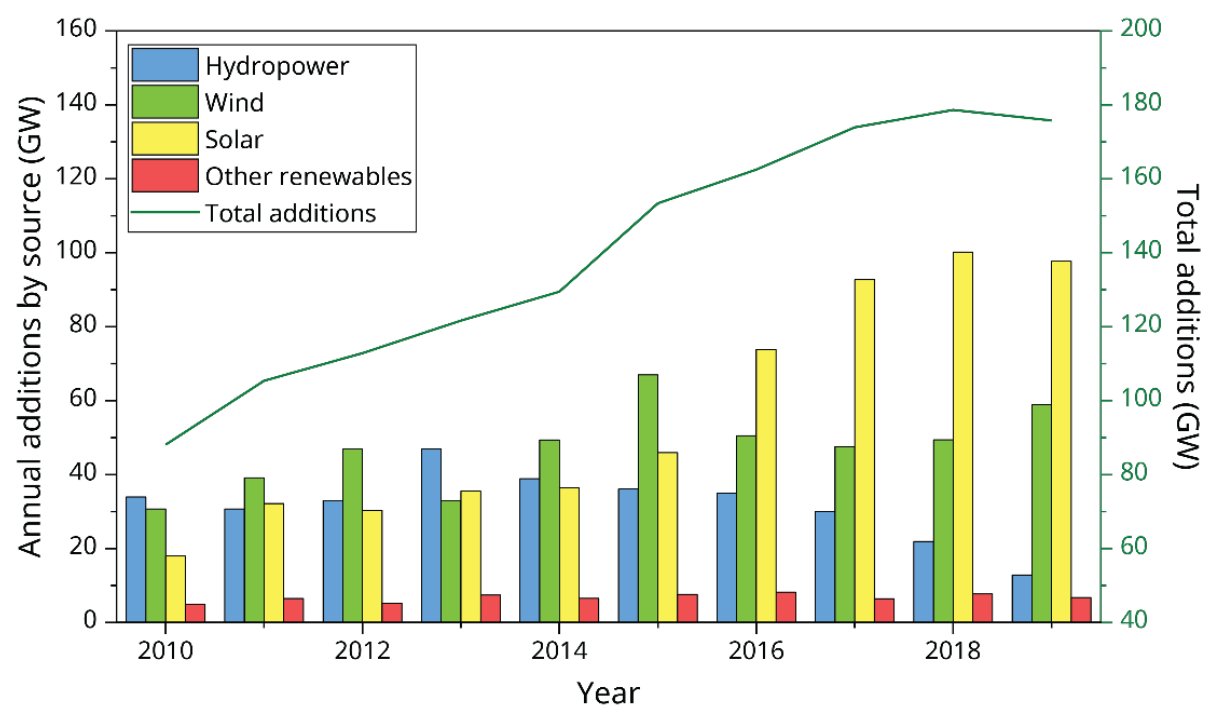

Figure 1-3 Annual additions of renewable power capacity, by source, and total.

Currently with each year, more electricity is being generated from renewable resources than in the previous years. As is shown in Figure 1-4, renewable sources provided $26.2 \%^{[14]}$ of global electricity production in 2018 . Among variable renewable sources, hydropower was still the principal source, accounting for $15.8 \%$ of global electricity production. Wind energy and solar photovoltaics (PV) supplied 5.5\% and 2.4\%, respectively, followed by bio-power technology $(2.2 \%)$ that converts renewable biomass fuels into heat and electricity. In 2018, there were at least 90 countries that had installed 
more than $1 \mathrm{GW}$ of electricity generation capacity and at least 30 countries exceeding 10 GW. Additionally, at least nine countries produced over $20 \%$ of their electricity from wind and solar PV resources. Overall, renewable energy sources are becoming increasingly preferred for new electricity generation.

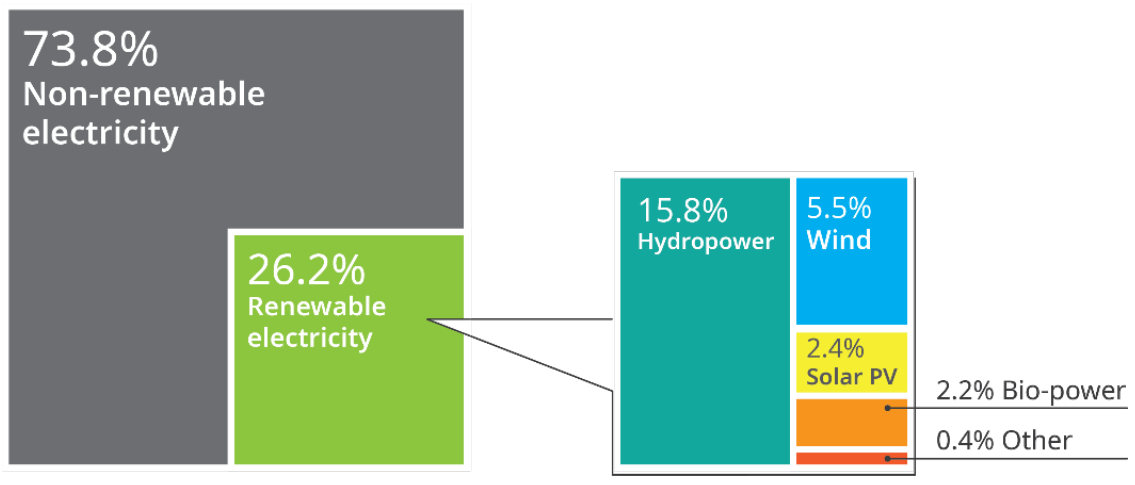

Figure 1-4 Estimated Renewable Energy Share of Global Electricity Production in 2018 ${ }^{[14]}$.

After two consecutive years of soaring over $2.5 \%$ production in 2017 and $2018^{[1]}$, the increasing rate of annual global $\mathrm{CO}_{2}$ emissions slowed down to $0.6 \%{ }^{[16]}$, which is in line with the expansion of renewable power in global electricity production. In fact, some regions, such as Australia, the US, and the European Union, have achieved significant reductions in $\mathrm{CO}_{2}$ emissions related to electricity generation through renewable power. In the US, total $\mathrm{CO}_{2}$ emissions decreased by $12 \%$ between 2005 and $2018^{[1]}$, and electricity generation related $\mathrm{CO}_{2}$ emissions fell over $30 \%{ }^{[14]}$.

\subsection{Solar energy and solar PV}

Solar energy, radiant light and heat from the Sun (a blackbody with a temperature of $5778 \mathrm{~K}$ ) is a vital source of renewable energy. The Earth receives 174 petawatts (PW) of solar radiation influx just outside Earth's atmosphere, or, equivalently, an average annual magnitude of $1,361 \mathrm{~W} / \mathrm{m}^{2}$ for a surface perpendicular to the Sun's rays ${ }^{[17]}$. At sea 
level, solar irradiance is attenuated by atmospheric absorption and scattering, as shown in Figure 1-5, leaving the maximum normal surface solar irradiance at about $1,000 \mathrm{~W} / \mathrm{m}^{2}$ in clear sky conditions $^{[18]}$.

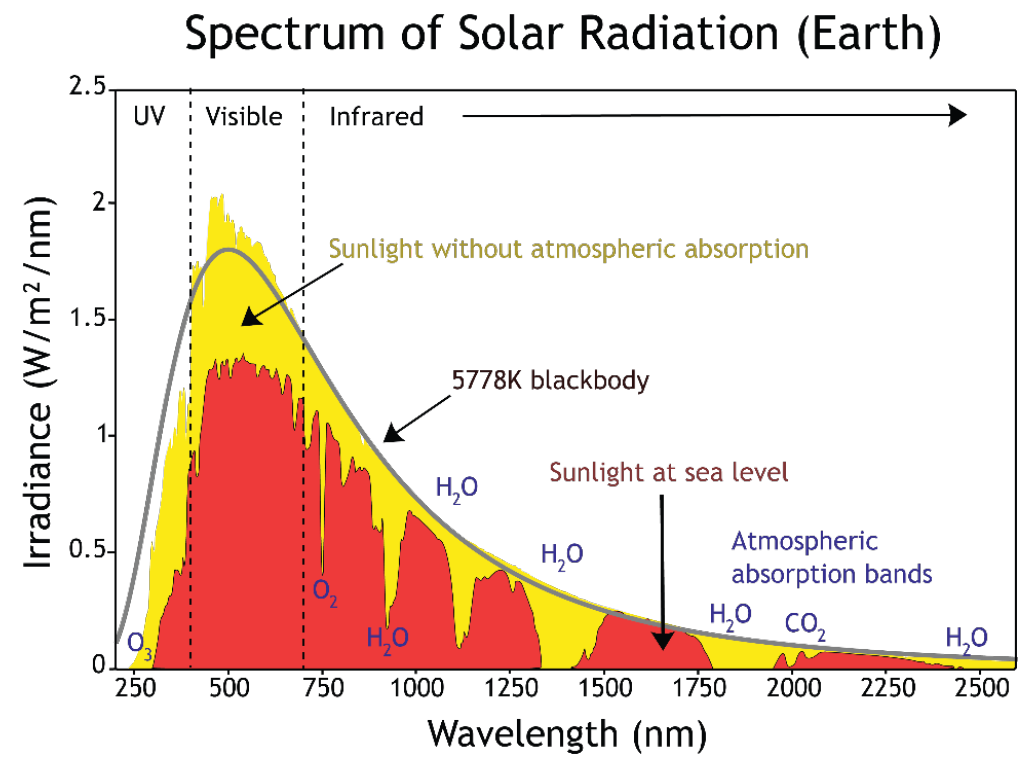

Figure 1-5 Solar irradiance spectrum above atmosphere and at sea level ${ }^{2}$.

Among all renewable sources, solar energy has the highest theoretical potential available for energy harvesting, $3.9 \times 10^{6}$ exajoule per year $(\mathrm{EJ} / \mathrm{yr})^{[18]}$. Even though such great potential is slashed by the geographical accessibility and the realistic conversion efficiencies, the technical potential of solar irradiance is estimated from 1,575 to 49,837 $\mathrm{EJ} / \mathrm{yr}$, or 437,850 to $13,854,686 \mathrm{TWh}^{[18]}$, which is approximately 3 to 90 times the global primary energy consumption in 2018.

Accordingly, solar technology, which converts solar irradiance to power and heat, can be categorized into passive and active solar technology depending on whether the use of specialized electrical and mechanical devices during the capture and conversion is

\footnotetext{
${ }^{2}$ Credit: Nick84[CC BY-SA 3.0], via Wikimedia Commons.
} 
required. Greenhouses, sunrooms, and Trombe walls are typical examples of passive solar design. Active solar energy technologies include photovoltaics (PV) and concentrating solar thermal power (CSP) systems to produce electricity, as well as solar collectors to produce thermal energy. Electricity generated by solar energy exceeded $10 \mathrm{TWh}$ in 2008 and has been increasing at a record pace ever since, producing nearly $600 \mathrm{TWh}$ of electricity in $2018^{[1,14]}$. In terms of annual additions of renewable power capacity, solar energy has been the leader since 2016, as shown in Figure 1-3.

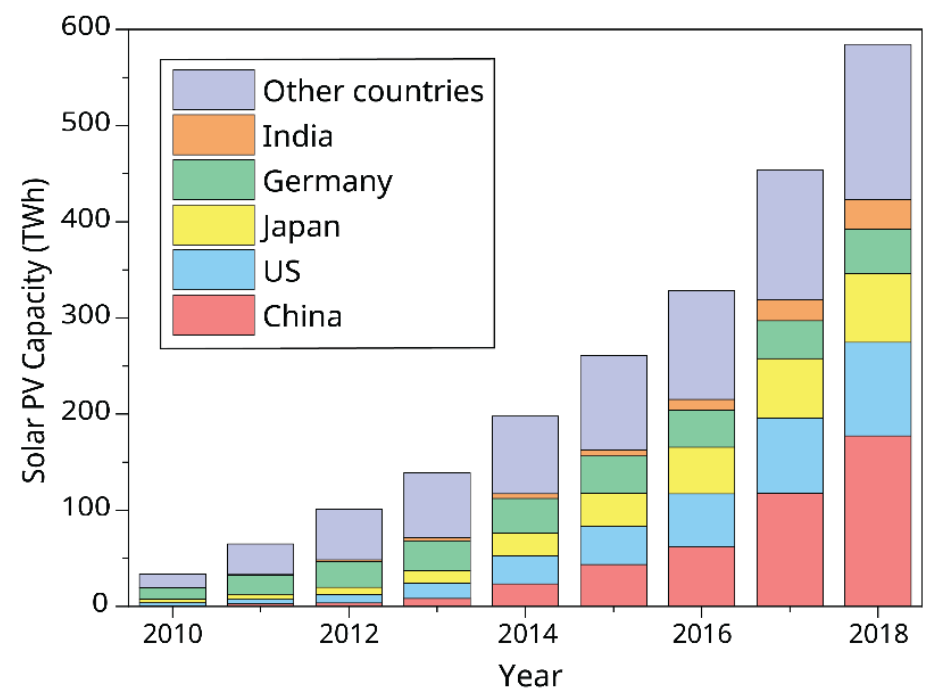

Figure 1-6 Cumulative solar PV capacity, by country, 2010 - 2018 ${ }^{[1]}$.

Solar PVs, or solar cells, convert solar irradiation into electricity by semiconducting materials that exhibit the photovoltaic effect. Demonstrated first by French physicist A. E. Becquerel in $1839^{[19]}$, the photovoltaic effect is a process in which voltage and electric current are generated in semiconducting materials upon exposure to light. However, early solar PV devices were too inefficient to be power sources for any practical application. It was not until April 25, 1954, that a team of scientists at Bell Lab announced to the world the invention of the first practical silicon solar cell ${ }^{[20,21]}$. The New York Times reported on 
its first page that the discovery "may mark the beginning of a new era, leading eventually to the realization of one of mankind's most cherished dreams - the harnessing of the almost limitless energy of the sun for the uses of civilization."

Nowadays, the solar power market is dominated by solar PV technology. In 2018, the global capacity and annual additions of solar PV reached $505 \mathrm{GW}$ and $100 \mathrm{GW}$, respectively ${ }^{[1]}$, while CSP technology, the second most deployed solar technology, reached just over $5 \mathrm{GW}$ of global capacity ${ }^{[14]}$. Solar PV has two distinct advantages: first, once professionally installed, no pollution nor GHG emissions during operation; second, simple scalability in terms of power demands. Solar PV is not only the most popular technology to convert solar energy to electricity but also the most competitive technology for electricity generation in progressively more markets around the world. At the end of 2018, China had the largest cumulative solar PV capacity, 176.1 GW, followed by the United States (97.1 GW), Japan (71.7 GW), Germany $(46.2 \mathrm{GW})$, and India $(30.7 \mathrm{GW})^{[1,22]}$, as shown in Figure 1-6.

\subsection{Dissertation research motivation and outline}

Renewable energy is the key to fight climate change, and solar PV technology is a significant contributor to renewable electricity generation. The cumulative solar PV power capacity is expected to reach $2840 \mathrm{GW}$ globally by 2030 and $8519 \mathrm{GW}$ by $2050^{[23]}$. To support the growth of such magnitude, the current generation of silicon solar cells is not sufficient due to its relatively low efficiency of converting solar energy to electricity in commercial modules and its relatively high manufacturing cost. The PV research community has been searching for the next-generation PV technology featuring high 
efficiency and cost-effective manufacturing methods. Recently, perovskite solar cell has emerged as a promising candidate for the next-generation PV technology, mainly due to its skyrocketing efficiency and low-cost fabrication process. This dissertation is focused on the organic-inorganic halide perovskite material, which is used as the active layer in the perovskite solar cells (PSCs).

Chapter 1 provides background knowledge for the general motivation of photovoltaic research. The demand for more energy consumption and climate change, which are the two challenges threatening sustainable development for the human race, are addressed. Renewable energy plays a vital role in the solution to these two challenges.

Chapter 2 details the theory for the operation of solar cells. A PV device is essentially a p-n junction that absorbs photons and generates charge carriers. The charge carriers are selectively collected at the two terminals of the p-n junction to form the photocurrent. The recombination mechanism in a solar cell is also discussed briefly, followed by introducing the four key performance metrics of a solar cell. The ShockleyQueisser model regarding the theoretical efficiency limit for a single-junction solar cell is introduced at the end of this chapter.

Chapter 3 covers the background knowledge about the organic-inorganic halide perovskite material and the perovskite solar cells. It starts with introducing the crystal structures for inorganic perovskite compounds and then introduces the organic-inorganic halide perovskite material focusing on its optoelectronic properties. A brief history of the PSCs is presented together with a short review of the deposition techniques for the perovskite active layer used in PSCs. This chapter ends with an introduction of the 
perovskite nanocrystals, covering the synthesis methods and the amazing optoelectronic properties for light emitting due to quantum confinement.

Chapter 4 discusses the synthesis and photoluminescence (PL) properties of the two-dimensional (2D) phenethylammonium lead bromide (PEPB) nanocrystals. Organicinorganic halide perovskite nanocrystals often feature different optoelectronic properties from their bulk crystals, which enables their potential application in light-emitting devices. A detailed discussion about the synthesis of 2D PEPB nanocrystals is presented. The PL properties of 2D PEPB nanocrystals are investigated by PL spectrum and time-resolved reflectance spectroscopy.

Chapter 5 is dedicated to the study of the perovskite solar cells. Methylammonium lead iodide $\left(\mathrm{MAPbI}_{3}\right)$ layer was spin-coated using a precursor solution prepared by a methylamine (MA) gas-mediated process. Compared to the conventional one-step spin coating using a Lewis-adduct precursor solution, the spin coating process is simplified, making it suitable for depositing large-scale $\mathrm{MAPbI}_{3}$ thin films. The $\mathrm{MAPb}_{3}$ thin film deposited using the MA gasmediated precursor solution has a preferred crystal orientation in the (110) direction. PSCs fabricated by the MA gas-mediated precursor solution demonstrates higher efficiencies than those fabricated by the Lewis-adduct precursor solution.

Chapter 6 concludes this dissertation with key findings and an outlook for future works.

\subsection{References}

1. BP Statistical Review of World Energy 2019, British Petroleum Company, London: British Petroleum Company, 2019.

2. Smil, V., Energy Transitions: Global and National Perspectives. 2nd expanded and updated ed.; Praeger: Santa Barbara, California, 2016. 
3. Ritchie, H.; Roser, M. 'Access to Energy'. Published online at OurWorldInData.org. https://ourworldindata.org/energy-access (accessed March 30, 2020).

4. Global Annual Mean Surface Air Temperature Change. NASA.Retrieved March $31,2020$.

5. Dr. Pieter Tans NOAA/ESRL (www.esrl.noaa.gov/gmd/ccgg/trends/); Dr. Ralph Keeling Scripps Institution of Oceanography. (scrippsco2.ucsd.edu/) (accessed April 7th, 2020).

6. $\quad$ Friedlingstein, P.; Jones, M. W.; amp; apos; Sullivan, M.; Andrew, R. M.; Hauck, J.; Peters, G. P.; Peters, W.; Pongratz, J.; Sitch, S.; Le Quéré, C.; Bakker, D. C. E.; Canadell, J. G.; Ciais, P.; Jackson, R. B.; Anthoni, P.; Barbero, L.; Bastos, A.; Bastrikov, V.; Becker, M.; Bopp, L.; Buitenhuis, E.; Chandra, N.; Chevallier, F.; Chini, L. P.; Currie, K. I.; Feely, R. A.; Gehlen, M.; Gilfillan, D.; Gkritzalis, T.; Goll, D. S.; Gruber, N.; Gutekunst, S.; Harris, I.; Haverd, V.; Houghton, R. A.; Hurtt, G.; Ilyina, T.; Jain, A. K.; Joetzjer, E.; Kaplan, J. O.; Kato, E.; Klein Goldewijk, K.; Korsbakken, J. I.; Landschützer, P.; Lauvset, S. K.; Lefèvre, N.; Lenton, A.; Lienert, S.; Lombardozzi, D.; Marland, G.; McGuire, P. C.; Melton, J. R.; Metzl, N.; Munro, D. R.; Nabel, J. E. M. S.; Nakaoka, S.-I.; Neill, C.; Omar, A. M.; Ono, T.; Peregon, A.; Pierrot, D.; Poulter, B.; Rehder, G.; Resplandy, L.; Robertson, E.; Rödenbeck, C.; Séférian, R.; Schwinger, J.; Smith, N.; Tans, P. P.; Tian, H.; Tilbrook, B.; Tubiello, F. N.; van der Werf, G. R.; Wiltshire, A. J.; Zaehle, S., Global Carbon Budget 2019. Earth System Science Data 2019, 11 (4), 1783-1838.

7. SEI; IISD; ODI; Climate Analytics; CICERO; UNEP, The Production Gap: The discrepancy between countries' planned fossil fuel production and global production levels consistent with limiting warming to $1.5^{\circ} \mathrm{C}$ or $2^{\circ} \mathrm{C}$; http://productiongap.org/: 2019 .

8. Le Quéré, C.; Andrew, R. M.; Friedlingstein, P.; Sitch, S.; Hauck, J.; Pongratz, J.; Pickers, P. A.; Korsbakken, J. I.; Peters, G. P.; Canadell, J. G.; Arneth, A.; Arora, V. K.; Barbero, L.; Bastos, A.; Bopp, L.; Chevallier, F.; Chini, L. P.; Ciais, P.; Doney, S. C.; Gkritzalis, T.; Goll, D. S.; Harris, I.; Haverd, V.; Hoffman, F. M.; Hoppema, M.; Houghton, R. A.; Hurtt, G.; Ilyina, T.; Jain, A. K.; Johannessen, T.; Jones, C. D.; Kato, E.; Keeling, R. F.; Goldewijk, K. K.; Landschützer, P.; Lefèvre, N.; Lienert, S.; Liu, Z.; Lombardozzi, D.; Metzl, N.; Munro, D. R.; Nabel, J. E. M. S.; Nakaoka, S.-i.; Neill, C.; Olsen, A.; Ono, T.; Patra, P.; Peregon, A.; Peters, W.; Peylin, P.; Pfeil, B.; Pierrot, D.; Poulter, B.; Rehder, G.; Resplandy, L.; Robertson, E.; Rocher, M.; Rödenbeck, C.; Schuster, U.; Schwinger, J.; Séférian, R.; Skjelvan, I.; Steinhoff, T.; Sutton, A.; Tans, P. P.; Tian, H.; Tilbrook, B.; Tubiello, F. N.; van der 
Laan-Luijkx, I. T.; van der Werf, G. R.; Viovy, N.; Walker, A. P.; Wiltshire, A. J.; Wright, R.; Zaehle, S.; Zheng, B., Global Carbon Budget 2018. Earth System Science Data 2018, 10 (4), 2141-2194.

9. U.S. Greenhouse Gas Emissions and Sinks 1990 - 2018. The United States Environmental Protection Agency (EPA).

10. Paris Agreement (Dec. 13, 2015). In UNFCCC, COP Report No. 21, Addenum, at 21, U.N. Doc. FCCC/CP/2015/10/Add, 1 (Jan. 29, 2016).

11. Jackson, R. B.; Friedlingstein, P.; Andrew, R. M.; Canadell, J. G.; Le Quéré, C.; Peters, G. P., Persistent fossil fuel growth threatens the Paris Agreement and planetary health. Environmental Research Letters 2019, 14 (12), 121001.

12. Marland, G.; Boden, T. A.; Andres, R. J., 2008, Global, Regional, and National Fossil Fuel CO2 Emissions. In Trends: A Compendium of Data on Global Change. Carbon Dioxide Information Analysis Center, Oak Ridge National Laboratory, U.S. Department of Energy, Oak Ridge, Tenn., U.S.A.

13. Ellabban, O.; Abu-Rub, H.; Blaabjerg, F., Renewable energy resources: Current status, future prospects and their enabling technology. Renewable and Sustainable Energy Reviews 2014, 39, 748-764.

14. REN21, Renewables 2019: Global status report. REN21 Secretariat 2019.

15. IRENA(2019). Renewable Energy Statistics 2019; The International Renewable Energy Agency, Abu Dhabi, 2019.

16. Peters, G. P.; Andrew, R. M.; Canadell, J. G.; Friedlingstein, P.; Jackson, R. B.; Korsbakken, J. I.; Le Quéré, C.; Peregon, A., Carbon dioxide emissions continue to grow amidst slowly emerging climate policies. Nature Climate Change 2019, 10 (1), 3-6.

17. Coddington, O.; Lean, J. L.; Pilewskie, P.; Snow, M.; Lindholm, D., A Solar Irradiance Climate Data Record. Bulletin of the American Meteorological Society 2016, 97 (7), 1265-1282.

18. Arvizu, D.; Bruckner, T.; Chum, H.; Edenhofer, O.; Estefen, S.; Faaij, A.; Fischedick, M.; Hansen, G.; Hiriart, G.; Hohmeyer, O.; Hollands, K. G. T.; Huckerby, 
J.; Kadner, S.; Killingtveit, Å.; Kumar, A.; Lewis, A.; Lucon, O.; Matschoss, P.; Maurice, L.; Mirza, M.; Mitchell, C.; Moomaw, W.; Moreira, J.; Nilsson, L. J.; Nyboer, J.; Pichs-Madruga, R.; Sathaye, J.; Sawin, J. L.; Schaeffer, R.; Schei, T. A.; Schlömer, S.; Seyboth, K.; Sims, R.; Sinden, G.; Sokona, Y.; Stechow, C. v.; Steckel, J.; Verbruggen, A.; Wiser, R.; Yamba, F.; Zwickel, T., 2011: Technical Summary. In IPCC Special Report on Renewable Energy Sources and Climate Change Mitigation [O. Edenhofer, R. Pichs-Madruga, Y. Sokona, K. Seyboth, P. Matschoss, S. Kadner, T. Zwickel, P. Eickemeier, G. Hansen, S. Schlömer, C. von Stechow (eds)]; Cambridge University Press, Cambridge, United Kingdom and New York, NY, USA.

19. Becquerel, E., Mémoire sur les effets électriques produits sous l'influence des rayons solaires. Comptes Rendus 1839, 9, 561-567.

20. Chapin, D. M.; Fuller, C. S.; Pearson, G. L., A New Silicon p - n Junction Photocell for Converting Solar Radiation into Electrical Power. Journal of Applied Physics 1954, 25 (5), 676-677.

21. April 25, 1954: Bell Labs Demonstrates the First Practical Silicon Solar Cell. APS News April 2009, 18 (2).

22. Masson, G.; Kaizuka, I.; Detolleanere, A.; Lindahl, J.; Jäger-Waldau, A., 2019 Snapshot of Global Photovoltaic Markets. 2019.

23. IRENA (2019), Future of Solar Photovoltaic: Deployment, investment, technology, grid integration and socio-economic aspects (A Global Energy Transformation: paper); International Renewable Energy Agency, Abu Dhabi. 


\section{CHAPTER 2. Device Physics of Solar Cells}

\subsection{Photovoltaic effect}

Photovoltaics (PV) is the use of semiconducting materials exhibiting the photovoltaic effect to convert solar irradiation directly to electricity. The photovoltaic effect is a phenomenon closely related to the photoelectric effect, where both phenomena involve the process of generation and emission of electrons by absorbing photons. The destination of the photogenerated electrons distinguishes the two processes, where in the photoelectric effect, the photoelectrons are emitted into space ${ }^{[1]}$, while in the photovoltaic effect, the electrons travel into another material.

Foundationally, the photoelectric effect is historically significant as it provided experimental evidence for the particle-like nature (quanta) of light ${ }^{[2]}$ and assisted in developing the concept of wave-particle duality. Einstein first postulated that for the emission of a photoelectron, the energy of the absorbed photon must exceed a specific threshold value, known as the work function $(\Phi)$ of the material ${ }^{[3]}$. For typical metals, the work functions are usually a few electron-volts $(\mathrm{eV})$, corresponding to short-wavelength visible or ultraviolet (UV) light. It is also possible to observe the photoelectric effect from insulating materials, but the energy of the absorbed photon would need to be much higher than that for metals.

The photovoltaic effect generates both a current and voltage upon the incident of light using a material that can absorb photons and generate electron-hole pairs. These electron-hole pairs must be able to move around by diffusion or drift before they are extracted and collected at the front and rear electrodes. When an external circuit is connected to the electrodes, the electrons from one terminal, driven by the potential 
difference between two terminals, can flow through the circuit, power up the external load, and recombine with the holes at the other terminal ${ }^{[4]}$. Although the photovoltaic effect has been observed from a variety of materials, a p-n or $p-i-n$ junction can be found in nearly every solar cell in practice.

In the following sections, the fundamental processes of the photovoltaic effect will be discussed after a brief introduction of the band structure of semiconducting materials. The equivalent circuit and the metrics of a solar cell will also be addressed.

\subsection{Band structure of semiconducting materials}

To understand the interaction between photons and electrons in a semiconducting material, a brief discussion of the electronic band structure would be informative. Figure 2-1 shows how electronic energy bands are formed by hypothetically bringing a large number of atoms together to form a crystal. For a single, isolated atom, each of its electrons occupies a unique quantum state, or orbital, with a discrete energy level. When two identical atoms are brought into close proximity to form a molecule, each atomic orbital splits into two molecular orbitals with different energies so that the electrons in these orbitals would be in the different quantum states to obey the Pauli exclusion principle. Thus, bringing more atoms together results in additional energy level splitting. In principle, the electron orbitals in a crystal can be obtained by combining all of the atomic orbitals of constituent atoms. As a result of the Pauli exclusion principle, each atomic orbital splits into $N$ discrete orbitals with different energy levels. As a crystal consists of a vast number $\left(N \sim 10^{23}\right)$ of atoms arranged in a highly ordered structure, the

energies of $N$ discrete orbitals would be so close $\left(\sim 10^{-23} \mathrm{eV}\right)$ that they practically fall in a continuum or an energy band, and the orbitals are delocalized over the entire crystal. 
Between two adjacent energy bands is a range of energy levels that are impossible for an electron to possess, i.e., the forbidden band or bandgap.

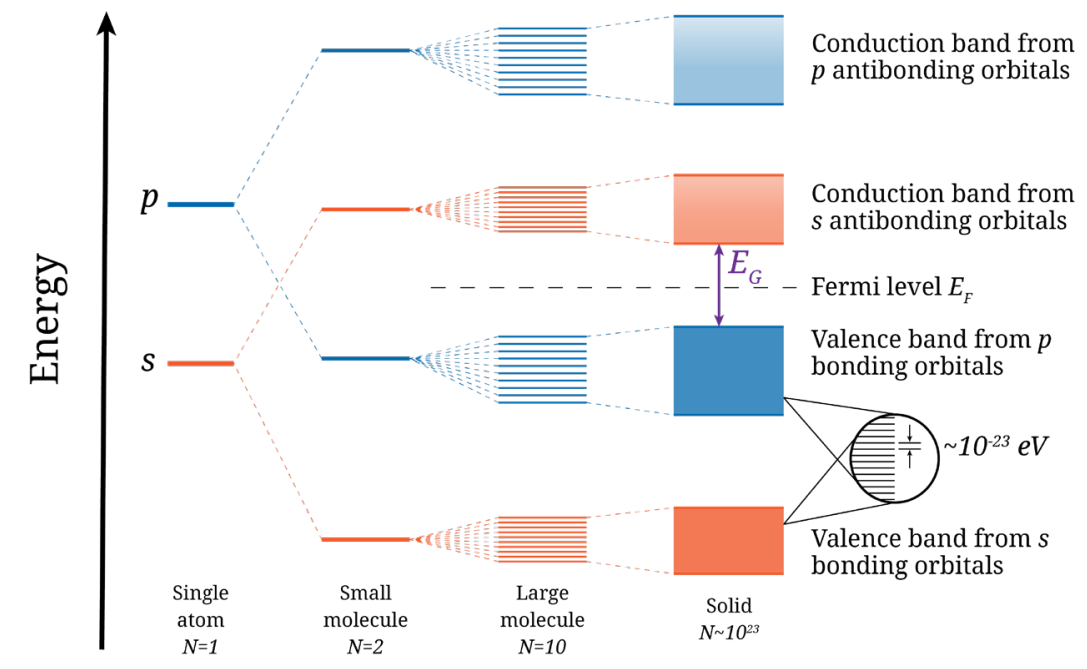

Figure 2-1 Diagram of the evolution of the atomic $s$ and $p$ orbitals into valence and conduction bands at zone center within the tight-binding approximation for a semiconductor.

The Fermi level $\left(\mathrm{E}_{\mathrm{F}}\right)$ is a hypothetical energy level of an electron such that at thermodynamic equilibrium, it would have a $50 \%$ probability of being occupied ${ }^{[3]}$. Valence bands (VBs) and conduction bands (CBs) are the energy bands below and above the Fermi level, respectively. In solid state physics, these two terms, VB and CB, refer to the energy bands closest to the Fermi level. Figure 2-2 shows the diagram of band structures of metal, semimetal, semiconductor, and insulator. In metals, the Fermi level lies in the $\mathrm{CB}$, whereas, in inorganic semiconductors, the Fermi level is within the bandgap $\left(\mathrm{E}_{\mathrm{G}}\right)$ between the $\mathrm{CB}$ and VB.

Valence band and conduction band are terms used to describe the band structure of inorganic semiconducting crystals. Organic semiconductors often do not have periodic crystal structures, and therefore, the idea of VB and $\mathrm{CB}$ is not applicable. However, a band-like structure can be defined by the molecular orbitals of constituent organic atoms. The highest occupied molecular orbital (HOMO) and lowest unoccupied molecular 
orbital (LUMO) levels are analogous to the valence band maximum (VBM) and the conduction band minimum $(\mathrm{CBM})$ of inorganic semiconductors, respectively ${ }^{[5]}$. The energy difference between HOMO and LUMO is termed the HOMO-LUMO gap, which is analogous to $\mathrm{E}_{\mathrm{G}}$ of inorganic semiconductors.

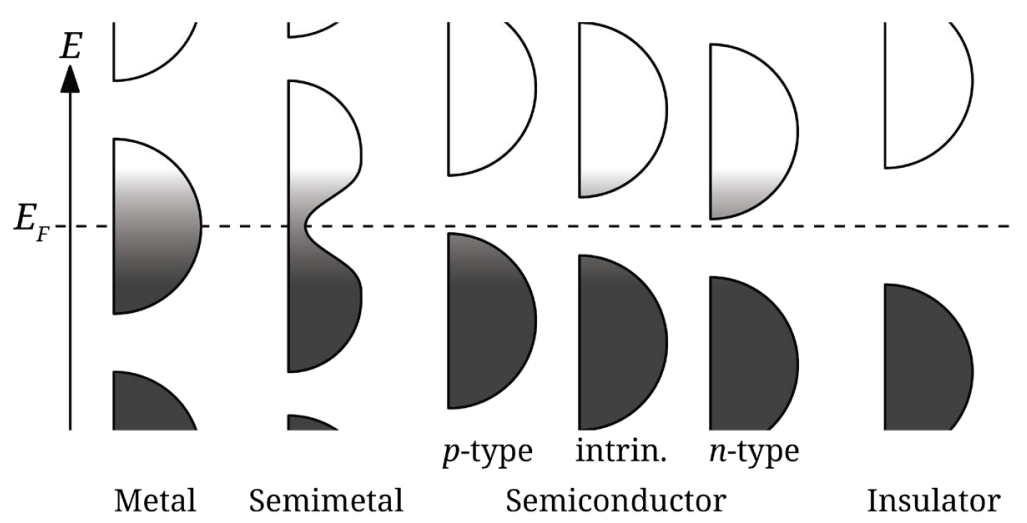

Figure 2-2 Band filling diagrams for metal, semimetal, semiconductor, and insulator ${ }^{3}$.

For both organic and inorganic semiconductors, orbitals in the VB (HOMO) or lower bands are completely filled with electrons, and orbitals in the CB (LUMO) or higher bands are empty or partially filled with electrons. Only electrons in energy bands near or above the Fermi level are free to move and act as charge carriers since the electrons can easily occupy vacant orbitals in higher energy bands.

\subsection{Theory of solar cells}

\subsubsection{P-N junction}

A photovoltaic device is essentially a large area $p-n$ junction, which is, in principle, a p-type semiconductor (acceptor) and an n-type semiconductor (donor) brought into contact with each other. Consider a p-n junction formed by p-type and n-type silicon.

\footnotetext{
${ }^{3}$ Credit: Nanite[CCO 1.0], via Wikimedia Commons.
} 
Assumably, the doped regions are uniformly doped, and the transition between the two regions is abrupt. Figure 2-3 shows the energy band diagram of the two semiconductors when they are apart. Since both semiconductors are made of silicon, the CBs and the VBs of these two semiconductors are aligned. However, as they are different types, the Fermi levels of these two semiconductors, $\mathrm{E}_{\mathrm{Fp}}$ and $\mathrm{E}_{\mathrm{Fn}}$, are not aligned.

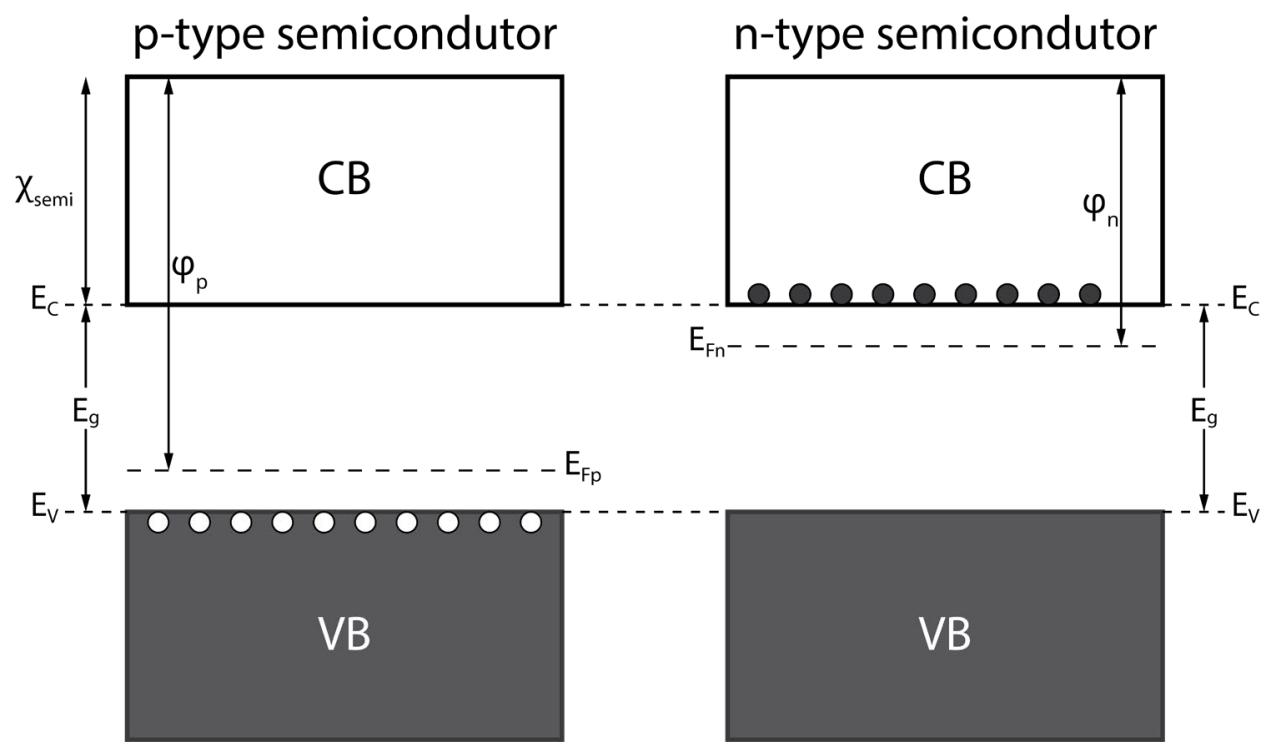

Figure 2-3 Energy band diagram of two different types (p-type and n-type) of silicon before the junction is formed. The solid and hollow circles represent the free electrons and free holes, respectively.

The principle of operation for a p-n junction will be explained using a thought experiment, in which the p-type $\mathrm{Si}$ and n-type $\mathrm{Si}$ are brought into contact with each other with no external electric field. Note that this does not automatically align $\mathrm{E}_{\mathrm{Fp}}$ and $\mathrm{E}_{\mathrm{Fn}}$. There are two causes for charge carrier motion in a p-n junction: diffusion driven by carrier concentration gradient, and drift driven by an internal or external electric field. Initially, there will be a sharp concentration gradient of electrons and holes, as shown by the solid red and blue lines in Figure 2-4. Electrons from the region of high electron concentration (n-type side) diffuse into the region of low electron concentration (p-type side), combine with the holes, and get eliminated. Likewise, the holes in the p-type side 
diffuse into the n-type side, combine with the electrons, and get eliminated. The flow of charge carriers continues until $\mathrm{E}_{\mathrm{Fp}}$ and $\mathrm{E}_{\mathrm{Fn}}$ are aligned.

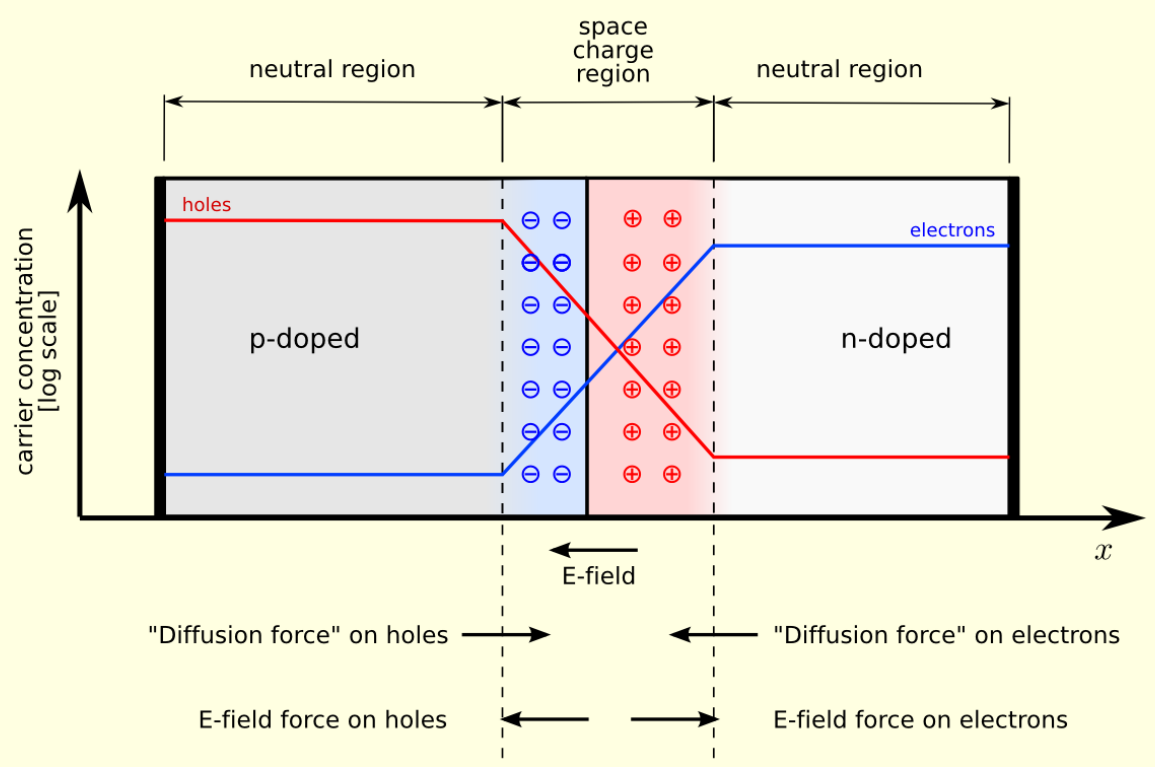

Figure 2-4 A p-n junction in thermal equilibrium with no external electric field.lue and red lines represent the electron and hole concentrations, respectively. The area between dashed lines is the depletion region or the space charge region. The red and blue circles represent the positively charged donor ions and the negatively charged acceptor ions, respectively. The red and blue shaded areas represent the positively charged and the negatively charged region, respectively. ${ }^{4}$

Therefore, in a region near the heterojunction, the n-type side loses its free electrons, and the p-type side loses its free holes. The region around the heterojunction loses its neutrality and majority charge carriers, forming the depletion region or the space charge region. Because of the movement of the majority charge carriers on both side of the p-n junction, the n-type side of the depletion region becomes positively charged (due to the positively charged donor ions), and the p-type side of the depletion region becomes negatively charged (due to the negatively charged acceptor ions), as shown in Figure 2-4. An electric field is thus created in the depletion region, which causes a charge flow, known as the drift current, in the opposite direction as the diffusion process for electrons

\footnotetext{
${ }^{4}$ Credit: TheNoise[CC BY-SA 3.0], via Wikimedia Commons.
} 
and holes. Concurrently, the diffusion and drift processes counterbalance each other and establish equilibrium.

When a p-n junction is in equilibrium, the Fermi level is constant across the entire junction. Thus, the CBs and VBs of the p-type and n-type semiconductors are not aligned. Figure 2-5 shows the space charge distribution, electric field distribution, electric potential distribution, and the band diagram of an abrupt p-n junction in equilibrium. Figure 2-5 (A) shows the space charge distribution in the depletion region. The vertical axis represents the charge density. The blue shaded region (p-type side) is negatively charged (thus below the x-axis) due to the negatively charged acceptor ions, and the red shaded region (n-type side) is positively charged (thus above the x-axis) due to the positively charged donor ions. The widths of the red and blue area, $\mathrm{W}_{\mathrm{Dn}}$ and $\mathrm{W}_{\mathrm{Dp}}$, are the depths of the depletion region in the n-type side and the p-type side, respectively. Due to the difference in doping densities on both sides, the depths of the depletion region on both sides are usually different. Here the full-depletion approximation is applied, meaning there are no free charge carriers within the depletion region. The electric field is created going from the n-type side to the p-type side, as shown in Figure 2-5 (B). By Gauss's law in the differential form, which states that the divergence of the electric field equals the charge density divided by the dielectric constant, one can immediately conclude that the electric field changes linearly with position. At equilibrium, there is no electric field outside the depletion region. Therefore, the electric field is zero at both ends of the depletion region $\left(x=-W_{D p}\right.$ and $\left.x=W_{D n}\right)$. At $x=0$, the electric field reaches the maximum and can be calculated by integrating from $x=-W_{D p}$ to $x=0$, or from $x=$ 
$W_{D n}$ to $x=0$. The electric field generates the built-in potential $\psi_{b i}$, which can be calculated by the area of the grey area in Figure 2-5 (B) and is shown in Figure 2-5 (C).

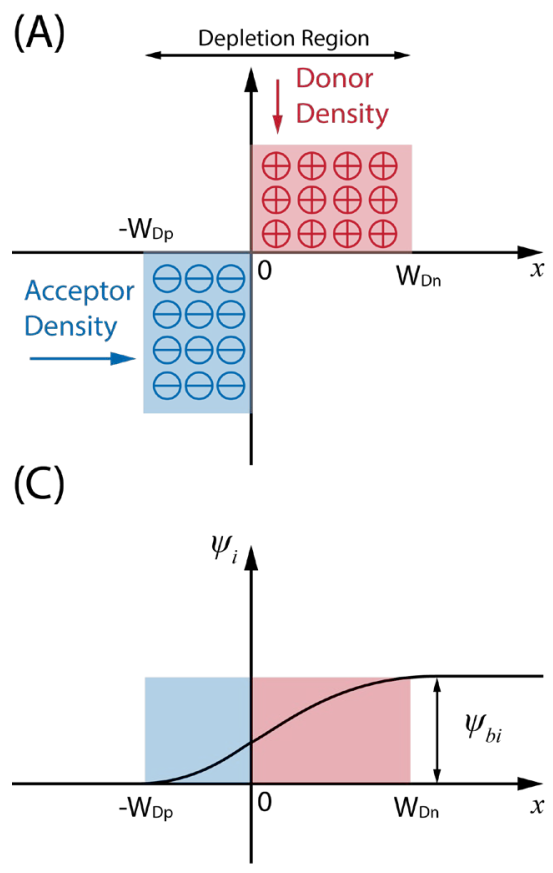

(B)

(D)
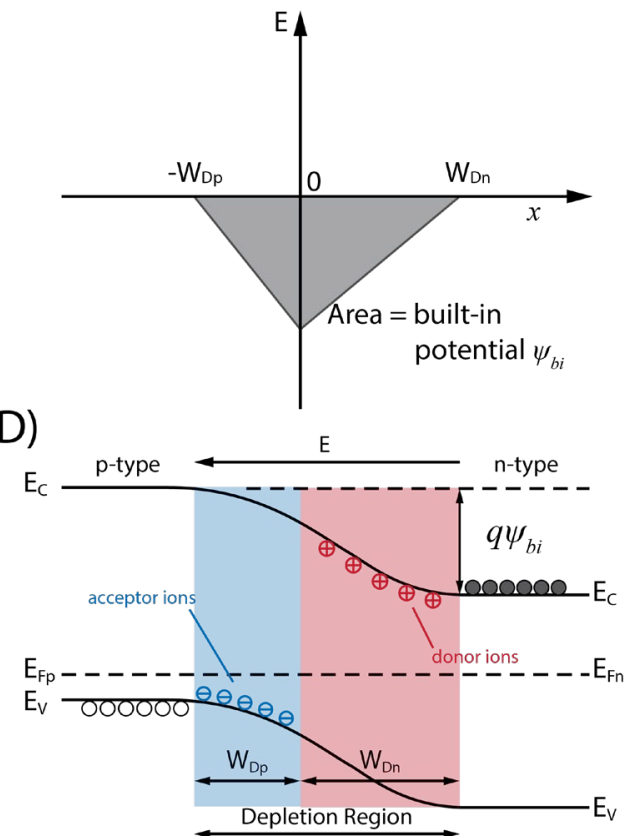

Figure 2-5 Abrupt p-n junction in thermal equilibrium adapted from reference ${ }^{[6]}$. (A) Space charge distribution. The red and blue circles represent the positively charged donor ions and the negatively charged acceptor ions, respectively. $\mathrm{W}_{\mathrm{Dp}}$ and $\mathrm{W}_{\mathrm{Dn}}$ represent the width of the depletion region in the p-type side and the n-type side, respectively. (B) Electric field distribution. (C) Electric potential distribution. $\psi_{b i}$ is the build-in potential. The red and blue shaded areas represent the positively charged and the negatively charged depletion region, respectively. (D) Energy band diagram. The solid and hollow circles represent the free electrons and holes, respectively.

The presence of the electric field and the potential leads to band bending, which can be shown by solving Poisson's equation ${ }^{[6]}$. The $\mathrm{CB}$ and the VB in the p-type side bend downward toward the interface, while the $\mathrm{CB}$ and the VB in the n-type side bend upward toward the interface. The energy bands vary continuously in the depletion region, as shown in Figure 2-5 (D). The free electrons in the n-type region would face an energy barrier, $q \psi_{b i}$, if they want to move to the p-type region. 


\subsubsection{Photogeneration of charge carriers}

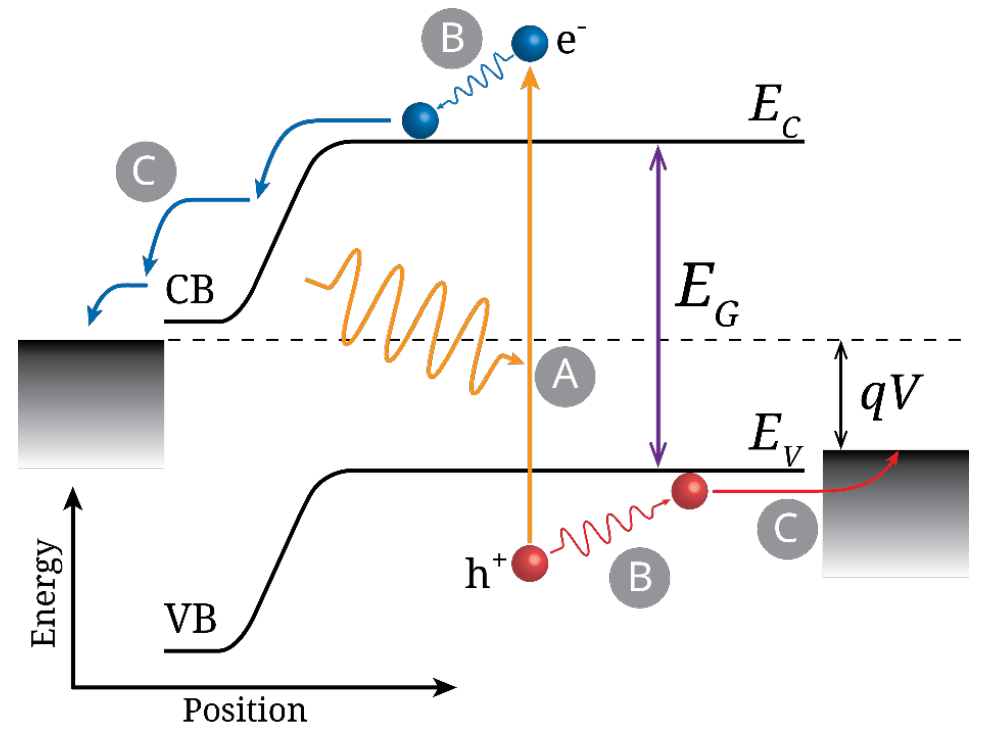

Figure 2-6 Diagram of the three stages of PV power conversion: (A) absorption of a photon and generation of an electron-hole pair, (B) thermalization of charge carriers, and (C) selective extraction of electrons and holes at two terminals.

As shown in Figure 2-6, when a photoactive semiconductor absorbs a photon with energy equivalent to or higher than $E_{G}$, the photon energy is transferred to an electron in the VB and excites it into the $\mathrm{CB}$ where it is free to move around, leaving the absence of an electron, a quasiparticle known as a hole in the VB. The photogenerated electron-hole pair is bound by the Coulomb force; such a bound state can be considered as a quasiparticle called an exciton. If the exciton binding energy is comparable to the thermal energy $\left(k_{B} T, \sim 26 \mathrm{meV}\right.$ at $\left.300 \mathrm{~K}\right)$, the bound electron-hole pair breaks the electrostatic bonding and disassociates into a free electron in the CB and a free hole in the VB. This process is called the photogeneration of charge carriers.

Further, the electron-hole pairs can relax towards the VB maximum $\left(E_{V}\right)$ and the $\mathrm{CB}$ minimum $\left(E_{C}\right)$ by giving the extra energy to lattice vibrations, or phonons. This process is called the thermalization of charge carriers (represented by the blue and red 
wavy arrows), and the result is that the absorbed photon energy above the bandgap $E_{G}$ is lost.

\subsubsection{Charge separation and photocurrent}

To complete the photovoltaic process and to generate a photocurrent and photovoltage, the free electrons and holes must be separated and transported out of the photoactive semiconductor selectively. This process is called charge separation.

If the photogenerated charge carriers are created in the depletion region, the strong electric field will push the electron toward the n-type side and the hole toward the p-type side. If the photogenerated charge carriers are created outside the depletion region, the electrons and holes can still move as a result of diffusion. If an electron on the p-type side reaches the depletion region, the electric field will sweep it from the p-type side to the ntype side. In a similar fashion, the electric field would sweep the holes reaching the depletion region on the n-type side to the p-type side. Therefore, on the p-type side, electrons are always the minority charge carriers, and on the n-type side, holes are always the minority charge carriers.

In conclusion, the electric field in the depletion region continuously sweeps the minority carriers across the heterojunction, making them the majority carriers on the other side of the junction. Such charge carrier flow is induced thermally (no illumination) or together with photon absorption (under illumination). For majority carriers, the diffusion process, resulting from the charge carrier concentration gradient, drives them into the depletion region. Most majority carriers are held back by the electric field in the depletion region. While a small number of the majority carriers, those with the highest kinetic energies, can fully diffuse across the depletion region and become the minority carriers 
on the other side. Once the drift of minority carriers and the diffusion of majority carriers reach a dynamic equilibrium, the charge carrier distribution is determined in the entire pn junction.

Ohmic metal-semiconductor electrodes are deposited to the terminals of both sides of the p-n junction as connections to an external load. The electrode on the n-type side collects electrons from two sources: free electrons created on the n-type side and free electrons created on the p-type side and swept to the n-type side. The collected electrons travel through the external circuit, power the load, and continue traveling through the wire until they reach the electrode on the p-type side. The electrons then recombine with the holes collected at the p-type terminal from two sources: holes that were created on the p-type side, and holes that were created on the n-type side, diffused to the depletion region and swept to the p-type side.

\subsection{Recombination}

Recombination is the reverse process of excitation or photogeneration. In general, an electron in the conduction band jumps back into the valence band and recombines with a hole, giving the energy off as light or heat. Recombination leads to the elimination of charge carriers and should be prevented in a photovoltaic device so that more charge carriers can be collected, and more photocurrent can be generated. On the contrary, a light-emitting diode (LED) is a device optimized for the recombination of charge carriers to release energy in the form of photons. There are three types of recombination in the bulk of a single crystal semiconductor according to the mechanism, as shown in Figure 2-7. 


\subsubsection{Radiative recombination}

Radiative recombination is the inverse process of photon absorption. An electron in the conduction band combines directly with a hole in the valence band, emitting a photon, as shown in Figure 2-7 (A). The emitted photon carries energy close to the bandgap of the semiconductor, and it is only weakly absorbed, making it able to exit the semiconductor. The radiative recombination is the basis of LED and the dominating recombination process in direct bandgap semiconductors, such as GaAs. However, crystalline silicon used widely in commercial solar cells is an indirect bandgap semiconducting material. A phonon is necessary for the radiative recombination process due to the conservation of momentum. Therefore, the radiative recombination is extremely low and can be neglected in crystalline silicon.
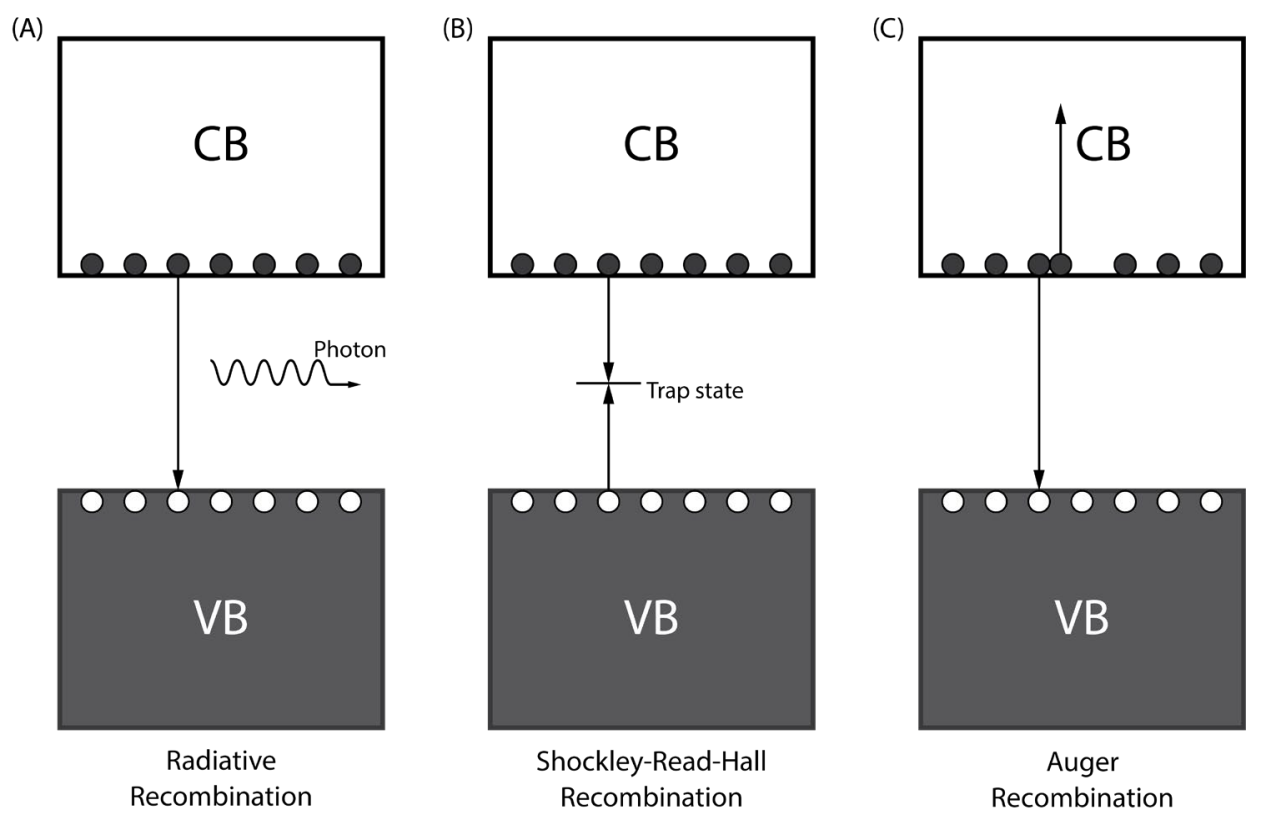

Figure 2-7 Schematic diagrams of (A) radiative, (B) Shockley-Read-Hall, and (C) Auger recombination. 


\subsubsection{Shockley-Read-Hall recombination}

Shockley-Read-Hall (SRH) recombination, also called the trap-assisted recombination, is a two-step process ${ }^{[7,8]}$, as shown in Figure 2-7 (B). Firstly, an electron (or hole) is trapped by an energy level in the forbidden band (trap level), which is caused by defects or dopants in the crystal lattice. The trapped electron can be released into the conduction band by thermal activation. However, if a hole (or an electron) is also trapped at the same energy state before the trapped electron (or hole) is thermally released, the two charge carriers recombine and release the energy as lattice vibration. If a trap level is close to the edge of the conduction band, excited electrons in the conduction band are likely to be trapped at this state rather than holes. Such a trap state is called an electron trap. Similarly, if a trap level is close to the edge of the valence band, it is called a hole trap.

The rate at which a charge carrier is trapped at an energy level in the forbidden band depends on the distance of the energy level to either of the band edges. Excited electrons in the conduction band are less likely to be trapped in hole traps, and holes in the valence band are less likely to be trapped in electron traps. Therefore, an electron trapped in an electron trap is likely to be released into the conduction band before it meets a trapped hole at the same energy level.

If the distance between a trap level and either band edge is less than the thermal energy $k_{B} T$, it is called a shallow trap. Otherwise, it is called a deep trap. Charge carriers trapped in a shallow trap are more likely to be released into the conduction band or the valence band than those trapped in the deep traps. 


\subsubsection{Auger recombination}

Auger recombination is a process involving three charge carriers. An excited electron in the conduction band and a hole in the valence band recombine. However, rather than releasing the energy as a photon or lattice vibration, the energy is given to a second electron in the conduction band, which is then excited to a higher energy level in the same energy band ${ }^{[9,10]}$, as shown in Figure 2-7 (C). After Auger recombination, the second electron eventually loses its excess energy to lattice vibration. Due to the involvement of three carriers, Auger recombination is only significant in non-equilibrium conditions where the carrier density is very high.

Carrier lifetime and diffusion length of a semiconductor are two important parameters relating to recombination rates. The minority carrier lifetime, $\tau_{n}$ or $\tau_{p}$, is the average time in which a minority carrier can exist in an excited state before recombination. Carrier diffusion length, $L_{n}$ or $L_{p}$, is the average length a carrier moves between generation and recombination. These two parameters are critical for the possibility of a charge carrier being collected before recombination. A higher carrier diffusion length usually means that charge carriers can travel longer distances before recombination and therefore are more likely to be collected. In a typical photovoltaic device, the thickness of the active layer is smaller or close to the carrier diffusion length so that the charge carriers can be effectively collected.

\subsection{Characterization of solar cells}

The most critical characterizing parameter of a solar cell is its energy conversion efficiency. For a typical energy conversion system, efficiency is defined as the ratio of 
energy in against energy out. For a solar cell, the input energy is the energy from the incident solar illumination, and the output is the electricity it generates. The efficiency of a solar cell, together with other key parameters, is embodied in its I-V curve, which depicts the relationship between output current and voltage of the device under particular illumination and temperature conditions.

\subsubsection{The solar spectrum}

The performance of a solar cell depends on the illumination intensity. Above the atmosphere, the Sun irradiates the Earth with an extra-terrestrial spectral irradiance known as the AM0 spectrum. The acronym stands for air mass zero, which means that the spectrum was measured with no air between the receiver and the Sun. Most solar cells are intended for use with sunlight illumination on the Earth. The AM0 spectrum applies only to space-based solar panels as the solar irradiance on the Earth's surface is rather different. As the sunlight passes through the atmosphere, the AM0 spectrum is attenuated by atmospheric absorption, scattering, and reflection from the surface of the Earth. Besides the spectral difference, solar irradiance on the Earth surface is also perpetually fluctuating in intensity. With such widely varying irradiance, the photovoltaic community has adopted a set of operating conditions for measuring the efficiency of solar cells.

The primary set of operating conditions is the Standard Reporting Conditions (SRC). The standard spectrum for SRC is the AM1.5G spectrum with a total irradiance of $1000 \mathrm{~W} / \mathrm{m}^{2}$. The AM1.5G spectrum, which is derived from measurements in space and an atmospheric transmittance model, corresponds to the amount of average sunlight available at all wavelengths that reach the Earth's surface at mid-latitudes after attenuation by 1.5 thickness of atmosphere (resulting from the solar zenith angle of $48.2^{\circ}$ ). 
Figure 2-8 shows the spectral irradiance outside the Earth's atmosphere with the AM1.5G and AM1.5D spectrum. The AM1.5G spectrum is suitable for flat PV panels, whereby the AM1.5D spectrum is useful for concentrating solar systems.

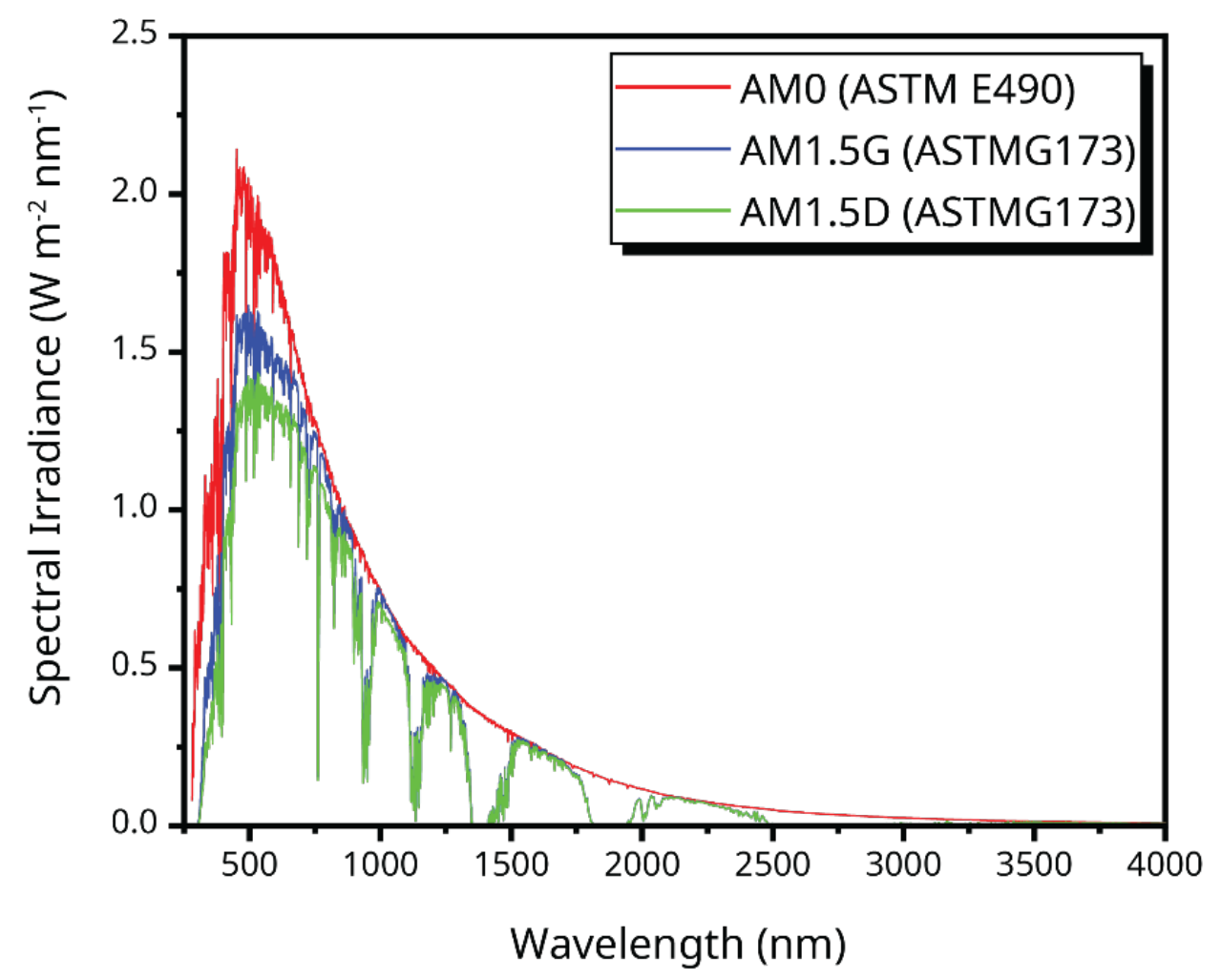

Figure 2-8 Spectral irradiance received outside the Earth's atmosphere (AM0), and on the surface of Earth at mid-latitudes, passing through 1.5 atmosphere thickness (AM1.5G and AM1.5D). Reproduced from data accessed from NREL ${ }^{[11]}$

\subsubsection{Equivalent circuit model of solar cells}

Figure 2-9 shows the equivalent circuit of a single p-n junction solar cell based on ideal electrical components. In the circuit diagram, $I_{L}$ is the photocurrent provided by the photoactive absorbing layer, $I_{D}$ is the diode current (also known as dark diode current), which represents current loss caused by the recombination of charge carriers. A shunt resistance and a series resistance are added to model a real solar cell, where $I_{S H}$ is the current through the shunt resistance. 


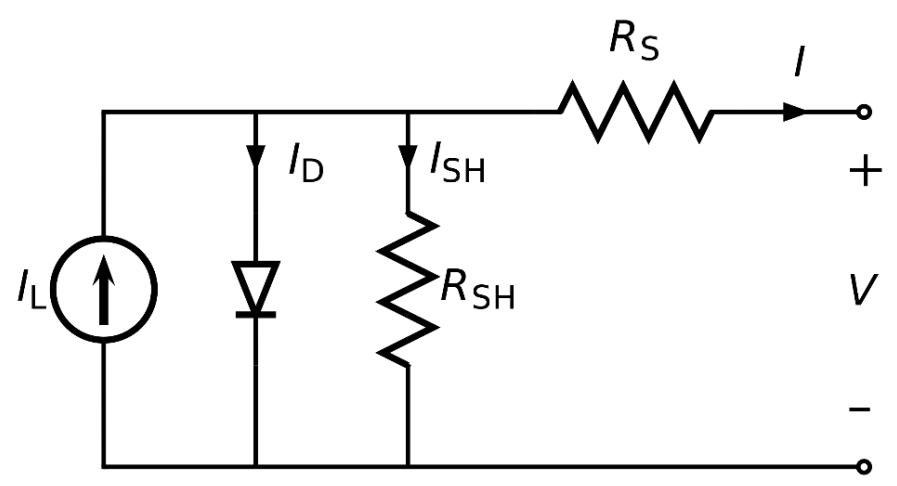

Figure 2-9 Equivalent circuit of a single-junction solar cell ${ }^{5}$.

The collected current between the output electrodes, $I$, evidently is:

$$
I(V)=I_{L}-I_{D}-I_{S H}
$$

The voltage across these components is:

$$
V_{j}=V+I R_{S}
$$

Where $V$ and $V_{j}$ are voltages across the electrodes and the diode, respectively.

The shunt current, $I_{S H}$, is simply,

$$
I_{S H}=\frac{V_{j}}{R_{S H}} .
$$

The diode current, $I_{D}$, is given by the Shockley diode equation.

$$
I_{D}=I_{0}\left[\exp \left(\frac{V_{j}}{n V_{T}}\right)-1\right]
$$

Where $I_{0}$ is the reverse saturation current of the diode, $n$ is diode ideality factor $(n=1$ for an ideal diode and between $1 \sim 2$ typically), $k_{B}$ is the Boltzmann's constant, $e$ is the elementary charge, and $V_{T}=k_{B} T / e$ is the thermal voltage, which is equal to $25.85 \mathrm{meV}$ at $300 \mathrm{~K}$. The reverse saturation current, $I_{0}$, is of fundamental importance as it is a measure of the recombination rate in the diode. A larger $I_{0}$ means the diode has a larger

\footnotetext{
${ }^{5}$ Credit: Squirmymcphee[CC BY-SA 3.0], via Wikimedia Commons.
} 
recombination rate. As the temperature of the diode increases, the recombination rate also increases, as does $I_{0}$. Substituting Eq. 2-2 through Eq. 2-4 into Eq. 2-1 produces:

$$
I(V)=I_{L}-I_{0}\left\{\exp \left[\frac{e\left(V+I R_{S}\right)}{n k_{B} T}\right]-1\right\}-\frac{V+I R_{S}}{R_{S H}}
$$

\subsubsection{Current-voltage measurement}

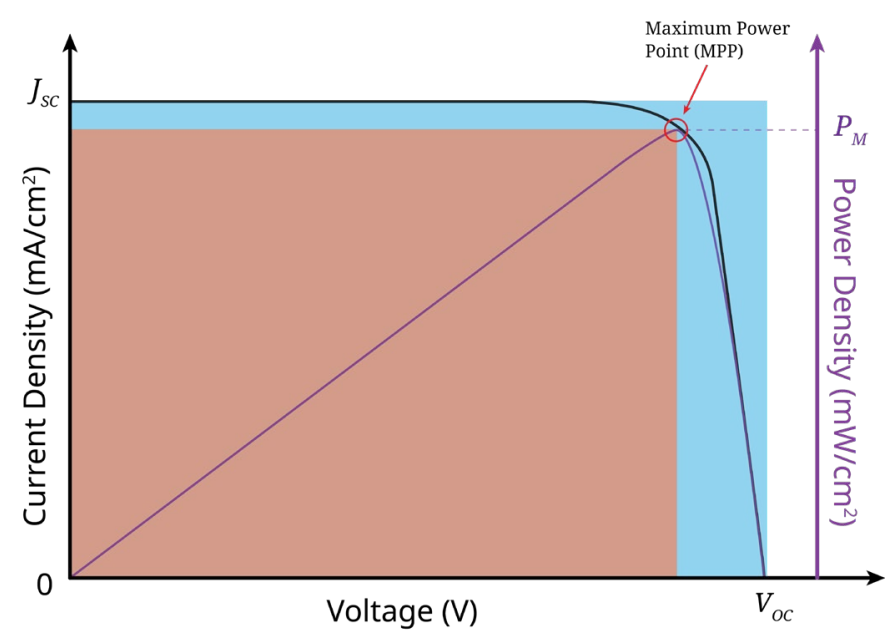

Figure 2-10 A generic J-V curve and power density output of a solar cell under sun illumination. The intercepts of the $\mathrm{J}-\mathrm{V}$ curve (black) on the $x$-axis and the $y$-axis are the $V_{O C}$ and $J_{S C}$, respectively. The maximum power point is located at the peak of the power density curve (purple). The blue rectangle is defined by the $x$-axis, $y$-axis, $V_{O C}$, and $J_{S C}$. The orange rectangle is defined by the $x$-axis, $y$-axis, and the maximum power point. The ratio of the orange area divided by the blue area is the fill factor.

Current-voltage (I-V) sweeps are the most widely used method to determine the solar cell performance metrics. In I-V measurements, a solar cell with a known area is connected to a source measure unit (SMU). The voltage bias provided by the SMU is sequentially changed within the desired range, and the corresponding current values are recorded. The I-V measurement can be done both under illumination (light I-V) and in the absence of light (dark I-V). To take into account the effect of the active area, the result of the I-V measurement is plotted as a current density-voltage $(\mathrm{J}-\mathrm{V})$ curve, with the voltage on the $x$-axis and the current density on the $y$-axis, as shown in Figure 2-10. The $\mathrm{J}-\mathrm{V}$ curve directly indicates the position of two key performance metrics: short circuit 
current density $\left(U_{S C}\right)$ and open circuit voltage $\left(V_{O C}\right)$. These two metrics, together with other metrics, are discussed below.

\subsubsection{Short circuit current density $\left(U_{S C}\right)$}

The short circuit current, $I_{S C}$ with unit of $A$ (Ampere), is defined as the current through the solar cell terminals when there is no external bias voltage applied. For a highquality solar cell with a small $R_{S}$, a small $I_{0}$, and a high $R_{S H}$, the short circuit current, $I_{S C}$, is approximately equivalent to the photocurrent, $I_{L}$. As the active area of a solar cell increases, more photons will be absorbed and $I_{S C}$ will also increase. To remove the

dependence upon the active area, the short circuit current density, $J_{S C}$ with units of $\frac{m A}{c m^{2}}$, is more widely used as the metric to compare different solar cells. In a plotted $\mathrm{J}-\mathrm{V}$ curve figure, $J_{S C}$ is the $y$-intercept, as labeled in Figure 2-10.

Photocurrent through the terminals of a solar cell is reduced by absorption loss, blackbody radiation, and recombination of charge carriers (both radiative and nonradiative). To maximize the photocurrent of a solar cell, one of the principal methods is to increase the number of absorbed photons. Therefore, the absorbing layer in a solar cell must be thick enough to absorb as many photons as possible, while keeping the energy loss in the charge carrier recombination process as low as possible.

\subsubsection{Open circuit voltage $\left(V_{o c}\right)$}

If a solar cell is operated at the open circuit, i.e., $I=0$, the voltage across the terminals of the solar cell is defined as the open circuit voltage, $V_{O C}$. It is also the maximum photovoltage that could be provided by the solar cell under illumination. When 
a bias voltage equal to $V_{O C}$ is applied to the terminals of a solar cell, the electric field of the bias voltage cancels out the electric field in the depletion region discussed in Section 2.3. Minority charge carriers will not be swept to the other side of the heterojunction and become the majority charge carriers. The charge carrier concentration gradient across the heterojunction will no longer exist because of the diffusion process, and charge carriers cannot be separated on the two sides of the heterojunction anymore.

The maximum photovoltage is determined mainly by the bandgap of the photoactive semiconducting material. Solar cells using an absorbing layer with a large bandgap usually have a large $V_{O C}$, and vice versa. The $V_{O C}$ is also affected by the energy band structure of the semiconducting layers used to selectively extract charge carriers from the absorbing layer and the work functions of the metal electrodes. The CB edge of the electron transporting layer (ETL) should be aligned with the CB edge of the active layer, and the VB edge of the hole transporting layer (HTL) should be aligned with the VB edge of the active layer. Otherwise, it would make it energetically unfavorable for charge carriers to be extracted from the active layer. These layers should also be of proper thicknesses to select electrons (holes) and block holes (electrons) while not causing any significant energy loss during charge carrier extraction.

The approximated equation of $V_{O C}$ can be deducted from Eq. 2-5 assuming the shunt resistance $R_{S H}$ is high enough to neglect the last term on the right-hand side.

$$
V_{O C} \approx \frac{n k_{B} T}{e} \ln \left(\frac{I_{L}}{I_{0}}+1\right)
$$

In a plotted $\mathrm{J}-\mathrm{V}$ curve figure, $V_{O C}$ is the $x$-intercept, as labeled in Figure 2-10. 


\subsubsection{Fill factor $(F F)$}

The I-V sweep provides information about the range of voltages and currents over which a solar cell can operate. The $V_{O C}$ and $I_{S C}$ are the maximum voltage and current that a solar cell can provide under illumination, respectively. The maximum power point of an $\mathrm{I}-\mathrm{V}$ curve is simply the point that maximizes $V \times I$. It represents the maximum electrical power that a solar cell can generate under a certain level of illumination. It should be noted that the maximum power point of a solar cell varies with the incident illumination.

As discussed in Section 2.5.3.1, the current, $I$, depends directly upon the active area of the solar cell. The point that maximizes the electrical power, $V \times I$, is also the point that maximizes the electrical power density, $V \times J$. To remove the dependence of active area when comparing between two solar cells, it is often more useful to define the maximum power point as the point that maximizes $V \times J$ rather than $V \times I$, and this will be the definition of the maximum power point throughout this dissertation.

As shown in Figure 2-10, the fill factor $(F F)$ is defined as the ratio of the available power density at the maximum power point $\left(P_{M}\right.$, with the unit of $\left.\frac{\mathrm{mW}}{\mathrm{cm}^{2}}\right)$, i.e. the orange area,

divided by the open circuit voltage $\left(V_{O C}\right)$ and the short circuit current density $\left(J_{S C}\right)$, i.e., the blue area.

$$
F F=\frac{P_{M}}{V_{O C} \times J_{S C}} \times 100 \%
$$

Fill factor is a metric to determine the quality of a solar cell, which should always be maximized during fabrication optimization by reducing the series resistance, $R_{S}$, and increase the shunt resistance, $R_{S H}$. 


\subsubsection{Power conversion efficiency}

By definition, the power conversion efficiency (PCE) is a percentage of the maximum power a solar cell can generate relative to the power of the incident illumination. It can also be expressed as the percentage of the maximum output power density to the incident radiation power density. The AM1.5G spectrum is the widely used standard solar irradiation spectrum for solar cell testing because it is representative of average conditions in the 48 contiguous states of the US. The incident power density of $\operatorname{AM} 1.5 \mathrm{G}$ spectrum $\left(P_{i n}\right)$ is $1000 \frac{\mathrm{W}}{\mathrm{m}^{2}}$, or $100 \frac{\mathrm{mW}}{\mathrm{cm}^{2}}$.

$$
P C E=\frac{P_{\text {out }}}{P_{\text {in }}}=\frac{P_{M}}{P_{\text {in }}}=\frac{V_{O C} \times J_{S C} \times F F}{100 \frac{\mathrm{mW}}{\mathrm{cm}^{2}}} \times 100 \%
$$

\subsubsection{Shunt resistance $\left(R_{S H}\right)$}

In a solar cell, the shunt resistance measures the resistance against the leakage current bypassing through the absorbing layer and the charge extraction semiconducting layers. In terms of thin-film solar cells, these leakage pathways are usually caused by incomplete layers, which might be the result of the high roughness of interfaces between layers or pinholes that penetrate through the entire thickness of the layer.

When the number of leakage pathways increases, the shunt resistance decreases, and more current leaks through the device. The decrease of the shunt resistance results in the part of the $\mathrm{J}-\mathrm{V}$ curve between the maximum power point and the current density axis (y-axis in Figure 2-11) dropping down like a slope, as shown in Figure 2-11, generating a significantly reduced current density. When a solar cell is heavily shunted, i.e., the shunt resistance is small, the $\mathrm{J}-\mathrm{V}$ curve of the solar cell will be close to a straight line, similar 
to the characteristics of a resistor and $V_{O C}$ will drop significantly. The shunt resistance can be approximated by taking the inverse of the slope of the I-V curve in the region near $J_{S C}$

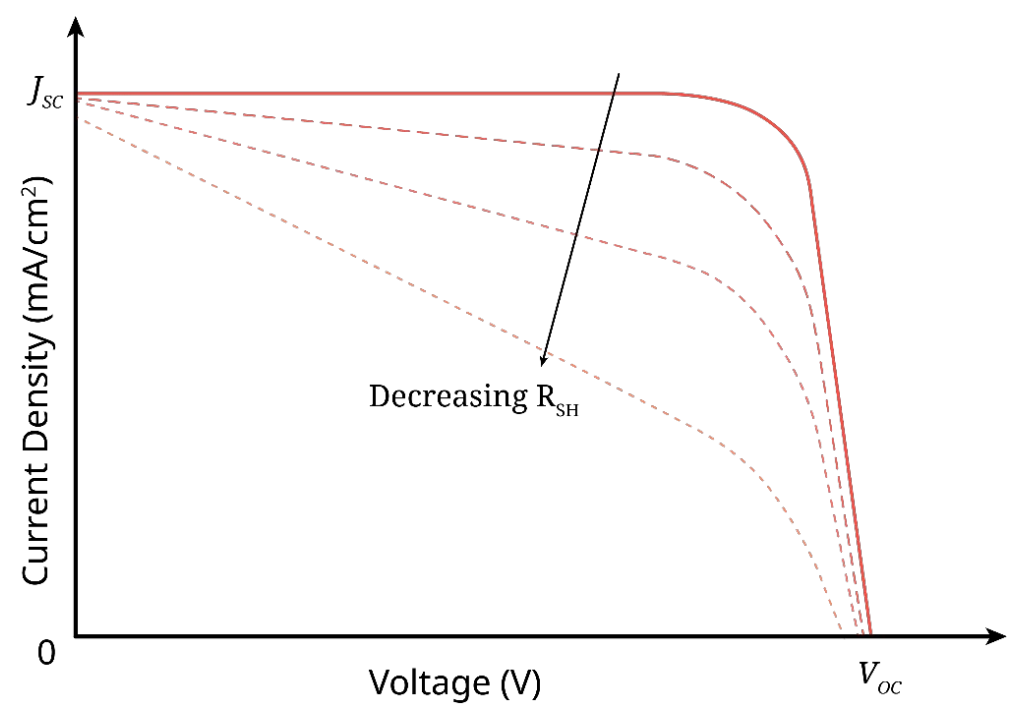

Figure 2-11 Effect of shunt resistance on the J-V curve of a solar cell.

\subsubsection{Series resistance $\left(R_{S}\right)$}

The series resistance of a solar cell measures all the resistance against the extraction and transportation of charge carriers. The causes of the series resistance in a solar cell include the low charge carrier mobility, trap density in either the absorbing layer or the charge extraction layer, the contact resistance between the metal electrode and charge extraction layer, and finally, the resistance of the top and rear metal electrodes.

If the charge carrier mobility in the absorbing layer or the charge extraction layer is not high enough for the charge carrier to travel through before being trapped or combined, the series resistance will increase. Similarly, an absorbing layer or charge extraction layer with a high density of defects will also increase the probability of recombination and the series resistance. Any energetic barriers at the interface between 
two layers caused by the not-well-aligned energy bands will hinder the flow of charge carriers from one layer to another, increase the probability of recombination, decrease the charge carrier mobility, and increase the series resistance.

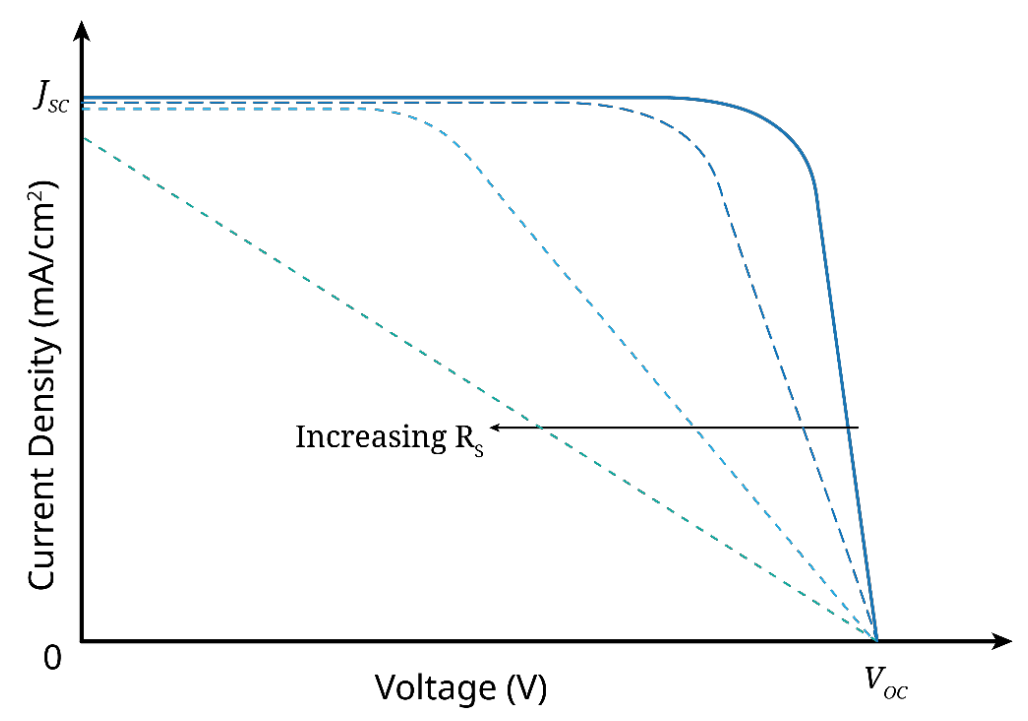

Figure 2-12 Effect of series resistance on the J-V curve of a solar cell.

When the series resistance increases, the part of the $\mathrm{J}-\mathrm{V}$ curve between the maximum power point and the voltage axis (x-axis in Figure 2-12) starts to incline towards the current density axis ( $y$-axis), with the $J_{S C}$ and the fill factor also decreasing, as shown in Figure 2-12. The series resistance can be approximated by taking the inverse of the slope of the $\mathrm{I}-\mathrm{V}$ curve in the region close to $V_{O C}$.

\subsection{The Shockley-Queisser limit}

The Shockley-Queisser limit refers to the maximum theoretical efficiency of a solar cell using a single p-n junction. In 1961, Shockley and Queisser (SQ) analyzed the theoretical limits of PV energy conversion efficiency by the thermodynamic principle of detailed balance ${ }^{[12]}$; therefore, it is also known as the detailed balance limit. The SQ-limit 
is of fundamental significance as it defines an ideal model as a reference for singlejunction solar cells.

\subsubsection{The SQ model}

The SQ-limit is calculated by examining the amount of electrical energy that is extracted per photon absorbed in an idealized model. The SQ model treats the power conversion process of a single-junction solar cell in three stages, as shown in Figure 2-6.

a) creation of a free electron in the $\mathrm{CB}$ and a free hole in the VB by absorbing a photon,

b) relaxation of the free electron and free hole towards $E_{C}$ and $E_{V}$, respectively, i.e., thermalization of charge carriers,

c) selective extraction of the electron and hole at two terminals, or their radiative recombination by emission of a photon.

The sources of loss in these three stages are assumed, by the SQ model, to be restricted to spectrum loss, blackbody radiation, and radiative recombination.

The spectrum loss comes from two assumptions. First, the probability of absorption of incident photons is a step function, 0 for $h v<E_{G}$ and 1 for $h v \geq E_{G}$. In other words, incident photons with energy $h v \geq E_{G}$ are entirely absorbed, whereas photons with energy $h v<E_{G}$ are not absorbed at all. Further, a single electron-hole pair is created with the absorption of a photon with energy $h v \geq E_{G}$. The second assumption is that any energy above $E_{G}$ is lost, i.e., the electron-hole pair is obliged to relax towards $E_{C}$ and $E_{V}$ respectively and transfers excess energy to phonons. In silicon, the effect of 
these two assumptions alone is the limit of $48 \%$ for the maximum theoretical conversion efficiency.

The blackbody radiation effect suggests that any material above absolute zero (0 Kelvin) emits electromagnetic radiation. The SQ model assumes that any energy lost in a solar cell is converted to heat, e.g., phonons created by the thermalization of charge carriers towards $E_{C}$ and $E_{V}$. As the temperature of the solar cell increases under illumination, the blackbody radiation also increases until an equilibrium is reached.

Radiative recombination is the process in which an electron and a hole meet and recombine, emitting a photon. It is the reverse process of the absorption of a photon in a semiconductor. Therefore, according to the principle of detailed balance, it must have the same rate as the absorption process when the semiconductor is in thermal equilibrium ${ }^{[13]}$. In the SQ model, the radiative recombination rate is a function of the voltage across the cell and remains the same whether the cell is illuminated or not.

As explained in Section 2.3.2, the bandgap between the VB and the $\mathrm{CB}$ in a semiconductor is vital for the absorption of photons. However, the SQ model suggests that there is an ideal bandgap for converting solar irradiation to electricity. A semiconducting material with a small bandgap would satisfy $h v \geq E_{G}$ for a large portion of the AM1.5G spectrum and leads to the absorption of the majority of incident photons. Yet a small bandgap results in more absorbed photon energy converted to heat as the energy over $E_{G}$ will be given to phonons when the excited charge carriers relax to $E_{C}$ and $E_{V}$. Conversely, a semiconducting material with a larger bandgap would only satisfy $h v \geq E_{G}$ for short wavelength, high-energy photons, making it impossible to absorb photons in the rest of the AM1.5 spectrum. The AM 1.5 solar spectrum is shown as the 
faded spectrum in Figure 2-13 (A) with the black dash line of $E_{G}$-corresponding to the bandgap of silicon-indicating the portion that can be absorbed by silicon. The spectrum labeled as thermalization represents the spectral distribution of absorbed energy after the thermalization of charge carriers. The maximum converted energy is also limited by the voltage loss between $q V$ and $E_{G}^{[14]}$. Figure 2-13 (B) shows the SQ-limit as a function of the bandgap and the record efficiencies for different PV materials up to April 2016.
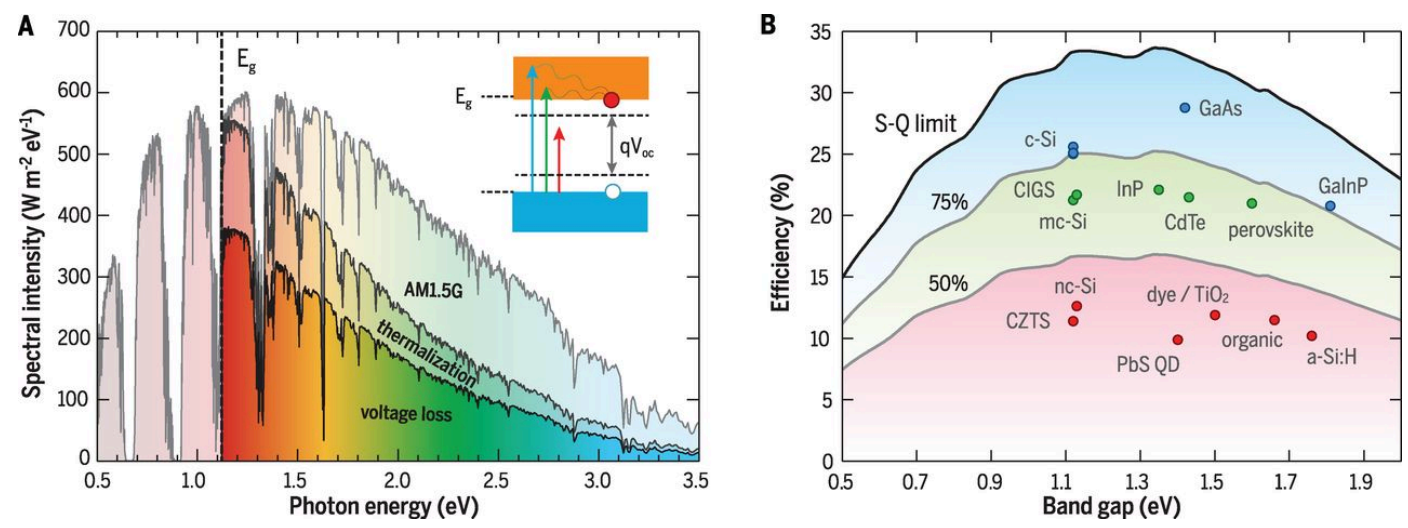

Figure 2-13 Fundamental solar cell efficiency limits and records up to April 2016. (A) AM1.5 solar spectrum with distinct dips due to molecular absorption in Earth's atmosphere. Photons with energy below the bandgap ( $E_{g}$, dashed black line corresponds to $\mathrm{Si}$ ) are not absorbed. Photons with more energy than bandgap are fully converted to free charge carriers due to thermalization. The maximum power generated is limited by voltage loss relative to the bandgap voltage. (B) Theoretical Shockley-Queisser detailed balance limit as a function of bandgap (black line) and $75 \%$ and $50 \%$ of the limit (gray lines). The record efficiencies for different materials are plotted for the corresponding bang gaps. From reference ${ }^{[14]}$. Reprinted with AAAS permission.

\subsubsection{Energy loss beyond the SQ model}

The SQ model only considers the most basic mechanisms of energy loss in a solar cell. However, for a real-world single p-n junction solar cell, several other factors are also limiting the theoretical power conversion efficiency. The first one is non-radiative recombination, which is often caused by defects and grain boundaries in the p-n junction. Even if there are no crystalline defects, Auger recombination is still inevitable, in which case, the recombination energy is given to a third charge carrier and excites it to a higher 
energy level in the same energy band ${ }^{[9,10]}$. Another factor is the limited charge carrier mobility. Generally, the mobility rates of electrons and holes in a semiconductor are not the same. In most cases, holes move much more slowly than electrons. Therefore, a free electron moving in the p-n junction could meet with a hole created earlier than the electron and recombine, whether radiative or non-radiative.

Nonetheless, the SQ-limit provides valuable information about the theoretical efficiency limit for single $\mathrm{p}-\mathrm{n}$ junction solar cells by calculating the amount of energy extracted per photon of incident sunlight. Nevertheless, it should be mentioned that the SQ-limit only applies to single p-n junction solar cells and that it can be outperformed by several strategies. For example, tandem solar cells use more than one p-n junctions with each junction tuned for absorbing a different wavelength of the solar spectrum. NREL has reported a PCE of $47.1 \%$ using four or more junctions with concentrated solar light ${ }^{[15]}$.

\subsection{References}

1. Lenard, P., Ueber die lichtelektrische Wirkung. Annalen der Physik 1902, 313 (5), 149-198.

2. $\quad$ Einstein, A., Über einen die Erzeugung und Verwandlung des Lichtes betreffenden heuristischen Gesichtspunkt. Annalen der Physik 1905, 322 (6), 132-148.

3. Kittel, C., Introduction to Solid State Physics. Wiley: 2004.

4. Bube, R. H., Photovoltaic materials. Imperial College Press: London, 1998.

5. $\quad$ Bredas, J.-L., Mind the gap! Mater. Horiz. 2014, 1 (1), 17-19.

6. Kasap, S., Principles of Electronic Materials and Devices. 4th ed.; McGraw-Hill Education: 2017. 
7. Shockley, W.; Read, W. T., Statistics of the Recombinations of Holes and Electrons. Physical Review 1952, 87 (5), 835-842.

8. Hall, R. N., Electron-Hole Recombination in Germanium. Physical Review 1952, 87 (2), 387-387.

9. $\quad$ Meitner, L., Über die Entstehung der $\beta$-Strahl-Spektren radioaktiver Substanzen. Zeitschrift für Physik 1922, 9 (1), 131-144.

10. Auger, P., Sur les rayons $\beta$ secondaires produits dans un gaz par des rayons X. C.R.A.S. 1923, 177.

11. NREL, 2020, Reference Air Mass 1.5 Spectra.

12. Shockley, W.; Queisser, H. J., Detailed Balance Limit of Efficiency of $\mathrm{p}-\mathrm{n}$ Junction Solar Cells. Journal of Applied Physics 1961, 32 (3), 510-519.

13. Bridgman, P. W., Note on the Principle of Detailed Balancing. Physical Review 1928, 31 (1), 101-102.

14. Polman, A.; Knight, M.; Garnett, E. C.; Ehrler, B.; Sinke, W. C., Photovoltaic materials: Present efficiencies and future challenges. Science 2016, 352 (6283), aad4424.

15. Best Research-Cell Efficiencies. National Renewable Energy Laboratory: https://www.nrel.gov/pv/assets/pdfs/best-research-cell-efficiencies.20200803.pdf, 2020. 


\section{CHAPTER 3. Organic-Inorganic Perovskite Materials and Perovskite Solar Cells}

\subsection{Introduction}

Perovskite is a class of material with the same type of crystal structure as calcium titanium oxide $\left(\mathrm{CaTiO}_{3}\right)$. The mineral consisting of $\mathrm{CaTiO}_{3}$ was first discovered in the Ural Mountains of Russia by Gustav Rose in 1839, further studied by and named after Russian mineralogist Lev Alekseyevich von Perovski $(1792-1856)^{[1,2]}$. Perovskite material has drawn tremendous attention as a result of its potential and existing applications in a wide range of applications spanning radioactive waste encapsulation ${ }^{[3]}$, wireless communication $^{[4]}$, energy harvest ${ }^{[5-12]}$, and superconductivity ${ }^{[13-15]}$.

\subsection{Crystal Structures for Perovskite Compounds}

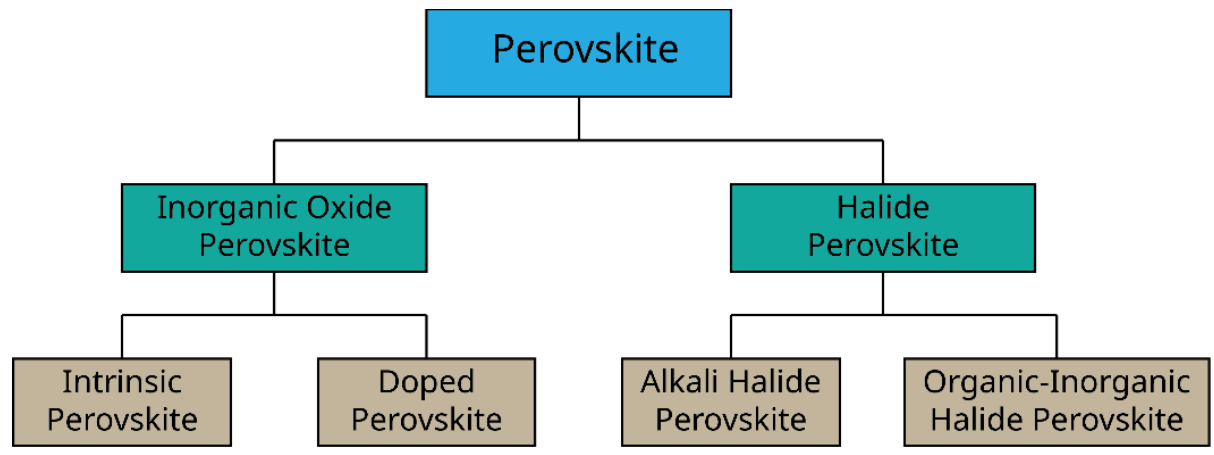

Figure 3-1 Categorization of perovskite compound.

Perovskite structure is commonly found in various compounds with the chemical formula of $\mathrm{ABX}_{3}$, where $\mathrm{A}$ and $\mathrm{B}$ are cations, and $\mathrm{X}$ is an anion. Perovskite materials can be categorized by their constituent elements, as shown in Figure 3-1. For metal oxide perovskites or inorganic oxide perovskites $\left(\mathrm{ABO}_{3}\right)$, the oxidation states of the two metal atoms must sum to six $\left(q^{A}+q^{B}=-3 q^{O}=6\right)$ because of charge balance requirement. Therefore, the general categories of cation-pairing for metal oxide perovskites are 
$\mathrm{A}^{+} \mathrm{B}^{5+} \mathrm{O}^{2-}{ }_{3}\left(\right.$ e.g. $\mathrm{LiNbO}_{3}$ and $\left.\mathrm{LiTaO}_{3}{ }^{[16]}\right), \mathrm{A}^{2+} \mathrm{B}^{4+} \mathrm{O}^{2-}{ }_{3}\left(\right.$ e.g. $\mathrm{BaTiO}_{3}{ }^{[17]}$ and $\mathrm{LaTiO}_{3}{ }^{[18]}$ ), and $\mathrm{A}^{3+} \mathrm{B}^{3+} \mathrm{O}^{2-}{ }_{3}\left(\right.$ e.g. $\mathrm{GdScO}_{3}$ and $\left.\mathrm{DyScO}_{3}{ }^{[19]}\right)$. For halide perovskites $\left(\mathrm{ABX}_{3}, \mathrm{X}=\mathrm{Cl}, \mathrm{Br}, \mathrm{I}\right)$, the only possible cation-pairing of $\mathrm{A}, \mathrm{B}$ and $\mathrm{X}$ is $\mathrm{A}^{+} \mathrm{B}^{2+} \mathrm{X}_{3}^{-}$(e.g. $\mathrm{CsSnCl}_{3}{ }^{[20]}$ ). When the inorganic $\mathrm{A}^{+}$cation is replaced by an organic cation with the same charge, the perovskite material is then called the organic-inorganic halide perovskite.

Although the ideal cubic perovskite crystal structure is almost self-explanatory, the family of perovskite compounds shows a large variety of structural variants. In the following sections, we describe several common examples of the perovskite crystal structure and discuss the implications of distortions.

\subsubsection{Cubic phase}

In an ideal cubic unit cell, the type 'A' atoms sit at the cube corners, the type 'B' atoms sit at the body centers, and the type ' $\mathrm{X}$ ' atoms sit at the face centers, as shown in Figure 3-2. The space group for cubic perovskite crystal structure is $P m \overline{3} m$ (No. 221) ${ }^{[21]}$ and the Wyckoff positions of the Group P $m \overline{3} m$ are shown in Table 3-1. On the other hand, the traditional view of the cubic crystal structure of perovskite is that it comprises a three-dimensional network formed by corner-sharing $\mathrm{BX}_{6}$ octahedra and $\mathrm{A}$ cations, which are 12 -fold coordinated by $\mathrm{X}$ anions from the eight $\mathrm{BX}_{6}$ octahedra surrounding it [Figure 3-7 (A)]. 


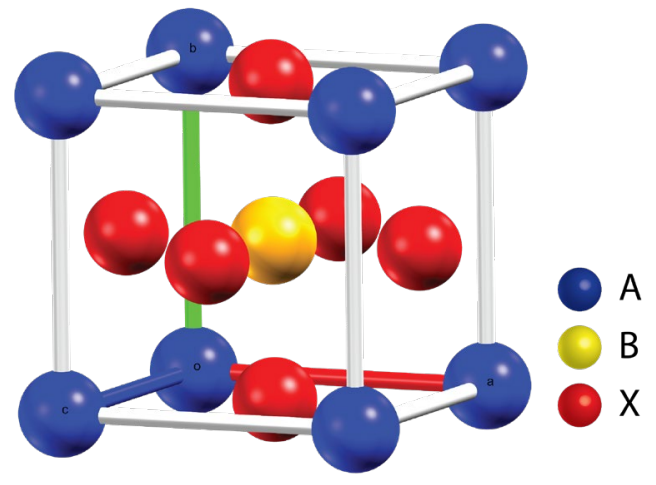

Figure 3-2 Cubic perovskite crystal structure for the $\mathrm{ABX}_{3}$ compound.

Table 3-1 The Wyckoff positions and the atomic coordinates of the Group Pm $m \overline{3} m$ for cubic perovskite structure ${ }^{[22]}$.

\begin{tabular}{|c||c||c|}
\hline Site & $\begin{array}{c}\text { Wyckoff } \\
\text { Position }\end{array}$ & Coordinates \\
\hline A cation & $2 \mathrm{a}$ & $(0,0,0)$ \\
\hline \hline B cation & $2 \mathrm{~b}$ & $\left(\frac{1}{2}, \frac{1}{2}, \frac{1}{2}\right)$ \\
\hline \hline X cation & $3 c$ & $\left(0, \frac{1}{2}, \frac{1}{2}\right)\left(\frac{1}{2}, 0, \frac{1}{2}\right)\left(\frac{1}{2}, \frac{1}{2}, 0\right)$ \\
\hline
\end{tabular}

\subsubsection{Hexagonal and tetragonal phase}

In practice, the ideal cubic geometry of perovskite crystals is often distorted by the tilting and rotation of the $\mathrm{BX}_{6}$ octahedra ${ }^{[23]}$. Perovskite crystals have been reported to exhibit a hexagonal or tetragonal lattice, depending on the tilting of the $\mathrm{BX}_{6}$ octahedra. The unit cell of the $P 6_{3} \mathrm{~cm}$ (No. 185) hexagonal structure and the equivalent atomistic positions can be found in Figure 3-3 and Table 3-2, respectively. The unit cell of the $I 4 / \mathrm{mcm}$ (No. 140) tetragonal structure and the equivalent atomistic positions can be found in Figure 3-4 and Table 3-3, respectively. 


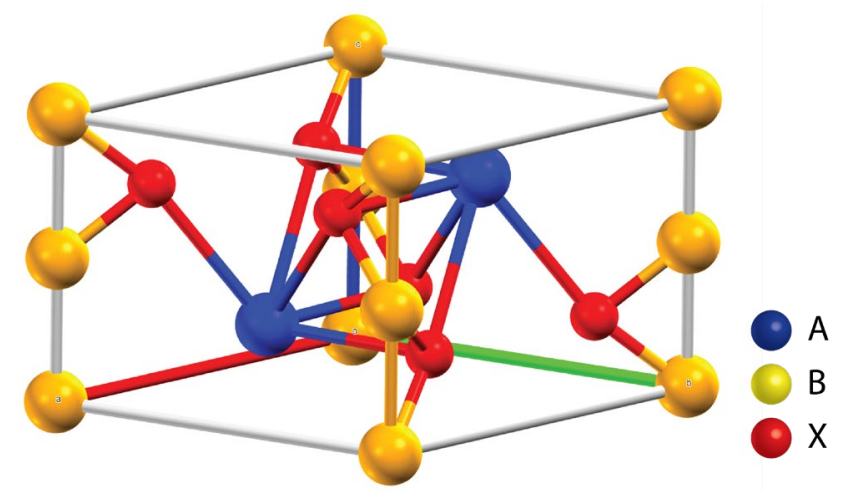

Figure 3-3 $\mathrm{P}_{3} \mathrm{~cm}$ hexagonal perovskite unit cell.

Table 3-2 The Wyckoff positions and the atomic coordinates of the Group $\mathrm{P}_{3} \mathrm{~cm}$ for hexagonal perovskite structure ${ }^{[24,25]}$.

\begin{tabular}{|c||c||c|}
\hline Site & $\begin{array}{c}\text { Wyckoff } \\
\text { Position }\end{array}$ & Coordinates \\
\hline $\mathrm{A}(1)$ cation & $2 \mathrm{a}$ & $(0,0, m)\left(0,0, m+\frac{1}{2}\right)$ \\
\hline $\mathrm{A}(2)$ cation & $4 \mathrm{~b}$ & $\left(\frac{1}{3}, \frac{2}{3}, m\right)\left(\frac{1}{3}, \frac{2}{3}, m+\frac{1}{2}\right)\left(\frac{2}{3}, \frac{1}{3}, m\right)\left(\frac{2}{3}, \frac{1}{3}, m+\frac{1}{2}\right)$ \\
\hline $\mathrm{B}$ cation & $6 \mathrm{c}$ & $(0, x, z)\left(0,1-x, z+\frac{1}{2}\right)\left(x, x, z+\frac{1}{2}\right)$ \\
\hline \hline $\mathrm{X}(1)$ anion & $6 \mathrm{c}$ & $(x, 0, z)\left(1-x, 0, z+\frac{1}{2}\right)(1-x, 1-x, z)$ \\
\hline \hline $\mathrm{X}(2)$ anion & $6 \mathrm{c}$ & $\left(-x, 0, z+\frac{1}{2}\right)\left(0,-x, z+\frac{1}{2}\right)\left(x, x, z+\frac{1}{2}\right)$ \\
\hline $\mathrm{X}(4)$ anion & $\left(-x^{\prime}, 0, z^{\prime}+\frac{1}{2}\right)\left(0,-x^{\prime}, z^{\prime}+\frac{1}{2}\right)\left(x^{\prime}, x^{\prime}, z^{\prime}+\frac{1}{2}\right)$ \\
\hline \hline $\mathrm{X}(3)$ anion & $2 \mathrm{~b}$ & $\left(\frac{1}{3}, \frac{2}{3}, k\right)\left(\frac{2}{3}, \frac{1}{3}, k+\frac{1}{2}\right)\left(\frac{1}{3}, \frac{2}{3}, k+\frac{1}{2}\right)\left(\frac{2}{3}, \frac{1}{3}, k\right)$ \\
\hline \hline
\end{tabular}




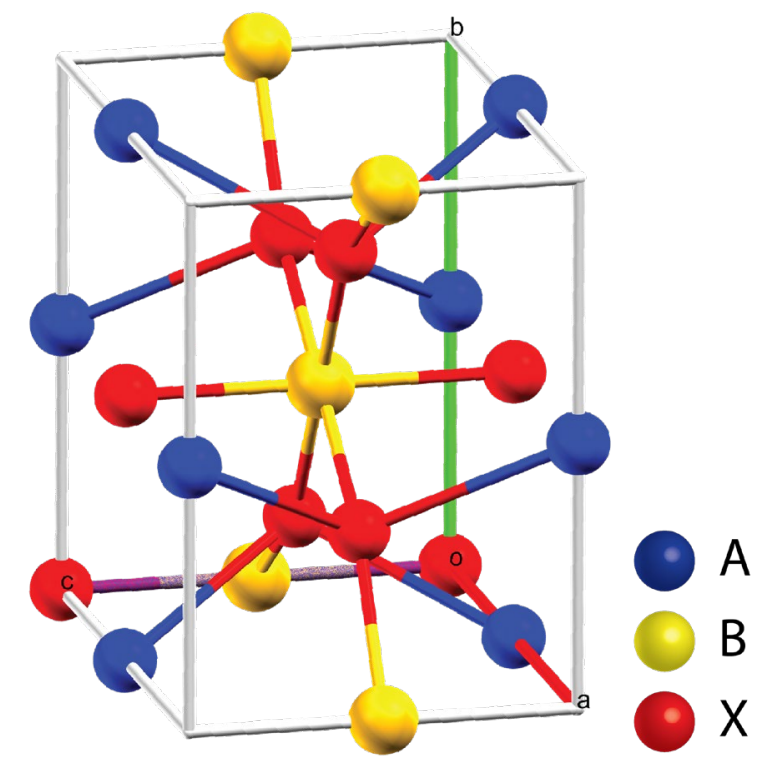

Figure 3-4 I4/ $\mathrm{mcm}$ tetragonal perovskite unit cell.

Table 3-3 The Wyckoff positions and the atomic coordinates of the Group I4/mcm for tetragonal perovskite structure ${ }^{[26]}$.

\begin{tabular}{|c||c||c|}
\hline Site & $\begin{array}{c}\text { Wyckof } \\
\text { Position }\end{array}$ & Coordinates \\
\hline \hline A cation & $4 \mathrm{~d}$ & $\left(\frac{1}{2}, 0,0\right)\left(0, \frac{1}{2}, 0\right)$ \\
\hline \hline B cation & $4 \mathrm{c}$ & $\left(\frac{1}{2}, \frac{1}{2}, \frac{1}{2}\right)\left(0,0, \frac{1}{2}\right)$ \\
\hline \hline $\mathrm{X}(1)$ anion & $4 \mathrm{c}$ & $(0,0,0)\left(\frac{1}{2}, \frac{1}{2}, 1\right)$ \\
\hline \hline$X(2)$ anion & $16 \mathrm{k}$ & $\left(-x, y, \frac{1}{2}\right)\left(x,-y, \frac{1}{2}\right)\left(y, x, \frac{1}{2}\right)\left(-y,-x, \frac{1}{2}\right)$ \\
\hline
\end{tabular}

\subsubsection{Orthorhombic phase}

Perovskite crystals can be further distorted and exhibit the orthorhombic Pnma (No. 62) lattice system with the space group Pnma ${ }^{[27]}$, as shown in Figure 3-5. The equivalent atomistic positions for an orthorhombic structure are shown in Table 3-4. 


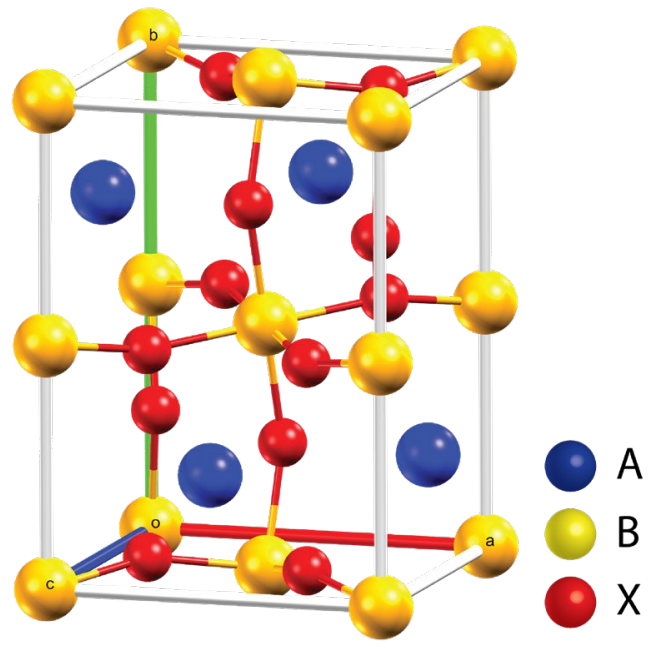

Figure 3-5 Orthorhombic Pnma perovskite structure unit cell. Note that the octahedron formed by one $\mathrm{B}$ cation and six $\mathrm{X}$ anions at the center of the unit cell is tilted.

Table 3-4 The Wyckoff positions and the atomic coordinates of the Pnma space group for the orthorhombic perovskite structure ${ }^{[22]}$.

\begin{tabular}{|c||c||c|}
\hline Site & $\begin{array}{c}\text { Wyckof } \\
\text { Position }\end{array}$ & Coordinates \\
\hline \hline A cation & $4 \mathrm{c}$ & $\pm\left[\left(x, y, \frac{1}{4}\right)\left(\frac{1}{2}-x, y+\frac{1}{2}, \frac{1}{4}\right)\right]$ \\
\hline \hline B cation & $4 \mathrm{~b}$ & $\left(0,0, \frac{1}{2}\right)\left(\frac{1}{2}, 0,0\right)\left(0, \frac{1}{2}, \frac{1}{2}\right)\left(\frac{1}{2}, \frac{1}{2}, 0\right)$ \\
\hline \hline $\mathrm{X}(1)$ anion & $4 \mathrm{c}$ & $\pm\left[\left(u, v, \frac{1}{4}\right)\left(\frac{1}{2}-u, v+\frac{1}{2}, \frac{1}{4}\right)\right]$ \\
\hline \hline $\mathrm{X}(2)$ anion & $8 \mathrm{~d}$ & $\pm\left[(l, m, n),\left(\frac{1}{2}-l, m+\frac{1}{2}, \frac{1}{2}-n\right)\right.$ \\
& \begin{tabular}{c}
$\left.\left(-l,-m, n+\frac{1}{2}\right)\left(l+\frac{1}{2}, \frac{1}{2}-m,-n\right)\right]$ \\
\hline
\end{tabular}
\end{tabular}

\subsubsection{Rhombohedral phase}

Rhombohedral lattice system with space group $R \overline{3} c(\text { No. } 167)^{[21]}$, as shown in Figure 3-6, is another phase for distorted perovskite crystals. The equivalent atomistic positions for the rhombohedral phase are shown in Table 3-5. 


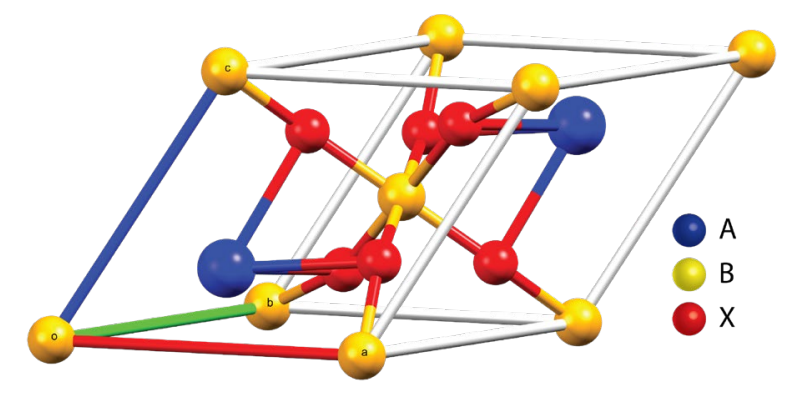

Figure 3-6 $R \overline{3} c$ rhombohedral perovskite structure unit cell.

Table 3-5 The Wyckoff positions and the atomistic positions in $R \overline{3} c$ rhombohedral perovskite structure $^{[21]}$.

\begin{tabular}{|c||c||c|}
\hline Site & $\begin{array}{c}\text { Wyckoff } \\
\text { Position }\end{array}$ & Coordinates \\
\hline \hline A cation & $(6 a)$ & $\left(x-y,-y, \frac{1}{2}-z\right)\left(\frac{2}{3}+x-y, \frac{1}{3}+x, \frac{1}{3}-z\right)$ \\
\hline \hline B cation & $(6 \mathrm{~b})$ & $(1-x+y, 1-x, z)\left(x-y,-y, \frac{1}{2}-z\right)$ \\
\hline \hline X cation & $(18 \mathrm{e})$ & $\left(-\frac{1}{3}+x-y,-\frac{2}{3}+x, \frac{1}{3}-z\right)\left(\frac{1}{3}+y, \frac{2}{3}-x+y, \frac{2}{3}-z\right)$ \\
& & $\left(\frac{2}{3}-x, \frac{1}{3}-y, \frac{1}{3}-z\right)$ \\
\hline
\end{tabular}

\subsubsection{Goldschmidt's tolerance factor}

The Goldschmidt's tolerance factor, $\tau$, is an indicator of the distortion of the perovskite crystals structure ${ }^{[28]}$. First described by Victor Moritz Goldschmidt in 1926, it is a dimensionless value calculated by the ratios of constituent ionic radii of $\mathrm{A}, \mathrm{B}$, and $\mathrm{X}$.

To help discussing about the tolerance factor, it is helpful to consider a closepacked cubic perovskite unit cell with A cations occupying the cuboctahedral cavities, each of which is formed by twelve nearest-neighbor $\mathrm{X}$ anions from eight corner-linked $\mathrm{BX}_{6}$ octahedra [Figure 3-7 (A)]. Looking at the (100) plane, the lattice constant is clearly determined by the ionic diameters of cation B and anion X [Figure 3-7 (B)]. On the other 
hand, the plane diagonal in the $(1 / 2,0,0)$ plane is determined by the ionic diameters of cation A and anion X [Figure 3-7 (C)]. To form an ideal cubic perovskite crystal, lattice constants $\mathrm{a}, \mathrm{b}$, and $\mathrm{c}$ should be equal. Therefore, the condition to yield an ideal, closepacked cubic perovskite structure is

$$
r_{X}+r_{A}=\sqrt{2}\left(r_{X}+r_{B}\right)
$$

Where $r_{A}, r_{B}$, and $r_{X}$ are the ionic radii of atom $\mathrm{A}, \mathrm{B}$, and $\mathrm{X}$, respectively. The Goldschmidt's tolerance factor, $\tau$, is defined as,

$$
\tau=\frac{r_{A}+r_{X}}{\sqrt{2}\left(r_{B}+r_{X}\right)}
$$
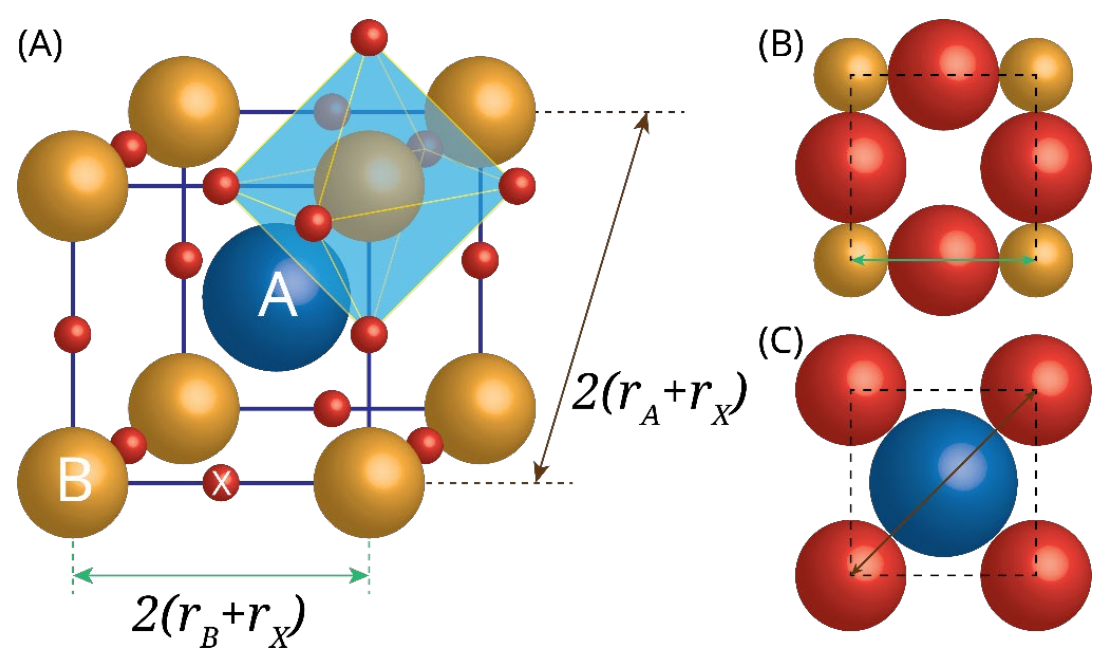

Figure 3-7 (A) Ball-stick model for close-packed cubic perovskite structure. For clarity, the radii of these spheres are smaller than the ionic radii of A, B, and X. (B) and (C): Cross-sectional view of (100) plane including $\mathrm{B}$ cations and $\mathrm{X}$ anions and $(1 / 2,0,0)$ plane including $\mathrm{A}$ cation and $\mathrm{X}$ anions, respectively. The blue, gold, and red spheres represent the A cation, B cations, and X anions, respectively.

Obviously, $\tau$ equals 1 for a cubic close-packed perovskite structure. In fact, when $\tau$ lies between $0.9 \sim 1$, the corresponding perovskite crystal will adopt a cubic lattice. When the deviation from $\tau=1$ becomes greater, perovskite compounds adopt crystal lattices of lower symmetry than cubic lattice. When $\tau$ is greater than 1 , the crystal structure will be distorted into a hexagonal or tetragonal lattice. When $\tau$ is within the 
range of 0.71 to 0.9 , perovskite compounds will adopt orthorhombic or rhombohedral lattices. When $\tau$ is smaller than 0.71 , the trigonal lattice is often observed in perovskite compounds, such as $\mathrm{FeTiO}_{3}$, because of the similar size of cations A and $\mathrm{B}$. To sum up, perovskite compounds have multiple Bravais lattice configurations, including cubic, tetragonal, hexagonal, orthorhombic, rhombohedral, and trigonal.

\subsection{Organic-inorganic halide perovskites}

For halide perovskite materials, the only viable cation-pairing of A, B, and X (X $=\mathrm{Cl}, \mathrm{Br}, \mathrm{I})$ is $\mathrm{A}^{+} \mathrm{B}^{2+} \mathrm{X}_{3}^{-}$. A relatively small size is necessary for the metal monovalent cation A to fit into the cavity. If the monovalent inorganic cation A is replaced by an organic cation of the same charge and appropriate size to fit into the interstice, the material is called organic-inorganic halide perovskite (OIHP) material or organicinorganic halide perovskite.

\subsubsection{Methylammonium lead iodide}

Among all kinds of organic-inorganic halide perovskite materials, $\mathrm{CH}_{3} \mathrm{NH}_{3} \mathrm{PbI}_{3}$ $\left(\mathrm{MAPbI}_{3}\right)$ is the most popular one for application in solar cells. The study on the crystal structure of $\mathrm{MAPbI}_{3}$ started long before its application in photovoltaics and found three phases of $\mathrm{MAPbI}_{3}$ : orthorhombic, tetragonal, and cubic Bravais lattices ${ }^{[29]}$. Figure 3-8 shows the diagram of the corresponding structure for each of these three crystal phases.

At temperatures lower than ca. $165 \mathrm{~K}$, orthorhombic lattice assigned to the Pnma space group, shown in Figure 3-8 (a), is the stable phase for $\mathrm{MAPbI}_{3}$ crystals ${ }^{[30]}$. In the low-temperature phase, each $\mathrm{CH}_{3} \mathrm{NH}_{3}{ }^{+}$cation is located at a fixed position, and the

$\mathrm{CH}_{3} \mathrm{NH}_{3}{ }^{+}$sublattice is fully ordered ${ }^{[31]}$. There are two phase transitions for $\mathrm{MAPbI}_{3}$ 
crystals. The first-order phase transition happens at ca. $165 \mathrm{~K}$, and $\mathrm{MAPbI}_{3}$ crystals change from the orthorhombic phase to the tetragonal phase assigned to the $14 / \mathrm{mcm}$ space group, shown in Figure 3-8 (b). In the mid-temperature phase, the organic $\mathrm{CH}_{3} \mathrm{NH}_{3}{ }^{+}$ cations are located between two non-equivalent positions in each cuboctahedral cavity, rather than at fixed positions in the orthorhombic phase ${ }^{[32]}$. The second-order phase transition happens at ca. $327 \mathrm{~K}$, and the $\mathrm{MAPbI}_{3}$ crystals change from tetragonal phase to cubic phase assigned to the $P m \overline{3} m$ space group, shown in Figure 3-8 (c), with an even higher level of molecular disorder.

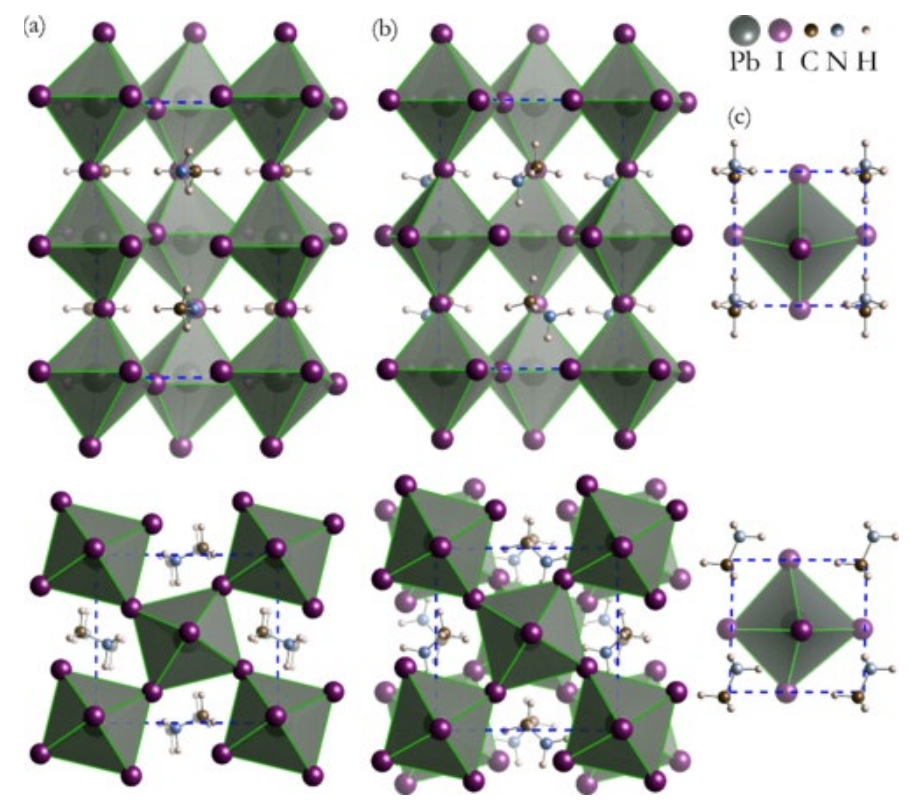

Figure 3-8 The crystal structures of the (a) orthorhombic, (b) tetragonal, and (c) cubic phases of $\mathrm{CH}_{3} \mathrm{NH}_{3} \mathrm{PbI}_{3}{ }^{[31]}$. The upper and lower panels are oriented through $<100>$ and $<001>$, respectively. The $\mathrm{PbI}_{6}$ octahedra are shaded gray. Reproduced with permission from reference ${ }^{[31]}$.

\subsubsection{Formamidinium lead iodide}

Another popular OIHP material for solar cells is $\left[\mathrm{CH}\left(\mathrm{NH}_{2}\right)_{2}\right] \mathrm{PbI}_{3}\left(\mathrm{FAPbI}_{3}\right)$. Table 3-6 summarizes the effective ionic radii of cations and anions in perovskite materials used for photovoltaic applications. Compared to the methylammonium cation $\mathrm{CH}_{3} \mathrm{NH}_{3}{ }^{+}$, which has a radius of $2.16 \AA$, the formamidinium cation $\mathrm{CH}\left(\mathrm{NH}_{2}\right)_{2}{ }^{+}$has a larger radius of 
$2.53 \AA$. Hence, the Goldschmidt's tolerance factor for $\mathrm{FAPbI}_{3}(\tau=0.987)$ is closer to the ideal value of 1 than that for $\mathrm{MAPbI}_{3}(\tau=0.910)$.

Table 3-6 Ionic radii of A cations, B cations, and X anions in perovskites for PV applications.

\begin{tabular}{|cc|cc||cc|}
\hline A cation & Ionic radii $^{[33]}$ & B cation & Ionic radii $^{[34]}$ & X anion & Ionic radii $^{[34]}$ \\
\hline \hline $\mathrm{Cs}^{+}$ & $0.181 \mathrm{~nm}$ & $\mathrm{~Pb}^{2+}$ & $0.119 \mathrm{~nm}$ & $\mathrm{Cl}^{-}$ & $0.181 \mathrm{~nm}$ \\
$\mathrm{CH}_{3} \mathrm{NH}_{3}{ }^{+}$ & $0.216 \mathrm{~nm}$ & $\mathrm{Sn}^{2+}$ & $0.069 \mathrm{~nm}$ & $\mathrm{Br}^{-}$ & $0.196 \mathrm{~nm}$ \\
$\mathrm{CH}\left(\mathrm{NH}_{2}\right)_{2}{ }^{+}$ & $0.253 \mathrm{~nm}$ & & & $\mathrm{I}^{-}$ & $0.220 \mathrm{~nm}$ \\
\hline
\end{tabular}

Early studies by Kanatzidis et al. found that $\mathrm{FAPbI}_{3}$ exhibited a $P 3 m 1$ trigonal space group at room temperature ${ }^{[35]}$. However, Pang et al. noticed that the $P 3 m I$ trigonal could be regarded as a $P m \overline{3} m$ cubic lattice system with a slight distortion when the orientation and displacement of $\mathrm{CH}\left(\mathrm{NH}_{2}\right)_{2}{ }^{+}$cations are ignored ${ }^{[36]}$. Later, Walsh et al. also reported the $P m \overline{3} m$ cubic space group for $\mathrm{FAPbI}_{3}$ at $298 \mathrm{~K}^{[37]}$, which is identical to the high-temperature crystal structure of $\mathrm{MAPbI}_{3}$. However, the $P m \overline{3} m$ cubic structure is metastable at room temperature. $\mathrm{FAPbI}_{3}$ can go through a room-temperature phase change from the cubic corner-sharing perovskite phase (black color, $\alpha$-phase) to a facesharing hexagonal non-perovskite phase (yellow color, $\delta$-phase $)^{[35,38]}$.

\subsection{Properties of organic-inorganic halide perovskites}

\subsubsection{High absorption coefficient and small Urbach energy}

The absorption coefficient of $\mathrm{CH}_{3} \mathrm{NH}_{3} \mathrm{PbI}_{3}$ is a primarily important characteristic for its application in photovoltaics. Park et al. first estimated the absorption coefficient of $\mathrm{MAPbI}_{3}$ to be $1.5 \times 10^{4} \mathrm{~cm}^{-1}\left(1.5 \mu \mathrm{m}^{-1}\right)$ at $550 \mathrm{~nm}^{[7]}$. In 2013, Sum et al. reported an absorption coefficient of $5.7 \times 10^{4} \mathrm{~cm}^{-1}\left(5.7 \mu \mathrm{m}^{-1}\right)$ at $600 \mathrm{~nm}$ for $\mathrm{MAPbI}_{3}{ }^{[39]}$. Several 
other groups have also reported high absorption coefficient for $\mathrm{MAPbI}_{3}$ and $\mathrm{MAPbI}_{3}$ ${ }_{\mathrm{x}} \mathrm{Cl}_{\mathrm{x}}{ }^{[40-50]}$, and the absorption coefficient profiles of these studies are shown in Figure 3-9 (A). Although the absorption coefficient from each research group deviates, all these curves have converged to show one common absorption edge at ca. $1.57 \mathrm{eV}(790 \mathrm{~nm})$ followed closely by an unusual sharp shoulder [labeled by the black arrow in Figure 3-9 (A) and the red arrow in Figure 3-9 (B)]. Remarkably, the shoulder occurs at higher absorption coefficients than most other well-developed photovoltaic semiconductors, which explains why very thin $\mathrm{MAPbI}_{3}$ films of only a few hundred nanometers thick suffice for absorbing most of the incident photons on earth.
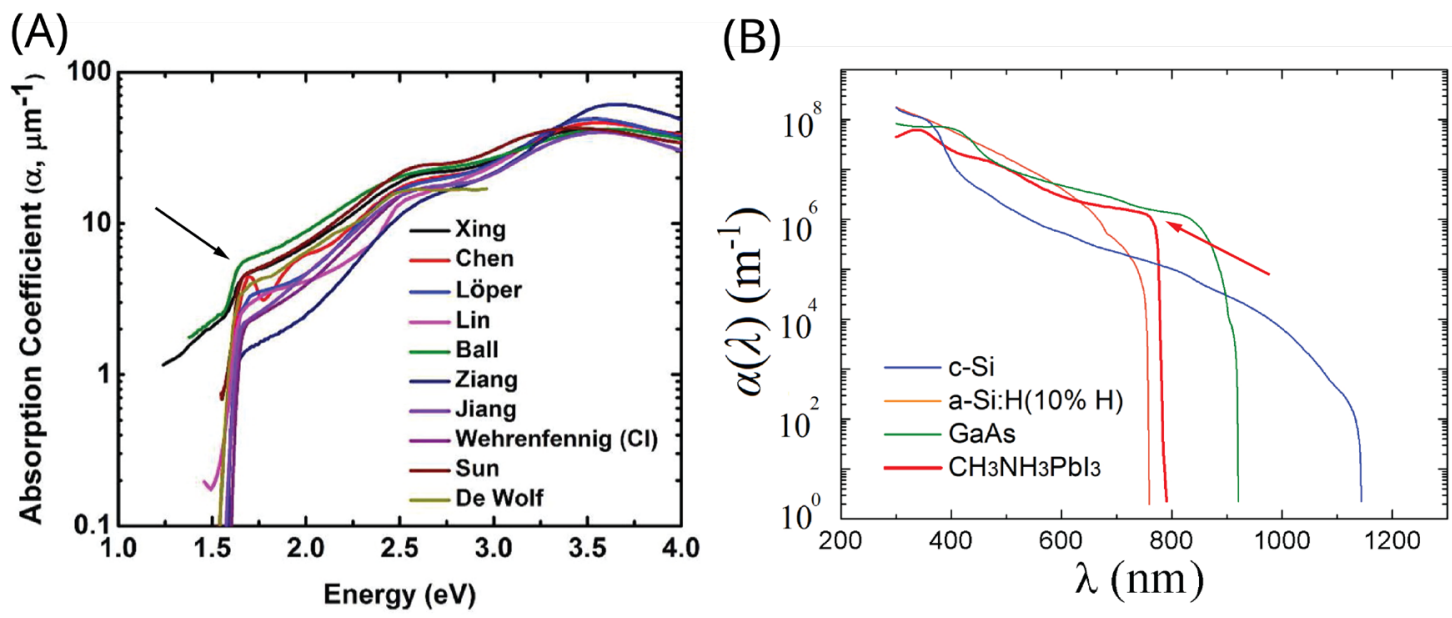

Figure 3-9 Absorption coefficients of $\mathrm{MAPbI}_{3}$ and $\mathrm{MAPbI}_{3-\mathrm{x}} \mathrm{Cl}_{\mathrm{x}}$. (A) Compilation of roomtemperature absorption coefficient data for $\mathrm{MAPbI}_{3}$ and $\mathrm{MAPbI}_{3-\mathrm{x}} \mathrm{Cl}_{\mathrm{x}}$. Reproduced with permission from reference ${ }^{[50]}$. Copyright 2015 American Chemical Society. (B) Comparison of absorption coefficients, $\alpha(\lambda)$, of four photovoltaic materials. Reproduced with permission from reference ${ }^{[46]}$. Copyright 2015 Optical Society of America.

Using the absorption coefficient spectrum, De Wolf et al. calculated the Urbach energy of $\mathrm{MAPbI}_{3}$ to be as low as $15 \mathrm{meV}^{[41]}$. This value is minimal among photovoltaic semiconductors and close to the Urbach energy of gallium arsenide (GaAs), which is a direct bandgap semiconductor with superior electronic properties compared to silicon. 
Figure 3-9 (B) shows the absorption coefficient profile of $\mathrm{MAPbI}_{3}$ and other common photovoltaic materials, such as crystalline silicon, amorphous silicon, and GaAs. Compared with amorphous silicon, $\mathrm{MAPbI}_{3}$ has a much stronger ability to absorb photons between about 620 and $800 \mathrm{~nm}$, although amorphous silicon shows a higher absorption coefficient between ca. 620 and $300 \mathrm{~nm}$. Throughout the visible wavelength range from approximately 380 to $800 \mathrm{~nm}, \mathrm{MAPbI}_{3}$ has a significantly higher absorption coefficient than crystalline silicon. Surprisingly, in the visible range, the absorption coefficient of $\mathrm{MAPbI}_{3}$ is nearly as high as that of GaAs, which is the photovoltaic semiconductor used in the most efficient single-junction solar cell by far.

\subsubsection{Long charge carrier diffusion length}

Perovskite materials for solar cells have been reported to have exceedingly high carrier diffusion lengths by multiple research groups. In 2013, Snaith et al. used transient absorption and PL-quenching techniques to measure the carrier diffusion lengths, diffusion constants, and lifetimes in $\mathrm{MAPbI}_{3-\mathrm{x}} \mathrm{Cl}_{\mathrm{x}}$ thin film and $\mathrm{MAPbI}_{3}$ thin film. They reported over $1 \mu m$ diffusion lengths for both electrons and holes in $\mathrm{MAPbI}_{3-\mathrm{x}} \mathrm{Cl}_{\mathrm{x}}$ thin film, and over $100 \mathrm{~nm}$ diffusion lengths for electrons and holes in $\mathrm{MAPbI}_{3}$ thin film ${ }^{[51]}$. Almost simultaneously, Sum et al. also reported diffusion lengths of $130 \mathrm{~nm}$ and $110 \mathrm{~nm}$ for electron and hole in solution-processed polycrystalline $\mathrm{MAPbI}_{3}$ thin film, respectively ${ }^{[39]}$. In 2014 , Zhu et al. reported electron diffusion length over $1 \mu m$ in mesostructured $\mathrm{MAPbI}_{3}$ solar cells ${ }^{[52]}$. In 2015, Marcus, Michel-Beyerle, and Chia et al. measured the carrier diffusion lengths at different temperatures and reported electronhole diffusion lengths close to $1 \mu \mathrm{m}$ at 285 and $180 \mathrm{~K}$. As for electron-hole diffusion 
lengths in $\mathrm{MAPbI}_{3}$ single crystals, Huang et al. reported that both electrons and holes have diffusion lengths over $1 \mu m$ under 1 sun illumination and over $3 \mathrm{~mm}$ under weak illumination $(0.003 \% \text { sun })^{[53]}$.

\subsubsection{Unique defect physics}

Organic-inorganic halide perovskite excels in its tolerance for defects. Yin et al. showed by first-principles density-functional theory (DFT) calculation that the dominant intrinsic defects in $\mathrm{MAPbI}_{3}$ create only shallow traps, which partially explains the reported long carrier diffusion length and small $\mathrm{V}_{\text {oc }}$ loss in solar cell devices ${ }^{[54]}$. Besides, Wang et al. reported self-doping in perovskite ${ }^{[55]}$. $\mathrm{MAPbI}_{3}$ can be either $n$ - or $p$-doped by varying the ratio of $\mathrm{MAI}$ and $\mathrm{PbI}_{2} . \mathrm{MAPbI}_{3}$ thin films with $\mathrm{MAI}$-rich or $\mathrm{PbI}_{2}$-rich composition were $p$-doped and $n$-doped, respectively.

\subsubsection{Electronic band structure and direct bandgap}

The electrical band structure of $\mathrm{MAPbI}_{3}$ is primarily determined by the electronic bonding orbitals of the lead cations and iodide anions. Electron configurations of $\mathrm{Pb}^{2+}$ cations and $\mathrm{I}^{-}$anions are $[\mathrm{Xe}] 4 \mathrm{f}^{14} 5 \mathrm{~d}^{10} 6 \mathrm{~s}^{2} 6 \mathrm{p}^{0}$ and $[\mathrm{Kr}] 4 \mathrm{~d}^{10} 5 \mathrm{~s}^{2} 5 \mathrm{p}^{6}$, respectively. Therefore, the conduction bands of $\mathrm{MAPbI}_{3}$ are associated with $6 \mathrm{p}$ orbitals of $\mathrm{Pb}^{2+}$ cations, and the valence bands are associated with 5p orbitals of $\mathrm{I}^{-}$anions. Figure 3-10 shows the diagram of cubic $P m \overline{3} m$ perovskite structure, the first Brillouin zone (BZ) of the $P m \overline{3} m$ space group, and the electronic band structure of $\mathrm{MAPbI}_{3}$. 


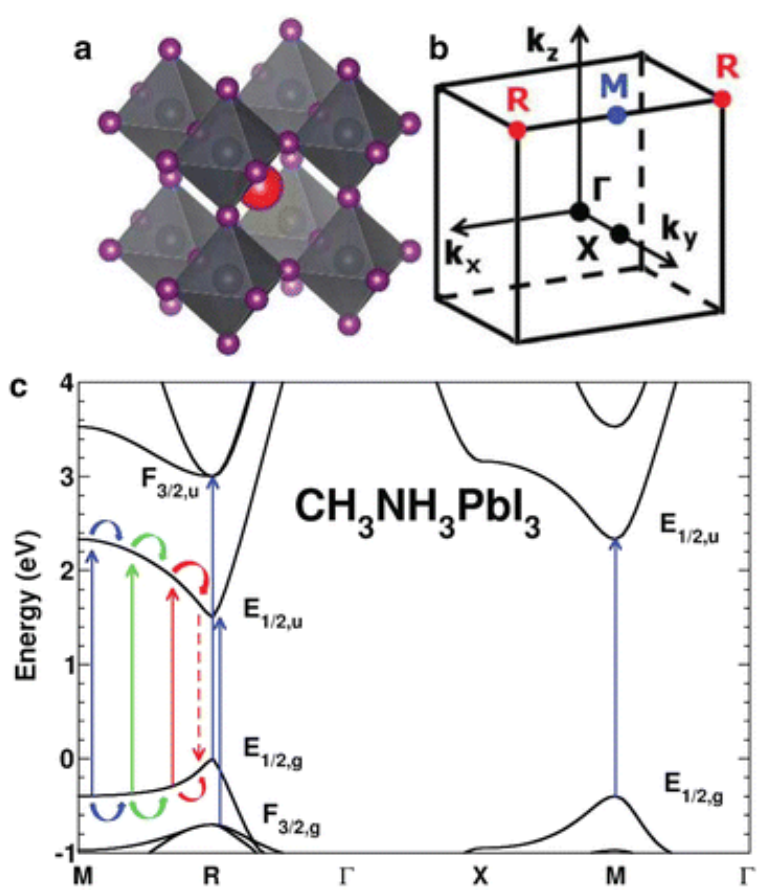

Figure 3-10 Electronic band structure of $\mathrm{MAPbI}_{3}$.(a) Real-space 3D view of the cubic crystal structure of $\mathrm{AMX}_{3}\left(\mathrm{~A}=\mathrm{Cs}, \mathrm{CH}_{3} \mathrm{NH}_{3}, \mathrm{M}=\mathrm{Pb}, \mathrm{Sn}\right.$, and $\left.\mathrm{X}=\mathrm{I}, \mathrm{Br}, \mathrm{Cl}\right)$ with the $P m 3 m$ space group. $\mathrm{CH}_{3} \mathrm{NH}_{3}{ }^{+}$cation (red ball) is located at the center of the cube. (b) Reciprocal-space 3D view showing the first Brillouin zone (BZ) of the $P m 3 m$ space group. Points of high symmetry in the cubic BZ: $\Gamma$ denotes the origin of the BZ; $\mathrm{X}$ is the center of a square face at the BZ boundary; $\mathrm{M}$ is a center of a cube edge, and Rs are vertices of the cube. (c) Electronic band structure for the high-temperature cubic $\mathrm{Pm} 3 m$ phase of $\mathrm{MAPbI}_{3}$ with spin-orbit coupling (SOC) at the local density approximation (LDA) level of theory. An upward energy shift of $1.4 \mathrm{eV}$ has been applied to match the experimental bandgap value at R. Irreducible representations obtained from a $P m 3 m$ double group analysis are given at $\mathrm{R}$ and $\mathrm{M}$ points for the electronic states close to the bandgap. Vertical arrows show various possible optical transitions close to the bandgap energy. Optical transitions along the line between the $\mathrm{M}$ and $\mathrm{R}$ points generate carriers that easily relax toward the R point. Reprinted with permission from reference ${ }^{[56]}$. Copyright 2015 American Chemical Society.

Like other popular materials for thin-film solar cells, including GaAs, CdTe, and CIGS, $\mathrm{MAPbI}_{3}$ is a direct bandgap semiconductor, as shown in Figure 3-10 (c), where the minimal-energy state in the conduction band (conduction band minimum, CBM) is aligned with the maximum-energy state in the valence band (valence band maximum, $\mathrm{VBM}$ ) at the same crystal momentum (k-vector). In direct bandgap semiconductors, a photon with energy close to the minimum bandgap can be absorbed, generating a pair of electron and hole carrying a k-vector near CBM and VBM. However, in indirect bandgap 
semiconductors, such a process is not possible as photons cannot carry crystal momentum. For a photon to be absorbed in an indirect bandgap semiconductor, the energy of the photon must be larger than the minimum bandgap, and the absorption process must involve the creation of a phonon. For this reason, photons can penetrate much farther before being absorbed in an indirect bandgap semiconductor than a direct bandgap semiconductor. The fact that $\mathrm{MAPbI}_{3}$ is a direct bandgap semiconductor, together with the remarkably high absorption coefficient in the visible range, suggests that $\mathrm{MAPbI}_{3}$ is a promising material for a very thin absorbing layer in thin-film solar cells.

Table 3-7 Bandgap $\left(E_{\mathrm{g}}\right)$, exciton binding energy $\left(\mathrm{R}^{*}\right)$, reduced effective mass $(\mu)$, effective dielectric constant $\left(\varepsilon_{e f f}\right)$ for $\mathrm{MAPbI}_{3}$ and $\mathrm{FAPbI}_{3}$. Reproduced from reference ${ }^{[57]}$ with permission from the Royal Society of Chemistry.

\begin{tabular}{c|ccccc}
\hline Compound & $\begin{array}{c}E_{g} \\
(\mathrm{meV})\end{array}$ & $\begin{array}{c}R^{*} \\
(\mathrm{meV})\end{array}$ & $\begin{array}{c}\mu \\
\left(m_{e}\right)\end{array}$ & $\begin{array}{c}\varepsilon_{\text {eff }} \\
\text { (10 }\end{array}$ & $\begin{array}{c}\text { Temperature } \\
(\mathrm{K})\end{array}$ \\
\hline \hline $\mathrm{FAPbI}_{3}$ & 1521 & 10 & 0.095 & 11.4 & $140-160$ \\
$\mathrm{MAPbI}_{3-\mathrm{x}} \mathrm{Cl}_{\mathrm{x}}$ & 1600 & 10 & 0.105 & 11.9 & $190-200$ \\
$\mathrm{MAPbI}_{3}$ & 1608 & 12 & 0.104 & 10.9 & $155-190$ \\
$\mathrm{FAPbBr}_{3}$ & 2294 & 24 & 0.13 & 8.6 & $160-170$ \\
\hline
\end{tabular}

The direct bandgap of $\mathrm{MAPbI}_{3}$ is located at the high symmetry point $\mathrm{R}$ with multiple optically allowed transitions, as shown in the E(k) diagram in Figure 3-10 (c). Effective masses for electron and hole can be obtained from second derivatives of $\mathrm{E}(\mathrm{k})$ with respect to $\mathrm{k}$. The approximated parabolic curves and the close symmetrical features of $\mathrm{CBM}$ and VBM in Figure 3-10 (c) suggest that the effective masses of electron and hole should be similar. Yamashita et al. estimated the effective masses of electron and hole in $\mathrm{MAPbI}_{3}$ to be 0.23 and 0.29 , respectively ${ }^{[58]}$. Bandgaps of OIHP materials for 
solar cells, such as $\mathrm{FAPbI}_{3}, \mathrm{FAPbBr}_{3}, \mathrm{MAPbI}$, and $\mathrm{MAPbI}_{3-\mathrm{x}} \mathrm{Cl}_{\mathrm{x}}$, are summarized in Table 3-7.

\subsection{Perovskite solar cells}

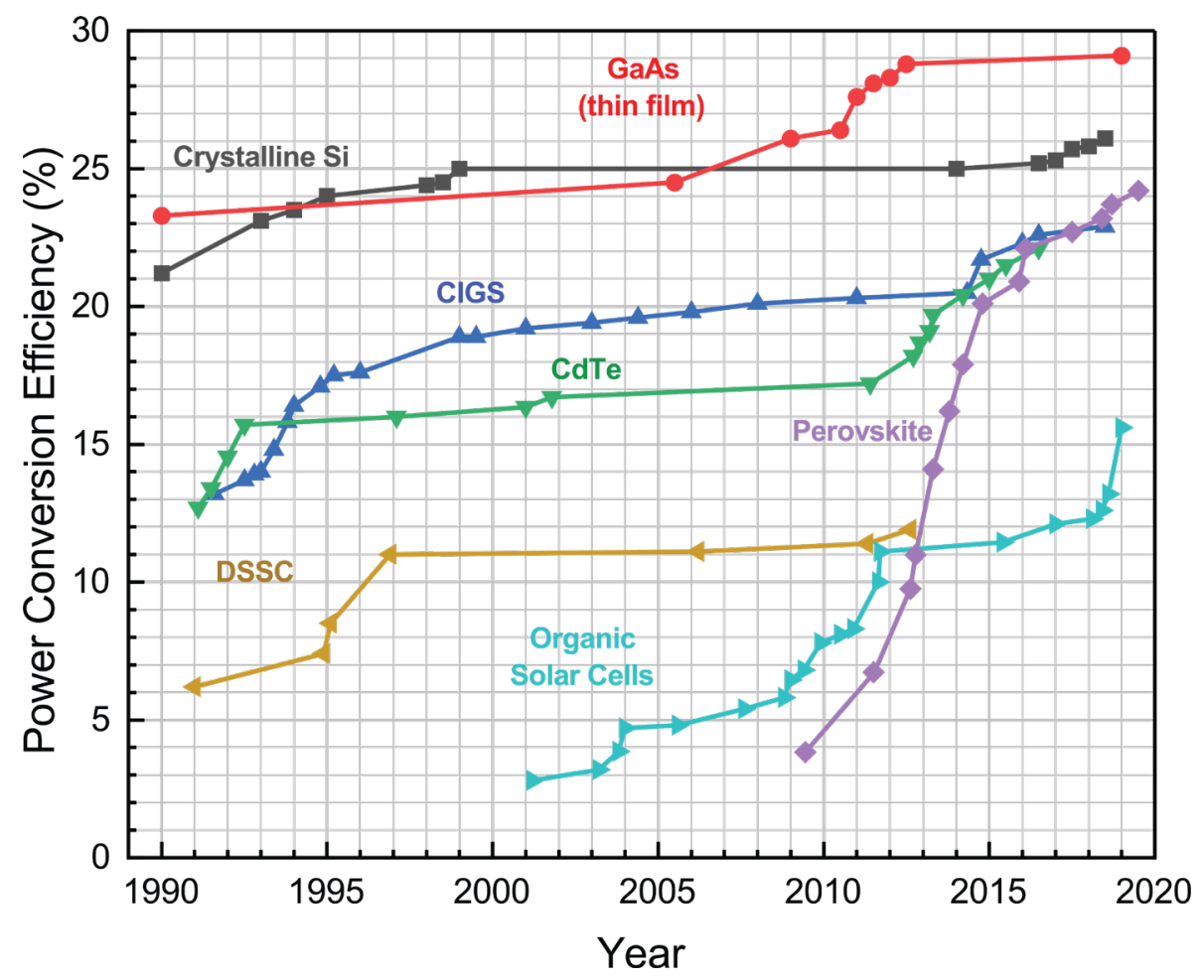

Figure 3-11 Improvement of the power conversion efficiencies of PSCs over time. The figure is drawn based on the data in Solar Cell Efficiency Tables (Version 33 to Version 53) of Wiley ${ }^{[59]}$ and the latest NREL best research-cell efficiencies chart ${ }^{[60]}$.

Since the first report on a long-term stable solid-state perovskite solar cell with a power conversion efficiency (PCE) of $9.7 \%$ using methylammonium lead iodide in 2012, the certified PCE record of perovskite solar cells has been skyrocketing at a speed that no other solar cell technologies can match $^{[60]}$ (Figure 3-11). Methylammonium lead halide perovskite materials were first attempted as sensitizers in a liquid electrolyte in dyesensitized solar cells in 2009, showing PCE as low as $4 \%$, which was almost doubled in performance by intensifying loading concentrations of perovskite in a thinner $\mathrm{TiO}_{2}$ 
film in 2011. Lead halide perovskites employing organic ammonium cations such as methylammonium and formamidinium are undoubtedly promising photovoltaic materials.

\subsubsection{Architecture evolution of perovskite solar cells}

The organic-inorganic perovskite material was first incorporated in solar cells as light absorbers in $2009^{[5]}$. Miyasaka et al. constructed dye-sensitized solar cells (DSSCs) built on photoelectrode of $\mathrm{TiO}_{2}$ coated with nano $\mathrm{MAPbX}_{3}(\mathrm{X}=\mathrm{Br}$, I) nano-crystalline particles. DSSCs incorporating $\mathrm{MAPbBr}_{3}$ and $\mathrm{MAPbI}_{3}$ demonstrated PCEs of $3.1 \%$ and $3.8 \%$, respectively ${ }^{[5]}$. In 2011, Park et al. nearly doubled the PCE of perovskite-sensitized DSSCs to $6.54 \%$ by using $\mathrm{MAPbI}_{3}$ quantum dots (QDs) as sensitizers ${ }^{[7]}$. However, it was observed that perovskites were easily dissolved in the presence of a liquid electrolyte, causing losses to the PCE and significantly affecting the device stability ${ }^{[7]}$.

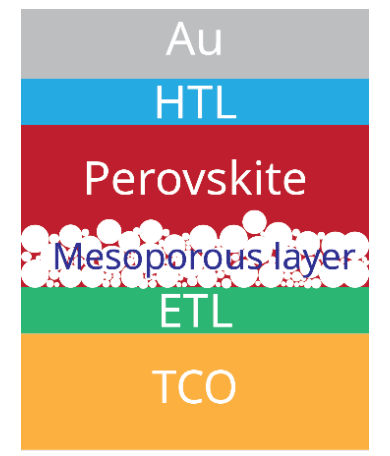

(A) Mesoporous Structure

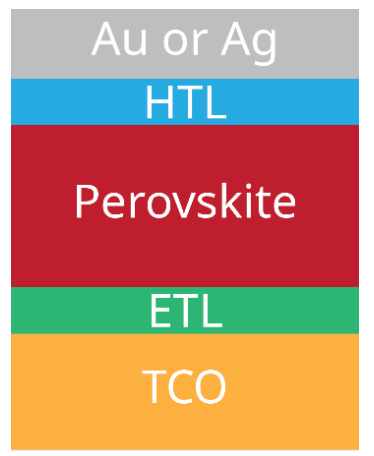

(B) Planar n-i-p (Regular)

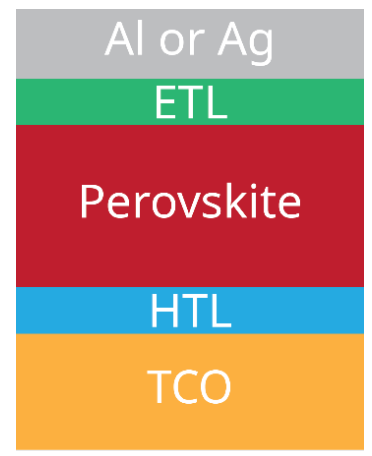

(C) Planar p-i-n (Inverted)

Figure 3-12 Device configuration of (A) mesoporous, planar (B) n-i-p, and (C) p-i-n structured perovskite solar cells.

In 2012, the liquid-electrolyte-induced instability issue was solved by replacing the liquid electrolyte with a solid electrolyte. Park and Gratzel et al. reported a solid-state mesoscopic perovskite solar cell architecture showing PCE of $9.7 \%{ }^{[61]}$, as shown in 
Figure 3-12 (A). $\mathrm{MAPbI}_{3}$ nanoparticles were deposited on $0.6 \mu \mathrm{m}$ thick mesoporous $\mathrm{TiO}_{2}\left(\mathrm{mp}-\mathrm{TiO}_{2}\right)$ layer, whose pores were infiltrated 2, 2', 7, 7'-tetrakis $(N, N$-pdimethoxy-phenylamino)-9, 9'-spirobifluorene (spiro-OMeTAD) as the hole transporting material ${ }^{[61]}$. Concurrently, Snaith et al. constructed solar cells based on mesoporous $\mathrm{Al}_{2} \mathrm{O}_{3}$ scaffold coated with a thin layer of $\mathrm{MAPbI}_{3-\mathrm{x}} \mathrm{Cl}_{\mathrm{x}}$ underneath the spiroOMeTAD layer, and the devices demonstrated a PCE of $10.9 \%$ together with a boosted open circuit voltage $\left(V_{o c}\right)$. This work also indicated that OIHP has the ability to transport electrons itself without adjacent electron transporting material ${ }^{[62]}$. Experimental evidences of electron-hole diffusion length over $1 \mu \mathrm{m}$ in $\mathrm{MAPbI}_{3-\mathrm{x}} \mathrm{Cl}_{\mathrm{x}}{ }^{[51]}$ and over $100 \mathrm{~nm}$ in $\mathrm{MAPbI}_{3}{ }^{[39]}$ were reported in 2013 and 2014, respectively. Such charge transporting ability of OIHP enabled the optimization of device configuration to fully utilize its beneficial optoelectronic properties.

Since 2012, a mesoporous $\mathrm{TiO}_{2}$ scaffold was often found as the electron transporting material in numerous highly efficient PSCs ${ }^{[12,63-66]}$. However, both the exceptionally long electron-hole diffusion length ${ }^{[39,51]}$ and the remarkably high charge carrier mobilities $^{[67]}$ of OIHP materials suggested the likelihood of highly efficient PSCs with planar heterojunction structures. The first perovskite solar cell adopting planar heterojunction structure was reported in 2013 with a top PCE of $15.4 \%$ by Snaith et al. ${ }^{[9]}$. $\mathrm{MAPbI}_{3-\mathrm{x}} \mathrm{Cl}_{\mathrm{x}}$ was deposited on top of a compact layer of $\mathrm{TiO}_{2}\left(\mathrm{c}-\mathrm{TiO}_{2}\right)$ by a dual-source vapor deposition method. The device was composed of three consecutive layers of c$\mathrm{TiO}_{2}, \mathrm{MAPbI}_{3-\mathrm{x}} \mathrm{Cl}_{\mathrm{x}}$, and spiro-OMeTAD sandwiched between the anode (FTO-coated glass substrate) and the cathode (silver), creating a planar n-i-p (in the direction of incident light) heterojunction structure ${ }^{[9]}$, as shown in Figure 3-12 (B). 
Planar p-i-n heterojunction architecture, adopted from organic solar cells, is also available for PSCs, as shown in Figure 3-12 (C). The first planar p-i-n heterojunction PSC was reported in early 2014 by Yang et al. ${ }^{[68]}$. Using a low-temperature solution-processed technique, planar p-i-n PSCs were assembled on rigid and flexible substrates using a substrate/ITO/PEDOT:PSS/MAPbI ${ }_{3-\mathrm{x}} \mathrm{Cl}_{\mathrm{x}} / \mathrm{PCBM} / \mathrm{Al}$ structure, where PEDOT:PSS and PCBM ([6,6]-Phenyl-C61-butyric acid methyl ester) are hole and electron transporting materials, respectively ${ }^{[68]}$. A PCE of $11.5 \%$ was obtained from PSC on a rigid glass/ITO substrate, while PSC on flexible polyethylene terephthalate/ITO substrate showed a PCE of $9.2 \%$.

\subsection{Versatile fabrication strategies for depositing perovskite thin films}

As the key photovoltaic material for perovskite solar cells, the quality of the perovskite layer plays a critical role in the final device performance. The formation of a dense, uniform, and highly crystalline perovskite layer is particularly susceptible to the parameters of the deposition procedure. Vacuum-based vapor deposition methods and solution-based deposition methods are the two major categories of deposition approaches for high-quality perovskite layers. The spin coating method is the most popular solutionbased methods, including spin coating, dip coating, spray coating, ink-jet coating, blade, D-bar, slot-die, screen printing, etc. Depending on the number of fabrication steps used, the spin coating strategy is categorized into the so-called "one-step" ${ }^{[62]}$ and "two-steps" ${ }^{\text {[69] }}$ approaches. 


\subsubsection{Vacuum-based vapor evaporation}

The vacuum-based vapor deposition approach is a solvent-free process. The dualsource vapor deposition approach, reported by Liu et al. ${ }^{[9]}$, was applied in planar perovskite solar cells in 2013. $\mathrm{PbCl}_{2}$ and MAI placed in a vacuum chamber can be vaporized simultaneously by heating and deposited on a rotating substrate, as depicted in

Figure 3-13. Perovskite thin films deposited by the vapor evaporation method showed substantially more uniform surface morphologies with no pin-holes compared to the perovskite films deposited by the solution-processing approach of that time. By this method, Liu et al. fabricated highly efficient planar n-i-p perovskite solar cells with PCE above $15 \%$.
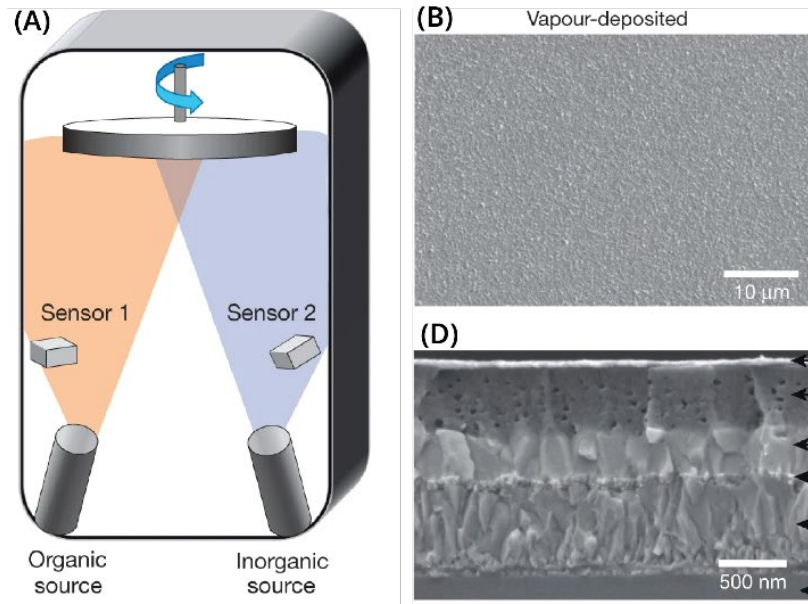

(C) Solution-processed

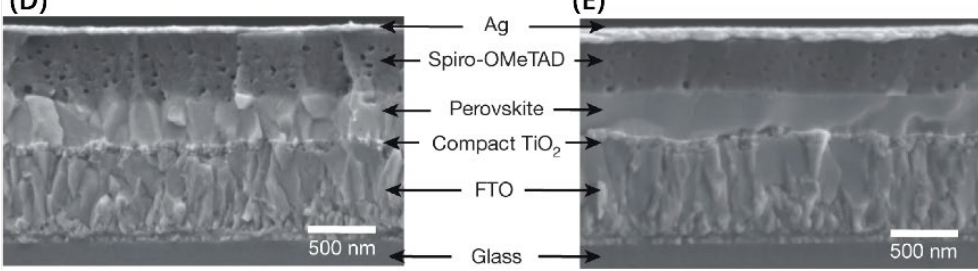

Figure 3-13 Perovskite thin film deposited by vapor evaporation. (A) Schematic illustration of a dual-source thermal evaporation system. MAI was the organic source, and $\mathrm{PbI}_{2}$ was the inorganic source. SEM top views of (B) a vapor-deposited $\mathrm{MAPbI}_{3}$ thin film and (C) a solution-processed $\mathrm{MAPbI}_{3}$ thin film. Cross-sectional SEM images of under high magnification of complete solar cells constructed from (D) a vapor-deposited $\mathrm{MAPbI}_{3}$ thin film and (E) a solution-processed $\mathrm{MAPbI}_{3}$ thin film. Reproduced with permission from reference ${ }^{[9]}$, Springer Nature Limited.

Inverted planar perovskite solar cells were also fabricated by this method. At the end of 2013, Malinkiewicz et al. ${ }^{[70]}$ demonstrated a planar p-i-n perovskite solar cell using 
vapor evaporated $\mathrm{MAPbI}_{3}$ layer with a $12 \%$ power-conversion efficiency. A higher PCE of $\sim 20 \%$ was achieved in 2016 in a fully evaporated PSC by a co-evaporation method ${ }^{[71]}$.

\subsubsection{One-step spin coating method}

One-step spin coating methods are based on the co-deposition of both the organic and inorganic precursors. Among the proposed one-step spin coating methods, the development of antisolvent engineering and Lewis acid-base adduct approaches were key milestones in achieving PSCs with a PCE of $>20 \%$.

\subsubsection{Antisolvent engineering}
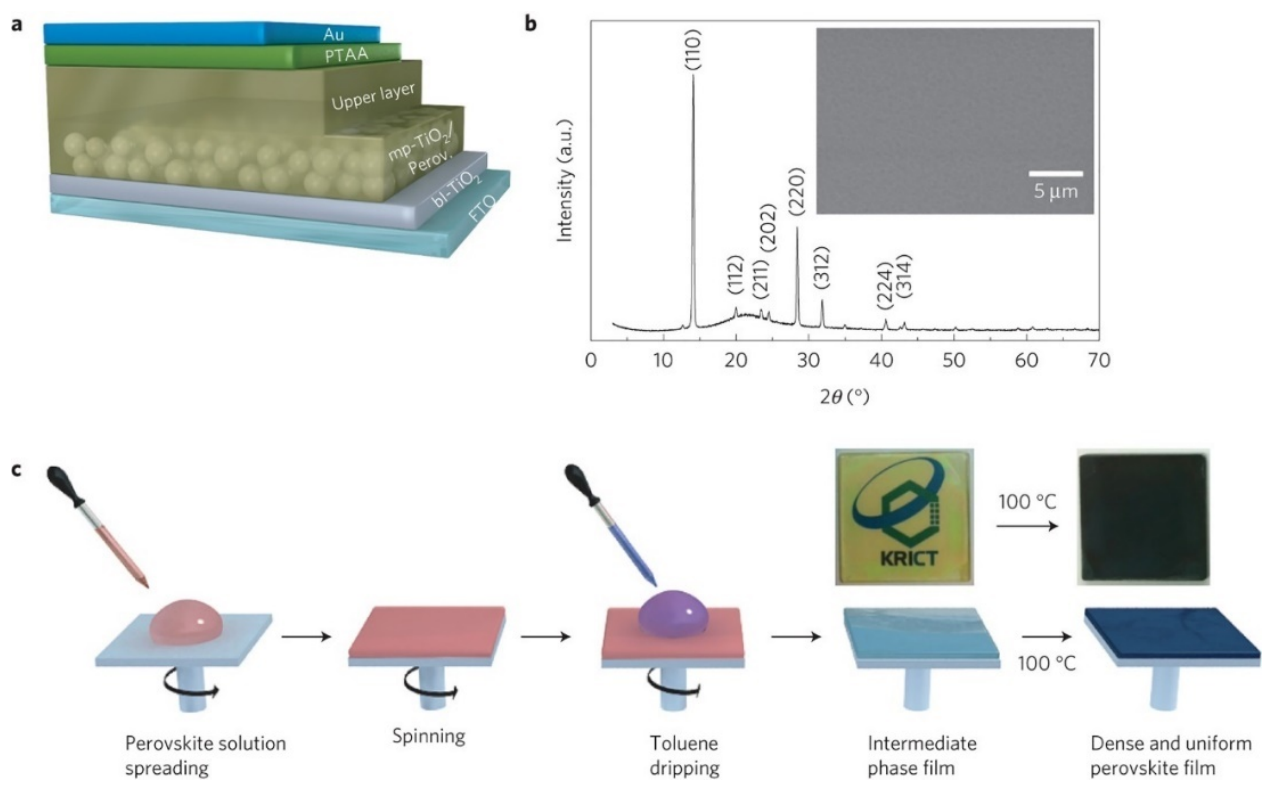

Figure 3-14 (a) Device architecture of the bilayered perovskite solar cell (glass/FTO/bl-TiO $2 / \mathrm{mp}$ $\mathrm{TiO}_{2}$-perovskite nanocomposite layer/perovskite upper layer/PTAA/Au). (b) XRD pattern of the annealed perovskite coating on fused silica substrate. The inset shows a SEM image of a surface

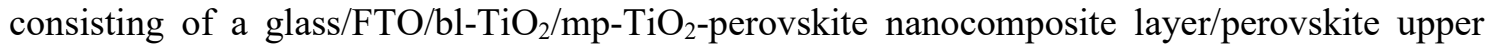
layer. (c) Solvent engineering procedure for preparing the uniform and dense perovskite film. Reprinted with permission from reference ${ }^{[64]}$, Springer Nature Limited.

Antisolvent engineering was developed to control the growth of the perovskite crystals. During the spin coating process, an antisolvent, in which the perovskite 
compound is insoluble, is dripped onto the spinning substrate ${ }^{[64]}$. The proposed mechanism of this approach is that the addition of antisolvents leads to immediate supersaturation and accelerates heterogeneous nucleation ${ }^{[72]}$. Jeon et al. ${ }^{[64]}$ used toluene as the antisolvent together with a perovskite precursor containing a mixed solvent of $\gamma$ butyrolactone (GBL) and DMSO to deposit extremely uniform and highly crystalline $\mathrm{MAPbI}_{3-\mathrm{x}} \mathrm{Br}_{\mathrm{x}}$ film and fabricated mesoporous-structured perovskite solar cells exhibiting 16.2 \% PCE, as depicted in Figure 3-14.

Paek et al. ${ }^{[73]}$ investigated the interaction between six antisolvents, including chlorobenzene, toluene, trifluorotoluene, $p$-xylene, diethyl ether, dichloromethane, and the perovskite precursor solution containing a mixed solvent of DMF and DMSO. For antisolvents that are miscible with the solution solvents, the formation of the perovskite phase took less than $15 \mathrm{~s}$. Whereas, for antisolvents that are not miscible with solution solvents, this process took $30-40$ s. Perovskite thin films prepared by miscible antisolvents delivered a higher PCE than those formed by the immiscible antisolvents.

\subsubsection{Lewis acid-base adduct method}

In 2015, Ahn et al. ${ }^{[66]}$ reported the Lewis acid-base adduct method to deposit perovskite thin films for highly efficient solar cells reproducibly. The precursor solution was prepared by dissolving a stoichiometric mixture of MAI, $\mathrm{PbI}_{2}$, and DMSO in DMF. During the spin coating process, diethyl ether was dripped onto the spinning substrate, as shown in Figure 3-15 (A), resulting in the formation of an intermediate adduct phase of $\mathrm{MAI} \cdot \mathrm{PbI}_{2} \cdot \mathrm{DMSO}$. The weak bonding in the adduct makes it possible to remove DMSO by heating at a low temperature $\left(65^{\circ} \mathrm{C}\right)$. Mesoporous-structured perovskite solar cells were fabricated based on $\mathrm{MAPbI}_{3}$ thin films deposited by this approach, and an average 
PCE of 18.3\% was achieved. Figure 3-15 (B) shows the cross-sectional SEM image of the device.

\section{(A)}

Perovskite precursors and Lewis base in solution (e.g. $\mathrm{MAl}+\mathrm{Pbl}_{2}+\mathrm{DMSO}$

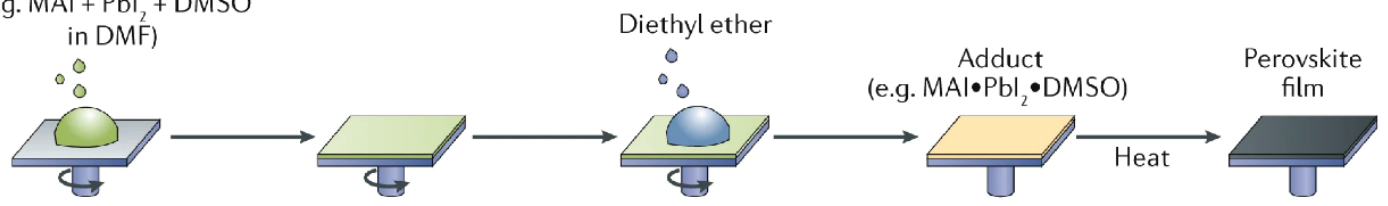

(B)

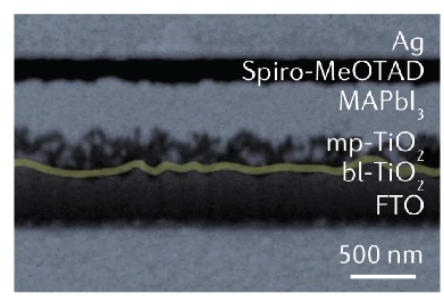

(C)

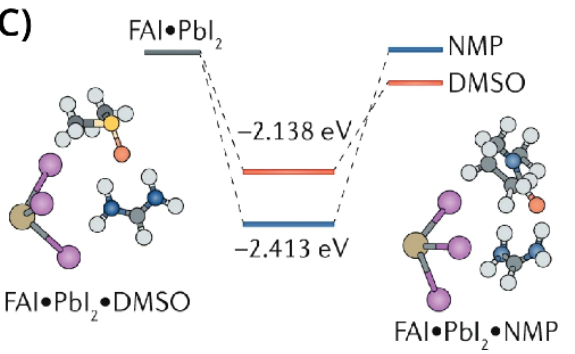<smiles>CN1CCCC1=O</smiles>

NMP<smiles>CS(C)(=O)=O</smiles>

Figure 3-15 (A) Illustration of the key steps in the Lewis acid-base adduct method in which an adduct film is formed by dripping on diethyl ether. (B) Cross-sectional scanning electron microscopy image of a perovskite solar cell containing a $\mathrm{MAPbI}_{3}$ film formed using the Lewis acid-base adduct approach. (C) Comparison of the interaction energy of an adduct formed between FAI (where $\mathrm{FA}^{+}$is formamidinium), $\mathrm{PbI}_{2}$ and dimethyl sulfoxide (DMSO) as the Lewis base and that of the related adduct formed with N-methyl-2-pyrrolidone (NMP) as the Lewis base. Reprinted with permission from reference ${ }^{[74]}$, Springer Nature Limited.

For $\mathrm{FAPbI}_{3}, \mathrm{~N}$-methyl-2-pyrrolidone (NMP) was used as the Lewis base instead of $\mathrm{DMSO}^{[75]}$. Lewis adduct formed by NMP was calculated to have a higher interaction energy than that formed by DMSO, as shown in Figure 3-15 (C), leading to a more stable adduct and more uniform thin films. The interactions between Lewis base and $\mathrm{FA}^{+}$or $\mathrm{MA}^{+}$is critical for the stability of the adduct film and the kinetic control of crystal growth. The guidelines for choosing the ideal Lewis-base have been proposed by Yang's $\operatorname{group}^{[75]}$. 


\subsubsection{Two-step spin coating method}

Two-step methods, or sequential methods, involve the deposition of the inorganic $\mathrm{PbX}_{2}(\mathrm{X}=\mathrm{Cl}, \mathrm{Br}, \mathrm{I})$ precursor and their subsequent transformation into the perovskite films. The transformation process can be done in different ways, such as dipping $\mathrm{PbX}_{2}$ film into MAX solution or spin coating MAX on top of $\mathrm{PbX}_{2}$.
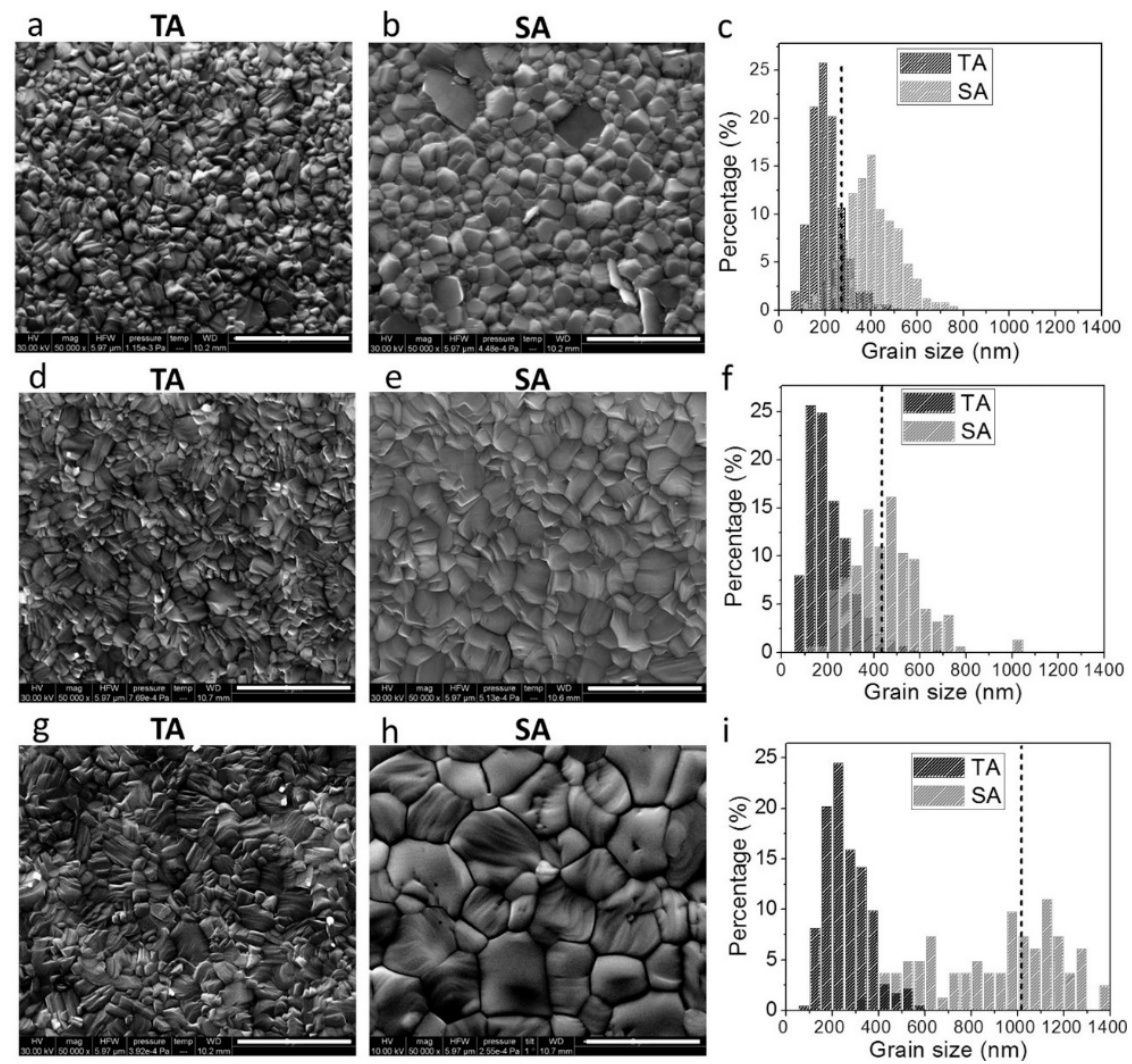

Figure 3-16 SEM images of thermally annealed (TA) perovskite films with thicknesses of 250 $\mathrm{nm}$ (a), $430 \mathrm{~nm}$ (d), and $1015 \mathrm{~nm}(\mathrm{~g})$, and solvent-annealed (SA) perovskite films with thicknesses of $250 \mathrm{~nm}(\mathrm{~b}), 430 \mathrm{~nm}$ (e), and $1015 \mathrm{~nm}$ (h); the scale bars are $2 \mu \mathrm{m}$. c,f,i) Grain-size distributions of the SEM images to the left. Reprinted with permission from reference ${ }^{[76]}$.

The first report of the two-step spin coating method was published in 2013. Burschka et al. ${ }^{[69]}$ spin-coated $\mathrm{PbI}_{2}$ film on top of a mesoporous $\mathrm{TiO}_{2}$ layer and subsequently dipped it in a MAI solution to convert the yellow $\mathrm{PbI}_{2}$ into a dark brown perovskite layer within seconds. PSCs fabricated using this method exhibited $15 \%$ PCE 
with high reproducibility. For planar perovskite solar cells, the conversion is protracted as it is harder for MAI to diffuse into a planar $\mathrm{PbI}_{2}$ layer ${ }^{[77,78]}$. Chen and Zhou et al. ${ }^{[79]}$ developed a vapor-assisted solution process (VASP), in which the spin-coated $\mathrm{PbI}_{2}$ layer was annealed in MAI vapor to form smooth, fully covered $\mathrm{MAPbI}_{3}$ film. Xiao et al. ${ }^{[76]}$ achieved large $\mathrm{MAPbI}_{3}$ crystal grain $(>1 \mu \mathrm{m})$ by annealing the as-spun thin film in an environment filled with the solvent vapor. This method is called the solvent annealing method, and the result is shown in Figure 3-16. The inverted (p-i-n) planar-structured solar cells reached the highest efficiency of $15.6 \%$.

\subsubsection{Intramolecular exchange}

One major disadvantage that hinders the two-step method is the incomplete conversion of $\mathrm{PbI}_{2}$ to the perovskite phase in films thicker than $500 \mathrm{~nm}$. The dipping method requires prolonged immersion for thicker $\mathrm{PbI}_{2}$ films (especially for planar devices), which increases the chance of peeling off the perovskite film in solution. The surface morphology of perovskite films prepared by the solvent annealing or the VASP methods is not as smooth as those prepared by the one-step antisolvent engineering method.

Further, Yang et al. ${ }^{[12]}$ reported the preparation of 560 nm-thick $\mathrm{FAPbI}_{3}$ film by the intramolecular exchange process (IEP) and fabricated perovskite solar cells exhibiting $>19 \%$ PCE repeatedly. Inspired by the antisolvent engineering approach ${ }^{[64]}$, Yang spin-coated a layer of $\mathrm{PbI}_{2}(\mathrm{DMSO})$ instead of $\mathrm{PbI}_{2 \cdot}{ }^{[12]}$ DMSO molecules were intercalated in $\mathrm{PbI}_{2}$ film with van der Waals interaction. During IEP, DMSO molecules were easily replaced by FAI molecules as a consequence of their higher affinity toward $\mathrm{PbI}_{2}$, and the inorganic framework was also retained, as shown in Figure 3-17 (A). 

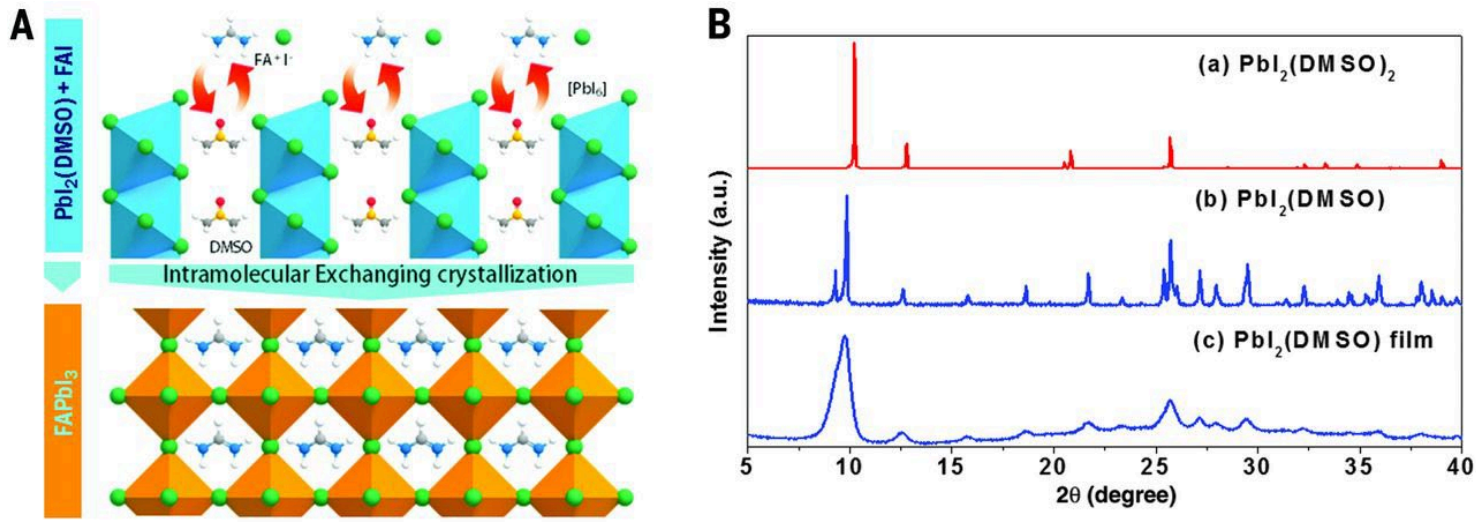

Figure 3-17 (A) Schematics of $\mathrm{FAPbI}_{3}$ perovskite crystallization involving the direct intramolecular exchange of DMSO molecules intercalated in $\mathrm{PbI}_{2}$ with formamidinium iodide (FAI). The DMSO molecules are intercalated between edge-sharing $\left[\mathrm{PbI}_{6}\right]$ octahedral layers. (B) XRD patterns of (a) as-prepared $\mathrm{PbI}_{2}(\mathrm{DMSO})_{2}$ powders, (b) vacuum-annealed $\mathrm{PbI}_{2}(\mathrm{DMSO})$ powders, and (c) as-deposited film on fused quartz substrate using $\mathrm{PbI}_{2}(\mathrm{DMSO})$ complex solution. Reprinted with permission from reference ${ }^{[12]}$.

To prepare $\mathrm{PbI}_{2}(\mathrm{DMSO})$ powder, $\mathrm{PbI}_{2}$ was first dissolved in $\mathrm{DMSO}$, and toluene was slowly added to the solution to precipitate $\mathrm{PbI}_{2}(\mathrm{DMSO})_{2} \cdot \mathrm{PbI}_{2}(\mathrm{DMSO})_{2}$ precipitation was dried at room temperature and annealed in a vacuum oven at $60{ }^{\circ} \mathrm{C}$ overnight to obtain $\mathrm{PbI}_{2}(\mathrm{DMSO})$ powder by removal of $1 \mathrm{~mol}$ DMSO. The XRD pattern of $\mathrm{PbI}_{2}$ (DMSO) did not match that of $\mathrm{PbI}_{2}(\mathrm{DMSO})_{2}$ [Figure 3-17 (B)], indicating these two compounds were in different phases. $\mathrm{FAPbI}_{3}$ films prepared by the $\mathrm{PbI}_{2}(\mathrm{DMSO})$ layers and IEP approach presented dense and highly crystalline structures with larger crystal grains than those prepared by the $\mathrm{PbI}_{2}$ layers and the conventional two-step spin coating approach.

\subsection{Perovskite nanocrystals}

Over the last decade, organic-inorganic halide perovskites have been attracting significant attention as a result of their exceptional optoelectronic properties for photovoltaic applications ${ }^{[74]}$. On top of their facile solution processability, this new family 
of semiconducting materials have high carrier mobility, long carrier diffusion length, and low trap density, making the perovskite nanocrystals (NCs) promising for light-emitting diodes (LEDs) and lasers ${ }^{[80-84]}$. For an organic-inorganic lead halide $\mathrm{NC}$, the dimensionality of its inorganic framework is associated with its stoichiometry. For example, the inorganic frameworks of $\mathrm{APbX}_{3}, \mathrm{~A}_{2} \mathrm{PbX}_{4}, \mathrm{~A}_{6} \mathrm{PbX}$, and $\mathrm{A}_{4} \mathrm{PbX} 6$ are $3 \mathrm{D}, 2 \mathrm{D}$, 1D, and $0 \mathrm{D}$, respectively ${ }^{[85-91]}$. Perovskite NCs have shown bright and narrow-band photoluminescence (PL) that is easily tunable by changing either the halide or the organic composition $^{[84,88,92-96]}$. The bandgaps of perovskite NCs can also depend on the size of the NCs, which is called the quantum confinement effect ${ }^{[97-101]}$. The quantum confinement effect is the phenomenon that a semiconducting crystal can demonstrate different electronic and optical properties from its bulk form when its size is on the nanoscopic scale. The size-dependent bandgaps provide approaches for tunable light emission by control of the particle size.

Schmidt et al. ${ }^{[87]}$ first reported the synthesis of 6-nm-sized $\mathrm{MAPbBr}_{3} \mathrm{NCs}$ using a medium- or long-chain alkylammonium cation to stabilize the NCs. The $\mathrm{MAPbBr}_{3} \mathrm{NCs}$ were stable in either solid state or dispersed in aprotic, moderate polarity, organic solvents. Both the colloidal solutions and thin films of $\mathrm{MAPbBr}_{3} \mathrm{NCs}$ showed strong symmetric light-emission peaks with a high quantum yield (ca. 20\%) at 530 and $533 \mathrm{~nm}$, respectively. Zhang et al. ${ }^{[96]}$ developed the ligand-assisted reprecipitation (LARP) strategy for the synthesis of color-tunable $(400-750 \mathrm{~nm})$ and brightly luminescent colloidal $\mathrm{MAPbX}_{3}(\mathrm{X}=\mathrm{Cl}, \mathrm{Br}$ and $\mathrm{I})$ quantum dots with an absolute $\mathrm{PL}$ quantum yield (PLQY) up to $70 \%$. Akkerman et al. ${ }^{[95]}$, used a modified LARP approach to synthesize fully inorganic perovskite $\mathrm{CsPbr}_{3}$ nanoplates with precise control over the thickness to 
3-5 monolayers. $\mathrm{Br}^{-}$anion in the $\mathrm{CsPbBr} 3$ nanoplates can be replaced by $\mathrm{Cl}^{-}$or $\mathrm{I}^{-}$anions by anion exchange. Yang's group ${ }^{[93]}$ reported the direct growth of atomically thin $2 \mathrm{D}$ $\left(\mathrm{C}_{4} \mathrm{H}_{9} \mathrm{NH}_{3}\right)_{2} \mathrm{PbX}_{4}(\mathrm{X}=\mathrm{Cl}, \mathrm{Br}$, and I) nanosheets by a solution-phase growth method, which exhibited efficient photoluminescence and color-tuning ability. The same group also reported the synthesis of $\mathrm{CsPbX}_{3}(\mathrm{X}=\mathrm{Br}$ and $\mathrm{I})$ nanowires ${ }^{[102]}$ by the hot-injection approach. They also synthesized $\mathrm{CsPbX}_{3}(\mathrm{X}=\mathrm{Cl}$ and $\mathrm{Br})$ nanowires by a lowtemperature, solution-phase growth method and successfully demonstrated for the first time of lasing in the as-grown $\mathrm{CsPbBr}_{3}$ nanowires with low lasing thresholds and a maximum quality factor of $1009^{[103]}$. Lasing under constant, pulsed excitation cycle was maintained for $10^{9}$ cycles (over 1 hour), and the $\mathrm{CsPbBr}_{3}$ nanowires remained stable.

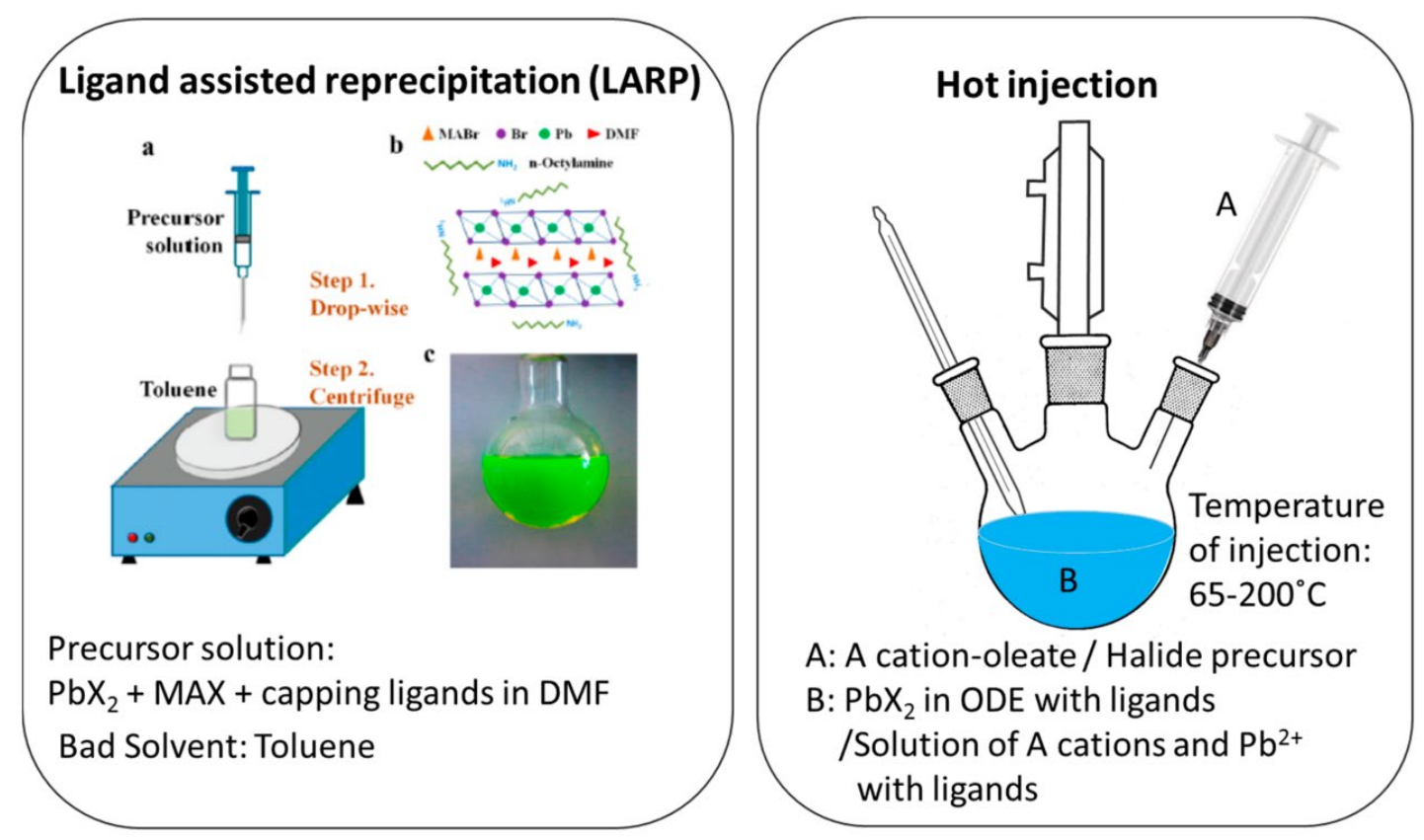

Figure 3-18 Schematic illustration showing the LARP and hot injection methods for colloidal synthesis of perovskite NCs. The schematic drawing for LARP is reproduced with permission from reference ${ }^{[96]}$. Copyright (2015) American Chemical Society. The diagram for hot injection is reproduced with permission from reference ${ }^{[104]}$.

The LARP ${ }^{[96]}$ and hot injection ${ }^{[86,102]}$ approaches, as shown in Figure 3-18, are the two main solution-phase strategies for synthesizing perovskite NCs. Zhang et al. ${ }^{[96]}$ 
developed the LARP technique for synthesizing $\mathrm{MAPbBr}_{3}$ QDs in 2015. MABr and $\mathrm{PbBr}_{2}$ were first dissolved in DMF with oleic acid and $n$-octylamine functioning as capping ligands to form a precursor solution. The precursor solution was then dropped into toluene with vigorous stirring. After centrifugation, a colloidal solution of $\mathrm{MAPbBr}_{3}$ QDs were obtained with a mean diameter of $3.3 \mathrm{~nm}$ and a narrow size distribution. The halide composition of perovskite NCs prepared by the LARP method can be easily tuned by manipulating the halide ratios in the precursor solution. Since then, the LARP method has been widely used for the synthesis of $\mathrm{APbX}_{3} \mathrm{NCs}$.

The hot injection approach was first introduced for synthesizing $\mathrm{CsPbX}_{3}(\mathrm{X}=\mathrm{Cl}$, $\mathrm{Br}, \mathrm{I}) \mathrm{NCs}$ by the Kovalenko group in $2015^{[92]} \cdot \mathrm{Cs}_{2} \mathrm{CO}_{3}$ was reacted with oleic acid in octadecene to prepare the Cs-oleate precursor. Hot Cs-oleate precursor solution $\left(100{ }^{\circ} \mathrm{C}\right)$ was quickly injected into the $\mathrm{PbX}_{2}$ solution in octadecene at an elevated temperature $\left(140-200{ }^{\circ} \mathrm{C}\right)$ with oleylamine and oleic acid as capping ligands. $\mathrm{CsPbX}_{3} \mathrm{NCs}$ were collected by centrifugation and redispersed in toluene or hexane. A protective atmosphere $\left(\mathrm{N}_{2}\right)$ is usually required for this approach, and the elevated temperature makes it hard to control during injection, which results in a low reproducibility.

\subsection{References}

1. Davidson, M. W.; Lofgren, G. E., Photomicrography in the Geological Sciences. Journal of Geological Education 1991, 39 (5), 403-418.

2. Wenk, H.-R.; Bulakh, A., Minerals. Their Constitution and Origin. 2nd edition. Cambridge University Press: New York, NY, 2016.

3. Hench, L. L.; Clark, D. E.; Harker, A. B., Nuclear waste solids. Journal of Materials Science 1986, 21 (5), 1457-1478. 
4. Sebastian, M. T., CHAPTER SIX - ABO3 TYPE PEROVSKITES. In Dielectric Materials for Wireless Communication, Mailadil T. Sebastian, Ed. Elsevier:

Amsterdam, 2008; pp 161-203.

5. Kojima, A.; Teshima, K.; Shirai, Y.; Miyasaka, T., Organometal halide perovskites as visible-light sensitizers for photovoltaic cells. J Am Chem Soc 2009, 131 (17), 6050-1.

6. $\quad$ Rong, Y.; Hu, Y.; Mei, A.; Tan, H.; Saidaminov, M. I.; Seok, S. I.; McGehee, M. D.; Sargent, E. H.; Han, H., Challenges for commercializing perovskite solar cells. Science 2018, 361 (6408), eaat8235.

7. Im, J. H.; Lee, C. R.; Lee, J. W.; Park, S. W.; Park, N. G., 6.5\% efficient perovskite quantum-dot-sensitized solar cell. Nanoscale 2011, 3 (10), 4088-93.

8. $\quad$ Etgar, L.; Gao, P.; Xue, Z.; Peng, Q.; Chandiran, A. K.; Liu, B.;

Nazeeruddin, M. K.; Gratzel, M., Mesoscopic CH3NH3PbI3/TiO2 heterojunction solar cells. J Am Chem Soc 2012, 134 (42), 17396-9.

9. Liu, M.; Johnston, M. B.; Snaith, H. J., Efficient planar heterojunction perovskite solar cells by vapour deposition. Nature 2013, 501 (7467), 395-8.

10. Bi, D.; Moon, S.-J.; Häggman, L.; Boschloo, G.; Yang, L.; Johansson, E. M. J.; Nazeeruddin, M. K.; Grätzel, M.; Hagfeldt, A., Using a two-step deposition technique to prepare perovskite $(\mathrm{CH} 3 \mathrm{NH} 3 \mathrm{PbI} 3)$ for thin film solar cells based on $\mathrm{ZrO} 2$ and TiO2 mesostructures. RSC Advances 2013, 3 (41), 18762-18766.

11. Noel, N. K.; Stranks, S. D.; Abate, A.; Wehrenfennig, C.; Guarnera, S.; Haghighirad, A.-A.; Sadhanala, A.; Eperon, G. E.; Pathak, S. K.; Johnston, M. B.; Petrozza, A.; Herz, L. M.; Snaith, H. J., Lead-free organic-inorganic tin halide perovskites for photovoltaic applications. Energy Environ. Sci. 2014, 7 (9), 3061-3068.

12. Yang, W. S.; Noh, J. H.; Jeon, N. J.; Kim, Y. C.; Ryu, S.; Seo, J.; Seok, S. I., SOLAR CELLS. High-performance photovoltaic perovskite layers fabricated through intramolecular exchange. Science 2015, 348 (6240), 1234-7.

13. Hazen, R. M.; Finger, L. W.; Angel, R. J.; Prewitt, C. T.; Ross, N. L.; Mao, H. K.; Hadidiacos, C. G.; Hor, P. H.; Meng, R. L.; Chu, C. W., Crystallographic description of phases in the Y-Ba-Cu-O superconductor. Physical Review B 1987, 35 (13), 7238-7241. 
14. Murphy, D. W.; Sunshine, S.; van Dover, R. B.; Cava, R. J.; Batlogg, B.; Zahurak, S. M.; Schneemeyer, L. F., New superconducting cuprate perovskites. Physical Review Letters 1987, 58 (18), 1888-1890.

15. He, T.; Huang, Q.; Ramirez, A. P.; Wang, Y.; Regan, K. A.; Rogado, N.; Hayward, M. A.; Haas, M. K.; Slusky, J. S.; Inumara, K.; Zandbergen, H. W.; Ong, N. P.; Cava, R. J., Superconductivity in the non-oxide perovskite MgCNi3. Nature 2001, 411 (6833), 54-56.

16. Ashkin, A.; Boyd, G. D.; Dziedzic, J. M.; Smith, R. G.; Ballman, A. A.; Levinstein, J. J.; Nassau, K., OPTICALLY - INDUCED REFRACTIVE INDEX INHOMOGENEITIES IN LiNbO3 AND LiTaO3. Applied Physics Letters 1966, 9 (1), $72-74$

17. Choi, K. J.; Biegalski, M.; Li, Y. L.; Sharan, A.; Schubert, J.; Uecker, R.; Reiche, P.; Chen, Y. B.; Pan, X. Q.; Gopalan, V.; Chen, L.-Q.; Schlom, D. G.; Eom, C. B., Enhancement of Ferroelectricity in Strained $\mathrm{BaTiO}_{3}$ Thin Films. Science 2004, 306 (5698), 1005-1009.

18. Khaliullin, G.; Maekawa, S., Orbital Liquid in Three-Dimensional Mott Insulator: $\mathrm{LaTiO}_{3}$. Physical Review Letters 2000, 85 (18), 3950-3953.

19. Biegalski, M.; Haeni, J.; Trolier-McKinstry, S.; Schlom, D.; Brandle, C.; Graitis, A. V., Thermal expansion of the new perovskite substrates $\mathrm{DyScO}_{3}$ and $\mathrm{GdScO}_{3}$. Journal of Materials Research 2005, 20 (4), 952-958.

20. Liang, J.; Liu, J.; Jin, Z., All-Inorganic Halide Perovskites for Optoelectronics: Progress and Prospects. Solar RRL 2017, 1 (10), 1700086.

21. Howard, C. J.; Kennedy, B. J.; Chakoumakos, B. C., Neutron powder diffraction study of rhombohedral rare-earth aluminates and the rhombohedral to cubic phase transition. Journal of Physics: Condensed Matter 1999, 12 (4), 349-365.

22. Zemann, J., Crystal structures, 2 nd edition, Vol. 2 by R. W. G. Wyckoff. Acta Crystallographica 1965, 19 (3), 490-490.

23. Glazer, A. M., The classification of tilted octahedra in perovskites. Acta Crystallographica Section B Structural Crystallography and Crystal Chemistry 1972, 28 (11), 3384-3392. 
24. Greedan, J. E.; Bieringer, M.; Britten, J. F.; Giaquinta, D. M.; zur Loye, H. C., Synthesis, Crystal Structure, and Unusual Magnetic Properties of InMnO3. Journal of Solid State Chemistry 1995, 116 (1), 118-130.

25. Gibbs, A. S.; Knight, K. S.; Lightfoot, P., High-temperature phase transitions of hexagonal $\mathrm{YMnO}_{3}$. Physical Review B 2011, 83 (9), 094111.

26. da Silva, E. L.; Skelton, J. M.; Parker, S. C.; Walsh, A., Phase stability and transformations in the halide perovskite $\mathrm{CsSnI}_{3}$. Physical Review B 2015, 91 (14), 144107.

27. Mori, T.; Kamegashira, N.; Aoki, K.; Shishido, T.; Fukuda, T., Crystal growth and crystal structures of the $\mathrm{LnMnO3}$ perovskites: $\mathrm{Ln}=\mathrm{Nd}, \mathrm{Sm}, \mathrm{Eu}$ and $\mathrm{Gd}$. Materials Letters 2002, 54 (2), 238-243.

28. Goldschmidt, V. M., Die Gesetze der Krystallochemie. Die Naturwissenschaften 1926, 14 (21), 477-485.

29. Onoda-Yamamuro, N.; Yamamuro, O.; Matsuo, T.; Suga, H., p-T phase relations of $\mathrm{CH} 3 \mathrm{NH} 3 \mathrm{PbX} 3(\mathrm{X}=\mathrm{Cl}, \mathrm{Br}, \mathrm{I})$ crystals. Journal of Physics and Chemistry of Solids 1992, 53 (2), 277-281.

30. Weller, M. T.; Weber, O. J.; Henry, P. F.; Di Pumpo, A. M.; Hansen, T. C., Complete structure and cation orientation in the perovskite photovoltaic methylammonium lead iodide between 100 and 352 K. Chemical Communications 2015, 51 (20), 4180-4183.

31. Brivio, F.; Frost, J. M.; Skelton, J. M.; Jackson, A. J.; Weber, O. J.; Weller, M. T.; Goñi, A. R.; Leguy, A. M. A.; Barnes, P. R. F.; Walsh, A., Lattice dynamics and vibrational spectra of the orthorhombic, tetragonal, and cubic phases of methylammonium lead iodide. Physical Review B 2015, 92 (14), 144308.

32. Baikie, T.; Fang, Y.; Kadro, J. M.; Schreyer, M.; Wei, F.; Mhaisalkar, S. G.; Graetzel, M.; White, T. J., Synthesis and crystal chemistry of the hybrid perovskite (CH3NH3)PbI3 for solid-state sensitised solar cell applications. Journal of Materials Chemistry A 2013, l (18), 5628-5641.

33. Kieslich, G.; Sun, S.; Cheetham, A. K., Solid-state principles applied to organic-inorganic perovskites: new tricks for an old dog. Chemical Science 2014, 5 (12), 4712-4715. 
34. Shannon, R., Revised effective ionic radii and systematic studies of interatomic distances in halides and chalcogenides. Acta Crystallographica Section A 1976, 32 (5), 751-767.

35. Stoumpos, C. C.; Malliakas, C. D.; Kanatzidis, M. G., Semiconducting tin and lead iodide perovskites with organic cations: phase transitions, high mobilities, and near-infrared photoluminescent properties. Inorg Chem 2013, 52 (15), 9019-38.

36. Pang, S.; Hu, H.; Zhang, J.; Lv, S.; Yu, Y.; Wei, F.; Qin, T.; Xu, H.; Liu, Z.; Cui, G., $\mathrm{NH} 2 \mathrm{CH}=\mathrm{NH} 2 \mathrm{PbI} 3$ : An Alternative Organolead Iodide Perovskite Sensitizer for Mesoscopic Solar Cells. Chemistry of Materials 2014, 26 (3), 1485-1491.

37. Weller, M. T.; Weber, O. J.; Frost, J. M.; Walsh, A., Cubic Perovskite Structure of Black Formamidinium Lead Iodide, $\alpha-[\mathrm{HC}(\mathrm{NH} 2) 2] \mathrm{PbI} 3$, at $298 \mathrm{~K}$. The Journal of Physical Chemistry Letters 2015, 6 (16), 3209-3212.

38. Xie, L.-Q.; Chen, L.; Nan, Z.-A.; Lin, H.-X.; Wang, T.; Zhan, D.-P.; Yan, J.W.; Mao, B.-W.; Tian, Z.-Q., Understanding the Cubic Phase Stabilization and Crystallization Kinetics in Mixed Cations and Halides Perovskite Single Crystals. Journal of the American Chemical Society 2017, 139 (9), 3320-3323.

39. Xing, G.; Mathews, N.; Sun, S.; Lim, S. S.; Lam, Y. M.; Gratzel, M.; Mhaisalkar, S.; Sum, T. C., Long-range balanced electron- and hole-transport lengths in organic-inorganic CH3NH3PbI3. Science 2013, 342 (6156), 344-7.

40. Lin, Q.; Armin, A.; Nagiri, R. C. R.; Burn, P. L.; Meredith, P., Electro-optics of perovskite solar cells. Nature Photonics 2015, 9 (2), 106-112.

41. De Wolf, S.; Holovsky, J.; Moon, S.-J.; Löper, P.; Niesen, B.; Ledinsky, M.; Haug, F.-J.; Yum, J.-H.; Ballif, C., Organometallic Halide Perovskites: Sharp Optical Absorption Edge and Its Relation to Photovoltaic Performance. The Journal of Physical Chemistry Letters 2014, 5 (6), 1035-1039.

42. Xing, G.; Mathews, N.; Lim, S. S.; Yantara, N.; Liu, X.; Sabba, D.; Gratzel, M.; Mhaisalkar, S.; Sum, T. C., Low-temperature solution-processed wavelengthtunable perovskites for lasing. Nat Mater 2014, 13 (5), 476-80.

43. Chen, C.-W.; Hsiao, S.-Y.; Chen, C.-Y.; Kang, H.-W.; Huang, Z.-Y.; Lin, H.$\mathrm{W}$., Optical properties of organometal halide perovskite thin films and general device 
structure design rules for perovskite single and tandem solar cells. Journal of Materials Chemistry A 2015, 3 (17), 9152-9159.

44. Löper, P.; Stuckelberger, M.; Niesen, B.; Werner, J.; Filipič, M.; Moon, S.-J.; Yum, J.-H.; Topič, M.; De Wolf, S.; Ballif, C., Complex Refractive Index Spectra of CH3NH3PbI3 Perovskite Thin Films Determined by Spectroscopic Ellipsometry and Spectrophotometry. The Journal of Physical Chemistry Letters 2015, 6 (1), 66-71.

45. Ball, J. M.; Stranks, S. D.; Hörantner, M. T.; Hüttner, S.; Zhang, W.; Crossland, E. J. W.; Ramirez, I.; Riede, M.; Johnston, M. B.; Friend, R. H.; Snaith, H. J., Optical properties and limiting photocurrent of thin-film perovskite solar cells. Energy \& Environmental Science 2015, 8 (2), 602-609.

46. Ziang, X.; Shifeng, L.; Laixiang, Q.; Shuping, P.; Wei, W.; Yu, Y.; Li, Y.; Zhijian, C.; Shufeng, W.; Honglin, D.; Minghui, Y.; Qin, G. G., Refractive index and extinction coefficient of $\mathrm{CH}_{3} \mathrm{NH}_{3} \mathrm{PbI}_{3}$ studied by spectroscopic ellipsometry. Opt.

Mater. Express 2015, 5 (1), 29-43.

47. Jiang, Y.; Green, M. A.; Sheng, R.; Ho-Baillie, A., Room temperature optical properties of organic-inorganic lead halide perovskites. Solar Energy Materials and Solar Cells 2015, 137, 253-257.

48. Wehrenfennig, C.; Liu, M.; Snaith, H. J.; Johnston, M. B.; Herz, L. M., Homogeneous Emission Line Broadening in the Organo Lead Halide Perovskite CH3NH3PbI3-xClx. The Journal of Physical Chemistry Letters 2014, 5 (8), 1300-1306.

49. Sun, S.; Salim, T.; Mathews, N.; Duchamp, M.; Boothroyd, C.; Xing, G.; Sum, T. C.; Lam, Y. M., The origin of high efficiency in low-temperature solutionprocessable bilayer organometal halide hybrid solar cells. Energy \& Environmental Science 2014, 7 (1), 399-407.

50. Green, M. A.; Jiang, Y.; Soufiani, A. M.; Ho-Baillie, A., Optical Properties of Photovoltaic Organic-Inorganic Lead Halide Perovskites. The Journal of Physical Chemistry Letters 2015, 6 (23), 4774-4785.

51. Stranks, S. D.; Eperon, G. E.; Grancini, G.; Menelaou, C.; Alcocer, M. J.; Leijtens, T.; Herz, L. M.; Petrozza, A.; Snaith, H. J., Electron-hole diffusion lengths exceeding 1 micrometer in an organometal trihalide perovskite absorber. Science 2013, 342 (6156), 341-4. 
52. Zhao, Y.; Nardes, A. M.; Zhu, K., Solid-State Mesostructured Perovskite CH3NH3PbI3 Solar Cells: Charge Transport, Recombination, and Diffusion Length. The Journal of Physical Chemistry Letters 2014, 5 (3), 490-494.

53. Dong, Q.; Fang, Y.; Shao, Y.; Mulligan, P.; Qiu, J.; Cao, L.; Huang, J., Solar cells. Electron-hole diffusion lengths $>175 \mu \mathrm{m}$ in solution-grown CH3NH3PbI3 single crystals. Science 2015, 347 (6225), 967-70.

54. Yin, W.-J.; Shi, T.; Yan, Y., Unusual defect physics in CH3NH3PbI3 perovskite solar cell absorber. Applied Physics Letters 2014, 104 (6), 063903.

55. Wang, Q.; Shao, Y.; Xie, H.; Lyu, L.; Liu, X.; Gao, Y.; Huang, J., Qualifying composition dependent $\mathrm{p}$ and $\mathrm{n}$ self-doping in $\mathrm{CH} 3 \mathrm{NH} 3 \mathrm{PbI}$. Applied Physics Letters 2014, 105 (16), 163508.

56. Even, J.; Pedesseau, L.; Katan, C.; Kepenekian, M.; Lauret, J.-S.; Sapori, D.; Deleporte, E., Solid-State Physics Perspective on Hybrid Perovskite Semiconductors. The Journal of Physical Chemistry C 2015, 119 (19), 10161-10177.

57. Galkowski, K.; Mitioglu, A.; Miyata, A.; Plochocka, P.; Portugall, O.; Eperon, G. E.; Wang, J. T.-W.; Stergiopoulos, T.; Stranks, S. D.; Snaith, H. J.; Nicholas, R. J., Determination of the exciton binding energy and effective masses for methylammonium and formamidinium lead tri-halide perovskite semiconductors. Energy \& Environmental Science 2016, 9 (3), 962-970.

58. Giorgi, G.; Fujisawa, J.-I.; Segawa, H.; Yamashita, K., Small Photocarrier Effective Masses Featuring Ambipolar Transport in Methylammonium Lead Iodide Perovskite: A Density Functional Analysis. The Journal of Physical Chemistry Letters 2013, 4 (24), 4213-4216.

59. Solar cell efficiency tables. https://onlinelibrary.wiley.com/action/doSearch?field $1=$ Title\&text $1=$ Solar+cell+efficie ncy + tables\&publication $\% 5 B \% 5 \mathrm{D}=1099159 x \& \mathrm{Ppub}=\&$ sortBy=Earliest (accessed May 17 th).

60. Best Research-Cell Efficiencies. National Renewable Energy Laboratory: https://www.nrel.gov/pv/assets/pdfs/best-research-cell-efficiencies.20200803.pdf, 2020.

61. Kim, H. S.; Lee, C. R.; Im, J. H.; Lee, K. B.; Moehl, T.; Marchioro, A.; Moon, S. J.; Humphry-Baker, R.; Yum, J. H.; Moser, J. E.; Gratzel, M.; Park, N. G., 
Lead iodide perovskite sensitized all-solid-state submicron thin film mesoscopic solar cell with efficiency exceeding 9\%. Sci Rep 2012, 2, 591.

62. Lee, M. M.; Teuscher, J.; Miyasaka, T.; Murakami, T. N.; Snaith, H. J., Efficient hybrid solar cells based on meso-superstructured organometal halide perovskites. Science 2012, 338 (6107), 643-7.

63. Jeon, N. J.; Noh, J. H.; Yang, W. S.; Kim, Y. C.; Ryu, S.; Seo, J.; Seok, S. I., Compositional engineering of perovskite materials for high-performance solar cells. Nature 2015, 517 (7535), 476-80.

64. Jeon, N. J.; Noh, J. H.; Kim, Y. C.; Yang, W. S.; Ryu, S.; Seok, S. I., Solvent engineering for high-performance inorganic-organic hybrid perovskite solar cells. Nat Mater 2014, 13 (9), 897-903.

65. Im, J. H.; Jang, I. H.; Pellet, N.; Gratzel, M.; Park, N. G., Growth of $\mathrm{CH} 3 \mathrm{NH} 3 \mathrm{PbI} 3$ cuboids with controlled size for high-efficiency perovskite solar cells. Nat Nanotechnol 2014, 9 (11), 927-32.

66. Ahn, N.; Son, D. Y.; Jang, I. H.; Kang, S. M.; Choi, M.; Park, N. G., Highly Reproducible Perovskite Solar Cells with Average Efficiency of $18.3 \%$ and Best Efficiency of 19.7\% Fabricated via Lewis Base Adduct of Lead(II) Iodide. $J$ Am Chem Soc 2015, 137 (27), 8696-9.

67. Wehrenfennig, C.; Eperon, G. E.; Johnston, M. B.; Snaith, H. J.; Herz, L. M., High charge carrier mobilities and lifetimes in organolead trihalide perovskites. $A d v$ Mater 2014, 26 (10), 1584-9.

68. You, J.; Hong, Z.; Yang, Y. M.; Chen, Q.; Cai, M.; Song, T. B.; Chen, C. C.; Lu, S.; Liu, Y.; Zhou, H.; Yang, Y., Low-temperature solution-processed perovskite solar cells with high efficiency and flexibility. ACS Nano 2014, 8 (2), 1674-80.

69. Burschka, J.; Pellet, N.; Moon, S. J.; Humphry-Baker, R.; Gao, P.; Nazeeruddin, M. K.; Gratzel, M., Sequential deposition as a route to high-performance perovskite-sensitized solar cells. Nature 2013, 499 (7458), 316-9.

70. Malinkiewicz, O.; Yella, A.; Lee, Y. H.; Espallargas, G. M.; Graetzel, M.; Nazeeruddin, M. K.; Bolink, H. J., Perovskite solar cells employing organic chargetransport layers. Nature Photonics 2013, 8 (2), 128-132. 
71. Momblona, C.; Gil-Escrig, L.; Bandiello, E.; Hutter, E. M.; Sessolo, M.; Lederer, K.; Blochwitz-Nimoth, J.; Bolink, H. J., Efficient vacuum deposited p-i-n and n-i-p perovskite solar cells employing doped charge transport layers. Energy \& Environmental Science 2016, 9 (11), 3456-3463.

72. Xiao, M.; Huang, F.; Huang, W.; Dkhissi, Y.; Zhu, Y.; Etheridge, J.; GrayWeale, A.; Bach, U.; Cheng, Y. B.; Spiccia, L., A fast deposition-crystallization procedure for highly efficient lead iodide perovskite thin-film solar cells. Angew Chem Int Ed Engl 2014, 53 (37), 9898-903.

73. Paek, S.; Schouwink, P.; Athanasopoulou, E. N.; Cho, K. T.; Grancini, G.; Lee, Y.; Zhang, Y.; Stellacci, F.; Nazeeruddin, M. K.; Gao, P., From Nano- to Micrometer Scale: The Role of Antisolvent Treatment on High Performance Perovskite Solar Cells. Chemistry of Materials 2017, 29 (8), 3490-3498.

74. Park, N.-G.; Zhu, K., Scalable fabrication and coating methods for perovskite solar cells and solar modules. Nature Reviews Materials 2020, 5 (5), 333-350.

75. Lee, J.-W.; Dai, Z.; Lee, C.; Lee, H. M.; Han, T.-H.; De Marco, N.; Lin, O.; Choi, C. S.; Dunn, B.; Koh, J.; Di Carlo, D.; Ko, J. H.; Maynard, H. D.; Yang, Y., Tuning Molecular Interactions for Highly Reproducible and Efficient Formamidinium Perovskite Solar Cells via Adduct Approach. Journal of the American Chemical Society 2018, 140 (20), 6317-6324.

76. Xiao, Z.; Dong, Q.; Bi, C.; Shao, Y.; Yuan, Y.; Huang, J., Solvent annealing of perovskite-induced crystal growth for photovoltaic-device efficiency enhancement. Adv Mater 2014, 26 (37), 6503-9.

77. $\quad$ Dharani, S.; Mulmudi, H. K.; Yantara, N.; Thu Trang, P. T.; Park, N. G.; Graetzel, M.; Mhaisalkar, S.; Mathews, N.; Boix, P. P., High efficiency electrospun $\mathrm{TiO} 2$ nanofiber based hybrid organic-inorganic perovskite solar cell. Nanoscale 2014, 6 (3), 1675-1679.

78. Hu, L.; Peng, J.; Wang, W.; Xia, Z.; Yuan, J.; Lu, J.; Huang, X.; Ma, W.; Song, H.; Chen, W.; Cheng, Y.-B.; Tang, J., Sequential Deposition of CH3NH3PbI3 on Planar NiO Film for Efficient Planar Perovskite Solar Cells. ACS Photonics 2014, 1 (7), 547-553.

79. Chen, Q.; Zhou, H.; Hong, Z.; Luo, S.; Duan, H. S.; Wang, H. H.; Liu, Y.; Li, G.; Yang, Y., Planar heterojunction perovskite solar cells via vapor-assisted solution process. J Am Chem Soc 2014, 136 (2), 622-5. 
80. Deschler, F.; Price, M.; Pathak, S.; Klintberg, L. E.; Jarausch, D. D.; Higler, R.; Huttner, S.; Leijtens, T.; Stranks, S. D.; Snaith, H. J.; Atature, M.; Phillips, R. T.; Friend, R. H., High Photoluminescence Efficiency and Optically Pumped Lasing in Solution-Processed Mixed Halide Perovskite Semiconductors. J Phys Chem Lett 2014, $5(8), 1421-6$.

81. Zhang, Q.; Ha, S. T.; Liu, X.; Sum, T. C.; Xiong, Q., Room-temperature nearinfrared high-Q perovskite whispering-gallery planar nanolasers. Nano Lett 2014, 14 (10), 5995-6001.

82. Zhu, H.; Fu, Y.; Meng, F.; Wu, X.; Gong, Z.; Ding, Q.; Gustafsson, M. V.; Trinh, M. T.; Jin, S.; Zhu, X. Y., Lead halide perovskite nanowire lasers with low lasing thresholds and high quality factors. Nat Mater 2015, 14 (6), 636-42.

83. Zhang, R.; Fan, J.; Zhang, X.; Yu, H.; Zhang, H.; Mai, Y.; Xu, T.; Wang, J.; Snaith, H. J., Nonlinear Optical Response of Organic-Inorganic Halide Perovskites. ACS Photonics 2016, 3 (3), 371-377.

84. Veldhuis, S. A.; Boix, P. P.; Yantara, N.; Li, M.; Sum, T. C.; Mathews, N.; Mhaisalkar, S. G., Perovskite Materials for Light-Emitting Diodes and Lasers. Adv Mater 2016, 28 (32), 6804-34.

85. González-Carrero, S.; Galian, R. E.; Pérez-Prieto, J., Organometal Halide Perovskites: Bulk Low-Dimension Materials and Nanoparticles. Particle \& Particle Systems Characterization 2015, 32 (7), 709-720.

86. Vybornyi, O.; Yakunin, S.; Kovalenko, M. V., Polar-solvent-free colloidal synthesis of highly luminescent alkylammonium lead halide perovskite nanocrystals. Nanoscale 2016, 8 (12), 6278-83.

87. Schmidt, L. C.; Pertegas, A.; Gonzalez-Carrero, S.; Malinkiewicz, O.; Agouram, S.; Minguez Espallargas, G.; Bolink, H. J.; Galian, R. E.; Perez-Prieto, J., Nontemplate synthesis of $\mathrm{CH} 3 \mathrm{NH} 3 \mathrm{PbBr} 3$ perovskite nanoparticles. J Am Chem Soc 2014, 136 (3), 850-3.

88. Bekenstein, Y.; Koscher, B. A.; Eaton, S. W.; Yang, P.; Alivisatos, A. P., Highly Luminescent Colloidal Nanoplates of Perovskite Cesium Lead Halide and Their Oriented Assemblies. J Am Chem Soc 2015, 137 (51), 16008-11. 
89. Cheng, Z.; Lin, J., Layered organic-inorganic hybrid perovskites: structure, optical properties, film preparation, patterning and templating engineering.

CrystEngComm 2010, 12 (10), 2646-2662.

90. Zhang, S.; Audebert, P.; Wei, Y.; Al Choueiry, A.; Lanty, G.; Bréhier, A.; Galmiche, L.; Clavier, G.; Boissière, C.; Lauret, J.-S.; Deleporte, E., Preparations and Characterizations of Luminescent Two Dimensional Organic-inorganic Perovskite Semiconductors. Materials 2010, 3 (5), 3385-3406.

91. Blancon, J. C.; Tsai, H.; Nie, W.; Stoumpos, C. C.; Pedesseau, L.; Katan, C.; Kepenekian, M.; Soe, C. M.; Appavoo, K.; Sfeir, M. Y.; Tretiak, S.; Ajayan, P. M.; Kanatzidis, M. G.; Even, J.; Crochet, J. J.; Mohite, A. D., Extremely efficient internal exciton dissociation through edge states in layered 2D perovskites. Science 2017, 355 (6331), 1288-1292.

92. Protesescu, L.; Yakunin, S.; Bodnarchuk, M. I.; Krieg, F.; Caputo, R.; Hendon, C. H.; Yang, R. X.; Walsh, A.; Kovalenko, M. V., Nanocrystals of Cesium Lead Halide Perovskites $(\mathrm{CsPbX}(3), \mathrm{X}=\mathrm{Cl}, \mathrm{Br}$, and I): Novel Optoelectronic Materials Showing Bright Emission with Wide Color Gamut. Nano Lett 2015, 15 (6), 3692-6.

93. Dou, L.; Wong, A. B.; Yu, Y.; Lai, M.; Kornienko, N.; Eaton, S. W.; Fu, A.; Bischak, C. G.; Ma, J.; Ding, T.; Ginsberg, N. S.; Wang, L. W.; Alivisatos, A. P.; Yang, P., Atomically thin two-dimensional organic-inorganic hybrid perovskites.

Science 2015, 349 (6255), 1518-21.

94. Wu, X.; Trinh, M. T.; Zhu, X. Y., Excitonic Many-Body Interactions in TwoDimensional Lead Iodide Perovskite Quantum Wells. The Journal of Physical Chemistry C 2015, 119 (26), 14714-14721.

95. Akkerman, Q. A.; Motti, S. G.; Srimath Kandada, A. R.; Mosconi, E.; D'Innocenzo, V.; Bertoni, G.; Marras, S.; Kamino, B. A.; Miranda, L.; De Angelis, F.; Petrozza, A.; Prato, M.; Manna, L., Solution Synthesis Approach to Colloidal Cesium Lead Halide Perovskite Nanoplatelets with Monolayer-Level Thickness Control. J Am Chem Soc 2016, 138 (3), 1010-6.

96. Zhang, F.; Zhong, H.; Chen, C.; Wu, X.-g.; Hu, X.; Huang, H.; Han, J.; Zou, B.; Dong, Y., Brightly Luminescent and Color-Tunable Colloidal CH3NH3PbX3 $(\mathrm{X}=\mathrm{Br}, \mathrm{I}, \mathrm{Cl})$ Quantum Dots: Potential Alternatives for Display Technology. ACS Nano 2015, 9 (4), 4533-4542. 
97. Even, J.; Pedesseau, L.; Katan, C., Understanding quantum confinement of charge carriers in layered 2D hybrid perovskites. Chemphyschem 2014, 15 (17), 373341 .

98. Sichert, J. A.; Tong, Y.; Mutz, N.; Vollmer, M.; Fischer, S.; Milowska, K. Z.; Garcia Cortadella, R.; Nickel, B.; Cardenas-Daw, C.; Stolarczyk, J. K.; Urban, A. S.; Feldmann, J., Quantum Size Effect in Organometal Halide Perovskite Nanoplatelets. Nano Lett 2015, 15 (10), 6521-7.

99. Wang, N.; Cheng, L.; Ge, R.; Zhang, S.; Miao, Y.; Zou, W.; Yi, C.; Sun, Y.; Cao, Y.; Yang, R.; Wei, Y.; Guo, Q.; Ke, Y.; Yu, M.; Jin, Y.; Liu, Y.; Ding, Q.; Di, D.; Yang, L.; Xing, G.; Tian, H.; Jin, C.; Gao, F.; Friend, R. H.; Wang, J.; Huang, W., Perovskite light-emitting diodes based on solution-processed self-organized multiple quantum wells. Nature Photonics 2016, 10 (11), 699-704.

100. Sapori, D.; Kepenekian, M.; Pedesseau, L.; Katan, C.; Even, J., Quantum confinement and dielectric profiles of colloidal nanoplatelets of halide inorganic and hybrid organic-inorganic perovskites. Nanoscale 2016, 8 (12), 6369-78.

101. Leng, K.; Fu, W.; Liu, Y.; Chhowalla, M.; Loh, K. P., From bulk to molecularly thin hybrid perovskites. Nature Reviews Materials 2020, 5 (7), 482-500.

102. Zhang, D.; Eaton, S. W.; Yu, Y.; Dou, L.; Yang, P., Solution-Phase Synthesis of Cesium Lead Halide Perovskite Nanowires. J Am Chem Soc 2015, 137 (29), 9230-3.

103. Eaton, S. W.; Lai, M.; Gibson, N. A.; Wong, A. B.; Dou, L.; Ma, J.; Wang, L.-W.; Leone, S. R.; Yang, P., Lasing in robust cesium lead halide perovskite nanowires. Proceedings of the National Academy of Sciences 2016, 113 (8), 1993-1998.

104. Ma, H. H.; Imran, M.; Dang, Z.; Hu, Z., Growth of Metal Halide Perovskite, from Nanocrystal to Micron-Scale Crystal: A Review. Crystals 2018, 8 (5), 182. 


\section{CHAPTER 4. Two-dimensional Phenethylammonium Lead Bromide (PEPB) \\ Perovskite NCs: Synthesis and Photoluminescence Properties}

Organic-inorganic halide perovskites have emerged as promising optoelectronic materials for applications in photovoltaic and optoelectronic devices. Particularly, twodimensional (2D) layer-structured OIHPs are of significant interest due to their remarkable optical and electrical properties, which can be easily tuned by selecting suitable organic and inorganic moieties during the material synthesis. In this chapter, the solution-phase synthesis and optical properties of 2D organic-inorganic halide perovskite nanocrystals will be discussed.

\subsection{Introduction}

The organic-inorganic lead halide perovskites, especially $\mathrm{CH}_{3} \mathrm{NH}_{3} \mathrm{PbI}_{3}$, have gained substantial attention owing to their application in the solution-processed photovoltaic devices that have reached over $25 \%$ power conversion efficiency. ${ }^{[1,2]}$ Compared to the $3 \mathrm{D}$ structured $\mathrm{CH}_{3} \mathrm{NH}_{3} \mathrm{PbI}_{3}$, an organic cation with a size bigger than three $C-C$ or $C-N$ bonds would potentially form a layered structure with distinct optical properties. ${ }^{[3]}$ These layered organic-inorganic lead halide perovskite crystals have a general form of $\mathrm{A}_{2} \mathrm{PbX}_{4}$, where $\mathrm{A}$ is an organic ammonium or diammonium, and $\mathrm{X}$ is a halide. Unit cells composed of one inorganic layer sandwiched between two organic layers stack up via Van der Waals interaction between adjacent organic tails and form a long-range ordering structure. Due to the difference between dielectric constants of the organic and inorganic moieties, the dielectric confinement effect leads to an increased exciton binding energy and hence strong photoluminescence. ${ }^{[4-6]}$ The bulk materials of layered perovskites have been 
well studied since the 1990s, and largely increased exciton binding energy has been observed in $\quad\left(\mathrm{C}_{6} \mathrm{H}_{5} \mathrm{C}_{2} \mathrm{H}_{4} \mathrm{NH}_{3}\right)_{2} \mathrm{PbI}_{4},{ }^{[4]} \quad\left(\mathrm{C}_{6} \mathrm{H}_{5} \mathrm{C}_{2} \mathrm{H}_{4} \mathrm{NH}_{3}\right)_{2} \mathrm{PbBr}_{\mathrm{x}} \mathrm{I}_{4-\mathrm{x} \times}{ }^{[6]}$ $\left(\mathrm{C}_{6} \mathrm{H}_{5} \mathrm{C}_{2} \mathrm{H}_{4} \mathrm{NH}_{3}\right)_{2} \mathrm{PbCl}_{\mathrm{x}} \mathrm{I}_{4}-\mathrm{X}^{[7]}$, and $\left(\mathrm{C}_{6} \mathrm{H}_{5} \mathrm{C}_{2} \mathrm{H}_{4} \mathrm{NH}_{3}\right)_{2} \mathrm{PbBr}_{\mathbf{x}} \mathrm{Cl}_{4-\mathrm{x} \times}{ }^{[8]}$

The layered perovskite forms a semiconductor/insulator multi-quantum-well system within which the inorganic semiconducting sheets composed of $\mathrm{PbX}_{6}^{4-}$ octahedrons act as the wells, and the surrounding insulating organic layers act as barriers. ${ }^{[9]}$ Such systems provide electronic and optical properties different from bulk materials. ${ }^{[10-24]}$ Benefiting from the flexibility of material selection of both the organic and inorganic moieties, a variety of atomically thin films of organic-inorganic perovskite materials can be synthesized to form a library of $2 \mathrm{D}$ materials..$^{[7,25]}$ Vertical and lateral heterostructures can be prepared, opening up intriguing possibilities for designing materials with distinctive new properties at the atomic scale. ${ }^{[10,14,15,17,18,26]}$ Both light-emitting diodes and planar solar cells based on solution-processed perovskite multiple quantum wells have been demonstrated with high external quantum efficiency and high stability in the ambient environment with encapsulation, respectively. ${ }^{[27,28]}$ Compared to the bulk material, the study on nanostructured perovskite materials has just started. ${ }^{[10,12,14-16,26,29]}$ Colloidal nanocrystals of $2 \mathrm{D}$ perovskite materials have been synthesized by using long cation to arrest crystal growth in certain dimensions ${ }^{[12,14,15,30,31]}$ or by antisolvent-solvent extraction process $^{[13]}$. Nanosheets or nanoflakes of 2D Perovskites can also be produced by mechanical exfoliation. ${ }^{[32,33]}$ Recently, L. Dou et al. obtained atomically thin 2D $\left(\mathrm{C}_{4} \mathrm{H}_{9} \mathrm{NH}_{3}\right)_{2} \mathrm{PbBr}_{4}$ perovskite material by solution-phase growth method, and a significantly increased PL quantum efficiency (QE) of $\sim 26 \%$ (compared to $<1 \%$ for bulk material) was observed which was attributed to the increase of the oscillator strength and 
the decrease of the non-radiative Auger recombination process in atomically thin 2D structures $^{[34]}$.

Although perovskite NCs demonstrated unique and attractive optoelectronic properties, which are important for developing perovskite-based light emitting devices and digital displays, the lack of material synthesis and limited characterization of perovskite NCs have delayed their applications. Here, we demonstrate the synthesis of a new 2D organic-inorganic perovskite nanocrystals of phenethylammonium lead bromide (PEPB), $\left(\mathrm{C}_{6} \mathrm{H}_{5} \mathrm{C}_{2} \mathrm{H}_{4} \mathrm{NH}_{3}\right)_{2} \mathrm{PbBr}_{4}$, using the solution-phase growth method. Uniform square-shaped 2D PEPB nanocrystals were synthesized successfully on $\mathrm{SiO}_{2} / \mathrm{Si}$ substrates. The pyramid structure formed on top of PEPB sheets was observed, and the thickness of the PEPB monolayer was calculated to be $1.8 \mathrm{~nm}$ by averaging the step heights of the pyramid. Over $50 \%$ of the synthesized 2D PEPB nanocrystals were composed of less than 30 layers. The photoluminescence showed a major band-edge emission at $409 \mathrm{~nm}$, which slightly blueshifted compared to that of the bulk single crystal. Besides the major photoluminescence peak, the PEPB nanocrystals exhibited two new PL peaks at $\sim 480$ and $525 \mathrm{~nm}$, which were not observed in bulk single crystals. The new PL peaks could probably be attributed to the radiative decay of the organic part. Time-resolved reflectance contrast was measured, and the result showed a broad induced absorption peak around $600 \mathrm{~nm}$, attributed to the excited state, with an amplitude-weighted lifetime of $16.7 \mathrm{ps}$. 


\subsection{Chemicals and synthesis methods}

Phenethylamine $\left(\mathrm{C}_{6} \mathrm{H}_{5} \mathrm{C}_{2} \mathrm{H}_{4} \mathrm{NH}_{2}\right)$ and lead bromide $\left(\mathrm{PbBr}_{2}\right)$ were purchased from Sigma Aldrich. Hydrobromic acid ( $\mathrm{HBr}, 48 \%$, w/w aq. solution) was purchased from Alfa Aesar. All chemicals were used as received.

\subsubsection{Synthesis of phenethylammonium bromide}

Phenethylammonium bromide $\left(\mathrm{C}_{6} \mathrm{H}_{5} \mathrm{C}_{2} \mathrm{H}_{4} \mathrm{NH}_{3} \mathrm{Br}\right.$, PEBr $)$ was synthesized by an acid-base reaction of phenethylamine and excessive $\mathrm{HBr}$ acid (molar ratio 1: 1.5), as shown in Eq. 4-1.

$$
\mathrm{C}_{6} \mathrm{H}_{5} \mathrm{C}_{2} \mathrm{H}_{4} \mathrm{NH}_{2}+\mathrm{HBr} \rightarrow \mathrm{C}_{6} \mathrm{H}_{5} \mathrm{C}_{2} \mathrm{H}_{4} \mathrm{NH}_{3} \mathrm{Br}
$$

$5 \mathrm{~mL}$ of phenethylamine $(39.69 \mathrm{mmol})$ and $30 \mathrm{~mL}$ of ethanol were mixed and stirred in a $250 \mathrm{~mL}$ 2-neck flask in an ice-water bath. Then, $6.79 \mathrm{~mL}$ of $\mathrm{HBr}$ acid $(60 \mathrm{mmol})$ was slowly added to the mixture. The mixture was stirred for 2 hours at $0{ }^{\circ} \mathrm{C}$ maintained using an ice-water bath. The resulting solution was transferred to a round-bottom flask and evaporated by a rotary evaporator that was connected to a low-vac pump. The temperature of the rotary evaporator was initially set up at $50{ }^{\circ} \mathrm{C}$ to remove ethanol and then increased to $70{ }^{\circ} \mathrm{C}$ to remove water. After removing the solvent, white precipitate was formed and collected. The white precipitate was then washed with diethyl ether by stirring for $30 \mathrm{~min}$ and collected by vacuum filtration, a step which was repeated three times. After filtration, the obtained PEBr white powder was collected and dried in a vacuum oven at $60{ }^{\circ} \mathrm{C}$ overnight. 


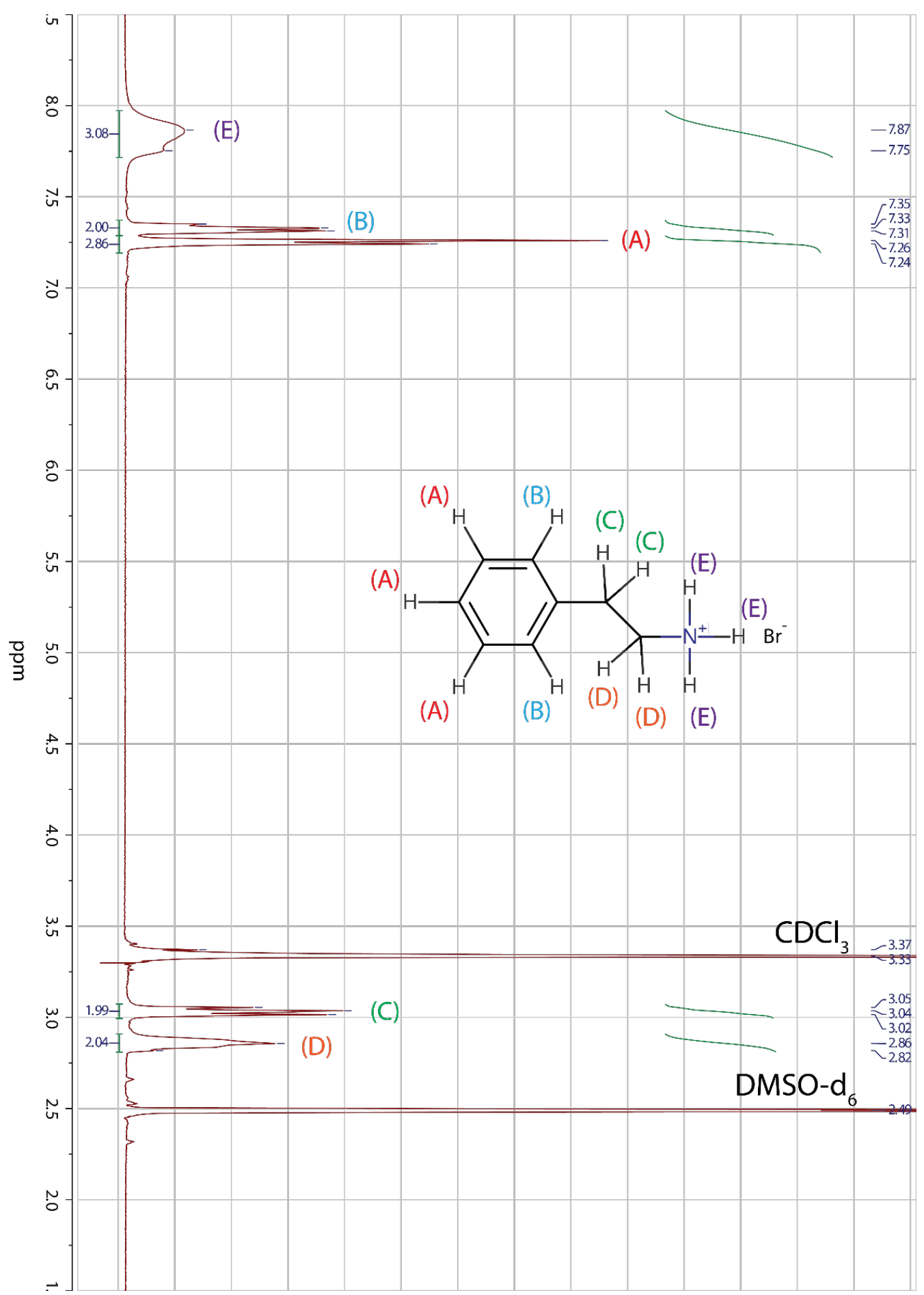

Figure 4-1 ${ }^{1} \mathrm{H}$ NMR spectroscopy of $\mathrm{C}_{6} \mathrm{H}_{5} \mathrm{C}_{2} \mathrm{H}_{4} \mathrm{NH}_{3} \mathrm{Br}(\mathrm{PEBr})$ in $\mathrm{CDCl}_{3}$ and DMSO- $\mathrm{d}_{6}$.

Nuclear magnetic resonance (NMR) spectroscopy of the product was measured by a JEOL ECA500 spectrometer with an $\mathrm{H} / \mathrm{F}-\mathrm{X}$ duel broadband $5 \mathrm{~mm}$ probe to check the 
purity of the product. Sample for NMR spectroscopy was prepared by dissolving a small amount of the product in deuterated chloroform $\left(\mathrm{CDCl}_{3}\right.$, Sigma-Aldrich) and deuterated dimethyl sulfoxide (DMSO-d 6 , Sigma-Aldrich). ${ }^{1} \mathrm{H}$ NMR spectroscopy is shown in Figure 4-1. Resonance peak located at the chemical shift of 2.49 was assigned to DMSO-d 6 . Resonance peaks located at the chemical shifts of 3.33 and 3.37 were assigned to $\mathrm{CDCl}_{3}$. The strength of every other resonance peak was integrated using JEOL Delta 5.3 software, and the relative intensity was printed below each peak. With the integration of resonance peaks revealing the ratio of one type of hydrogen to another within a molecule, and with the ${ }^{1} \mathrm{H}$ NMR spectroscopy of phenethylamine, these resonance peaks were assigned to the set of hydrogens in PEBr molecules, as shown in Figure 4-1. The ${ }^{1} \mathrm{H}$ NMR spectroscopy showed no other unassigned resonance peaks, indicating that the final product was $\mathrm{PEBr}$ of high purity. The mass of the final product, $\mathrm{PEBr}$, was measured to be $6.8881 \mathrm{~g}$ (34.08 $\mathrm{mmol}$ ). The percentage yield (molar / molar) of the synthetic process was therefore

$$
\frac{34.08}{39.69} \times 100 \%=85.87 \%
$$

\subsubsection{Deposition of PEPB thin film}

$\left(\mathrm{C}_{6} \mathrm{H}_{5} \mathrm{C}_{2} \mathrm{H}_{4} \mathrm{NH}_{3}\right)_{2} \mathrm{PbBr}_{4}$ thin film was deposited by spin coating in a $\mathrm{N}_{2}$-filled glovebox. $100.6 \mathrm{mg} \operatorname{PEBr}(0.274 \mathrm{mmol})$ and $110.8 \mathrm{mg} \mathrm{PbBr}_{2}(0.137 \mathrm{mmol})$ were mixed and dissolved in $2 \mathrm{~mL}$ DMF (anhydrous, Sigma-Aldrich). The solution was stirred gently for $30 \mathrm{~min}$ to obtain a clear, colorless solution with a concentration of $10 \mathrm{wt}$ \%.

Ultra-flat quartz coated glass (UFG) substrate was sequentially cleaned by ultrasonication in soap water, deionized (DI) water, acetone, and ethanol for $15 \mathrm{~min}$, 
respectively. The substrate was then dried in a forced air convention oven at $70{ }^{\circ} \mathrm{C}$ for 15 min. The quartz substrate was cleaned following the same process.

PEPB thin films were deposited on UFG and quartz substrates by spin coating. Immediately prior to spin coating, both substrates were treated by UV-ozone for $15 \mathrm{~min}$. $45 \mu \mathrm{L}$ of 10 wt. \% PEPB in DMF solution was cast onto still substrates at room temperature and coated at a spin speed of $1000 \mathrm{rpm}$ for $60 \mathrm{~s}, 2000 \mathrm{rpm}$ for $30 \mathrm{~s}, 2500 \mathrm{rpm}$ for $30 \mathrm{~s}$, and $3000 \mathrm{rpm}$ for $30 \mathrm{~s}$, respectively. After spin coating, the substrate was annealed at $95{ }^{\circ} \mathrm{C}$ for $1 \mathrm{~min}$ to evaporate the residual solvent and obtain a fully crystalline PEPB thin film.

PEPB thin films were colorless at room temperature. The thicknesses of deposited films were measured by a DektakXT stylus profilers at the center of the substrate and shown in Table 4-1. It should be pointed out that PEPB thin film spin-coated at $1000 \mathrm{rpm}$ was not uniform due to the low spin speed, and that thickness at the edges of this sample could be larger than that at the center.

Table 4-1 Thickness of spin-coated PEPB film on ultra-flat quartz coated glass substrate.

\begin{tabular}{ccccc}
\hline Speed (rpm) & 1000 & 2000 & 2500 & 3000 \\
\hline \hline Thickness (nm) & 110 & 80 & 70 & 60 \\
\hline
\end{tabular}

\subsubsection{Growth method for PEPB single crystal}

$\left(\mathrm{C}_{6} \mathrm{H}_{5} \mathrm{C}_{2} \mathrm{H}_{4} \mathrm{NH}_{3}\right)_{2} \mathrm{PbBr}_{4}$ single crystal was synthesized by reacting $\mathrm{PbBr}_{2}$ and $\mathrm{C}_{6} \mathrm{H}_{5} \mathrm{C}_{2} \mathrm{H}_{4} \mathrm{NH}_{3} \mathrm{Br}$ precursors in the $\mathrm{HBr}$ water solution. Typically, $36.7 \mathrm{mg}$ of $\mathrm{PbBr}_{2}$ and $40.42 \mathrm{mg}$ of as-synthesized $\mathrm{C}_{6} \mathrm{H}_{5} \mathrm{C}_{2} \mathrm{H}_{4} \mathrm{NH}_{3} \mathrm{Br}$ were added into $0.2 \mathrm{~mL}$ of $\mathrm{HBr}$ acid (48 wt. $\%$ in water) in a sealed vial. The mixture was heated up and maintained at $120^{\circ} \mathrm{C}$ until all the solids were dissolved. The solution was then slowly cooled down to room temperature 
overnight, and small white plate-like $\left(\mathrm{C}_{6} \mathrm{H}_{5} \mathrm{C}_{2} \mathrm{H}_{4} \mathrm{NH}_{3}\right)_{2} \mathrm{PbBr}_{4}$ crystals were precipitated. The crystals were then collected by vacuum filtration, washed with pure ethanol (200 proof), and dried in a vacuum oven overnight at $60{ }^{\circ} \mathrm{C}$.

\subsubsection{Synthesis of 2D PEPB NCs}

Two-dimensional $\left(\mathrm{C}_{6} \mathrm{H}_{5} \mathrm{C}_{2} \mathrm{H}_{4} \mathrm{NH}_{3}\right)_{2} \mathrm{PbBr}_{4}$ nanocrystals were synthesized using a solution-phase growth method. All the solution preparation and nanocrystals growth processes were carried out in a nitrogen-filled glove box. The as-synthesized $\mathrm{C}_{6} \mathrm{H}_{5} \mathrm{C}_{2} \mathrm{H}_{4} \mathrm{NH}_{3} \mathrm{Br}$ (404.2 mg, 2mmol) and $\mathrm{PbBr}_{2}(367 \mathrm{mg}$, 1mmol, Sigma-Aldrich) were mixed in $4 \mathrm{~mL}$ of anhydrous dimethylformamide (DMF). The mixture, which was labeled as Solution 1, was gently stirred at room temperature until all the solids were dissolved. 50 $\mu \mathrm{L}$ of Solution 1 was further diluted 100 times by $4950 \mu \mathrm{L}$ DMF/chlorobenzene (CB) (1:1 volume ratio) co-solvent resulting in a solution with a $\mathrm{Pb}^{2+}$ concentration of $2.5 \mathrm{mmol} / \mathrm{L}$, which was labeled as Solution 2. Prior to use, $50 \mu \mathrm{L}$ of Solution 2 was mixed with 527.8 $\mu \mathrm{L} \mathrm{CB}$ and 547.2 $\mu \mathrm{L}$ acetonitrile (ACN) to make the final precursor solution, or Solution 3. The concentration of $\mathrm{Pb}^{2+}$ in Solution 3 was $0.222 \mathrm{mM}$. The volume ratio of DMF, CB, and $\mathrm{ACN}$ was 1:22: 22.

The optical absorption and PL spectra of the three precursor solutions were shown in Figure 4-2. The UV-Vis spectra of Solution 1 and 2 showed absorption onsets at 407 and $351 \mathrm{~nm}$, respectively. However, the UV-Vis spectrum of Solution 3 showed no absorption onset but an excitonic absorption peak at $310 \mathrm{~nm}$. In the PL spectra of all three solutions, the sharp peak located at $377 \mathrm{~nm}$ was attributed to the incident UV-LED spectrum. The major PL peaks of the three solutions were located at $561.1 \mathrm{~nm}(2.210 \mathrm{eV})$, 
$608.4 \mathrm{~nm}(2.038 \mathrm{eV})$, and $606.8 \mathrm{~nm}(2.043 \mathrm{eV})$, respectively. All three solutions showed the same weak peak at $413 \mathrm{~nm}$, which was likely attributed to the nano-scaled PEPB clusters in the solutions.
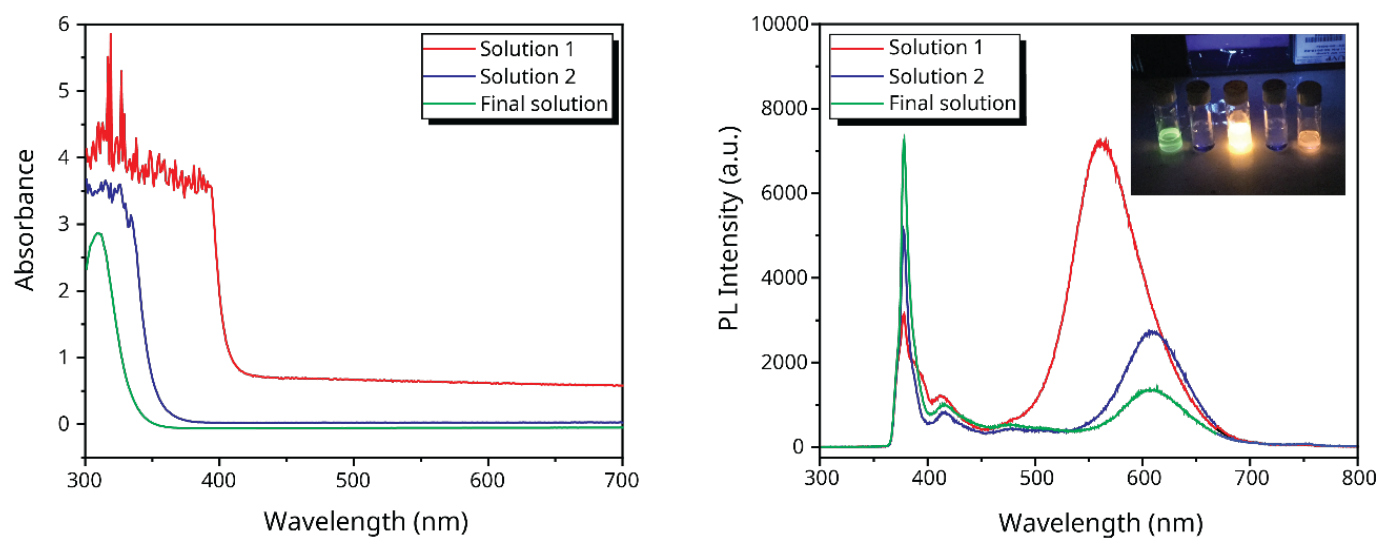

Figure 4-2 (A) UV-Vis absorption and (B) PL spectra of the precursor solutions for the synthesis of 2D PEPB nanocrystals. (B) inset is the light emission of the precursor solutions under UV illumination (from left to right: Solution 1, co-solvent of DMF and CB, Solution 2, co-solvent of $\mathrm{CB}$ and $\mathrm{ACN}$, the final precursor solution).

The $\mathrm{SiO}_{2} / \mathrm{Si}$ substrates were cleaned by ultra-sonication sequentially in isopropyl alcohol, acetone, deionized water, and isopropyl alcohol for $5 \mathrm{~min}$, respectively, then dried by a nitrogen spray gun. Immediately before use, the substrates were treated by UV-Ozone for $15 \mathrm{~min}$, then transferred into a glovebox and preheated at $75^{\circ} \mathrm{C}$ for $5 \mathrm{~min}$ on a hot plate. Typically, $3 \mu L$ of the final precursor solution was dropped onto the surface of the substrate and dried at $75{ }^{\circ} \mathrm{C}$ for 5 min. Thin square-shaped nanocrystals of $\left(\mathrm{C}_{6} \mathrm{H}_{5} \mathrm{C}_{2} \mathrm{H}_{4} \mathrm{NH}_{3}\right)_{2} \mathrm{PbBr}_{4}$ grew spontaneously on the surface of the substrate as the solvent evaporated.

The concentration and solvent volume ratio of the final precursor solution are critical parameters for the synthesis of 2D PEPB nanocrystals. These two parameters can be adjusted easily by manipulating the volume of solvents used for dilution. Table 4-2 shows the sets of these two parameters that had been tried and produced 2D PEPB nanocrystals on $\mathrm{SiO}_{2} / \mathrm{Si}$ substrates. 
Table 4-2 Concentrations and solvent volume ratios of the final precursor solutions for the synthesis of 2D PEPB nanocrystals on $\mathrm{SiO}_{2} / \mathrm{Si}$ and quartz substrates.

\begin{tabular}{|l|l|l|l|}
\hline \multirow{2}{*}{$\begin{array}{l}\mathbf{P b}^{2+} \text { concentration } \\
(\mathbf{m M})\end{array}$} & \multicolumn{3}{|c|}{ Volume Ratio } \\
\cline { 2 - 4 } & DMF & Chlorobenzene & Acetonitrile \\
\hline 0.5 & 1 & 13 & 6 \\
\hline 0.25 & 1 & 20 & 19 \\
\hline 0.25 & 1 & 22 & 17 \\
\hline 0.222 & 1 & 22 & 22 \\
\hline 0.2 & 1 & 22 & 27 \\
\hline 0.125 & 1 & 22 & 17 \\
\hline 0.111 & 1 & 22 & 22 \\
\hline 0.1 & 1 & 22 & 27 \\
\hline
\end{tabular}

The first set of concentration and solvent volume ratio, as shown in the first row in Table 4-2, was inspired by the research of Dou et al. on the synthesis of 2D $\left(\mathrm{C}_{4} \mathrm{H}_{9} \mathrm{NH}_{3}\right)_{2} \mathrm{PbBr}_{4}$ nanocrystals ${ }^{[34]}$. The procedure for making the precursor solution was the same as that reported by Dou et al., with $\mathrm{C}_{4} \mathrm{H}_{9} \mathrm{NH}_{3} \mathrm{Br}$ replaced with an equimolar amount of $\mathrm{C}_{6} \mathrm{H}_{5} \mathrm{C}_{2} \mathrm{H}_{4} \mathrm{NH}_{3} \mathrm{Br}$. The preponderance of the PEPB nanocrystals synthesized by this precursor solution were squares with yellow to orange colors, as shown in Figure 4-3 (A). Atomic force microscope (AFM) measurement revealed that these nanocrystals were close to or over $100 \mathrm{~nm}$ thick. 

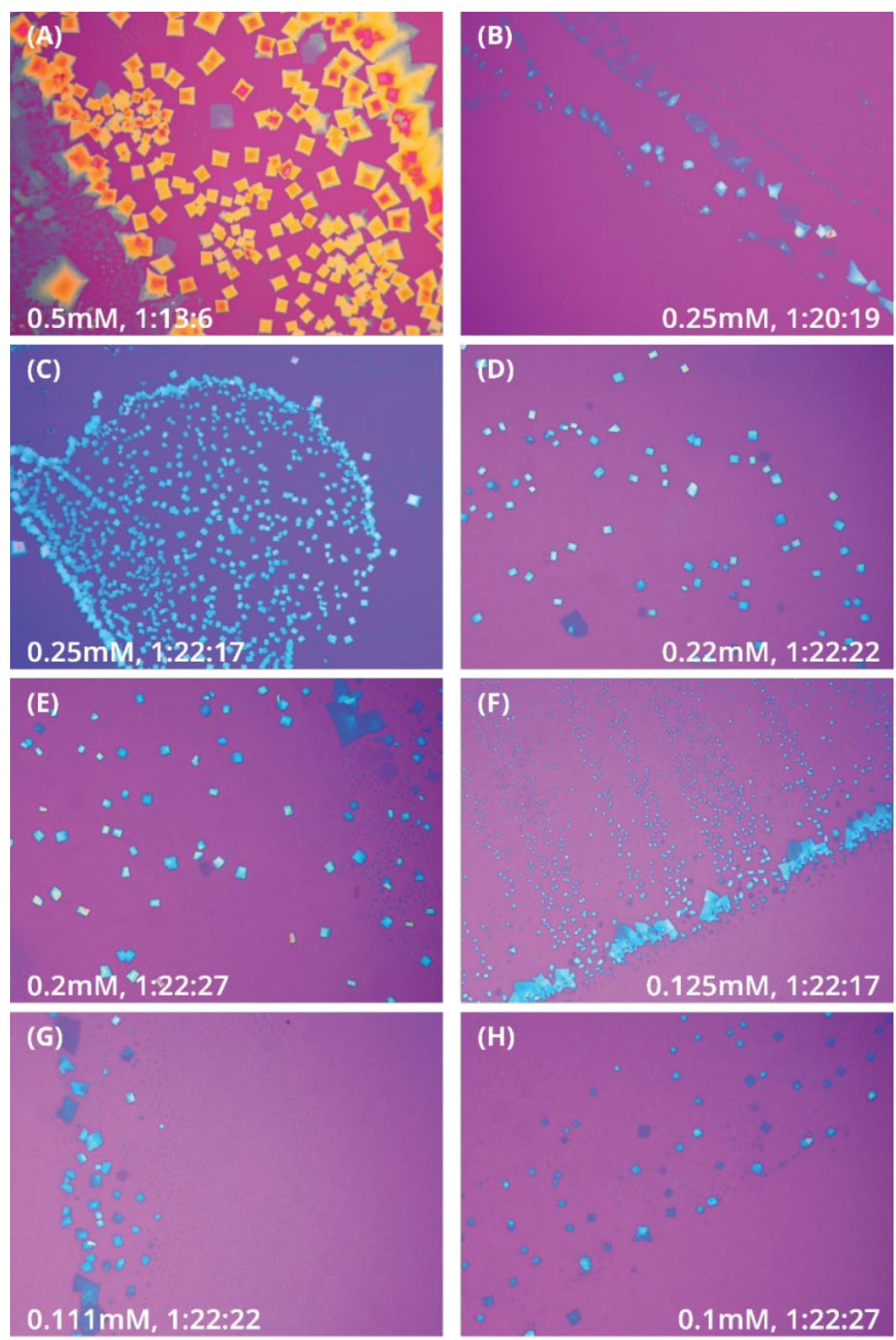

Figure 4-3 A series of optical microscopy images (magnification: 50X) of the 2D PEPB nanocrystals synthesized by solutions with $\mathrm{Pb}^{2+}$ concentrations and solvent volume ratios in Table 4-2.

To synthesize thinner PEPB nanocrystals, the concentration of the final precursor solution was reduced by half. The solvent volume ratio was tuned, and the optical microscopy images indicated precursor solutions with 1:20:19 and 1:22:17 solvent volume ratios (Table 4-2 Row 2 and 3) produced PEPB nanocrystals, as shown in Figure 4-3 (B) 
and (C). Although the blue nanocrystals were thinner $(\sim 30$ to $\sim 60 \mathrm{~nm})$, the nanocrystals were either in irregular shapes or smaller sizes. Further experiments showed that the combinations of concentration and solvent volume ratio in Table 4-2 Row 4 and 5 provided well-distributed, blue, square, or rectangular nanocrystals, as shown in Figure 4-4 (D) and (E). If the concentration was further reduced (Table 4-2 Row 6, 7, and 8), the synthesized PEPB nanocrystals were often found to be small, as shown in Figure 4-3 (F), or distorted, as shown in Figure 4-3 (G) and $(\mathrm{H})$.
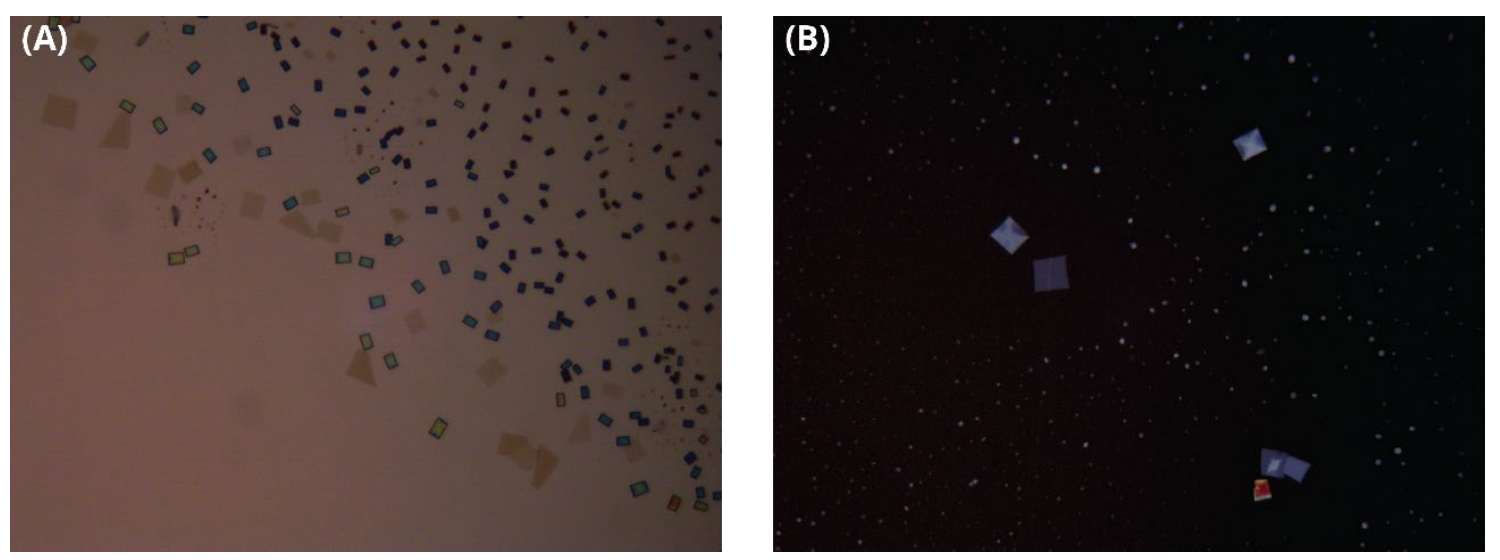

Figure 4-4 Optical microscopy images of 2D PEPB nanocrystals synthesized on (A) conductive $\mathrm{Si}$ and (B) quartz substrates.

2D PEPB nanocrystals were also synthesized on conductive Si and quartz substrates using a precursor solution with $\mathrm{Pb}^{2+}$ concentration of $0.222 \mathrm{mM}$ and solvent volume ratio of 1:22: 22 (Table 4-2 Row 4). The growth procedure was the same as that for synthesizing 2D PEPB nanocrystals on $\mathrm{SiO}_{2} / \mathrm{Si}$ substrates. The majority of the PEPB nanocrystals synthesized on conductive Si substrates were rectangles showing blue to green colors, as shown in Figure 4-4 (A). Square-, trapezoid-, and right-triangle-shaped nanosheets were also observed, which were attributed to 2D PEPB nanocrystals with thicknesses around $30 \mathrm{~nm}$ or less. PEPB nanocrystals on the quartz substrates were often 
observed to be light grey and square-shaped nanostructures. Unlike on the $\mathrm{SiO}_{2} / \mathrm{Si}$ or conductive Si substrates, searching for the PEPB nanocrystals on the quartz substrates using an optical microscope was more challenging as the color of the substrate and the colors of the nanocrystals in the microscopy did not have sufficient contrast, as shown in Figure 4-4 (B).

\subsection{Characterization methods}

X-ray diffraction (XRD). X-ray diffraction (XRD) measurement was performed on a Rigaku MiniFlex 600 benchtop powder XRD instrument with $\mathrm{Cu} \mathrm{K} \alpha$ radiation $(\lambda=1.5406 \AA)$ at a voltage of $40 \mathrm{kV}$ and $15 \mathrm{~mA}$ at room temperature. For PEPB thin films deposited on substrates, the diffraction pattern was scanned with a step size of $0.02^{\circ}$

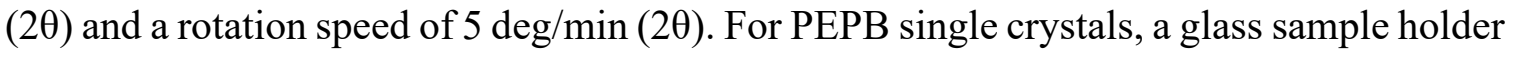
with $20 \times 20 \times 0.2 \mathrm{~mm}$ square indent was used. PEPB single crystals were placed at the center of the indent, and the sample surface was flattened to flush with the indent edge using an optical slide. The diffraction pattern of PEPB single crystal was scanned with a step of $0.02^{\circ}(2 \theta)$ and a rotation speed of $3 \mathrm{deg} / \mathrm{min}(2 \theta)$.

Optical Microscopy. An Olympus BX51M microscope was used to take optical

microscope images. PEPB nanocrystals were observed with the reflected light path using a 12V/100W halogen lamp (Olympus). The objective lenses used for observing PEPB NCs were $10 \times, 20 \times$, and 50× Olympus M Plan Semi-Apochromat lenses (MPLFLN10xBD, MPLFLN20xBD, and MPLFLN50xBD). For PEPB single crystals, the $10 \times$ objective lens was used. Olympus UC30 color CCD was used to capture the images in the Full-resolution mode. 
UV-visible spectroscopy (UV-Vis). Optical absorption properties were measured using an Agilent Cary $60 \mathrm{UV}$-Visible spectrometer at room temperature. PEPB precursor solutions were put in a quartz cuvette during measurement. For PEPB single crystals, a quartz substrate was used as the sample holder. The absorbance A was calculated as $A=$ $2-\log (\% T)$. For all UV-Vis measurements, the absorbance spectrum of the corresponding cuvette or substrate was taken and used as the baseline before measuring the sample.

Atomic Force Microscopy (AFM). Tapping mode Atomic force microscopy (AFM) (Veeco Instrument, Inc.) measurements were performed to investigate the surface morphology of the 2D PEPB nanocrystals on $\mathrm{SiO}_{2} / \mathrm{Si}$ substrates. Imaging was performed with antinomy (n) doped silicon tips (TESPA, Brukerprobes) of $125 \mu \mathrm{m}$ in length with a typical spring constant of $42 \mathrm{~N} / \mathrm{m}$ and drive frequency of $320 \mathrm{kHz}$. During imaging, the height images of both forward and reverse scan directions, amplitude image, and phase image were collected simultaneously at a constant scan rate of $0.5 \mathrm{~Hz}$. Gwyddion 2.47 was used to analyze the height images and to obtain particle sizes.

Photoluminescence (PL). PL spectra were measured by a home-built PL system based on Horiba iHR320 Spectrometer equipped with thermoelectric cooling Synapse CCD. For PEPB thin films, a $337 \mathrm{~nm}$ nitrogen laser (5 ns period) as the incident light source. For 2D PEPB nanocrystals, a $365 \mathrm{~nm}$ UV LED with a bandpass filter was used as the excitation source. The light beam was focused onto the sample by a $100 \times$ objective lens, and the photoluminescence signal was collected by the same objective lens. Long pass filters were applied to block the $365 \mathrm{~nm}$ component for 2D PEPB NCs. The measurement was done at ambient temperature $\approx 25^{\circ} \mathrm{C}$ and relative humidity in the range of $40-45 \%$. 
Time-Resolved Reflectance Measurements. The measurements were carried out on a home-built femtosecond pump-probe spectrometer (PPS). A full description of the PPS can be found elsewhere ${ }^{[35]}$. Briefly, the PPS is based on a titanium sapphire (Ti:Sa) oscillator (Micra, Coherent) with its output seeded by a Ti:Sa Coherent Legend (USP-HE) amplifier operating at $1 \mathrm{kHz}$ repetition rate. This amplifier produces pulses centered at 800 $\mathrm{nm}$ with $\sim 45$ fs duration and $2.2 \mathrm{~mJ}$ energy per pulse. The pump pulse at $400 \mathrm{~nm}$ is the second harmonic of the fundamental output of the Legend amplifier. A small portion ( 2 $\mu \mathrm{J})$ of the beam from the Legend amplifier was focused onto a $2 \mathrm{~mm}$ thick sapphire window to generate the white light continuum probe, which covers a spectral region from $450 \mathrm{~nm}$ to $950 \mathrm{~nm}$. On the sample, the pump and probe spot sizes were $\sim 7 \mathrm{~mm}$. The pump fluence was kept below $2 \mu \mathrm{J} / \mathrm{cm}^{2}$. A spectrograph (Shamrock 303i, Andor) coupled with a CCD (Andor Newton) equipped with an electron multiplier was used for detecting the reflected white light probe. At each time delay between the pump and the probe, the percentage change in the reflectance contrast $\Delta R / R(\%)$ was calculated as $R C C=-\left[\left(R-R_{0}\right) / R_{0}\right] \times 100$, where $\mathrm{R}$ and $\mathrm{R}_{0}$ are the intensities of the reflected probe with the pump on and off, respectively.

\subsection{Results and discussion}

\subsubsection{Crystal structure of PEPB thin films}

XRD spectra of 60-, 70-, 80-, and 110-nm-thick PEPB thin films on UFG substrates are presented in Figure 4-5 (A), showing sharp $\left(\begin{array}{lll}0 & 2 n\end{array}\right)(n=1-7)$ peaks associated with $\left(\mathrm{C}_{6} \mathrm{H}_{5} \mathrm{C}_{2} \mathrm{H}_{4} \mathrm{NH}_{3}\right)_{2} \mathrm{PbBr}_{4}$ crystals across all four spin-coated PEPB thin films. These 
diffraction peaks clearly demonstrated that spin-coated PEPB thin films were highly oriented, with the $c$ axis perpendicular to the surface of the substrate. The positions ( $2 \theta$ angles) of $\left(\begin{array}{lll}0 & 2 & 2 n\end{array}\right)(n=1-7)$ peaks in the XRD spectra for four spin-coated PEPB thin films with different thicknesses in Figure 4-5 (A) were measured and shown in Table 4-3.
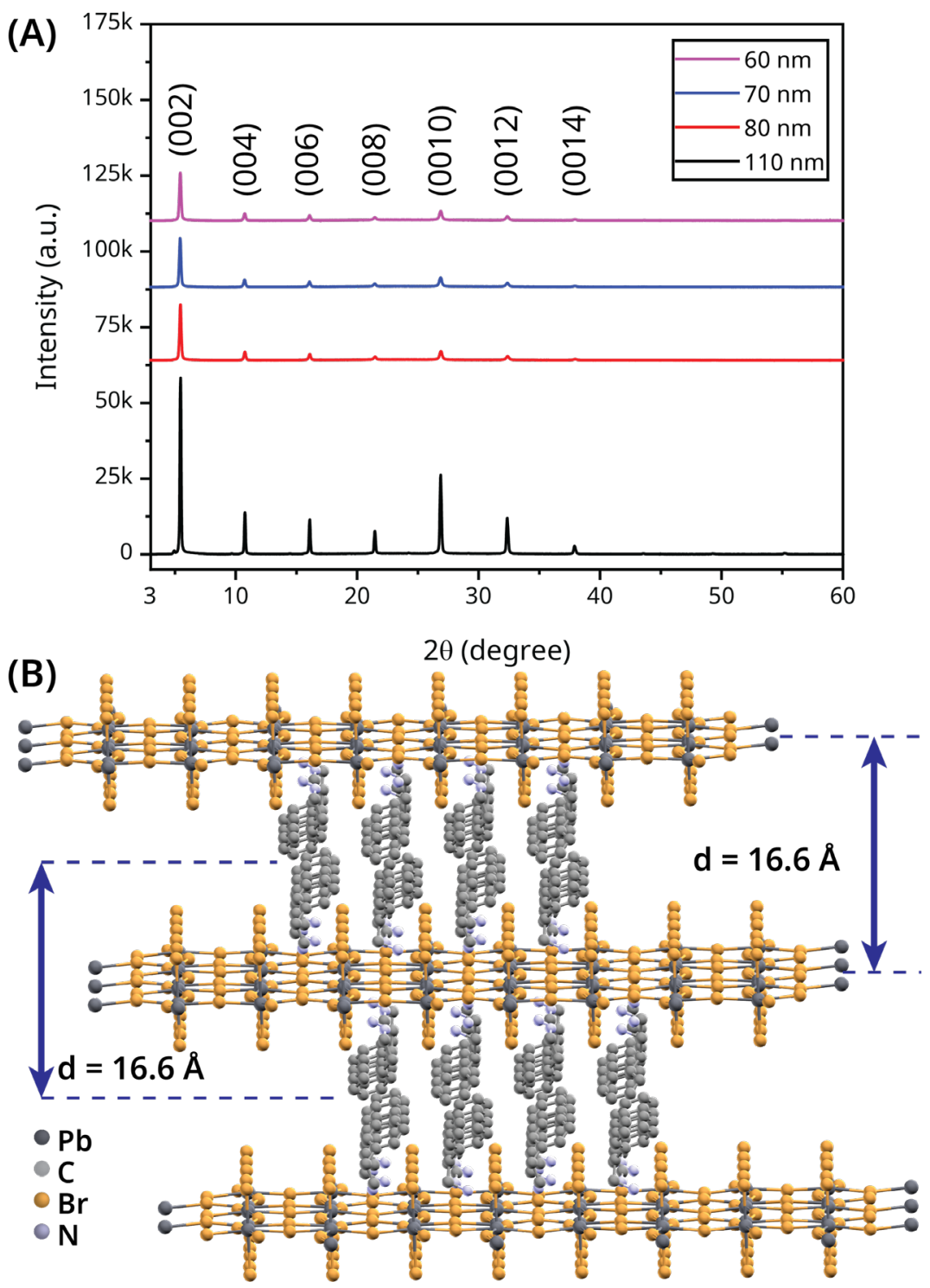

Figure 4-5 (A) XRD spectra of 60-, 70-, 80-, and 110-nm-thick spin-coated PEPB thin films on ultra-flat quartz coated glass substrates. (B) Ball-and-stick model of the crystal structure of $\left(\mathrm{C}_{6} \mathrm{H}_{5} \mathrm{C}_{2} \mathrm{H}_{4} \mathrm{NH}_{3}\right)_{2} \mathrm{PbBr}_{4}$ showing the interplanar distance, $d$. Only non-hydrogen atoms are presented in the schematic illustration. 
As stated by Bragg's law, the angles for coherent and incoherent scatterings from a crystal is given by Eq. 4-2,

$$
n \lambda=2 d \sin \theta
$$

where $n$ is a positive integer, $\lambda$ is the wavelength of the incident $\mathrm{X}$-ray wave, $d$ is the interplanar distance, and $\theta$ is the glancing angle.

Table 4-3 Miller notation and the positions $(\mathbf{2 \theta})$ of peaks in the XRD spectra of PEPB thin film.

\begin{tabular}{cccccc}
\hline $\begin{array}{c}\text { Miller } \\
\text { Notation }\end{array}$ & $60 \mathrm{~nm}\left(^{\circ}\right)$ & $70 \mathrm{~nm}\left(^{\circ}\right)$ & $80 \mathrm{~nm}\left(^{\circ}\right)$ & $110 \mathrm{~nm}\left(^{\circ}\right)$ & Average $\left(^{\circ}\right)$ \\
\hline$(002)$ & 5.46 & 5.44 & 5.42 & 5.44 & 5.44 \\
$(004)$ & 10.76 & 10.76 & 10.72 & 10.74 & 10.75 \\
$(006)$ & 16.10 & 16.10 & 16.08 & 16.08 & 16.09 \\
$(008)$ & 21.46 & 21.48 & 21.44 & 21.46 & 21.46 \\
$(0010)$ & 26.88 & 26.90 & 26.88 & 26.88 & 26.89 \\
$(0012)$ & 32.36 & 32.38 & 32.38 & 32.36 & 32.37 \\
\hline
\end{tabular}

The linear relationship between $\frac{n \lambda}{2}$ and $\sin (\theta)$, as shown in Eq.4-2, suggests that the interplanar distance, $d$, can be calculated by linear regression using the ordinary least squares method. The glancing angle, $\theta$, for each peak was calculated based on the average positions of the peak in Table 4-3 and shown in Table 4-4. Linear regression revealed that the interplanar distance, $d$, equals to $16.6 \AA$. $\left(\mathrm{C}_{6} \mathrm{H}_{5} \mathrm{C}_{2} \mathrm{H}_{4} \mathrm{NH}_{3}\right)_{2} \mathrm{PbBr}_{4}$ crystal is a typical selforganized layered perovskite compound of the Ruddlesden-Popper phase. The interplanar distance can be regarded either as the distance between two adjacent $\mathrm{PbBr}_{4}{ }^{2-}$ layers, or the height of a unit layer of one $\mathrm{PbBr}_{4}{ }^{2-}$ layer sandwiched between two $\mathrm{C}_{6} \mathrm{H}_{5} \mathrm{C}_{2} \mathrm{H}_{4} \mathrm{NH}_{3}{ }^{+}$layers, as shown in Figure 4-5 (B). 
Table 4-4 $\sin (\theta)$ and $\frac{n \lambda}{2}(\AA)$ of XRD spectra of PEPB thin films.

\begin{tabular}{ccccc}
\hline$n$ & Miller notation & $2 \theta\left(^{\circ}\right)$ & $\sin (\theta)$ & $\frac{n \lambda}{2}(\AA)$ \\
\hline 1 & $(002)$ & 5.44 & 0.04746 & 0.7703 \\
2 & $(004)$ & 10.75 & 0.09367 & 1.5406 \\
3 & $(006)$ & 16.09 & 0.13995 & 2.3109 \\
4 & $(008)$ & 21.46 & 0.18618 & 3.0812 \\
5 & $(0010)$ & 26.89 & 0.23251 & 3.8515 \\
6 & $(0012)$ & 32.37 & 0.27874 & 4.6218 \\
\hline
\end{tabular}

\subsubsection{Optical absorption spectrum of PEPB thin films}

The ultraviolet-visible (UV-Vis) absorption spectra of 60-, 70-, 80-, and 110-nmthick PEPB thin films deposited on UFG substrates are shown in Figure 4-6 (A). In the absorption spectra of all four PEPB thin films, a strong and sharp absorption peak located at $403 \mathrm{~nm}(3.077 \mathrm{eV})$ was observed, together with two strong absorption bands at $304 \mathrm{~nm}$ (4.078 eV), $248 \mathrm{~nm}(5.020 \mathrm{eV})$, and two absorption shoulders at $316 \mathrm{~nm}(3.924 \mathrm{eV}), 265$ $\mathrm{nm}(4.679 \mathrm{eV})$. Nevertheless, no clear edges of continuous absorption were observed across all four spectra. The sharp absorption peak at $403 \mathrm{~nm}$ has been attributed to the excitons, which were bounded electron-hole pairs formed by the transition of electrons from $\mathrm{Pb}^{2+}$ (6s) to $\mathrm{Pb}^{2+}(6 \mathrm{p})^{[36]}$.

UV-Vis absorption spectrum of 70-nm-thick PEPB thin film spin-coated on the quartz substrate was also measured and shown in Figure 4-6 (B). Compare with 70-nmthick PEPB thin film on the UFG substrate, the absorption spectra of PEPB thin film on both substrates (UFG and quartz) closely resembled each other in wavelength above 240 
nm. Both spectra showed a sharp, strong excitonic absorption peak at $403 \mathrm{~nm}$ with two absorption bands (304 nm, $248 \mathrm{~nm}$ ) and two absorption shoulders (316 nm, $265 \mathrm{~nm})$. The difference in absorbance between 240 and $375 \mathrm{~nm}$ was attributed to the absorption of substrates. PEPB thin film on the quartz substrate showed high and ever-increasing absorbance in wavelength below $235 \mathrm{~nm}$ [black curve in Figure 4-6 (B)], which is attributed to the absorption of the quartz substrate. For PEPB thin film on the UFG substrate, the absorbance below $238 \mathrm{~nm}$ first increased to over 1.25 and then dropped abruptly to zero due to the subtraction of the absorbance of the UFG substrate.
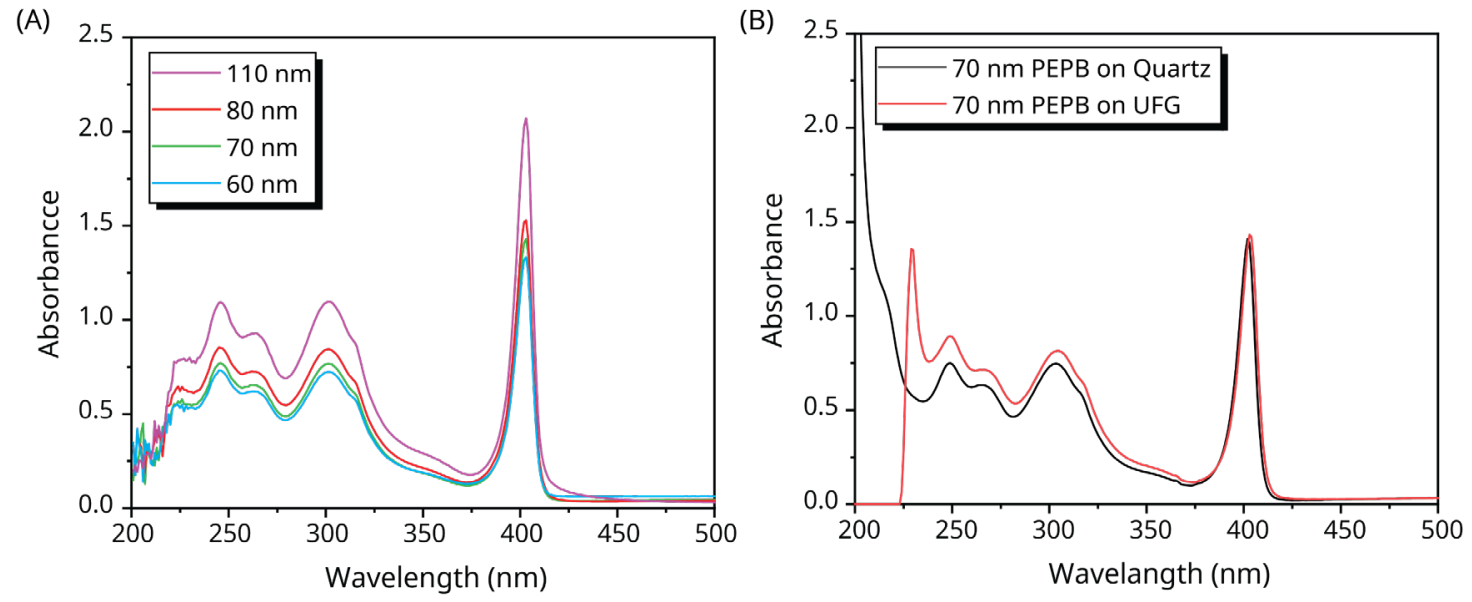

Figure 4-6 (A) Optical absorption spectra of 60-, 70-, 80-, and 110-nm-thick spin-coated PEPB thin films on ultra-flat quartz coated glass substrates. (B) Optical absorption spectra of 70-nm-thick spin-coated PEPB thin films on ultra-flat quartz coated glass (UFG) and quartz substrates.

\subsubsection{PL properties of PEPB thin films}

The sharp, strong absorption peak observed at $403 \mathrm{~nm}$ in the room-temperature UVVis absorption spectrum of PEPB thin film indicated the formation of bounded electronhole pairs, i.e., excitons, upon absorbing photons of higher energy than its bandgap. Excitons are the preeminent mechanism for light emission in semiconducting materials when thermal energy, $k_{B} T$, is less than the exciton binding energy. Blue light emitted from 
PEPB thin film on quartz substrate can be easily observed using a compact handheld UV lamp, as shown in the inset of Figure 4-7 (C).
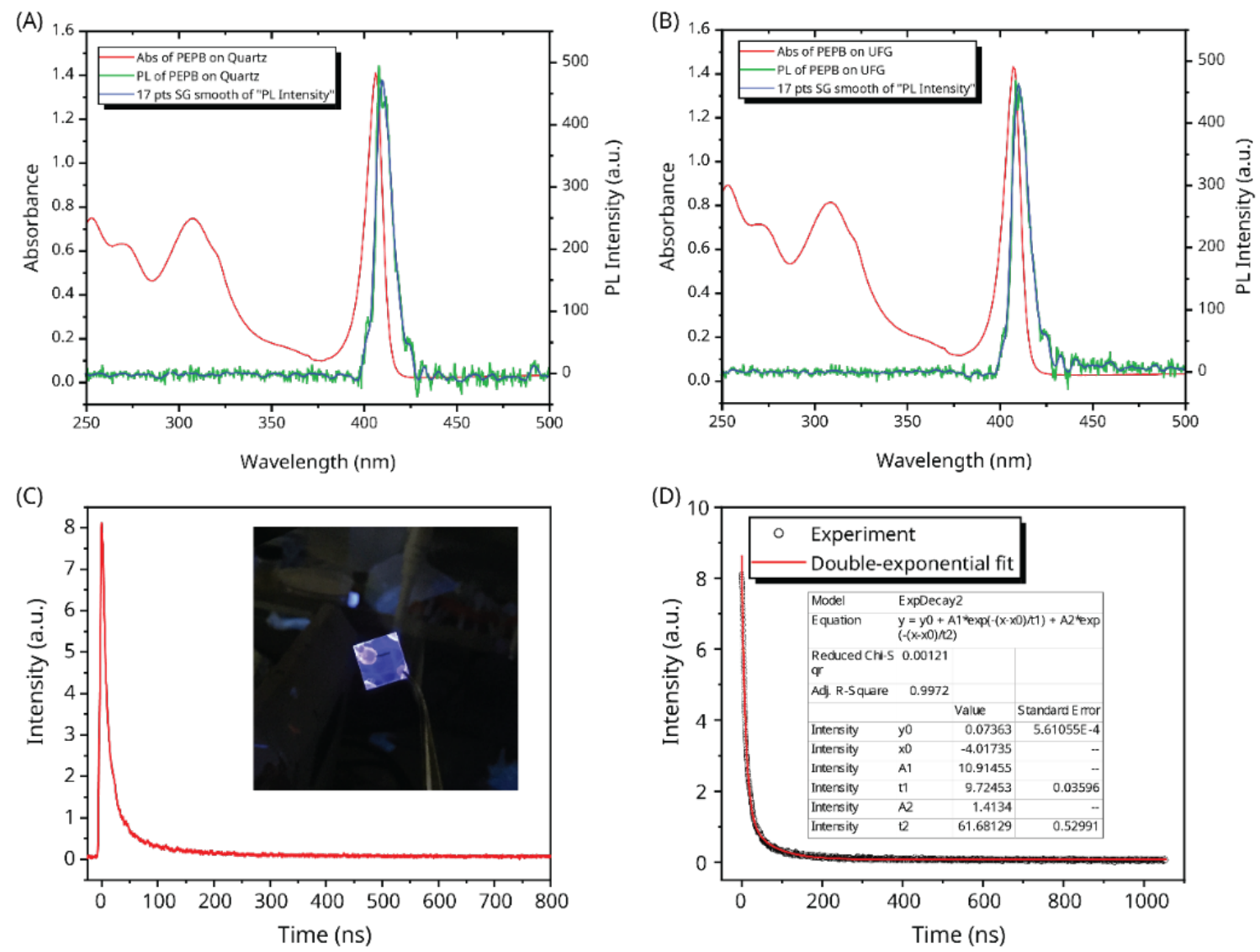

Figure 4-7 Steady PL and time-resolved PL spectra of PEPB thin films. (A) and (B): UV-Vis absorption (red lines) and steady PL spectra (green lines) of PEPB thin films on the UFG substrate and the quartz substrate, respectively. The PL spectra were smoothed by Savitzky-Golay method (blue lines). (C): Time-resolved PL spectrum of PEPB thin film on quartz substrate. The inset is the blue light emitted from PEPB film on the quartz substrate under a compact handheld UV lamp. (D) Time-resolved PL spectrum (circle) was well fitted by a double-exponential function (red line), with the fitting result displayed in the inset.

The steady PL spectra of 70 -nm-thick PEPB thin films on quartz and UFG substrates are shown as the green lines in Figure 4-7 (A) and (B), respectively, together with the UV-Vis absorption spectra (red lines). The PL spectra were smoothed by SavitzkyGolay method, using a quadratic polynomial with the window width of 17 data points, and shown as blue lines in Figure 4-7 (A) and (B). A sharp peak was observed in both PL 
spectra, which is attributed to the radiative recombination of excitons. In the PL spectrum of PEPB thin film on the quartz substrate, the peak is located at $410.7 \mathrm{~nm}$ with a FWHM of $10.95 \mathrm{~nm}$. In the PL spectrum of PEPB thin film on UFG substrate, the peak is located at $411.0 \mathrm{~nm}$ with a FWHM of $10.71 \mathrm{~nm}$.

The time-resolved PL spectrum of PEPB thin film is displayed in Figure 4-7 (C). The spectrum was well fitted to a double-exponential decay function with decay times $\tau_{1}=$ $9.72 \mathrm{~ns}$ and $\tau_{2}=61.68 \mathrm{~ns}$. The complete fitting result is shown in the inset of Figure 4-7 (D). However, it should be pointed out that $\tau_{1}=9.72 \mathrm{~ns}$ is comparable to the $5 \mathrm{~ns}$ period of the incident $\mathrm{N}_{2}$ laser. Therefore, this result needs to be further confirmed by picosecond or femtosecond laser.

\subsubsection{Crystal structure of PEPB bulk single crystals}

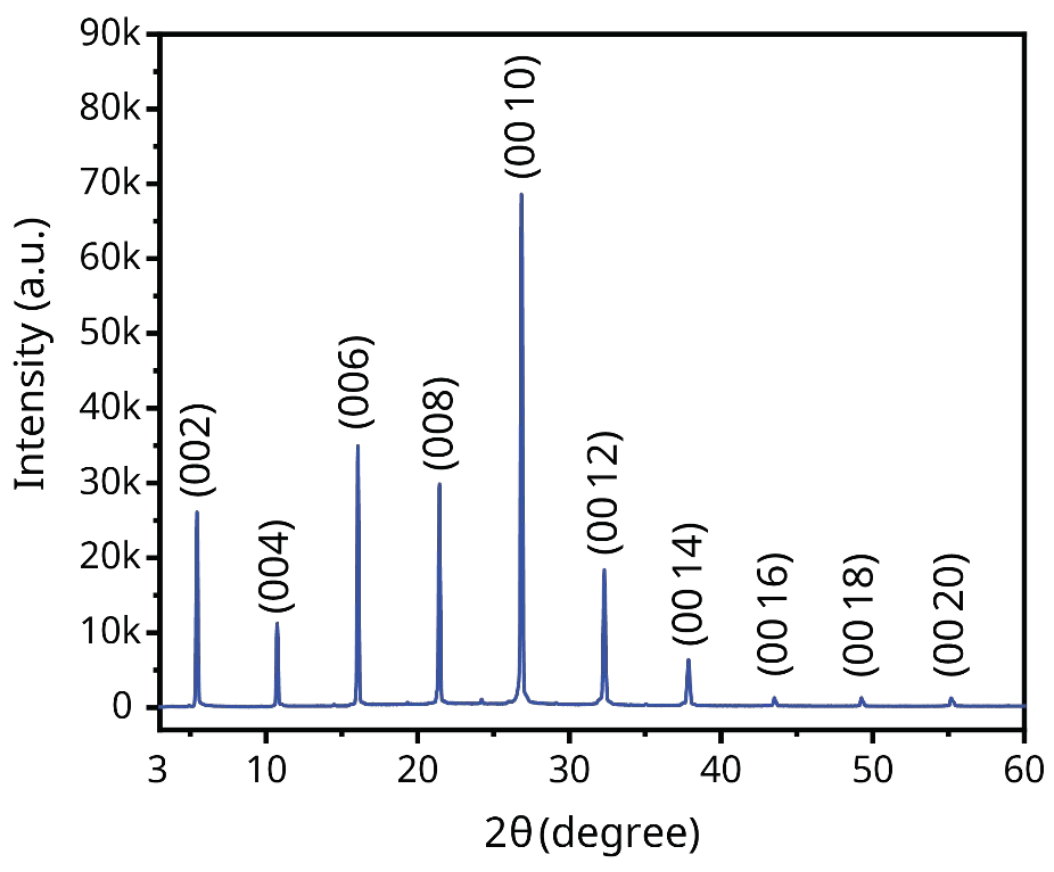

Figure 4-8 Powder XRD spectrum of PEPB single crystals. 
The XRD spectrum of $\left(\mathrm{C}_{6} \mathrm{H}_{5} \mathrm{C}_{2} \mathrm{H}_{4} \mathrm{NH}_{3}\right)_{2} \mathrm{PbBr}_{4}$ single crystals is shown in Figure 4-8. Sharp XRD peaks were observed in the spectrum and attributed to $\left(\begin{array}{lll}0 & 0 & 2 n\end{array}\right)(n=$ 1-10) planes in the Bravais lattice of PEPB crystal. The XRD result indicates that the PEPB bulk single crystals feature the tetragonal structure with the $14 / \mathrm{mmm}$ space group.

Table 4-5 $\sin (\theta)$ and $\frac{n \lambda}{2}(\AA)$ of XRD spectra of PEPB single crystals.

\begin{tabular}{ccccc}
\hline$n$ & Miller notation & $2 \theta\left(^{\circ}\right)$ & $\sin (\theta)$ & $\frac{n \lambda}{2}(\AA)$ \\
\hline 1 & $(002)$ & 5.44 & 0.04746 & 0.7703 \\
2 & $(004)$ & 10.74 & 0.09359 & 1.5406 \\
3 & $(006)$ & 16.06 & 0.13969 & 2.3109 \\
4 & $(008)$ & 21.44 & 0.18601 & 3.0812 \\
5 & $(0010)$ & 26.84 & 0.23209 & 3.8515 \\
6 & $(0012)$ & 32.30 & 0.27815 & 4.6218 \\
7 & $(0014)$ & 37.90 & 0.32474 & 5.3921 \\
8 & $(0016)$ & 43.50 & 0.37056 & 6.1624 \\
9 & $(0018)$ & 49.26 & 0.41676 & 6.9327 \\
10 & $(0020)$ & 55.23 & 0.46353 & 7.7030 \\
\hline
\end{tabular}

The positions ( $2 \theta$ angles) of XRD peaks were measured and shown in Table 4-5. Using Eq.4-2, the interplanar distance, $d$, was calculated by linear regression using the ordinary least squares method. The fitting result indicated that the interplanar distance, $d$, of PEPB single crystal equals to $16.6 \AA$, which is consistent with the interplanar distance of PEPB thin films on the UFG substrates. 


\subsubsection{Optical absorption spectrum of PEPB bulk single crystals}

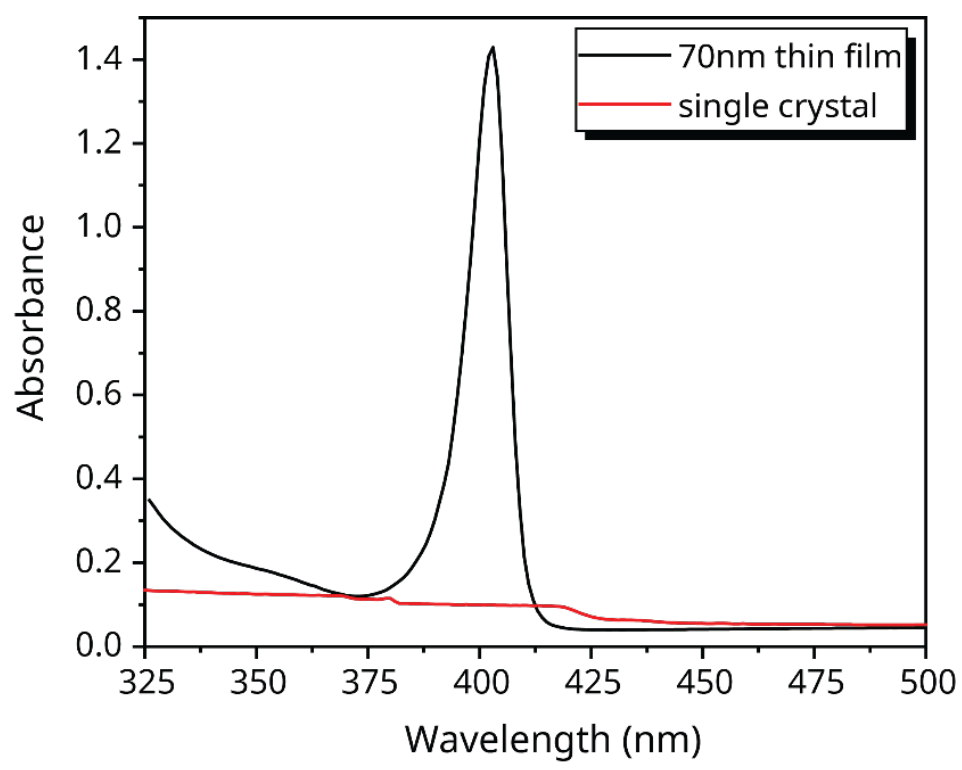

Figure 4-9 UV-Vis absorption spectrum of $\left(\mathrm{C}_{6} \mathrm{H}_{5} \mathrm{C}_{2} \mathrm{H}_{4} \mathrm{NH}_{3}\right)_{2} \mathrm{PbBr}_{4}$ single crystal.

Unlike the consistency between the XRD spectra of PEPB thin films and PEPB single crystals, the optical absorption property of PEPB single crystal is divergent from that of PEPB thin films, as shown in Figure 4-9. Compare to the 70-nm-thick PEPB thin film on the quartz substrate, the UV-Vis absorption spectrum of PEPB single crystals showed no excitonic absorption peak. Instead, a weak absorption onset was observed at $425 \mathrm{~nm}$, which is attributed to the band-to-band absorption. The disappearance of the excitonic absorption peak in the absorption spectrum of PEPB single crystals indicates the absence of excitons. As the thickness of PEPB bulk crystal is much larger than that of the PEPB thin films, the quantum confinement effect is much weaker. Without the quantum confinement effect, the exciton binding energy is reduced, and more excitons can be dissociated by thermal energy. Actually, in the absorption spectra of PEPB thin films shown in Figure 4-6 (A), the intensity of the excitonic absorption peak is decreasing with 
the film thickness increasing, which is in line with the disappearance of the excitonic absorption peak in the absorption spectrum of PEPB bulk single crystal.

\subsubsection{Surface morphology of 2D PEPB NCs}
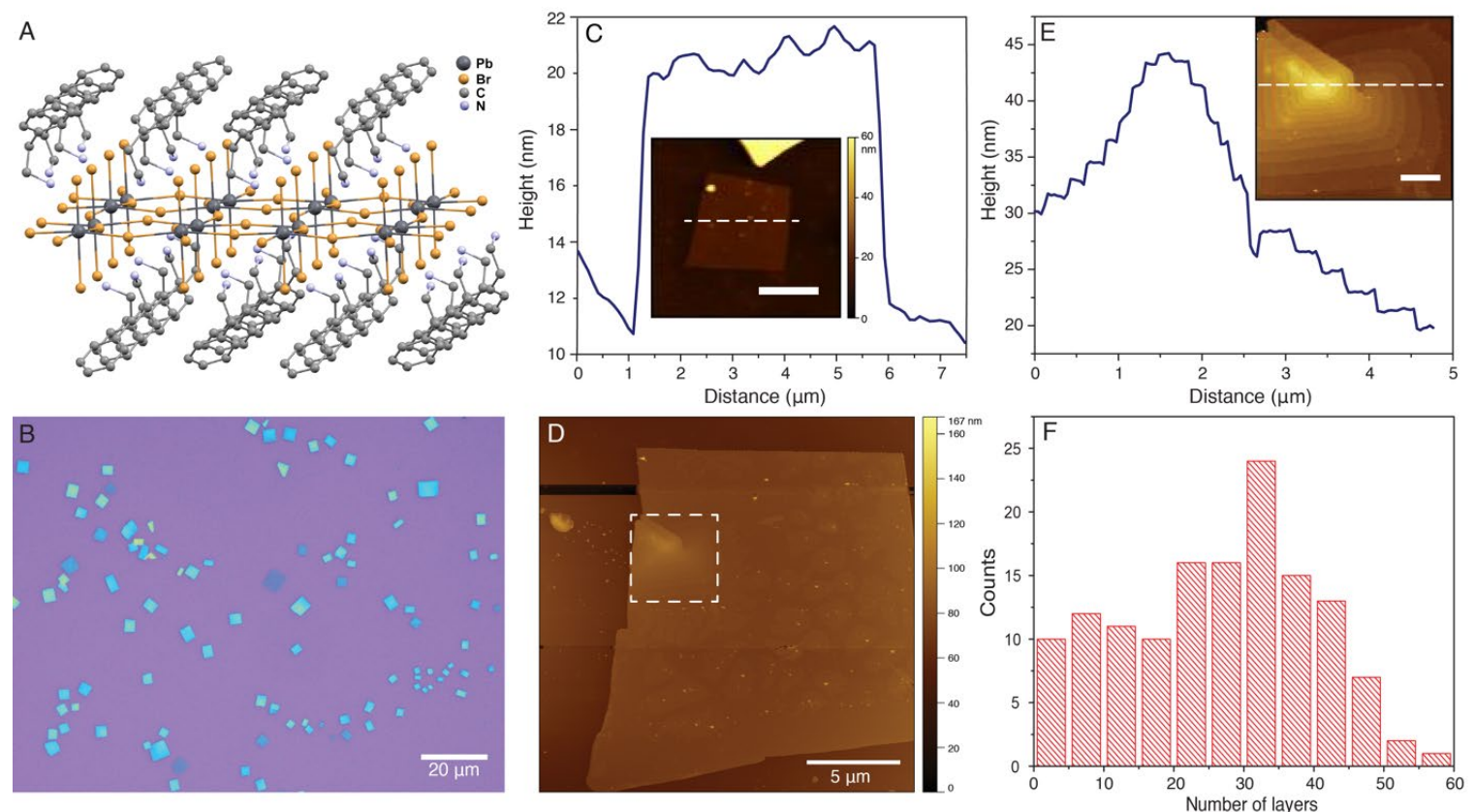

Figure 4-10 (A) Structural illustration of a single layer $\left(\mathrm{C}_{6} \mathrm{H}_{5} \mathrm{C}_{2} \mathrm{H}_{4} \mathrm{NH}_{3}\right)_{2} \mathrm{PbBr}_{4}(\mathrm{PEPB})$ (black balls: lead atoms; gold balls: bromine atoms; grey balls: carbon atoms; light blue balls: nitrogen atoms; $\mathrm{H}$ atoms were removed for clarity). (B) Bright-field optical images of the 2D PEPB nanocrystals on $\mathrm{SiO}_{2} / \mathrm{Si}$ substrate. (C) Height profile of a 2D PEPB nanocrystal. The inset shows the AFM image with a scale bar of $3 \mu \mathrm{m}$. (D) AFM image of a pyramid formed on top of a PEPB nanocrystal. (E) Height profile of the pyramid. A magnified image of the pyramid is shown in the inset. Scale bar in the inset: $2 \mu \mathrm{m}$. (F) Thickness distribution statistics of 2D PEPB nanocrystals synthesized on $\mathrm{SiO}_{2} / \mathrm{Si}$ substrates.

A schematic illustration in Figure 4-10 (A) shows the structure of a monolayer of PEPB crystal. Each $\mathrm{Pb}^{2+}$ cation is positioned inside an octahedral cage formed by six $\mathrm{Br}^{-}$ anions, and every in-plane $\mathrm{Br}^{-}$anion is shared by the adjoining $\mathrm{PbBr}_{6}^{4-}$ octahedrons. The $\left(\mathrm{C}_{6} \mathrm{H}_{5} \mathrm{C}_{2} \mathrm{H}_{4} \mathrm{NH}_{3}\right)_{2} \mathrm{PbBr}_{4}$ unit cell self-assembles into a two-dimensional sheet of cornershared $\mathrm{PbBr}_{4}{ }^{2-}$ which lies in between two layers of organic moieties consisted of $\mathrm{C}_{6} \mathrm{H}_{5} \mathrm{C}_{2} \mathrm{H}_{4} \mathrm{NH}_{3}{ }^{+}$. An optical microscope was used to examine the 2D nanocrystals of PEPB 
grown on $\mathrm{SiO}_{2} / \mathrm{Si}$ substrates, and the result is shown in Figure 4-10 (B). Blue square-shaped 2D nanocrystals with edge length around $5 \mu \mathrm{m}$ could be easily distinguished from the purple background of the substrate. Some square-shaped 2D PEPB nanocrystals can have an edge length of up to $30 \mu \mathrm{m}$. Atomic force microscope (AFM) measurement showed that the thickness of these nanocrystals varied from a few to around one hundred nanometers, with the corresponding color in optical microscope images changing from blue to yellow. AFM image of one PEPB nanocrystal showed a thickness of $\sim 9.1 \mathrm{~nm}$ (Figure 4-10 (C)). The thinnest $2 \mathrm{D}$ crystal was measured to be $\sim 5.7 \mathrm{~nm}( \pm 0.2 \mathrm{~nm})$ thick.

It should also be noted that a pyramid-shaped structure was occasionally formed on top of some of the flat PEPB nanocrystals with thickness over $20 \mathrm{~nm}$. Figure 4-10 (D) shows such a pyramid formed on a 20-nm-thick crystal. Figure 4-10 (E) shows the height profile of the pyramid, as shown in the inset, which is a close-up view of the boxed area in Figure 4-10 (D). The inset in Figure 4-10 (E) showed a clear layer-by-layer structure with each layer in a rounded rectangle shape. AFM measurement in Figure 4-10 (E)showed that the height of each step was less than $2 \mathrm{~nm}$. Considering that the d-spacing of PEPB bulk single crystal is $1.67 \mathrm{~nm}^{[25]}$, each step of the pyramid in the AFM image should be corresponding to one monolayer of PEPB. From the AFM measurement, the average height of each stage, i.e., the thickness of PEPB monolayer, was $\sim 1.8 \mathrm{~nm}( \pm 0.3 \mathrm{~nm})$. This number is larger than the d-spacing of the bulk PEPB crystals. The larger thickness measured from AFM could have resulted from the settings of the tapping mode of the AFM, which was intended to avoid the sample damage. The relaxation of the organic moiety located at the top of PEPB nanocrystals could also contribute to the increased height. The height profile indicated that the very top step of the pyramid was only $\sim 0.8 \mathrm{~nm}$ thick (Figure $4-10$ (E)), 
which was probably a sublayer of $\mathrm{C}_{6} \mathrm{H}_{5} \mathrm{C}_{2} \mathrm{H}_{4} \mathrm{NH}_{3} \mathrm{Br}$ bonded to the PEPB layer beneath it by van der Waals force. After measuring the thicknesses of 137 crystals synthesized using the same solution-phase growth procedure on $7 \mathrm{SiO}_{2} / \mathrm{Si}$ substrates by $\mathrm{AFM}$, the distribution of the number of layers of 2D PEPB nanocrystals was calculated and presented in a histogram in Figure 4-10 (F). The thickest nanocrystal had a total of 60 layers, the thinnest one had only 3 layers, and over half of the nanocrystals had less than 30 layers ( $\sim 54 \mathrm{~nm})$. The possibility to obtain 2D PEPB nanocrystals with $30 \sim 35$ layers was nearly $20 \%$, which was the highest, while the possibility to obtain nanocrystals with more than 50 layers was merely $2 \%$, which was the lowest.

\subsubsection{PL properties of PEPB NCs}

Figure 4-11 (A) displays the PL spectra of the bulk single crystal of PEPB and 2D nanocrystals with different thicknesses grown on the $\mathrm{SiO}_{2} / \mathrm{Si}$ substrate. The bulk single crystal shows a PL peak at $414 \mathrm{~nm}(2.99 \mathrm{eV})$, and the nanocrystals have blue-shifted peaks at $\sim 409 \mathrm{~nm}(3.03 \mathrm{eV})$. The bandgap of 2D PEPB nanocrystals increased for $40 \mathrm{meV}$ compared to the bulk single crystal. The increase of the bandgap is probably due to the relaxation and expansion of the $\mathrm{PbBr}_{4}{ }^{2-}$ frame within which the $\mathrm{Pb}-\mathrm{Br}-\mathrm{Pb}$ bond between

adjoining $\mathrm{PbBr}_{6}^{4-}$ octahedrons was distorted in bulk single crystal. ${ }^{[25,34]}$ The PL spectra peaks of both bulk single crystal and nanocrystals are asymmetric, indicating the existence of multiple excitonic states or the coupling of excitons to phonons. ${ }^{[37]}$ 

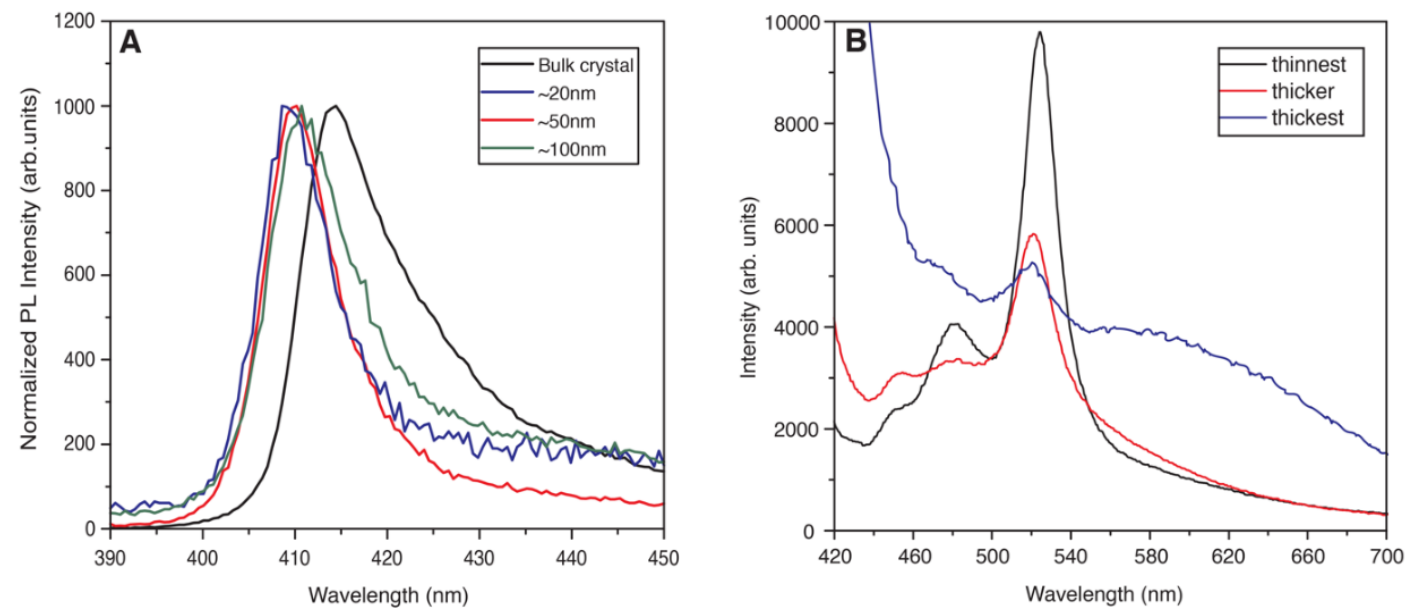

Figure 4-11 PL properties of the 2D $\left(\mathrm{C}_{6} \mathrm{H}_{5} \mathrm{C}_{2} \mathrm{H}_{4} \mathrm{NH}_{3}\right)_{2} \mathrm{PbBr}_{4}$ nanocrystals. (A) Steady-state PL spectrum of a piece of bulk crystal and three $2 \mathrm{D}\left(\mathrm{C}_{6} \mathrm{H}_{5} \mathrm{C}_{2} \mathrm{H}_{4} \mathrm{NH}_{3}\right)_{2} \mathrm{PbBr}_{4}$ nanocrystals measured using a UV-LED source. (B) PL peaks of three 2D nanocrystals located at $480 \mathrm{~nm}$ and $525 \mathrm{~nm}$, obtained using a $405 \mathrm{~nm}$ laser as excitation and a $410 \mathrm{~nm}$ long-pass filter.

To further study the photoluminescence of the 2D PEPB nanocrystals, a $405 \mathrm{~nm}$ wavelength laser diode was used as a strong photoexcitation source, and a $410 \mathrm{~nm}$ longpass filter was used to block the laser signal as well as the strong PL peak at $\sim 410 \mathrm{~nm}$. Two new PL peaks located at around $480 \mathrm{~nm}$ and $525 \mathrm{~nm}$ and a shoulder located at around 448 $\mathrm{nm}$ were observed for the nanocrystals, as shown in Figure 4-11 (B). With the increase of the thickness of the nanocrystals, these two PL peaks became shallow and wide. The 480 nm peak almost disappeared in the PL spectrum of the thickest nanocrystal. The same PL tests were also performed on the PEPB bulk single crystal samples, and these PL peaks were not observed in the spectra. Recently, J. Blancon et al. reported PL emission with less energy than the bandgap from the layer-edge-states of the exfoliated $\left(\mathrm{C}_{4} \mathrm{H}_{9} \mathrm{NH}_{3}\right)_{2}\left(\mathrm{CH}_{3} \mathrm{NH}_{3}\right)_{\mathrm{n}-1} \mathrm{~Pb}_{\mathrm{n}} \mathrm{I}_{3 \mathrm{n}+1}$ nanocrystals with $\mathrm{n}=3-5$. However, for the $\mathrm{n}=1$ nanocrystal, i.e. $\left(\mathrm{C}_{4} \mathrm{H}_{9} \mathrm{NH}_{3}\right)_{2} \mathrm{PbI}_{4}, \mathrm{PL}$ emission from the layer-edge-states was not observed ${ }^{[38]}$ Therefore, for our 2D PEPB nanocrystals in which $n=1$, the two PL peaks at 480 and $525 \mathrm{~nm}$ were probably not the result of the radiative recombination of the layer- 
edge-states. It is speculated that these new PL peaks in our 2D PEPB nanocrystals probably originate from the radiative decay of the excited organic part, which might indicate the energy/charge transfer between the inorganic and organic moieties after excitation. Theoretical calculation may help to confirm our hypothesis.

\subsubsection{Time-resolved reflectance spectroscopy of PEPB NCs}

To study the dynamic processes of the absorption, time-resolved reflectance contrast changes (RCCs) of the 2D PEPB nanocrystals prepared on $\mathrm{SiO}_{2} / \mathrm{Si}$ substrates were measured following the photoexcitation at $405 \mathrm{~nm}$.
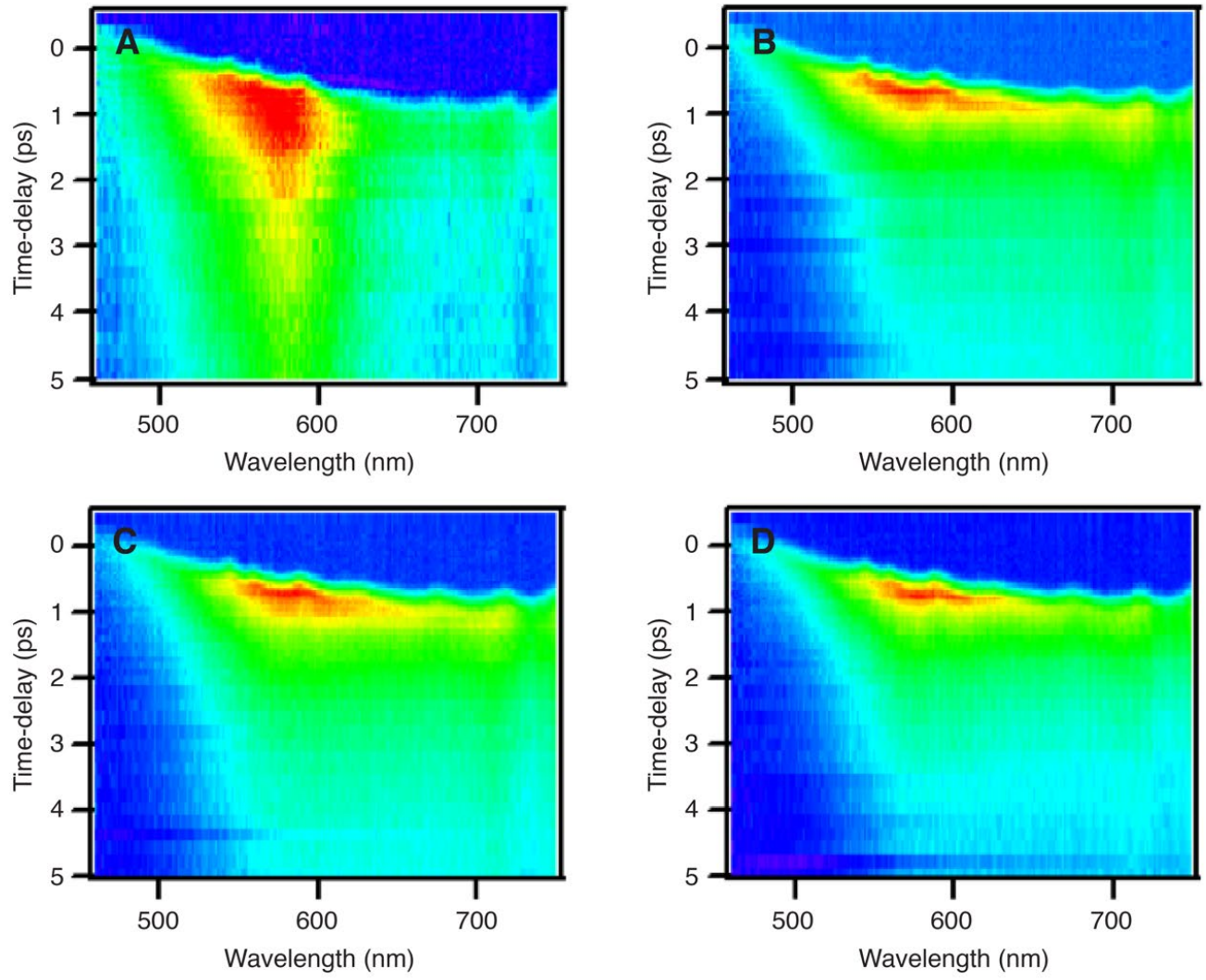

Figure 4-12 Time-resolved reflectance contrast of four 2D PEPB nanocrystals. 
Figure 4-12 shows the results of four different 2D PEPB nanocrystals with different thicknesses. The results showed a broad positive RCC peak between $500 \mathrm{~nm}$ and $650 \mathrm{~nm}$ (red-colored area in Figure 3), indicating an induced absorption attributed to the excited state. It is clear that the RCC signal shown in Figure 4-12 (A) had a longer lifetime than that in Figure 4-12 (B) (D), although we are not able to correlate the thickness of these samples to their RCC signals in this report.
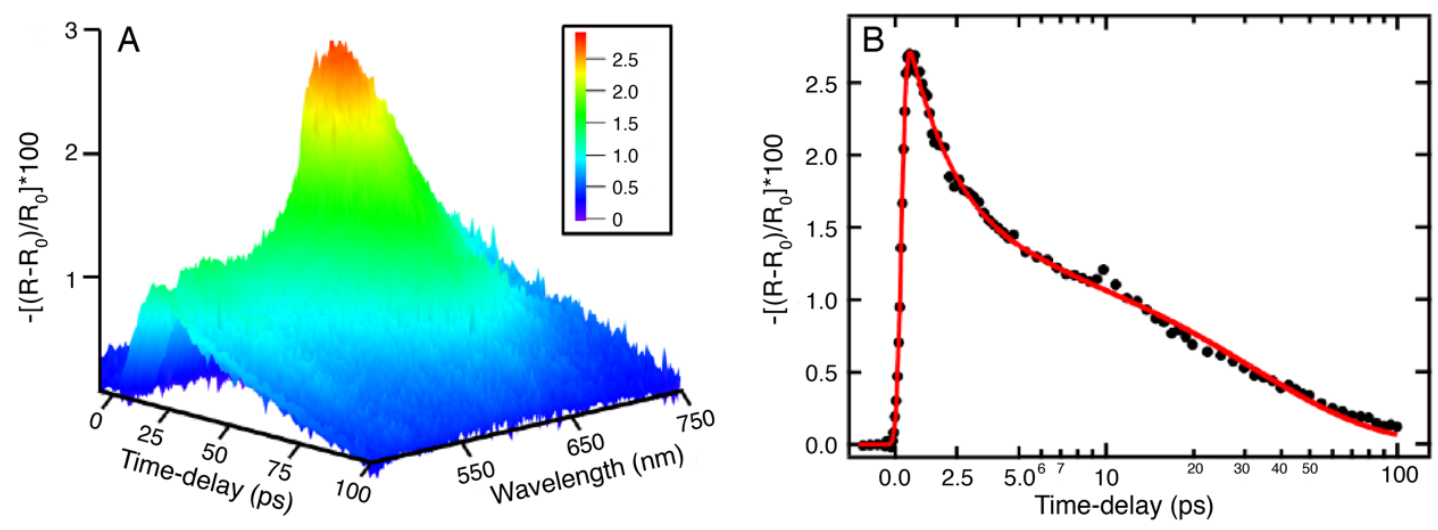

Figure 4-13 (A) Time-resolved reflection contrast change up to 100 ps time-delay. (B) Dynamics of the induced absorption signal averaged around the peak at $600 \mathrm{~nm}$ (symbols). The experimental data were fitted to a biexponential decay function (solid line).

Table 4-6 Parameters returned by the converged fit to the decay of the excited state induced absorption signal shown in Figure 4-13 (B). $A_{i}(\%)$ and $T_{i}(p s)$ are the amplitude and the time constant of the exponential decay component i. The amplitude-weighted lifetime $\boldsymbol{\tau}$ is calculated as $\tau=\frac{\sum_{i} A_{i} T_{i}}{\sum_{i} A_{i}}$.

\begin{tabular}{|c|c|c|c|c|}
\hline $\mathrm{A}_{1}(\%)$ & $\mathrm{T}_{1}(\%)$ & $\mathrm{A}_{2}(\%)$ & $\mathrm{T}_{2}(\%)$ & $\tau(\mathrm{ps})$ \\
\hline 53 & 2.0 & 47 & 33.3 & 16.7 \\
\hline
\end{tabular}

Figure 4-13 (A) is the RCC measurement up to 100 ps time-delay. The amplitude of the induced excited-state absorption following the $405 \mathrm{~nm}$ excitation increased up to 3 times. To calculate the lifetime of the excited state, the decay of excited state induced absorption signal averaged around $600 \mathrm{~nm}$ was fitted to a bi-exponential decay function 
convoluted with a Gaussian excitation pulse with a 45 fs pulse duration [Figure 4-13 (B)]. The converged fitting result showed two time constants of 2.0 ps and 33.3 ps with an amplitude-weighted lifetime of $\tau \sim 16.7$ ps (Table 4-6).

\subsection{Summary}

The solution-processed 2D phenethylammonium lead bromide (PEPB) perovskite nanocrystals were presented with a fundamental study on the exciton dynamics of new $2 \mathrm{D}$ perovskite material utilizing photoluminescence and time-resolved reflectance measurements. Square-shaped 2D PEPB nanocrystals have been synthesized with edge length up to $30 \mu \mathrm{m}$ and thickness of a few tens nanometers. The pyramid structure formed by PEPB on top of a thin sheet was observed. The average height of the steps in the pyramid structure suggested that the thickness of a single layer of PEPB nanocrystal was $\sim 1.8 \mathrm{~nm}$ $( \pm 0.3 \mathrm{~nm})$, which was significantly larger than the d-spacing $(1.67 \mathrm{~nm})$ of PEPB bulk single crystal. The distribution of the number of layers of synthesized PEPB nanocrystals showed that over half of them were composed of less than 30 layers and that it is practical to obtain thin nanocrystals with few layers. The PL results have shown that the 2D nanocrystals of PEPB exhibited an asymmetric PL peak at $409 \mathrm{~nm}$, slightly blue-shifted compare to the PL peak of PEPB single crystal. Besides, two new PL peaks at $480 \mathrm{~nm}$ and $525 \mathrm{~nm}$ were observed from the 2D PEPB nanocrystals, and they probably resulted from the radiative decay in the organic moiety of the material, indicating energy/charge transfer between inorganic and organic moieties. Time-resolved reflectance measurements showed

a broad induced absorption peak, attributed to the excited state. The lifetime of the excited 
state was calculated to be $16.7 \mathrm{ps}$ by fitting the decay of the induced absorption signal to a bi-exponential decay function.

\subsection{References}

1. Yang, W. S.; Noh, J. H.; Jeon, N. J.; Kim, Y. C.; Ryu, S.; Seo, J.; Seok, S. I., SOLAR CELLS. High-performance photovoltaic perovskite layers fabricated through intramolecular exchange. Science 2015, 348 (6240), 1234-7.

2. Son, D.-Y.; Lee, J.-W.; Choi, Y. J.; Jang, I.-H.; Lee, S.; Yoo, P. J.; Shin, H.; Ahn, N.; Choi, M.; Kim, D.; Park, N.-G., Self-formed grain boundary healing layer for highly efficient $\mathrm{CH}_{3} \mathrm{NH}_{3} \mathrm{PbI}_{3}$ perovskite solar cells. Nature Energy 2016, 1, 16081.

3. Veldhuis, S. A.; Boix, P. P.; Yantara, N.; Li, M.; Sum, T. C.; Mathews, N.; Mhaisalkar, S. G., Perovskite Materials for Light-Emitting Diodes and Lasers. Adv Mater 2016, 28 (32), 6804-34.

4. Hong, X.; Ishihara, T.; Nurmikko, A. V., Dielectric confinement effect on excitons in PbI4-based layered semiconductors. Phys Rev B Condens Matter 1992, 45 (12), 6961-6964.

5. Shimizu, M.; Fujisawa, J.-I.; Ishi-Hayase, J., Influence of dielectric confinement on excitonic nonlinearity in inorganic-organic layered semiconductors. Physical Review $B$ 2005, 71 (20).

6. Kitazawa, N., Optical Absorption and Photoluminescence Properties of $\mathrm{Pb}(\mathrm{I}, \mathrm{Br})-$ Based Two-Dimensional Layered Perovskite. Japanese Journal of Applied Physics 1997, 36 (4R), 2272.

7. Kitazawa, N., Compositional Modulation of Two-Dimensional Layered Perovskite $\left(\mathrm{RNH}_{3}\right)_{2} \mathrm{~Pb}(\mathrm{Cl}, \mathrm{Br}, \mathrm{I})_{4}$ and Its Optical Properties. Japanese Journal of Applied Physics 1996, 35 (12R), 6202.

8. Kitazawa, N., Excitons in two-dimensional layered perovskite compounds: $\left(\mathrm{C}_{6} \mathrm{H}_{5} \mathrm{C}_{2} \mathrm{H}_{4} \mathrm{NH}_{3}\right)_{2} \mathrm{~Pb}(\mathrm{Br}, \mathrm{I})_{4}$ and $\left(\mathrm{C}_{6} \mathrm{H}_{5} \mathrm{C}_{2} \mathrm{H}_{4} \mathrm{NH}_{3}\right)_{2} \mathrm{~Pb}(\mathrm{Cl}, \mathrm{Br})_{4}$. Materials Science and Engineering: $B$ 1997, 49 (3), 233-238. 
9. Even, J.; Pedesseau, L.; Katan, C., Understanding quantum confinement of charge carriers in layered 2D hybrid perovskites. Chemphyschem 2014, 15 (17), 3733-41.

10. Sapori, D.; Kepenekian, M.; Pedesseau, L.; Katan, C.; Even, J., Quantum confinement and dielectric profiles of colloidal nanoplatelets of halide inorganic and hybrid organic-inorganic perovskites. Nanoscale 2016, 8 (12), 6369-78.

11. Ahmad, S.; Prakash, G. V., Strong room-temperature ultraviolet to red excitons from inorganic organic-layered perovskites, (R-NH3)2MX4 (M=Pb2+, Sn2+, $\mathrm{Hg} 2+$; $\mathrm{X}=\mathrm{I}-, \mathrm{Br}-$ ). Journal of Nanophotonics 2014, 8 (1), 083892.

12. Akkerman, Q. A.; Motti, S. G.; Srimath Kandada, A. R.; Mosconi, E.; D'Innocenzo, V.; Bertoni, G.; Marras, S.; Kamino, B. A.; Miranda, L.; De Angelis, F.; Petrozza, A.; Prato, M.; Manna, L., Solution Synthesis Approach to Colloidal Cesium Lead Halide Perovskite Nanoplatelets with Monolayer-Level Thickness Control. J Am Chem Soc 2016, 138 (3), 1010-6.

13. Naphade, R.; Nagane, S.; Shanker, G. S.; Fernandes, R.; Kothari, D.; Zhou, Y.; Padture, N. P.; Ogale, S., Hybrid Perovskite Quantum Nanostructures Synthesized by Electrospray Antisolvent-Solvent Extraction and Intercalation. ACS Appl Mater Interfaces 2016, 8 (1), 854-61.

14. Bekenstein, Y.; Koscher, B. A.; Eaton, S. W.; Yang, P.; Alivisatos, A. P., Highly Luminescent Colloidal Nanoplates of Perovskite Cesium Lead Halide and Their Oriented Assemblies. J Am Chem Soc 2015, 137 (51), 16008-11.

15. Sichert, J. A.; Tong, Y.; Mutz, N.; Vollmer, M.; Fischer, S.; Milowska, K. Z.; Garcia Cortadella, R.; Nickel, B.; Cardenas-Daw, C.; Stolarczyk, J. K.; Urban, A. S.; Feldmann, J., Quantum Size Effect in Organometal Halide Perovskite Nanoplatelets. Nano Lett 2015, 15 (10), 6521-7.

16. Vybornyi, O.; Yakunin, S.; Kovalenko, M. V., Polar-solvent-free colloidal synthesis of highly luminescent alkylammonium lead halide perovskite nanocrystals. Nanoscale 2016, 8 (12), 6278-83.

17. Wong, A. B.; Lai, M.; Eaton, S. W.; Yu, Y.; Lin, E.; Dou, L.; Fu, A.; Yang, P., Growth and Anion Exchange Conversion of CH3NH3PbX3 Nanorod Arrays for Light-Emitting Diodes. Nano Lett 2015, 15 (8), 5519-24. 
18. Xu, Y.; Chen, Q.; Zhang, C.; Wang, R.; Wu, H.; Zhang, X.; Xing, G.; Yu, W. W.; Wang, X.; Zhang, Y.; Xiao, M., Two-Photon-Pumped Perovskite Semiconductor Nanocrystal Lasers. J Am Chem Soc 2016, 138 (11), 3761-8.

19. Zhang, D.; Eaton, S. W.; Yu, Y.; Dou, L.; Yang, P., Solution-Phase Synthesis of Cesium Lead Halide Perovskite Nanowires. J Am Chem Soc 2015, 137 (29), 9230-3.

20. Zhang, S.; Lanty, G.; Lauret, J.-S.; Deleporte, E.; Audebert, P.; Galmiche, L., Synthesis and optical properties of novel organic-inorganic hybrid nanolayer structure semiconductors. Acta Materialia 2009, 57 (11), 3301-3309.

21. Zhang, Y.; Liu, J.; Wang, Z.; Xue, Y.; Ou, Q.; Polavarapu, L.; Zheng, J.; Qi, X.; Bao, Q., Synthesis, properties, and optical applications of low-dimensional perovskites. Chem Commun (Camb) 2016, 52 (94), 13637-13655.

22. Zheng, K.; Žídek, K.; Abdellah, M.; Messing, M. E.; Al-Marri, M. J.; Pullerits, T., Trap States and Their Dynamics in Organometal Halide Perovskite Nanoparticles and Bulk Crystals. The Journal of Physical Chemistry C 2016, 120 (5), 3077-3084.

23. Zhu, H.; Fu, Y.; Meng, F.; Wu, X.; Gong, Z.; Ding, Q.; Gustafsson, M. V.; Trinh, M. T.; Jin, S.; Zhu, X. Y., Lead halide perovskite nanowire lasers with low lasing thresholds and high quality factors. Nat Mater 2015, 14 (6), 636-42.

24. Zhuo, S.; Zhang, J.; Shi, Y.; Huang, Y.; Zhang, B., Self-template-directed synthesis of porous perovskite nanowires at room temperature for high-performance visible-light photodetectors. Angew Chem Int Ed Engl 2015, 54 (19), 5693-6.

25. Kawano, N.; Koshimizu, M.; Sun, Y.; Yahaba, N.; Fujimoto, Y.; Yanagida, T.; Asai, K., Effects of Organic Moieties on Luminescence Properties of Organic-Inorganic Layered Perovskite-Type Compounds. The Journal of Physical Chemistry C 2014, 118 (17), 9101-9106.

26. Ha, S.-T.; Shen, C.; Zhang, J.; Xiong, Q., Laser cooling of organic-inorganic lead halide perovskites. Nature Photonics 2015, 10 (2), 115-121.

27. Wang, N.; Cheng, L.; Ge, R.; Zhang, S.; Miao, Y.; Zou, W.; Yi, C.; Sun, Y.; Cao, Y.; Yang, R.; Wei, Y.; Guo, Q.; Ke, Y.; Yu, M.; Jin, Y.; Liu, Y.; Ding, Q.; Di, D.; Yang, L.; Xing, G.; Tian, H.; Jin, C.; Gao, F.; Friend, R. H.; Wang, J.; Huang, 
W., Perovskite light-emitting diodes based on solution-processed self-organized multiple quantum wells. Nature Photonics 2016, 10 (11), 699-704.

28. Chen, Y.; Sun, Y.; Peng, J.; Zhang, W.; Su, X.; Zheng, K.; Pullerits, T.; Liang, Z., Tailoring Organic Cation of 2D Air-Stable Organometal Halide Perovskites for Highly Efficient Planar Solar Cells. Advanced Energy Materials 2017, 7 (18), 1700162n/a.

29. Gonzalez-Carrero, S.; Espallargas, G. M.; Galian, R. E.; Pérez-Prieto, J., Blueluminescent organic lead bromide perovskites: highly dispersible and photostable materials. Journal of Materials Chemistry A 2015, 3 (26), 14039-14045.

30. Protesescu, L.; Yakunin, S.; Bodnarchuk, M. I.; Krieg, F.; Caputo, R.; Hendon, C. H.; Yang, R. X.; Walsh, A.; Kovalenko, M. V., Nanocrystals of Cesium Lead Halide Perovskites ( $\mathrm{CsPbX}(3), \mathrm{X}=\mathrm{Cl}, \mathrm{Br}$, and I): Novel Optoelectronic Materials Showing Bright Emission with Wide Color Gamut. Nano Lett 2015, 15 (6), 3692-6.

31. Schmidt, L. C.; Pertegas, A.; Gonzalez-Carrero, S.; Malinkiewicz, O.; Agouram, S.; Minguez Espallargas, G.; Bolink, H. J.; Galian, R. E.; Perez-Prieto, J., Nontemplate synthesis of $\mathrm{CH} 3 \mathrm{NH} 3 \mathrm{PbBr} 3$ perovskite nanoparticles. $\mathrm{J} \mathrm{Am} \mathrm{Chem} \mathrm{Soc}$ 2014, $136(3), 850-3$.

32. Yaffe, O.; Chernikov, A.; Norman, Z. M.; Zhong, Y.; Velauthapillai, A.; van der Zande, A.; Owen, J. S.; Heinz, T. F., Excitons in ultrathin organic-inorganic perovskite crystals. Physical Review B 2015, 92 (4), 045414.

33. Wu, X.; Trinh, M. T.; Zhu, X. Y., Excitonic Many-Body Interactions in TwoDimensional Lead Iodide Perovskite Quantum Wells. The Journal of Physical Chemistry C 2015, 119 (26), 14714-14721.

34. Dou, L.; Wong, A. B.; Yu, Y.; Lai, M.; Kornienko, N.; Eaton, S. W.; Fu, A.; Bischak, C. G.; Ma, J.; Ding, T.; Ginsberg, N. S.; Wang, L. W.; Alivisatos, A. P.; Yang, P., Atomically thin two-dimensional organic-inorganic hybrid perovskites. Science 2015, 349 (6255), 1518-21.

35. Boulesbaa, A.; Wang, K.; Mahjouri-Samani, M.; Tian, M.; Puretzky, A. A.; Ivanov, I.; Rouleau, C. M.; Xiao, K.; Sumpter, B. G.; Geohegan, D. B., Ultrafast Charge Transfer and Hybrid Exciton Formation in 2D/0D Heterostructures. $J$ Am Chem Soc 2016, 138 (44), 14713-14719. 
36. Fujita, M.; Nakagawa, H.; Fukui, K.; Matsumoto, H.; Miyanaga, T.; Watanabe, M., Polarized Reflection Spectra of Orthorhombic $\mathrm{PbCl} 2$ and $\mathrm{PbBr} 2$. Journal of the Physical Society of Japan 1991, 60 (12), 4393-4394.

37. Gauthron, K.; Lauret, J. S.; Doyennette, L.; Lanty, G.; Al Choueiry, A.; Zhang, S. J.; Brehier, A.; Largeau, L.; Mauguin, O.; Bloch, J.; Deleporte, E., Optical spectroscopy of two-dimensional layered $(\mathrm{C}(6) \mathrm{H}(5) \mathrm{C}(2) \mathrm{H}(4)-\mathrm{NH}(3))(2)-\mathrm{PbI}(4)$ perovskite. Opt Express 2010, 18 (6), 5912-9.

38. Blancon, J. C.; Tsai, H.; Nie, W.; Stoumpos, C. C.; Pedesseau, L.; Katan, C.; Kepenekian, M.; Soe, C. M.; Appavoo, K.; Sfeir, M. Y.; Tretiak, S.; Ajayan, P. M.; Kanatzidis, M. G.; Even, J.; Crochet, J. J.; Mohite, A. D., Extremely efficient internal exciton dissociation through edge states in layered 2D perovskites. Science 2017, 355 (6331), 1288-1292. 


\section{CHAPTER 5. MA-gas-assisted Deposition of MAPbI 3 Thin Film for Highly Efficient Perovskite Solar Cells}

\subsection{Introduction}

Organic-inorganic hybrid perovskite solar cells (PSCs) have attracted immense attention in the field of emerging photovoltaics (PV) in the last decade ${ }^{[1-5]}$. Since the first application of methylammonium lead iodide $\left(\mathrm{CH}_{3} \mathrm{NH}_{3} \mathrm{PbI}_{3}\right.$ or $\left.\mathrm{MAPbI}_{3}\right)$ as the light absorbing nanoparticles in dye-sensitized solar cells in $2009^{[6]}$, the certified power conversion efficiencies (PCEs) for single-junction PSCs, recorded in the best researchcell efficiency chart provided by the National Renewable Energy Laboratory, has achieved a massive leap from $3.8 \%$ to $25.2 \%{ }^{[7]}$, rivaling mainstream multi-crystalline silicon solar cells. Such unprecedented PCE advancement is the fastest among all the next-generation photovoltaic devices, which is highly attributed to the optimization of the composition of perovskite ${ }^{[8-14]}$, improved crystal growth control ${ }^{[15-22]}$, as well as interface $^{[23-26]}$ and device engineering ${ }^{[27-32]}$. As a result of its many preferred characteristics, including low-cost fabrication process, high absorption coefficient in the visible range ${ }^{[1,33]}$, high charge carrier mobility ${ }^{[34,35]}$, long diffusion length ${ }^{[14,36,37]}$, and tunable direct bandgap ${ }^{[38,39]}$, perovskite solar cell has been viewed as the leading candidate for the next generation PV technologies.

On top of the preeminently high PCE among variable next-generation PV technologies, the ease of processing, with which high-quality organic-inorganic hybrid perovskites thin films can be deposited ${ }^{[40]}$, is another characteristic that makes these materials extremely attractive for solar cell devices. Although various methods have been developed to deposit perovskite films ${ }^{[40,41]}$, one-step spin coating remains the easiest and 
quickest route to depositing high-quality perovskite layers. The choices of available solvents are limited due to the low solubility of $\mathrm{PbI}_{2}$ in most common nonpolar solvents or polar protic solvents. The most common solvents used in one-step spin coating are dimethylformamide $(\mathrm{DMF})^{[16,42]}$, dimethyl sulfoxide (DMSO) $)^{[43-45]}$, and $\gamma$-butyrolactone $(\mathrm{GBL})^{[46]}$, all of which are polar aprotic solvents with high boiling temperatures $\left(>100^{\circ} \mathrm{C}\right)$. During spin coating, these polar aprotic solvents are generally removed by the centrifugal force. An anti-solvent dripping process is usually required for a dense and pinhole-free thin film ${ }^{[42,46,47]}$. The as-spun thin film is usually in an intermediate phase formed by the complex or adduct of the perovskite solute and the solvent molecules ${ }^{[16}$, ${ }^{43}$. In the annealing process, the solvent molecules are evaporated by heat, converting the intermediate phase to perovskite crystals. Therefore, the physical properties of the solvents are critical for perovskite crystallization.

However, the one-step spin coating method with anti-solvent dripping is not applicable for coating large-area perovskite thin films. Recently, many alternative methods have been developed for coating large-area perovskite thin films, including blade $^{[48]}$, D-bar ${ }^{[5]}$, slot-die ${ }^{[49]}$, spray coating ${ }^{[50]}$, stamping ${ }^{[45]}$, and pressure process ${ }^{[51]}$. One common point shared by some of these methods is preparing the perovskite precursor solution through a methylamine (MA) gas-mediated solid-liquid transition. Such effect was first reported in an MA-gas-induced defect healing technique in $2015^{[52]}$. A solid perovskite film can be quickly converted to a liquid phase with the presence of MA gas. The liquid phase can return to the solid perovskite phase with a better crystalline quality once the MA gas atmosphere is removed. This technique has been applied to prepare the perovskite precursor solutions to fabricate large-scale PSCs ${ }^{[5,53]}$. 
Manufacturing solar panels based on the PSC technology requires further development of large-scale deposition methods, optimization of device structure, and a comprehensive strategy to improve device stability. Although various deposition methods have been developed for depositing high-quality perovskite thin films for PSCs, there is still a lack of comprehensive understanding of the relation between the perovskite thin film crystal structure and the PSC device performance. MA-gas-mediated solid-liquid transition provided alternative methods for depositing high-quality perovskite thin films without anti-solvent dripping. Here, we demonstrate the preparation of MA-gas-mediated $\mathrm{MAPbI}_{3}$ precursor solution in the ambient environment $\left(25^{\circ} \mathrm{C}, 50 \%\right.$ relative humidity). High-quality spin-coated $\mathrm{MAPbI}_{3}$ thin films showed a preferred (110) orientation in the crystal structure and larger crystal grains than the $\mathrm{MAPbI}_{3}$ films deposited by the Lewis adduct method ${ }^{[44]}$. Planar PSCs with a configuration of $\mathrm{FTO} / \mathrm{SnO}_{2} / \mathrm{MAPbI}_{3} /$ spiroOMeTAD/Au have been fabricated by both the MA-gas-mediated precursor and the Lewis adduct precursor. The PSC devices using the MA-gas-mediated precursor exhibited superior performance to the devices using the Lewis adduct method and achieved the maximum PCE of $19.28 \%$.

\subsection{Fabrication of perovskite solar cells}

\subsubsection{Chemicals}

The list of chemicals used in this project is shown in Table 5-1. 
Table 5-1 Details of chemicals used in the fabrication of perovskite solar cells.

\begin{tabular}{|l||l|}
\hline Lead (II) iodide & $99.999 \%$ trace metals basis, perovskite grade, Sigma-Aldrich \\
\hline \hline Methylamine solution & 40 wt. $\%$ in $\mathrm{H}_{2} \mathrm{O}$, Sigma-Aldrich \\
\hline \hline $\mathrm{SnO}_{2}$ colloidal dispersion & $15 \%$ in $\mathrm{H}_{2} \mathrm{O}$ colloidal dispersion, Alfa Aesar \\
\hline \hline Li-TFSI & $99.95 \%$ trace metals basis, Sigma-Aldrich \\
\hline \hline TBP & $98 \%$, Sigma-Aldrich \\
\hline \hline Ethanol & $99.5 \%$, ACS reagent, absolute, 200 proof, ACROS Organics \\
\hline \hline Diethyl ether & ACS reagent, anhydrous, ACROS Organics \\
\hline \hline DMF & Anhydrous, $99.8 \%$, Alfa Aesar \\
\hline \hline DMSO & Anhydrous, $\geq 99.9 \%$, Sigma-Aldrich \\
\hline \hline ACN & Anhydrous, $99.9 \%$, AcroSeal, ACROS Organic \\
\hline \hline CB & Anhydrous, $99.8 \%$, Sigma-Aldrich \\
\hline \hline GBL & ReagentPlus, $\geq 99.9 \%$, Sigma-Aldrich \\
\hline
\end{tabular}

\subsubsection{Deposition of $\mathrm{MAPbI}_{3}$ thin films by spin coating}

\subsubsection{Lewis adduct method}

The recipe for the $\mathrm{MAPbI}_{3} \cdot \mathrm{DMSO}$ precursor was based on the Lewis adduct method published by Park et al. ${ }^{[16]}$. Typically, $159 \mathrm{mg}$ MAI and $461 \mathrm{mg} \mathrm{PbI}_{2}$ were mixed in $633 \mu \mathrm{L}$ DMF and $70.8 \mu \mathrm{L}$ DMSO inside a $\mathrm{N}_{2}$-filled glovebox. The mixture was stirred for 2 hours for a clear, light yellow solution. The substrate was treated with UV-ozone for 10 min and used immediately. $45 \mu \mathrm{L} \mathrm{MAPbI}_{3} \cdot \mathrm{DMSO}$ precursor was cast onto the substrate and spin-coated at 4000 r.p.m. with a ramp of 2000 r.p.m. per second in the ambient environment. After the substrate had been spinning at 4000 r.p.m. for 10 s, 900 
$\mu \mathrm{L}$ diethyl ether was gently and continuously casted onto the substrate within $2 \mathrm{~s}$. The spinning substrate was stopped immediately, and a transparent, light green film was formed on top of the substrate. The substrate was then baked on a hot plate at $65{ }^{\circ} \mathrm{C}$ for 1 min and $90{ }^{\circ} \mathrm{C}$ for $2 \mathrm{~min}$. During the annealing process, the color of the deposited film quickly changed from light green to brown color after annealing at $65^{\circ} \mathrm{C}$ and then to a dark brown color after annealing at $90{ }^{\circ} \mathrm{C} . \mathrm{MAPbI}_{3}$ thin film deposited by this method will be referred to as ' $\mathrm{MAPbI}_{3}$ by Lewis adduct' in the following article.

\subsubsection{MA gas-assisted deposition method}

The $\mathrm{MAPbI}_{3} \cdot \mathrm{MA}_{\mathrm{x}}$ precursor solution in $\mathrm{ACN}$ was prepared in an ambient environment. Typically, $190.8 \mathrm{mg}$ MAI (1.2 mmol) and $553.2 \mathrm{mg}$ lead iodide (1.2 mmol) were mixed in $2 \mathrm{~mL}$ anhydrous $\mathrm{ACN}$ and stirred for $30 \mathrm{~min}$ to obtain a black suspension. To produce MA gas, Ar was bubbled at a flow rate of $40 \mathrm{sccm}$ into the methylamine solution in ethanol maintained at $0{ }^{\circ} \mathrm{C}$ by an ice bath. The produced MA gas was passed through drying tubes filled with drierite and calcium oxide powder, and then bubbled directly into the black $\mathrm{MAPbI}_{3} / \mathrm{ACN}$ suspension until the black perovskite precipitates were completely dissolved, resulting in a clear, transparent, light-yellow solution. After bubbling, the clear solution was filtered through a PTFE syringe filter ( 0.2 um pore size) and stored in a sealed vial before use.

$50 \mu \mathrm{L}$ precursor solution was cast onto the substrate and spin-coated at 2000 r.p.m. for $35 \mathrm{~s}$ with a ramp of 1000 r.p.m. per second in the ambient environment. Immediately after spin coating, a uniform, dense, and mirror-like brown perovskite thin film was deposited, and it was annealed on a hot plate at $90^{\circ} \mathrm{C}$ for 5 min. During the annealing

process, the substrate was covered by a glass petri dish, and dried MA/Ar gas was passed 
into the petri dish. $\mathrm{MAPbI}_{3}$ thin film deposited by this method will be referred to as ' $\mathrm{MAPbI}_{3}$ by $\mathrm{MAPbI}_{3} \cdot \mathrm{MA}_{\mathrm{x}}$ ' in the following article.

\subsubsection{Fabrication procedures for perovskite solar cells}

The substrates used for PSC are glass substrates $(15 \mathrm{~mm} \times 15 \mathrm{~mm})$ covered with FTO thin films. Pre-patterned FTO substrates (TEC-15) were obtained from Suzhou Solarflex Optoelectronic Technology Co., LTD. Only half the area on the front side of the substrate is covered with FTO, as shown in Figure 5-1 (A), and there is no coating on the backside of the substrate. The sheet resistance of the FTO layer is less than $15 \mathrm{Ohm}$ per square, and the thicknesses of glass and the FTO layer are $2.2 \mathrm{~mm}$ and $350 \mathrm{~nm}$, respectively. The average transmittance of the FTO substrates in the visible region is above $80 \%$.

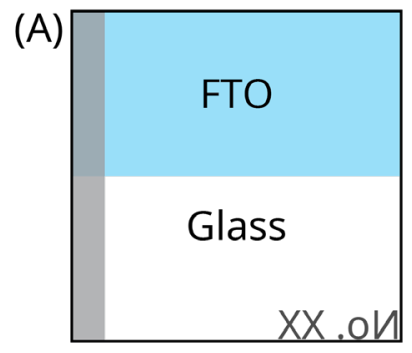

Front FTO side

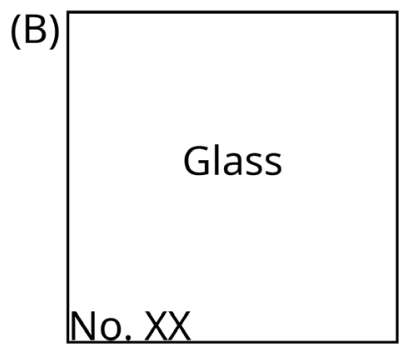

\section{Back} Glass side

Figure 5-1 Diagrams of the front (A) and back (B) side of the FTO substrates for PSCs. Only half of the front side, i.e., the blue area, of the substrate is covered with FTO. Notice that the label on the back of the substrate is flipped when observed from the front side.

Each substrate is labeled on the back with a diamond-tipped scribe before cleaning, as shown in Figure 5-1 (B). It should be emphasized that the label should be placed at a position that has no influence on the illumination over the FTO coated area on the front side, which serves as the back contact for PSC devices. The substrates were sequentially 
cleaned by ultra-sonication in soap water, deionized (DI) water, acetone, and ethanol for 15 min, respectively. The substrates were then dried at $70{ }^{\circ} \mathrm{C}$ for $10 \mathrm{~min}$.

The cleaned FTO substrate was treated by UV-Ozone for $20 \mathrm{~min}$ before depositing the ETL. $\mathrm{SnO}_{2}$ colloid precursor was diluted by deionized $\mathrm{H}_{2} \mathrm{O}$ to 8 wt. \% before use. The diluted $\mathrm{SnO}_{2}$ precursor solution was spin-coated onto the FTO substrate at 2000 r.p.m. for 30 s. Right after spin coating, a cotton swab rinsed with ethanol was used to wipe the edge of the substrate, which is shown as the grey area in Figure 5-1 (A). The substrate was then dried at $80^{\circ} \mathrm{C}$ for $10 \mathrm{~min}$, followed by annealing in air at $165^{\circ} \mathrm{C}$ for $30 \mathrm{~min}$.

After depositing the perovskite thin film by the methods described in Section 5.2.2, the HTL was deposited by spin coating. The precursor solution for the HTL was prepared inside a $\mathrm{N}_{2}$-filled glovebox by dissolving $72.3 \mathrm{mg}$ of spiro-OMeTAD, $28.8 \mu \mathrm{L}$ of TBP, and $17.5 \mu \mathrm{L}$ of Li-TFSI solution (520 mg Li-TFSI in $1 \mathrm{~mL}$ anhydrous $\mathrm{ACN}$ ) in $1 \mathrm{~mL}$ of anhydrous chlorobenzene. The HTL was deposited on top of the perovskite film by spin coating $55 \mu \mathrm{L}$ precursor solution at 4000 r.p.m. for $40 \mathrm{~s}$ in ambient. The sample was stored inside a desiccator with a relative humidity of $15 \%$ or less overnight for oxygen doping. Finally, a $150 \mathrm{~nm}$-thick gold counter electrode was deposited using an ebeam evaporator at a vacuum pressure of $3 \times 10^{-6}$ torr. The area of each solar cell device is $0.12 \mathrm{~cm}^{2}$.

\subsection{Characterization methods}

The morphology of the perovskite thin film, as well as the cross-section of the fabricated device, was observed by a field emission scanning electron microscope (FESEM, JEOL 6335F). An atomic force microscopy (AFM) in tapping mode (Veeco 
Multimode Nanoscope III D) was used to characterize the surface morphology and the height profile of the perovskite thin film. Optical absorption properties were characterized using a UV-Vis spectrometer (Agilent Cary 5000 UV-Vis-NIR spectrometer). Crystal structure analysis of the perovskite films was carried out by an X-ray diffractometer (Siemens D5000) with a $\mathrm{Cu} \mathrm{K \alpha}$ source $(\lambda=1.5406 \AA)$ at room temperature. The $\mathrm{J}-\mathrm{V}$ curve of the solar cell was measured using a source meter (Keithley 2400) under the AM1.5G condition from a solar simulator (Newport).

\subsection{Results and discussion}

The schematic illustration of the experimental setup to dissolve the precipitate in ACN using MA gas is shown in Figure 5-2(A). $\mathrm{PbI}_{2}$ and $\mathrm{MAPbI}_{3}$ have low solubility in acetonitrile at room temperature. As MA gas was being introduced and dissolved in acetonitrile, the undissolved $\mathrm{MAPbI}_{3}$ was gradually dissolved, revealing unreacted yellow cores of $\mathrm{PbI}_{2}$, which indicates the incomplete reaction between $\mathrm{PbI}_{2}$ and $\mathrm{MAI}$. Instead of being converted to perovskite first, the yellow $\mathrm{PbI}_{2}$ core was dissolved directly with the help of MA gas, which is in line with earlier reports that $\mathrm{CH}_{3} \mathrm{NH}_{2}$ molecule could interact with layered $\mathrm{PbI}_{2}$ crystals ${ }^{[51]}$. When all precipitate was dissolved, the final product was a clear, transparent, light yellow solution shown in Figure 5-2 (B). The reaction between $\mathrm{PbI}_{2}$ and $\mathrm{MA}$ in the presence of moisture would result in the formation of $\mathrm{PbO}$ and $\mathrm{Pb}(\mathrm{OH})_{2}$ [(Eq. 5-1) through (Eq. 5-3)]. Therefore, it is vital to ensure that the entire setup is tightly sealed and adequately purged to minimize the influence of moisture. Otherwise, moisture would lead to the white precipitate in a light-yellow solution shown in Figure 5-2 (C). 


$$
\begin{gathered}
3 \mathrm{PbI}_{2}+2 \mathrm{CH}_{3} \mathrm{NH}_{2}+\mathrm{H}_{2} \mathrm{O} \rightarrow 2 \mathrm{CH}_{3} \mathrm{NH}_{3} \mathrm{PbI}_{3}+\mathrm{PbO} \downarrow \\
\mathrm{CH}_{3} \mathrm{NH}_{2}+\mathrm{H}_{2} \mathrm{O} \rightarrow \mathrm{CH}_{3} \mathrm{NH}_{3} \mathrm{OH} \\
3 \mathrm{PbI}_{2}+2 \mathrm{CH}_{3} \mathrm{NH}_{3} \mathrm{OH} \rightarrow 2 \mathrm{CH}_{3} \mathrm{NH}_{3} \mathrm{PbI}_{3}+\mathrm{Pb}(\mathrm{OH})_{2} \downarrow
\end{gathered}
$$
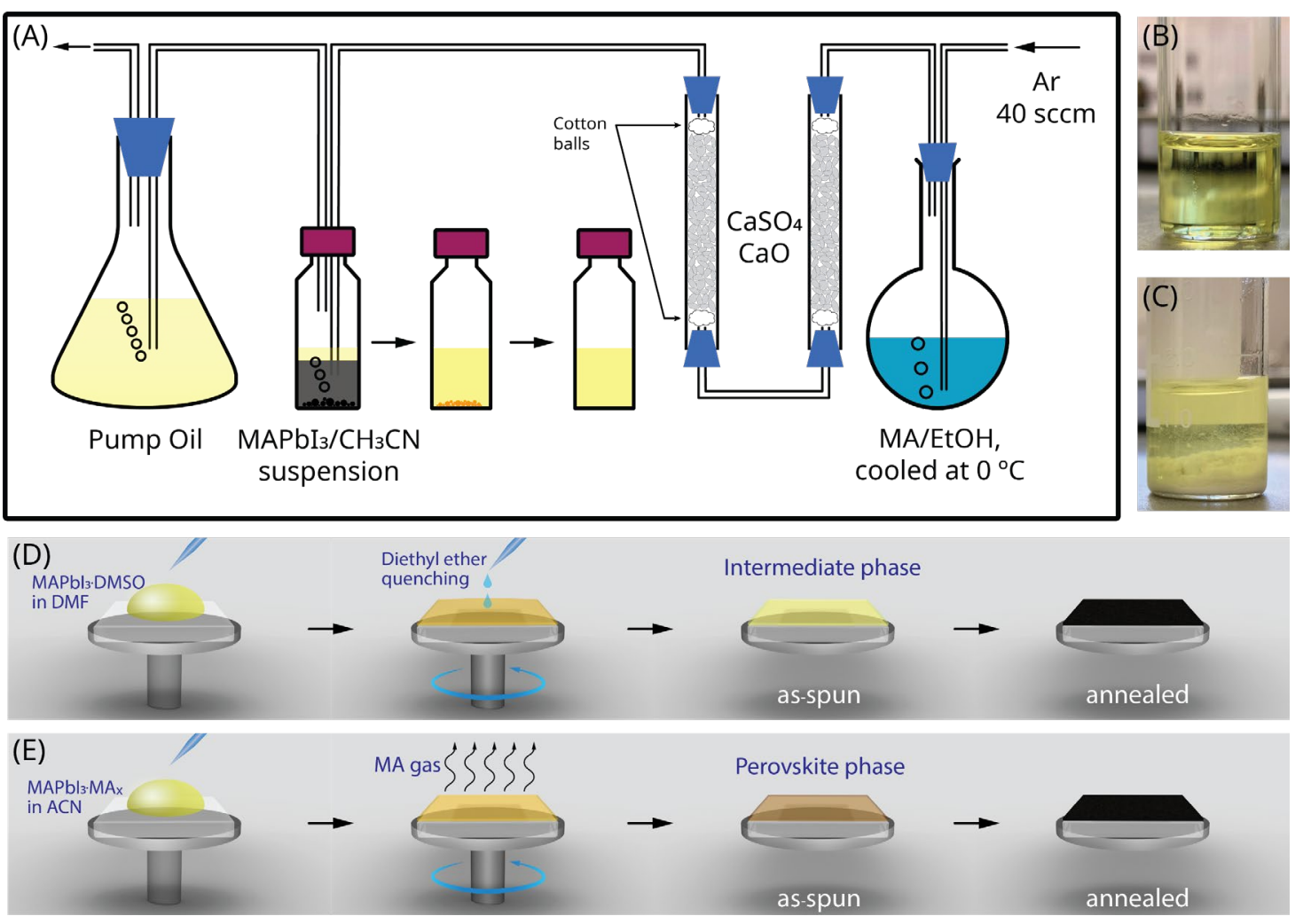

Figure 5-2 (A) Schematic illustration of the experimental setup to prepare the $\mathrm{MAPbI}_{3} \cdot \mathrm{MA}_{\mathrm{x}}$ precursor solution. (B) and (C): images of the $\mathrm{MAPbI}_{3} \cdot \mathrm{MA}_{\mathrm{x}}$ solutions prepared with and without moisture, respectively. (D) and (E): diagrams of the deposition procedures using the $\mathrm{MAPbI}_{3} \cdot \mathrm{DMSO}$ and the $\mathrm{MAPbI}_{3} \cdot \mathrm{MA}_{\mathrm{x}}$ precursor solutions, respectively.

Figure 5-2 (D) and (F) show the diagram of the deposition procedure using the $\mathrm{MAPbI}_{3} \cdot \mathrm{DMSO}$ Lewis adduct precursor and the $\mathrm{MAPbI}_{3} \cdot \mathrm{MA}_{\mathrm{x}}$ precursor, respectively. For the $\mathrm{MAPbI}_{3} \cdot \mathrm{DMSO}$ Lewis adduct precursor, the anti-solvent quenching process is crucial for depositing a dense and pin-hole free $\mathrm{MAPbI}_{3}$ thin film. The as-spun thin film is in an intermediate phase rather than the perovskite phase. When the as-spun thin film was heated, DMSO molecules were evaporated, converting the intermediate phase to the perovskite phase. For the $\mathrm{MAPbI}_{3} \cdot \mathrm{MA}_{\mathrm{x}}$ precursor, the spin coating procedure is much 
simplified as it does not require the antisolvent quenching process and is, therefore, more suitable for depositing large-scale perovskite thin films than that of the $\mathrm{MAPbI}_{3} \cdot \mathrm{DMSO}$ precursor. Moreover, the as-spun thin film is composed of $\mathrm{MAPbI}_{3}$ crystals for the MA molecules were evaporated during the spin coating process.

\subsubsection{Surface morphology and optical absorption of $M_{A P b} I_{3}$ thin films}

The surface morphology of the $\mathrm{MAPbI}_{3}$ thin films were characterized by SEM and AFM, as shown in Figure 5-3(A) through (D). Both the SEM and AFM topography images indicate the formation of highly crystalline, dense, and pinhole-free $\mathrm{MAPbI}_{3}$ thin films deposited by both methods. The 3D views implied that $\mathrm{MAPbI}_{3}$ thin film deposited by $\mathrm{MAPbI}_{3} \cdot \mathrm{MA}_{\mathrm{x}}$ precursor solution [Figure 5-3 $\left.(\mathrm{F})\right]$ had a smaller surface roughness than that deposited by Lewis adduct precursor solution [Figure 5-3 (E)]. The root mean square (RMS) roughness $\left(R_{q}\right)$ was calculated for both samples. $\mathrm{MAPbI}_{3}$ thin film by Lewis adduct had a $R_{q}$ of $17.7 \mathrm{~nm}$, while $\mathrm{MAPbI}_{3}$ thin film by $\mathrm{MAPbI}_{3} \cdot \mathrm{MA}_{\mathrm{x}}$ had a $R_{q}$ of 9.4 nm, a nearly $50 \%$ reduction.

The diameters of the crystal grains were measured as the maximum horizontal sizes of the crystal grains in the SEM images and displayed as histograms in Figure 5-3 $(\mathrm{G})$ and $(\mathrm{H})$. The histograms were fitted to the Gamma distribution model, which are shown as the solid blue and red curves in Figure 5-3 (G) and (H), respectively. Both the histograms and the distribution curves revealed that the $\mathrm{MAPbI}_{3}$ film prepared by the $\mathrm{MAPbI} \cdot \mathrm{MA}_{\mathrm{x}}$ precursor had larger crystal grains than that prepared by the Lewis-adduct precursor. The average diameter of crystal grains in the $\mathrm{MAPbI}_{3}$ film by the 
$\mathrm{MAPbI}_{3} \cdot \mathrm{MA}_{\mathrm{x}}$ precursor was $433 \mathrm{~nm}$, whereas the average diameter of crystal grains in the $\mathrm{MAPbI}_{3}$ film by the Lewis-adduct precursor was only $221 \mathrm{~nm}$.
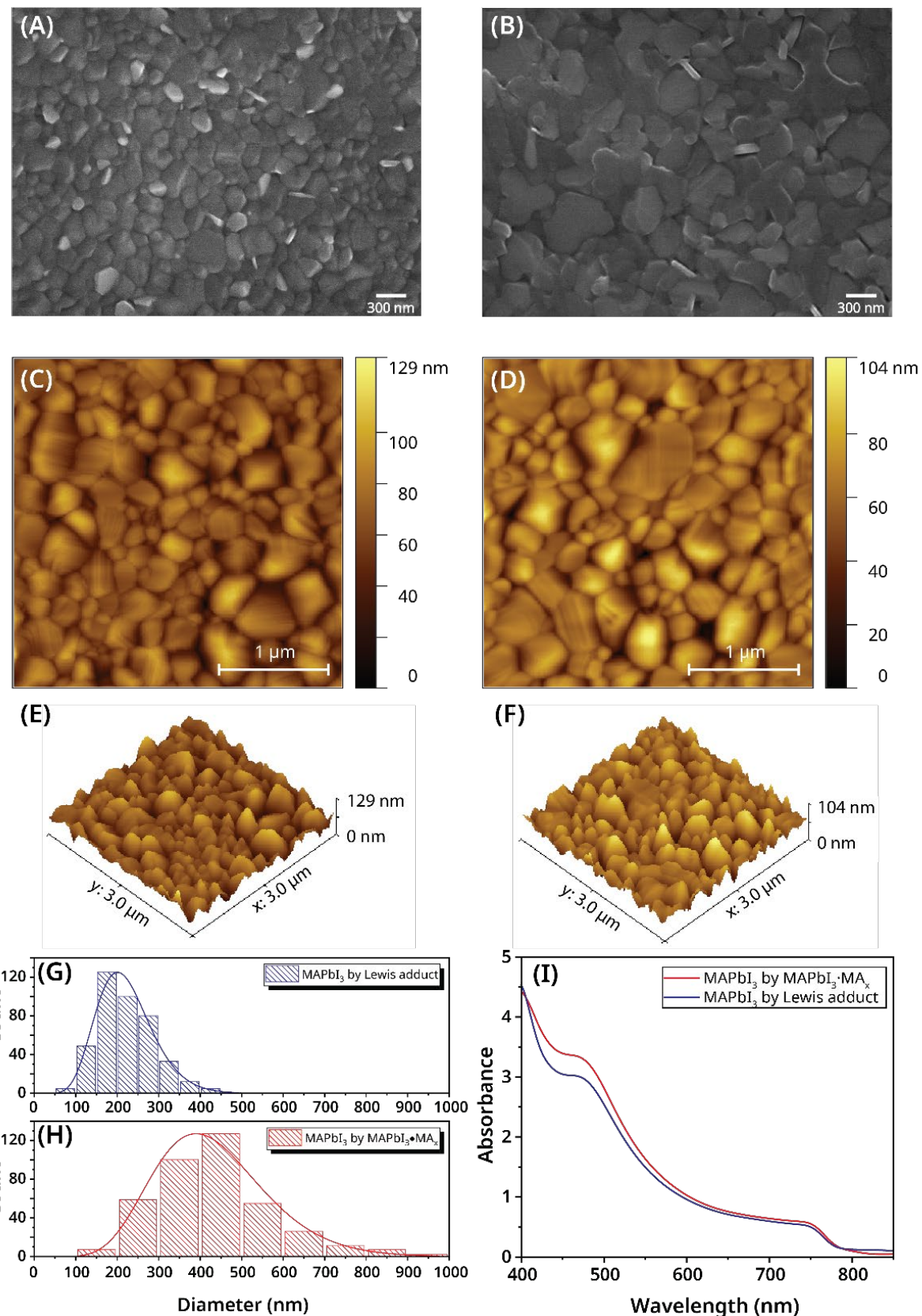

Figure 5-3 SEM images of $\mathrm{MAPbI}_{3}$ by Lewis adduct $(\mathrm{A})$ and $\mathrm{MAPbI}_{3}$ by $\mathrm{MAPbI}_{3} \cdot \mathrm{MA}_{\mathrm{x}}(\mathrm{B})$. AFM topography images of $\mathrm{MAPbI}_{3}$ by Lewis adduct $(\mathrm{C})$ and $\mathrm{MAPbI}_{3}$ by $\mathrm{MAPbI}_{3} \cdot \mathrm{MA}_{\mathrm{x}}(\mathrm{D})$ and the corresponding 3d views in (E) and (F). Diameter distribution of crystal grains measured in the SEM images of $\mathrm{MAPbI}_{3}$ by Lewis adduct $(\mathrm{G})$ and $\mathrm{MAPbI}_{3}$ by $\mathrm{MAPbI}_{3} \cdot \mathrm{MA}_{\mathrm{x}}(\mathrm{H})$. (I) Optical absorption spectra of $\mathrm{MAPbI}_{3}$ by Lewis adduct and $\mathrm{MAPbI}_{3}$ by $\mathrm{MAPbI}_{3} \cdot \mathrm{MA}_{\mathrm{x}}$.

Figure 5-3 (I) shows the optical absorption spectra for $\mathrm{MAPbI}_{3}$ thin film by both

precursors. Both samples showed high absorbance in the visible wavelength range with 
clear absorption onsets. The slight absorbance difference across the range of 400 to 750 $\mathrm{nm}$ between the two samples was likely attributed to the slight difference in thin film thicknesses. $\mathrm{MAPbI}_{3}$ by $\mathrm{MAPbI}_{3} \cdot \mathrm{MA}_{\mathrm{x}}$ showed less absorption in the range beyond the absorption onset compared to $\mathrm{MAPbI}_{3}$ by Lewis adduct, which is in line with the surface roughness measured by AFM.

\subsubsection{Crystal structures of $\mathrm{MAPbI}_{3}$ thin films}

Crystal structure analysis of thin films deposited on top of $\mathrm{SnO}_{2}$-coated FTO substrates by both methods was carried out by X-ray diffraction (XRD) spectra. XRD pattern of $\mathrm{MAPbI}_{3}$ thin film by Lewis adduct is shown in Figure 5-4 (A). The positions

of the peaks were measured and checked with previous reports ${ }^{[46,54]}$ to label each peak with the corresponding miller index, which specified a tetragonal $(I 4 / \mathrm{mcm})$ crystal structure for $\mathrm{MAPbI}_{3}$ thin film deposited by the Lewis adduct precursor. Multiple peaks, including (110), (114), (321), (312), and (121), were observed, suggesting that $\mathrm{MAPbI}_{3}$ thin film deposited by the Lewis adduct precursor solution did not show any preferential orientation.

To study the crystal structure of $\mathrm{MAPbI}_{3}$ thin films by $\mathrm{MAPbI}_{3} \cdot \mathrm{MAx}_{\mathrm{x}}, \mathrm{XRD}$ spectra of as-spun $\mathrm{MAPbI}_{3}$ thin film, $\mathrm{MAPb}_{3}$ thin film baked in air, and $\mathrm{MAPbI}_{3}$ thin film baked in air with MA gas were measured and displayed in Figure 5-4 (B), (C), and (D), respectively. All three $\mathrm{MAPbI}_{3}$ thin films exhibited the same tetragonal phase structure as the $\mathrm{MAPbI}_{3}$ thin film deposited by the Lewis adduct method. However, compared to $\mathrm{MAPbI}_{3}$ thin films by the Lewis adduct method, $\mathrm{MAPbI}_{3}$ thin films by $\mathrm{MAPbI}_{3} \cdot \mathrm{MA}_{\mathrm{x}}$ showed tremendously stronger (110) and (220) peaks over other peaks even before annealing. Moreover, the heights and intensities of the (110) and (220) peaks were 
further enhanced by the annealing process, as shown in Figure 5-4 (C) and (D). The full widths at half maximum (FWHMs) of (110) and (220) peaks in Figure 5-4 (A) through (D) were measured and plotted in Figure 5-4 (E). The comparison between FWHMs of the (110) and (220) peaks of three $\mathrm{MAPbI}_{3}$ thin films deposited by $\mathrm{MAPbI}_{3} \cdot \mathrm{MA}_{\mathrm{x}}$ precursor clearly indicates that the MA gas atmosphere helps to reduce the FWHMs of (110) and (220) peaks and increase crystallinity. Comparing with FWHMs of the (110) peak of $\mathrm{MAPbI}_{3}$ thin film by the Lewis adduct method, the (110) peak of $\mathrm{MAPbI}_{3}$ thin film deposited by $\mathrm{MAPbI}_{3} \cdot \mathrm{MA}_{\mathrm{x}}$ and annealed in air with $\mathrm{MA}$ gas exhibited a smaller FWHM. It is clear that $\mathrm{MAPbI}_{3}$ thin film deposited by $\mathrm{MAPbI}_{3} \cdot \mathrm{MA}_{x}$ exhibited higher crystallinity and a preferred crystal orientation in the (110) direction that was also observed in defective $\mathrm{MAPbI}_{3}$ thin films healed by MA gas treatment ${ }^{[52,55,56]}$.

XRD spectra of $\mathrm{MAPbI}_{3}$ films deposited by filtered (by a PTFE syringe filter with a pore size of $0.2 \mathrm{um}$ ) and unfiltered $\mathrm{MAPbI}_{3} \cdot \mathrm{MA}_{\mathrm{x}}$ precursor solutions were measured and shown in Figure 5-4 (F). The XRD patterns depict that $\mathrm{MAPbI}_{3}$ deposited by the unfiltered $\mathrm{MAPbI}_{3} \cdot \mathrm{MA}_{\mathrm{x}}$ precursor showed stronger and sharper (110) and (220) peaks, hence stronger crystal orientation preference in the (110) direction. Park et al. ${ }^{[5]}$ suggested that the cluster-like $\mathrm{MAPbI}_{3}$ nanocrystals (NCs) existed in the $\mathrm{MAPbI}_{3} \cdot \mathrm{MA}_{\mathrm{x}}$ precursor solution. Acting as the seed crystals, these clusters played a crucial role in initiating and facilitating $\mathrm{MAPbI}_{3}$ nucleation during the spin coating process. Unfiltered $\mathrm{MAPbI}_{3} \cdot \mathrm{MA}_{\mathrm{x}}$ precursor contained more seeds, especially larger seeds, for nucleation, potentially explaining the more preferred (110) orientation. The preferred orientation mechanism is not fully understood yet, and more experiments are needed to investigate it further. 

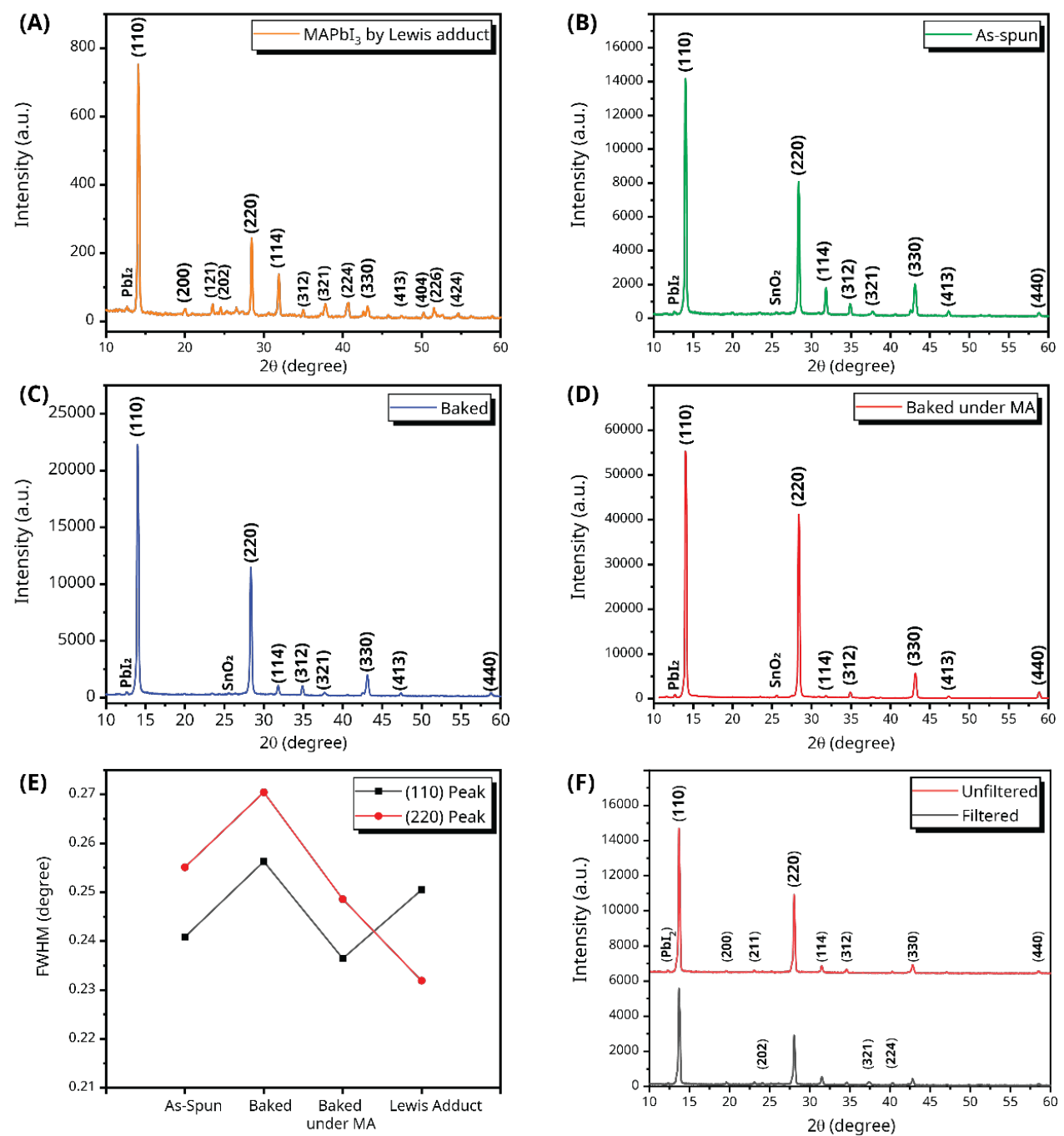

Figure 5-4 XRD spectra of (A) $\mathrm{MAPbI}_{3}$ by Lewis adduct, (B) as-spun $\mathrm{MAPbI}_{3}$ thin film by $\mathrm{MAPbI}_{3} \cdot \mathrm{MA}_{x},(\mathrm{C}) \mathrm{MAPbI}_{3}$ by $\mathrm{MAPbI}_{3} \cdot \mathrm{MA}_{\mathrm{x}}$ baked in Ar-enriched environment, and (D) $\mathrm{MAPbI}_{3}$ by $\mathrm{MAPbI}_{3} \cdot \mathrm{MA}_{\mathrm{x}}$ baked in MA-gas-enriched environment. (E) full widths at half maximum (FWHMs) of (110) peak (solid red line) and (220) peak (solid black line), and the ratio of integrated peak intensity of (110) vs. (220) peak (blue dash line) of XRD spectra in (A) to (D). (F) spectra of the $\mathrm{MAPbI}_{3}$ thin film deposited by filtered and unfiltered $\mathrm{MAPbI}_{3} \cdot \mathrm{MA}_{\mathrm{x}}$ precursor solutions.

\subsubsection{Performances of the perovskite solar cells}

The cross-sectional SEM of the assembled PSC device and the device structure diagram are shown in Figure 5-5 (A). The cross-sectional SEM shows a clear layer-bylayer structure sandwiching a $\mathrm{MAPbI}_{3}$ layer with a thickness of about $370 \mathrm{~nm}$, which lies between the average crystal grain sizes of the thin film deposited by the Lewis adduct 
precursor and that deposited by the $\mathrm{MAPbI}_{3} \cdot \mathrm{MA}_{\mathrm{x}}$ precursor. Figure 5-5 (B) shows the J$\mathrm{V}$ curves of PSC devices using the Lewis adduct precursor and the $\mathrm{MAPbI}_{3} \cdot \mathrm{MA}_{\mathrm{x}}$ precursor. It is clear that the device fabricated by the $\mathrm{MAPbI}_{3} \cdot \mathrm{MA}_{\mathrm{x}}$ precursor had higher $\mathrm{V}_{\mathrm{OC}}$ and $\mathrm{J}_{\mathrm{SC}}$ compared to the device by the Lewis adduct precursor. The highest PCE for the PSC device by the $\mathrm{MAPbI}_{3} \cdot \mathrm{MA}_{x}$ precursor was observed in reverse scan, providing $V o c=1.073 \mathrm{~V}, J_{s c}=24.169 \mathrm{~mA} / \mathrm{cm}^{2}, F F=74.37 \%$, and $P C E=19.28 \%$, shown as the solid black line in Figure 5-5 (B). PSC device by the Lewis adduct precursor showed $V o c=1.020 \mathrm{~V}, J_{s c}=23.421 \mathrm{~mA} / \mathrm{cm}^{2}, F F=76.09 \%$, and $P C E=$ 18.17\%, shown as the dashed black line in Figure 5-5 (B). For both devices, the hysteresis effect was observed between the forward- and reverse-scanned J-V curves, with smaller $\mathrm{V}_{\mathrm{OC}}$ and $\mathrm{J}_{\mathrm{SC}}$ obtained from the forward scan.

A comparison of PCEs involving a total of 64 PSC devices fabricated side-byside using the Lewis adduct precursor and the $\mathrm{MAPbI}_{3} \cdot \mathrm{MA}_{\mathrm{x}}$ precursor was conducted. For the devices fabricated by the Lewis adduct precursor, the histogram of PCEs is shown in Figure 5-5 (C) and fitted with the Gaussian distribution model. For the devices fabricated by the $\mathrm{MAPbI}_{3} \cdot \mathrm{MA}_{\mathrm{x}}$ precursor, the histogram of PCEs is shown in Figure 5-5 (D) and fitted with the Weibull distribution model. The statistical result showed clearly that PSC devices by the $\mathrm{MAPbI}_{3} \cdot \mathrm{MA}$ x precursor had a higher average PCE and a smaller deviation $(16.28 \pm 2.38 \%)$ than those devices by the Lewis adduct precursor $(12.59 \pm$ 4.01\%). After measuring $320 \mathrm{PSC}$ devices by the $\mathrm{MAPbI}_{3} \cdot \mathrm{MA}_{\mathrm{x}}$ precursor, the histogram of the PCEs of these devices was plotted and displayed in Figure 5-5 (E) and fitted to a Weibull distribution model. The average PCE of all 320 devices fabricated by the $\mathrm{MAPbI} \cdot \mathrm{MA}_{\mathrm{x}}$ precursor was $14.08 \pm 2.73 \%$. 
(A)

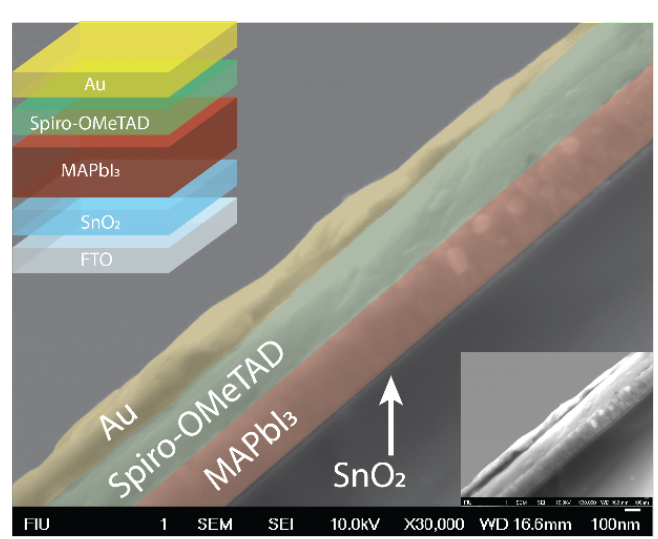

(C)

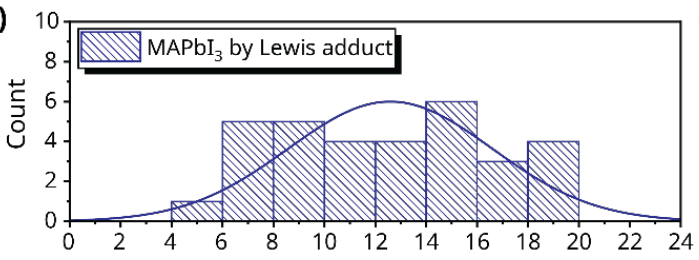

(D)

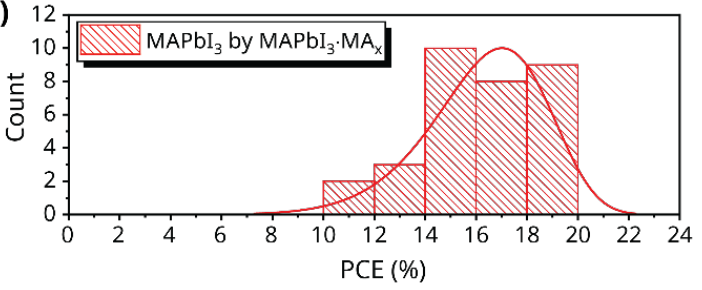

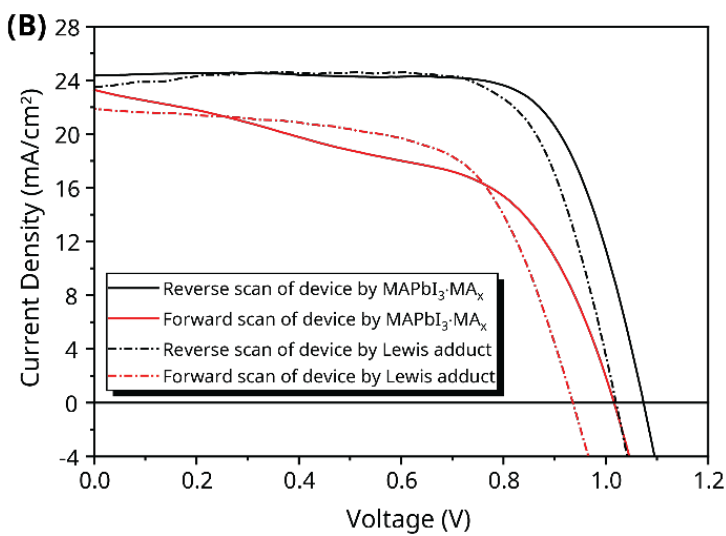

(E) 1

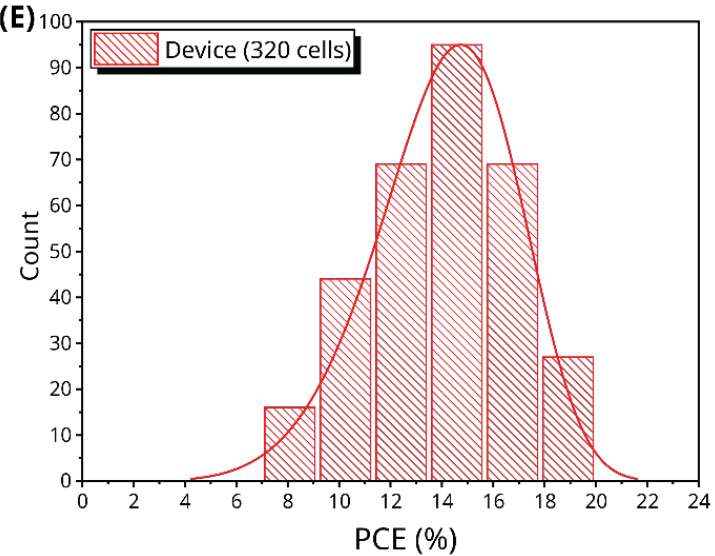

Figure 5-5 (A) Cross-section SEM and schematic illustration of the device structure. Au, spiroOMeTAD, and $\mathrm{MAPbI}_{3}$ layers were labeled by gold, green and red colors, respectively. The small inset on the bottom right corner is the original SEM image. (B) Forward- and reverse-scanned J$\mathrm{V}$ curves of PSC by the Lewis adduct precursor and the $\mathrm{MAPbI}_{3} \cdot \mathrm{MA}_{\mathrm{x}}$ precursor. (C) and (D): histograms and distribution curves of the PCEs of devices by the Lewis adduct precursor and the $\mathrm{MAPbI}_{3} \cdot \mathrm{MA}_{\mathrm{x}}$ precursor. (E) histogram of PCEs of 320 devices by the $\mathrm{MAPbI}_{3} \cdot \mathrm{MA}_{\mathrm{x}}$ precursor.

\subsection{Summary}

MA-gas-mediated $\mathrm{MAPbI}_{3} \cdot \mathrm{MA}_{\mathrm{x}}$ precursor solution was prepared in the ambient environment, and high-quality $\mathrm{MAPbI}_{3}$ thin films was achieved by spin-coating the $\mathrm{MAPbI}_{3} \cdot \mathrm{MA}_{\mathrm{x}}$ precursor with high reproducibility. Compared to films deposited by the Lewis adduct method, perovskite films deposited by the $\mathrm{MAPbI}_{3} \cdot \mathrm{MA}_{\mathrm{x}}$ precursor showed much-reduced surface roughness, enlarged crystal grains, and preferred crystal orientation in the (110) direction. The preferred crystal orientation was further enhanced by annealing the as-deposited films in a MA gas atmosphere. Planar PSCs with a 
configuration of $\mathrm{FTO} / \mathrm{SnO}_{2} / \mathrm{MAPbI}_{3} / \mathrm{spiro}-\mathrm{OMeTAD} / \mathrm{Au}$ have been fabricated using both the $\mathrm{MAPbI}_{3} \cdot \mathrm{MA}_{\mathrm{x}}$ precursor and the Lewis adduct precursor. Devices made by the $\mathrm{MAPbI}_{3} \cdot \mathrm{MA}_{\mathrm{x}}$ precursor exhibited superior performance to the devices made by the Lewis adduct method. Comparing the two types of devices fabricated in the same batch, the average PCEs of the devices by the $\mathrm{MAPbI}_{3} \cdot \mathrm{MA}_{\mathrm{x}}$ precursor and the Lewis adduct precursor were $16.28 \%$ vs. $12.59 \%$, respectively. The maximum and average PCEs of the PSCs by the $\mathrm{MAPbI}_{3} \cdot \mathrm{MA}_{\mathrm{x}}$ precursor was $19.28 \%$ and $14.08 \%$.

\subsection{References}

1. $\quad$ Kim, H. S.; Lee, C. R.; Im, J. H.; Lee, K. B.; Moehl, T.; Marchioro, A.; Moon, S. J.; Humphry-Baker, R.; Yum, J. H.; Moser, J. E.; Gratzel, M.; Park, N. G., Lead iodide perovskite sensitized all-solid-state submicron thin film mesoscopic solar cell with efficiency exceeding 9\%. Sci Rep 2012, 2, 591.

2. $\quad$ Lee, M. M.; Teuscher, J.; Miyasaka, T.; Murakami, T. N.; Snaith, H. J., Efficient hybrid solar cells based on meso-superstructured organometal halide perovskites. Science 2012, 338 (6107), 643-7.

3. Xiao, Z.; Dong, Q.; Bi, C.; Shao, Y.; Yuan, Y.; Huang, J., Solvent annealing of perovskite-induced crystal growth for photovoltaic-device efficiency enhancement. Adv Mater 2014, 26 (37), 6503-9.

4. Yang, W. S.; Noh, J. H.; Jeon, N. J.; Kim, Y. C.; Ryu, S.; Seo, J.; Seok, S. I., SOLAR CELLS. High-performance photovoltaic perovskite layers fabricated through intramolecular exchange. Science 2015, 348 (6240), 1234-7.

5. Jeong, D.-N.; Lee, D.-K.; Seo, S.; Lim, S. Y.; Zhang, Y.; Shin, H.; Cheong, H.; Park, N.-G., Perovskite Cluster-Containing Solution for Scalable D-Bar Coating toward High-Throughput Perovskite Solar Cells. ACS Energy Letters 2019, 4 (5), 11891195.

6. Kojima, A.; Teshima, K.; Shirai, Y.; Miyasaka, T., Organometal halide perovskites as visible-light sensitizers for photovoltaic cells. J Am Chem Soc 2009, 131 (17), 6050-1. 
7. Best Research-Cell Efficiencies. National Renewable Energy Laboratory: https://www.nrel.gov/pv/assets/pdfs/best-research-cell-efficiencies.20200803.pdf, 2020.

8. $\quad$ Lee, J. W.; Seol, D. J.; Cho, A. N.; Park, N. G., High-efficiency perovskite solar cells based on the black polymorph of $\mathrm{HC}(\mathrm{NH} 2) 2 \mathrm{PbI} 3$. Adv Mater 2014, 26 (29), 4991-8.

9. $\quad$ Jeon, N. J.; Noh, J. H.; Yang, W. S.; Kim, Y. C.; Ryu, S.; Seo, J.; Seok, S. I., Compositional engineering of perovskite materials for high-performance solar cells. Nature 2015, 517 (7535), 476-80.

10. Turren-Cruz, S.-H.; Hagfeldt, A.; Saliba, M., Methylammonium-free, highperformance, and stable perovskite solar cells on a planar architecture. Science 2018, 362 (6413), 449-453.

11. Correa-Baena, J.-P.; Luo, Y.; Brenner, T. M.; Snaider, J.; Sun, S.; Li, X.; Jensen, M. A.; Hartono, N. T. P.; Nienhaus, L.; Wieghold, S.; Poindexter, J. R.; Wang, S.; Meng, Y. S.; Wang, T.; Lai, B.; Holt, M. V.; Cai, Z.; Bawendi, M. G.; Huang, L.; Buonassisi, T.; Fenning, D. P., Homogenized halides and alkali cation segregation in alloyed organic-inorganic perovskites. Science 2019, 363 (6427), 627631.

12. Qiu, L.; He, S.; Jiang, Y.; Son, D.-Y.; Ono, L. K.; Liu, Z.; Kim, T.; Bouloumis, T.; Kazaoui, S.; Qi, Y., Hybrid chemical vapor deposition enables scalable and stable Cs-FA mixed cation perovskite solar modules with a designated area of 91.8 cm2 approaching 10\% efficiency. Journal of Materials Chemistry A 2019, 7 (12), 69206929.

13. Parvazian, E.; Abdollah-zadeh, A.; Dehghani, M.; Taghavinia, N., Photovoltaic Performance Improvement in Vacuum-Assisted Meniscus Printed Triple-Cation MixedHalide Perovskite Films by Surfactant Engineering. ACS Applied Energy Materials 2019, 2 (9), 6209-6217.

14. Tong, J.; Song, Z.; Kim, D. H.; Chen, X.; Chen, C.; Palmstrom, A. F.; Ndione, P. F.; Reese, M. O.; Dunfield, S. P.; Reid, O. G.; Liu, J.; Zhang, F.; Harvey, S. P.; Li, Z.; Christensen, S. T.; Teeter, G.; Zhao, D.; Al-Jassim, M. M.; van Hest, M. F. A. M.; Beard, M. C.; Shaheen, S. E.; Berry, J. J.; Yan, Y.; Zhu, K., Carrier lifetimes of \&gt; $1 \mu$ in $\mathrm{Sn}-\mathrm{Pb}$ perovskites enable efficient all-perovskite tandem solar cells. Science 2019, 364 (6439), 475-479. 
15. Jung, J. W.; Williams, S. T.; Jen, A. K. Y., Low-temperature processed highperformance flexible perovskite solar cells via rationally optimized solvent washing treatments. RSC Adv. 2014, 4 (108), 62971-62977.

16. Ahn, N.; Son, D. Y.; Jang, I. H.; Kang, S. M.; Choi, M.; Park, N. G., Highly Reproducible Perovskite Solar Cells with Average Efficiency of $18.3 \%$ and Best Efficiency of 19.7\% Fabricated via Lewis Base Adduct of Lead(II) Iodide. $J$ Am Chem Soc 2015, 137 (27), 8696-9.

17. Bi, C.; Wang, Q.; Shao, Y.; Yuan, Y.; Xiao, Z.; Huang, J., Non-wetting surface-driven high-aspect-ratio crystalline grain growth for efficient hybrid perovskite solar cells. Nat Commun 2015, 6, 7747.

18. Nie, W.; Tsai, H.; Asadpour, R.; Blancon, J. C.; Neukirch, A. J.; Gupta, G.; Crochet, J. J.; Chhowalla, M.; Tretiak, S.; Alam, M. A.; Wang, H. L.; Mohite, A. D., Solar cells. High-efficiency solution-processed perovskite solar cells with millimeterscale grains. Science 2015, 347 (6221), 522-5.

19. Rong, Y.; Tang, Z.; Zhao, Y.; Zhong, X.; Venkatesan, S.; Graham, H.; Patton, M.; Jing, Y.; Guloy, A. M.; Yao, Y., Solvent engineering towards controlled grain growth in perovskite planar heterojunction solar cells. Nanoscale 2015, 7 (24), 10595-10599.

20. Xue, J.; Wang, R.; Yang, Y., The surface of halide perovskites from nano to bulk. Nature Reviews Materials 2020.

21. Yang, B.; Dyck, O.; Poplawsky, J.; Keum, J.; Puretzky, A.; Das, S.; Ivanov, I.; Rouleau, C.; Duscher, G.; Geohegan, D.; Xiao, K., Perovskite Solar Cells with Near 100\% Internal Quantum Efficiency Based on Large Single Crystalline Grains and Vertical Bulk Heterojunctions. J Am Chem Soc 2015, 137 (29), 9210-3.

22. Dunlap-Shohl, W. A.; Zhou, Y.; Padture, N. P.; Mitzi, D. B., Synthetic Approaches for Halide Perovskite Thin Films. Chemical Reviews 2019, 119 (5), 31933295.

23. Zhou, H.; Chen, Q.; Li, G.; Luo, S.; Song, T. B.; Duan, H. S.; Hong, Z.; You, J.; Liu, Y.; Yang, Y., Photovoltaics. Interface engineering of highly efficient perovskite solar cells. Science 2014, 345 (6196), 542-6. 
24. Jiang, Q.; Zhao, Y.; Zhang, X.; Yang, X.; Chen, Y.; Chu, Z.; Ye, Q.; Li, X.; Yin, Z.; You, J., Surface passivation of perovskite film for efficient solar cells. Nature Photonics 2019, 13 (7), 460-466.

25. Tan, H.; Jain, A.; Voznyy, O.; Lan, X.; Garcia de Arquer, F. P.; Fan, J. Z.; Quintero-Bermudez, R.; Yuan, M.; Zhang, B.; Zhao, Y.; Fan, F.; Li, P.; Quan, L. N.; Zhao, Y.; Lu, Z. H.; Yang, Z.; Hoogland, S.; Sargent, E. H., Efficient and stable solution-processed planar perovskite solar cells via contact passivation. Science 2017, 355 (6326), 722-726.

26. Li, W.; Zhang, W.; Van Reenen, S.; Sutton, R. J.; Fan, J.; Haghighirad, A. A.; Johnston, M. B.; Wang, L.; Snaith, H. J., Enhanced UV-light stability of planar heterojunction perovskite solar cells with cesium bromide interface modification. Energy \& Environmental Science 2016, 9 (2), 490-498.

27. Shao, Y.; Xiao, Z.; Bi, C.; Yuan, Y.; Huang, J., Origin and elimination of photocurrent hysteresis by fullerene passivation in $\mathrm{CH} 3 \mathrm{NH} 3 \mathrm{PbI} 3$ planar heterojunction solar cells. Nat Commun 2014, 5, 5784.

28. Chen, W.; Wu, Y.; Yue, Y.; Liu, J.; Zhang, W.; Yang, X.; Chen, H.; Bi, E.; Ashraful, I.; Gratzel, M.; Han, L., Efficient and stable large-area perovskite solar cells with inorganic charge extraction layers. Science 2015, 350 (6263), 944-8.

29. Jiang, Q.; Zhang, X.; You, J., SnO2 : A Wonderful Electron Transport Layer for Perovskite Solar Cells. Small 2018, 14 (31), e1801154.

30. Yang, M.; Kim, D. H.; Klein, T. R.; Li, Z.; Reese, M. O.; Tremolet de Villers, B. J.; Berry, J. J.; van Hest, M. F. A. M.; Zhu, K., Highly Efficient Perovskite Solar Modules by Scalable Fabrication and Interconnection Optimization. ACS Energy Letters 2018, 3 (2), 322-328.

31. Cui, P.; Wei, D.; Ji, J.; Huang, H.; Jia, E.; Dou, S.; Wang, T.; Wang, W.; Li, M., Planar $\mathrm{p}-\mathrm{n}$ homojunction perovskite solar cells with efficiency exceeding $21.3 \%$. Nature Energy 2019, 4 (2), 150-159.

32. Jung, E. H.; Jeon, N. J.; Park, E. Y.; Moon, C. S.; Shin, T. J.; Yang, T.-Y.; Noh, J. H.; Seo, J., Efficient, stable and scalable perovskite solar cells using poly(3hexylthiophene). Nature 2019, 567 (7749), 511-515. 
33. De Wolf, S.; Holovsky, J.; Moon, S.-J.; Löper, P.; Niesen, B.; Ledinsky, M.; Haug, F.-J.; Yum, J.-H.; Ballif, C., Organometallic Halide Perovskites: Sharp Optical Absorption Edge and Its Relation to Photovoltaic Performance. The Journal of Physical Chemistry Letters 2014, 5 (6), 1035-1039.

34. Stoumpos, C. C.; Malliakas, C. D.; Kanatzidis, M. G., Semiconducting tin and lead iodide perovskites with organic cations: phase transitions, high mobilities, and near-infrared photoluminescent properties. Inorg Chem 2013, 52 (15), 9019-38.

35. Rehman, W.; Milot, R. L.; Eperon, G. E.; Wehrenfennig, C.; Boland, J. L.; Snaith, H. J.; Johnston, M. B.; Herz, L. M., Charge-Carrier Dynamics and Mobilities in Formamidinium Lead Mixed-Halide Perovskites. Adv Mater 2015, 27 (48), 7938-44.

36. Xing, G.; Mathews, N.; Sun, S.; Lim, S. S.; Lam, Y. M.; Gratzel, M.; Mhaisalkar, S.; Sum, T. C., Long-range balanced electron- and hole-transport lengths in organic-inorganic CH3NH3PbI3. Science 2013, 342 (6156), 344-7.

37. Stranks, S. D.; Eperon, G. E.; Grancini, G.; Menelaou, C.; Alcocer, M. J.; Leijtens, T.; Herz, L. M.; Petrozza, A.; Snaith, H. J., Electron-hole diffusion lengths exceeding 1 micrometer in an organometal trihalide perovskite absorber. Science 2013, 342 (6156), 341-4.

38. Noh, J. H.; Im, S. H.; Heo, J. H.; Mandal, T. N.; Seok, S. I., Chemical management for colorful, efficient, and stable inorganic-organic hybrid nanostructured solar cells. Nano Lett 2013, 13 (4), 1764-9.

39. Eperon, G. E.; Stranks, S. D.; Menelaou, C.; Johnston, M. B.; Herz, L. M.; Snaith, H. J., Formamidinium lead trihalide: a broadly tunable perovskite for efficient planar heterojunction solar cells. Energy \& Environmental Science 2014, 7 (3), 982988.

40. Li, Z.; Klein, T. R.; Kim, D. H.; Yang, M.; Berry, J. J.; van Hest, M. F. A. M.; Zhu, K., Scalable fabrication of perovskite solar cells. Nature Reviews Materials 2018, 3 (4), 18017.

41. Park, N.-G.; Zhu, K., Scalable fabrication and coating methods for perovskite solar cells and solar modules. Nature Reviews Materials 2020, 5 (5), 333-350.

42. Zhao, P.; Kim, B. J.; Ren, X.; Lee, D. G.; Bang, G. J.; Jeon, J. B.; Kim, W. B.; Jung, H. S., Antisolvent with an Ultrawide Processing Window for the One-Step 
Fabrication of Efficient and Large-Area Perovskite Solar Cells. Advanced Materials 2018, 30 (49), 1802763.

43. Rong, Y.; Venkatesan, S.; Guo, R.; Wang, Y.; Bao, J.; Li, W.; Fan, Z.; Yao, Y., Critical kinetic control of non-stoichiometric intermediate phase transformation for efficient perovskite solar cells. Nanoscale 2016, 8 (26), 12892-9.

44. Lee, J. W.; Kim, H. S.; Park, N. G., Lewis Acid-Base Adduct Approach for High Efficiency Perovskite Solar Cells. Acc Chem Res 2016, 49 (2), 311-9.

45. Zhang, Y.; Kim, S.-G.; Lee, D.; Shin, H.; Park, N.-G., Bifacial stamping for high efficiency perovskite solar cells. Energy \& Environmental Science 2019, 12 (1), 308-321.

46. Jeon, N. J.; Noh, J. H.; Kim, Y. C.; Yang, W. S.; Ryu, S.; Seok, S. I., Solvent engineering for high-performance inorganic-organic hybrid perovskite solar cells. Nat Mater 2014, 13 (9), 897-903.

47. Paek, S.; Schouwink, P.; Athanasopoulou, E. N.; Cho, K. T.; Grancini, G.; Lee, Y.; Zhang, Y.; Stellacci, F.; Nazeeruddin, M. K.; Gao, P., From Nano- to Micrometer Scale: The Role of Antisolvent Treatment on High Performance Perovskite Solar Cells. Chemistry of Materials 2017, 29 (8), 3490-3498.

48. Deng, Y.; Zheng, X.; Bai, Y.; Wang, Q.; Zhao, J.; Huang, J., Surfactantcontrolled ink drying enables high-speed deposition of perovskite films for efficient photovoltaic modules. Nature Energy 2018, 3 (7), 560-566.

49. Kim, J.-E.; Jung, Y.-S.; Heo, Y.-J.; Hwang, K.; Qin, T.; Kim, D.-Y.; Vak, D., Slot die coated planar perovskite solar cells via blowing and heating assisted one step deposition. Solar Energy Materials and Solar Cells 2018, 179, 80-86.

50. Park, M.; Cho, W.; Lee, G.; Hong, S. C.; Kim, M.-c.; Yoon, J.; Ahn, N.; Choi, M., Highly Reproducible Large-Area Perovskite Solar Cell Fabrication via Continuous Megasonic Spray Coating of CH3NH3PbI3. Small 2019, 15 (1), 1804005.

51. Chen, H.; Ye, F.; Tang, W.; He, J.; Yin, M.; Wang, Y.; Xie, F.; Bi, E.; Yang, X.; Gratzel, M.; Han, L., A solvent- and vacuum-free route to large-area perovskite films for efficient solar modules. Nature 2017, 550 (7674), 92-95. 
52. Zhou, Z.; Wang, Z.; Zhou, Y.; Pang, S.; Wang, D.; Xu, H.; Liu, Z.; Padture, N. P.; Cui, G., Methylamine-Gas-Induced Defect-Healing Behavior of CH3NH3PbI3 Thin Films for Perovskite Solar Cells. Angew Chem Int Ed Engl 2015, 54 (33), 9705-9.

53. Noel, N. K.; Habisreutinger, S. N.; Wenger, B.; Klug, M. T.; Hörantner, M. T.; Johnston, M. B.; Nicholas, R. J.; Moore, D. T.; Snaith, H. J., A low viscosity, low boiling point, clean solvent system for the rapid crystallization of highly specular perovskite films. Energy \& Environmental Science 2017, 10 (1), 145-152.

54. Weller, M. T.; Weber, O. J.; Henry, P. F.; Di Pumpo, A. M.; Hansen, T. C., Complete structure and cation orientation in the perovskite photovoltaic methylammonium lead iodide between 100 and 352 K. Chemical Communications 2015, 51 (20), 4180-4183.

55. Raga, S. R.; Jiang, Y.; Ono, L. K.; Qi, Y., Application of Methylamine Gas in Fabricating Organic-Inorganic Hybrid Perovskite Solar Cells. Energy Technology 2017, $5(10), 1750-1761$.

56. Yang, J.-a.; Qin, T.; Xie, L.; Liao, K.; Li, T.; Hao, F., Methylamine-induced defect-healing and cationic substitution: a new method for low-defect perovskite thin films and solar cells. Journal of Materials Chemistry C 2019, 7 (35), 10724-10742. 


\section{CHAPTER 6. Conclusion and Future Work}

\subsection{Conclusion}

Perovskite NCs have demonstrated attractive and distinctive optoelectronic properties for light-emitting applications. And yet, much remains to be done before they can be implemented in LEDs and digital displays. The lack of material synthesis and limited characterization of perovskite NCs are two major hurdles that need to be overcome in the first place. In this dissertation, the solution-phase synthesis of $2 \mathrm{D}$ organic-inorganic halide perovskite nanocrystals of $\left(\mathrm{C}_{6} \mathrm{H}_{5} \mathrm{C}_{2} \mathrm{H}_{4} \mathrm{NH}_{3}\right)_{2} \mathrm{PbBr}_{4}(\mathrm{PEPB})$ has been demonstrated. PEPB NCs showed a blue-shifted PL peak indicating an increased bandgap which is attributed to the lattice expansion and the quantum confinement effect. The observation of two unique PL peaks suggested the probability of energy or charge transportation between the inorganic framework and the organic cations. The study on its exciton dynamics showed an exciton induced absorption peak with a lifetime of $16.7 \mathrm{ps}$. The discussion on the growth parameters and the study on the optical properties of PEPB NCs have provided valuable insight for developing light-emitting devices based on perovskite nanocrystals.

The performance of PSCs is highly dependent on the structure and crystallinity of the perovskite thin films. Although the one-step spin coating methods have proved its ability to deposit dense, uniform, and highly crystalline perovskite thin films, the antisolvent dripping process makes it less effective towards the scaling up of PSCs. In this dissertation, the preparation of $\mathrm{MA}$-gas-mediated $\mathrm{MAPbI}_{3}$ precursor solution has been demonstrated in the ambient environment. The spin-coated $\mathrm{MAPbI}_{3}$ thin film showed a preferred (110) orientation in the crystal structure and larger crystal grains than that 
deposited by the conventional one-step spin coating method. Compare to the PSC devices fabricated using the conventional one-step spin coating method, devices made by the MAgas-mediated precursor exhibited superior performance. The successful fabrication of highly efficient PSC devices in the air using the MA-gas-mediated precursor suggested the great potential of the MA-gas-mediated precursor solution for depositing large-area high-quality perovskite thin films for PV applications.

\subsection{Future work}

My research in this dissertation has been focused on two parts: the synthesis and PL properties of the perovskite nanocrystals; and optimizing the fabrication method for highly efficient planar perovskite solar cells. Future work can be carried on the following aspects.

The method used to synthesis 2D PEPB NCs can be applied to other layered organic-inorganic halide perovskites. Perovskite NCs have shown distinctive optoelectronic properties due to the quantum confinement, such as the strong PL near the bandgap due to the extensively increased excitonic binding energy, which makes them promising candidates for light-emitting devices and lasing. Further studies could be focused on the PL properties of perovskite NCs at low temperatures to investigate the changes in the electronic band structure due to the quantum confinement effect. Ultrafast laser spectroscopy could also be applied to study the dynamics of photon absorbing, exciton relaxation, and charge carrier recombination.

$\mathrm{MAPbI}_{3}$ thin film deposited by the $\mathrm{MAPbI}_{3} \cdot \mathrm{MA}_{\mathrm{x}}$ precursor solution demonstrated a strong preference in the (110) direction for crystal grain orientations. The same preferred crystal orientation was also observed in $\mathrm{MAPbI}_{3}$ thin films healed by MA 
treatment. The MA-gas-assisted preparation method has also been applied to prepare $\mathrm{MAPbI}_{3}$ precursor solutions for other deposition techniques, including blade coating, Dbar, and pressure processing, which are more applicable than the spin coating method in terms of the roll-to-roll printing of large-scale commercial PSCs. However, the mechanism of the preferred orientation is not fully understood yet. The structure of the clusters of $\mathrm{MAPbI}_{3}$ nanocrystals in the $\mathrm{MAPbI}_{3} \cdot \mathrm{MA}_{\mathrm{x}}$ precursor solution can be modeled computationally, and ultrafast laser spectroscopy can help uncover the early stage of nucleation during drying or degassing of the $\mathrm{MAPbI}_{3} \cdot \mathrm{MA}_{\mathrm{x}}$ precursor solution. $\mathrm{A}$ fundamental and comprehensive understanding of this mechanism would, in all probability, offer valuable insights into clearing the hurdles to commercialization.

A third aspect is to fabricate PSCs based on mixed-organic-cation perovskite, or the Ruddlesden-Popper perovskite, for improved device stability. Layered organicinorganic perovskite material containing $\mathrm{Br}$ and $\mathrm{Cl}$ anions are usually more stable than $\mathrm{MAPbI}_{3}$ or $\mathrm{FAPbI}_{3}$. However, they are generally not very efficient photovoltaic materials due to their larger bandgaps. An absorbing layer consisting of a mixture of 3D-structured $\mathrm{MAPbI}_{3}$ (or $\mathrm{FAPbI}_{3}$ ) and other OIHPs with 2D structures combines the advantages of both material, making it an efficient light-absorbing material with better stability in air. The mixed-organic-cation perovskite materials have not been extensively studied, and the MA-gas-assisted method can be applied to prepare the precursor solution for deposition. An efficient PSC based on the Ruddlesden-Popper perovskite material with high device stability will doubtlessly benefit the field and the commercialization of PSCs as well. 


\section{APPENDICES}

\section{Procedures for the J-V Measurement of Perovskite Solar Cells}

\section{Instrument}
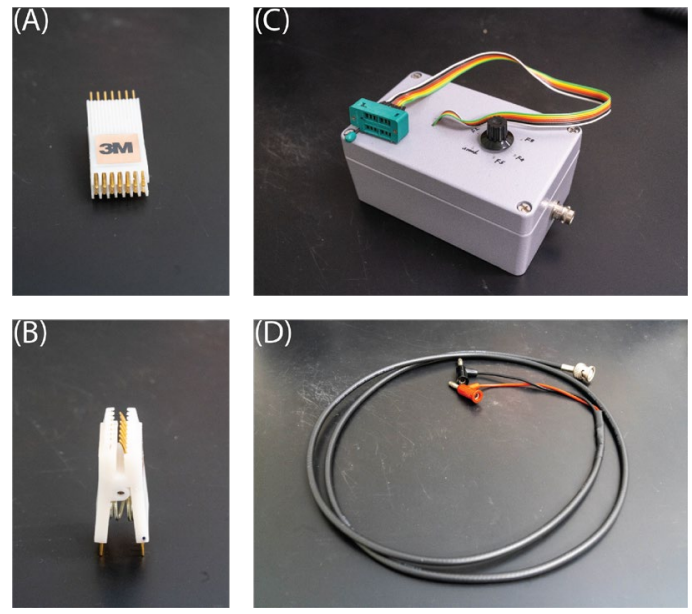

Figure A1 (A) Top view of the 3M test clip. (B) side view of the $3 \mathrm{M}$ test clip. Note that the gold pins on the right side were bent to ensure good electrical contact with the gold electrodes on top of the fabricated PSC devices. (C) Switch box and the DIP socket. (D) Coaxial cable with BNC male plug and dual banana male jacks.

- $\quad$ PC running 64-bit Windows 10 (version 1909 or newer);

- Keithley 2400 SourceMeter SMU;

- Keithley KUSB-488B USB to GPIB converter;

- Solar simulator, New Port, 69907 arc lamp power supply, 67005 arc lamp housing, and 6255 Xenon arc lamp;

- Oriel PV reference cell system (Model 91150V);

- $\quad 3 \mathrm{M}^{\mathrm{TM}} 2 \times 7$ Test Clip Gold Dip .30” (Manufacturer Product Number: 92373914), Figure A1 (A) and (B);

- Switch box connected with $3 \mathrm{M}^{\mathrm{TM}}$ ZIF DIP Socket (Manufacturer Product Number: 214-3339-00-0602J) through ribbon cable, Figure A1 (C);

- Coaxial cable, BNC male plug to dual banana male jack, Figure A1 (D). 


\section{Preparation}

1. Install LabVIEW NXG Runtime (Version 5.0 or newer) on the host PC. The software can be downloaded at the link below.

https://www.ni.com/en-us/support/downloads/software-

products/download.labview-nxg-runtime.html\#346283

Before installation, read the system requirements of the software if necessary.

2. Install driver for KUSB-488B USB to GPIB converter on the host PC. NOTE: when asked about VISA compatible option, make sure to choose 'NI Command Compatible'. At the time of writing, the latest driver is Version

3.13.2, which can be downloaded at the link below.

https://uk.tek.com/accessory/ki-488/3-1-3-2

3. Connect Keithley 2400 SMU to the host PC using the Keithley KUSB-488B. The GPIB port can be found at the back of Keithley 2400 SMU. Read the manual for Keithley 2400 SMU if necessary.

4. Use the coaxial cable to connect the switch box to the INPUT/OUTPUT ports on the front panel of Keithley 2400 SMU.

5. Turn on the solar simulator and do the calibration using the reference cell. Read the user manuals for the 69907 power supply and the $91150 \mathrm{~V}$ reference cell for more information.

\section{Measurement Procedures}

1. Connect the fabricated PSC device to the test clip. In Figure A2, a clean FTO substrate coated with gold electrodes is used as an example. A flat piece of 
plastic is used as a spacer to ensure good electrical contact between the pins and the gold electrodes on the substrate, as shown in Figure A2 (C). Pay close attention to the alignment between the electrodes on the substrate and the gold pins of the test clip. The short electrode on a fabricated PSC device is the back contact deposited directly on FTO. When the test clip is positioned as shown in Figure A2 (D), the short electrode on the substrate should be aligned to the rightmost pin in the test clip. Refer to Figure A2 (E) and (F) for more information if necessary.
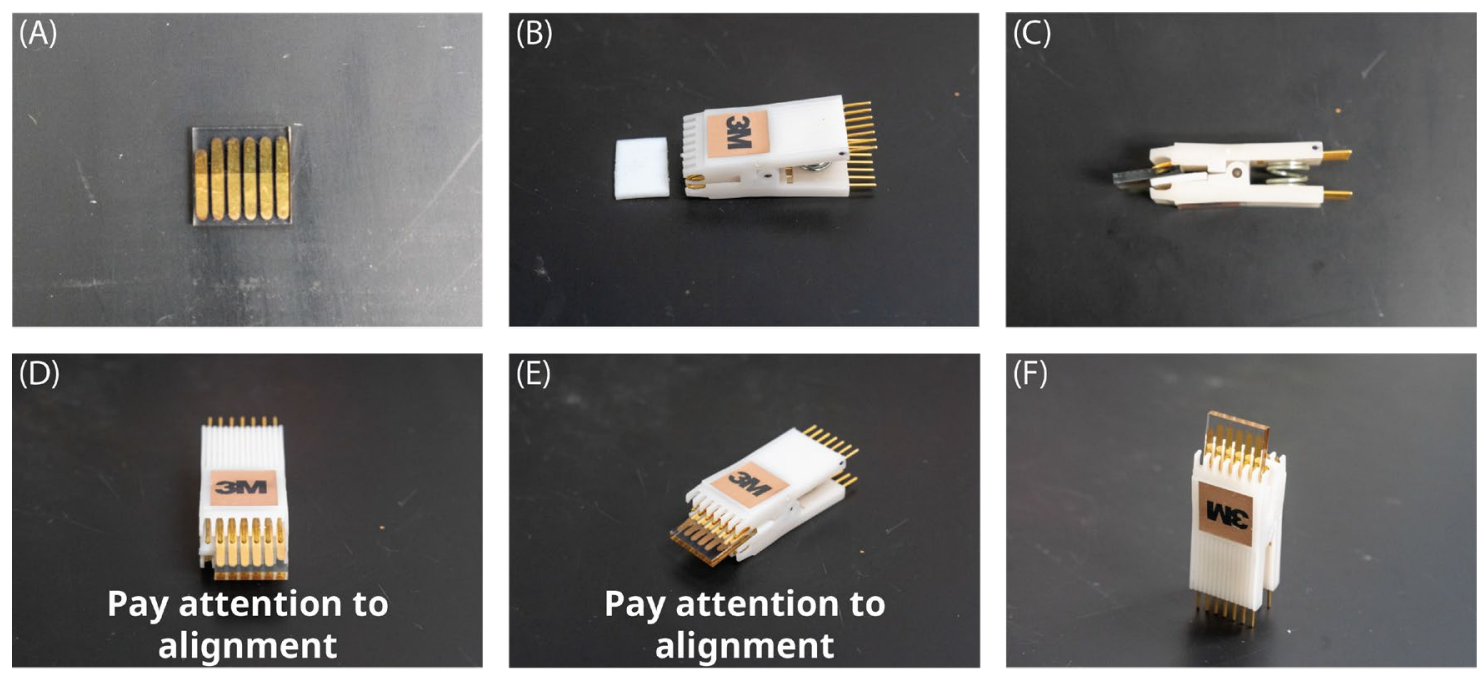

Figure A2 (A) A FTO substrate with gold electrodes deposited on top. (B) A small piece of plastic is used as a spacer to ensure good electric contact between the device and the clip. (C) Side view of the connected clip and substrate. (D) to (F) Views of the connected clip and substrate from multiple angles. Pay attention to the alignment of electrodes and pins.

2. Connect the test clip to the DIP socket, as shown in Figure A3 (A) and (B). Make sure to lock the DIP to secure the test clip. Figure A3 (C) shows the diagram of the complete setup for J-V measurement. 

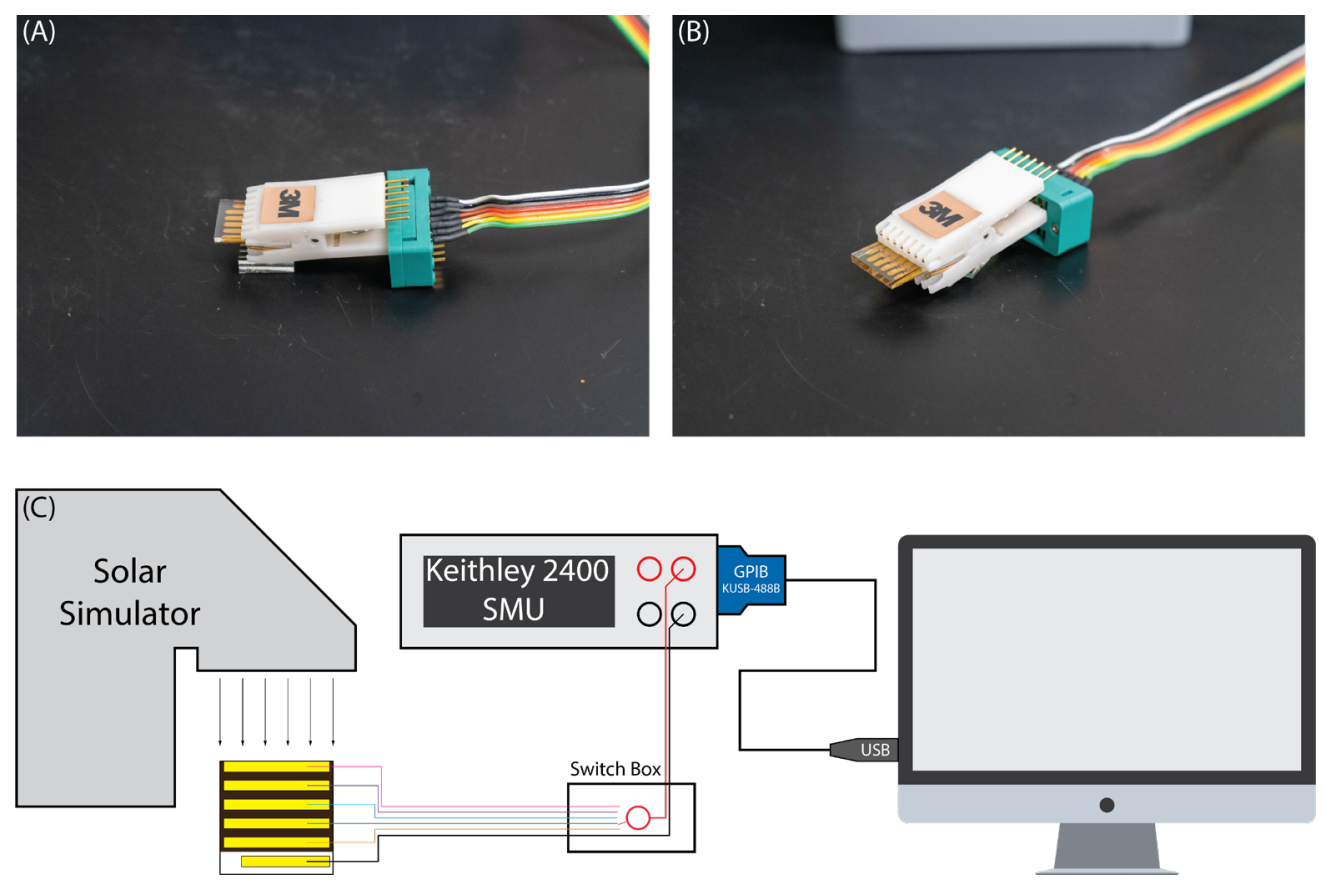

Figure A3 (A) and (B) Views of the test clip and the DIP socket. (C) Diagram of the complete setup for $\mathrm{J}-\mathrm{V}$ measurement.

3. Turn on the Keithley 2400 SMU and the host PC. After logging in, click and run program "Solar NXG 5.exe". The Home page of the main window is shown in Figure A4.

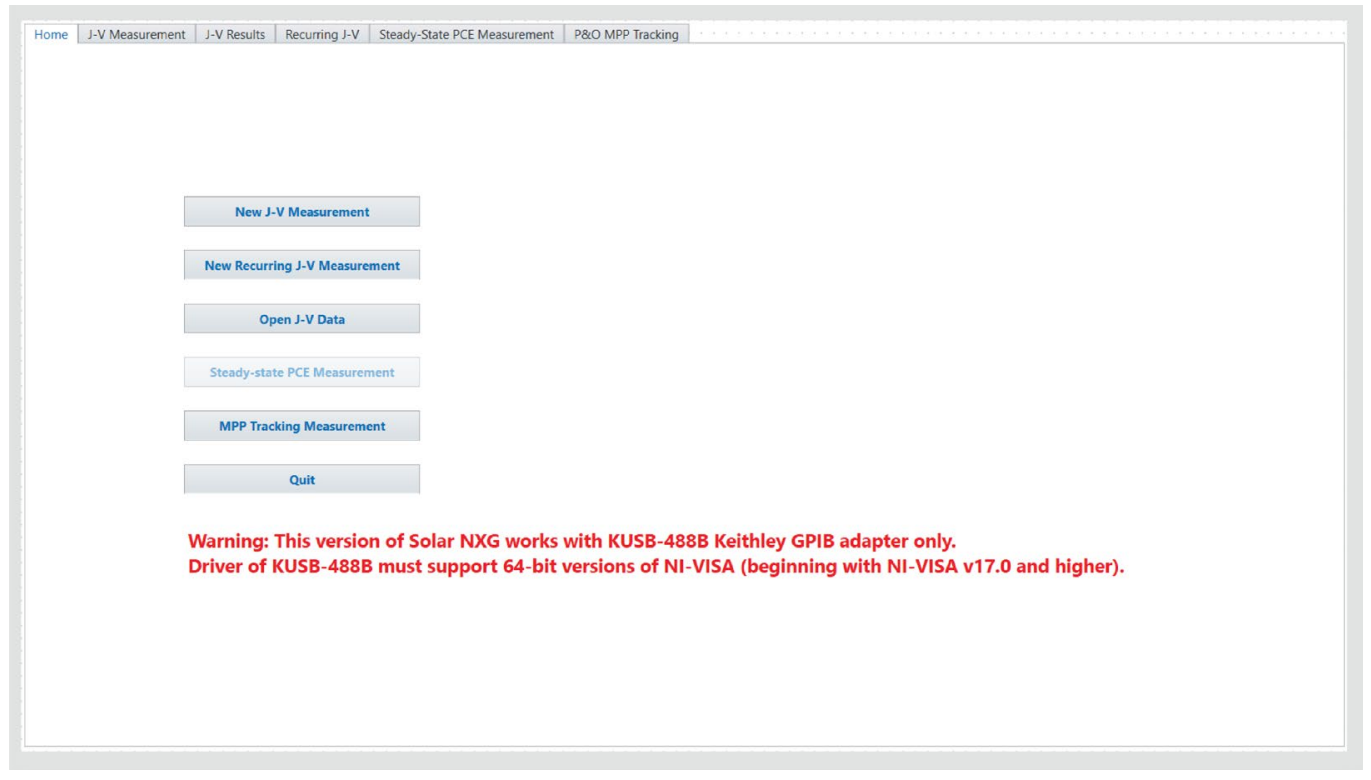

Figure A4 Home page of the program "Solar NXG 5.exe". 
4. Click "New J-V measurement" and the program would change to the "J-V measurement" page, as shown in Figure A5. Follow the steps below to input measurement parameters. Each step is marked at the corresponding position with red numbers in Figure A5.

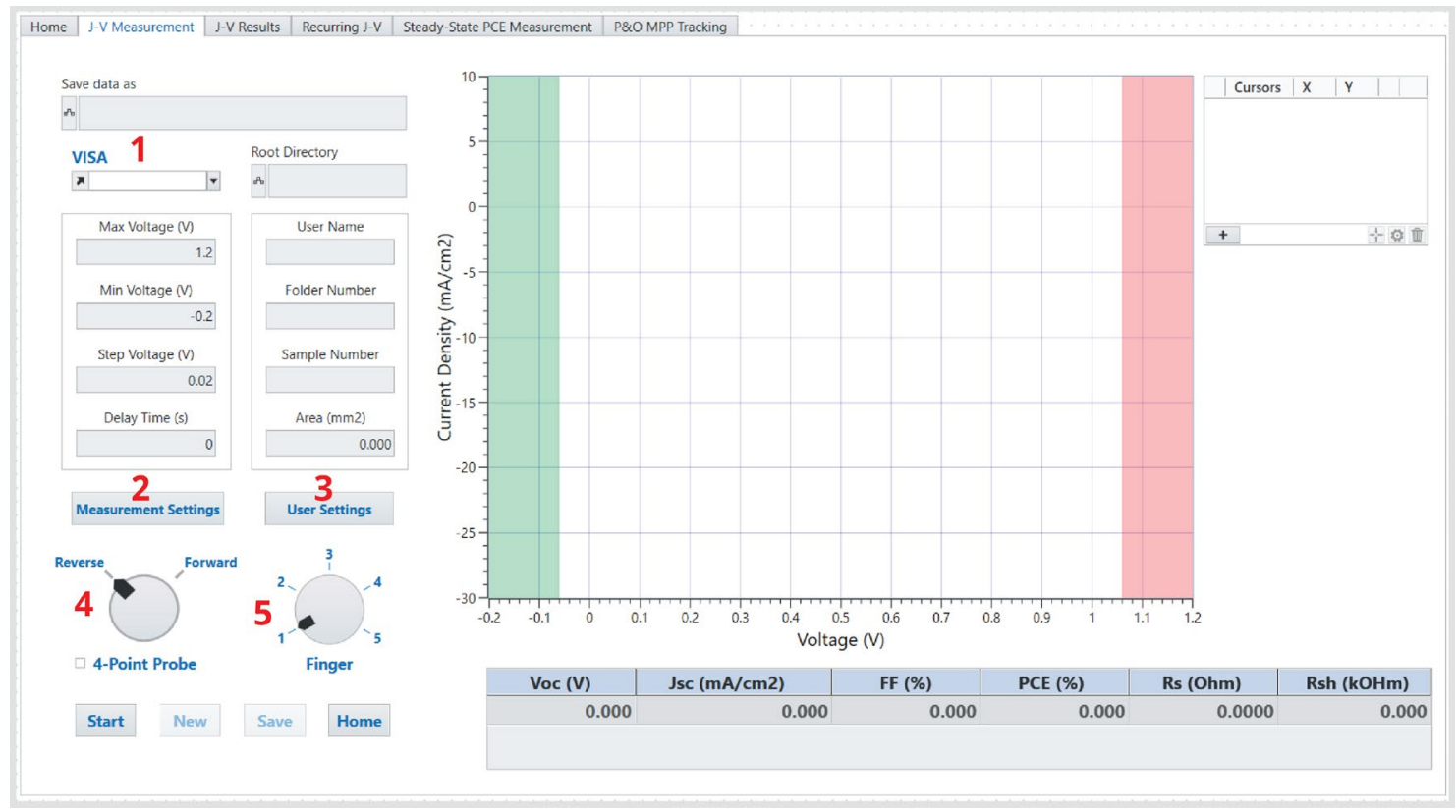

Figure A5 J-V measurement page.

1) Click the "VISA" dropdown menu to select the GPIB card.

2) Click "Measurement Settings" and type in the max voltage, min voltage, step voltage, and delay time in the new window. Click "Save" to confirm and return to the main window. The max and min voltages define the rage of voltage output from Keithley 2400 SMU.

3) Click "User Settings" and choose the root folder's path; type in user name, folder name, sample number, and the area of each device. Click "Save" to confirm and return to the main window. The data will be saved at the pathway shown in the "Save data as" window. 
4) Turn the "Reverse/Forward" switch for reverse or forward measurement. The reverse measurement will start from the maximum voltage and end at the minimum voltage. The forward measurement will start from the minimum voltage and end at the maximum voltage.

5) Turn the "Finger" switch to select which finger to measure. Make sure to turn the switch on the switch box accordingly.

5. Put the sample at the center of illumination. Click "Start" to start the measurement. A new window, as shown in Figure A6, will open to show the real-time $\mathrm{J}-\mathrm{V}$ curve during the measurement process. Click the green button to stop the measurement at any time if necessary.

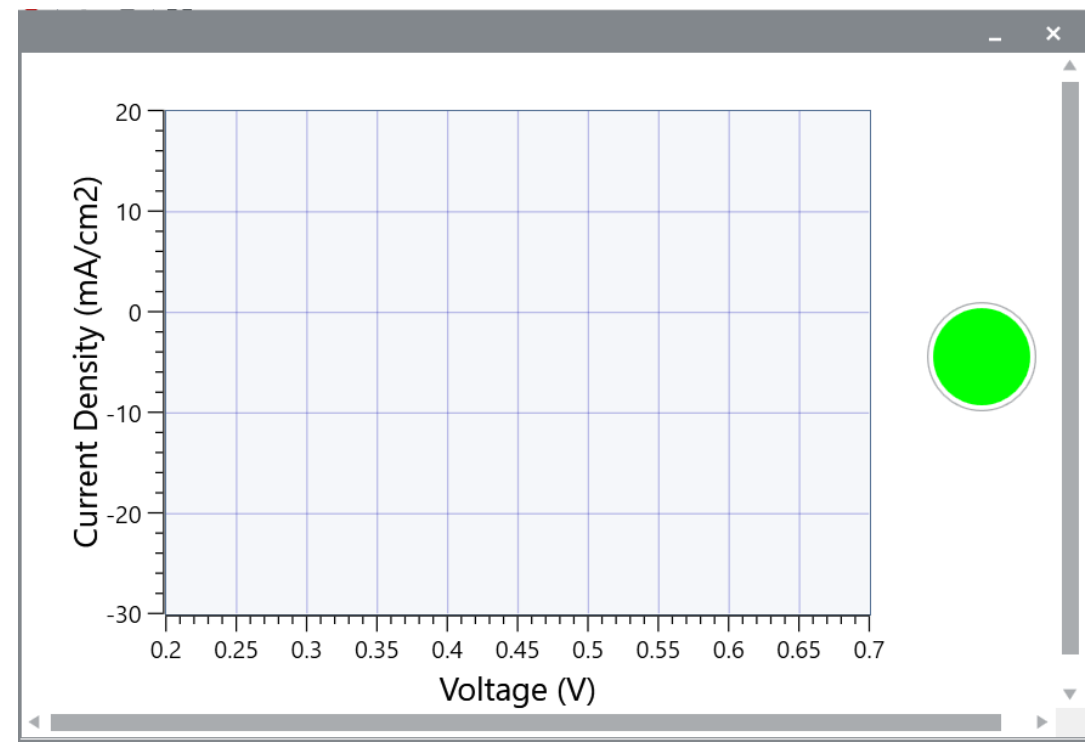

Figure A6 Window for displaying real-time J-V curve during measurement.

6. Once the measurement stops, the program will return to the main window and show the complete $\mathrm{J}-\mathrm{V}$ graph at the center of the window. The performance metrics will be shown in the table below the graph. 
7. Click "Save" to save the data. Or click "New" to change the input parameters and start a new measurement. Note: if "New" is clicked, any unsaved data will be lost. Click "Home" to return to the home page.

8. Once the new J-V curve is saved, the program will change to the "J-V Results" page, as shown in Figure A7. All the measurements saved in the data file will be shown here. Click the check box to choose the measurements and click "Plot" to show the J-V curves. Click "Open New File" to select another data file for view. Click "New J-V" to return to the "J-V Measurement" page. Click "Save table as Excel" to save the data table on the left as an Excel sheet. The Excel sheet will be saved in the same folder as the data file. Click "Quit" to shut down the program.

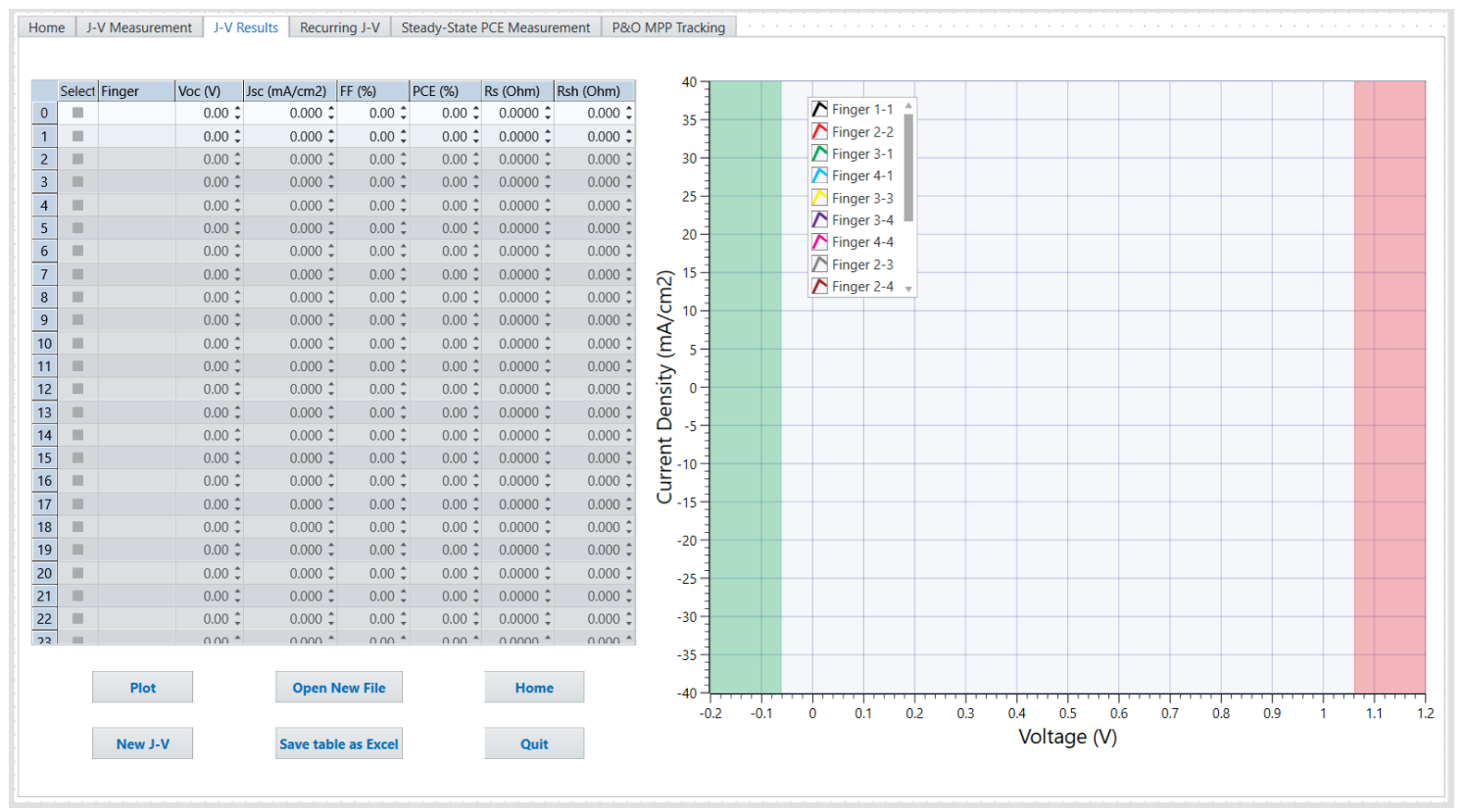

Figure A7 The "J-V Result" page is used for quick comparison between measurements and plotting J-V curves. 


\section{Data File Structure}

The measurement data is saved as "UserName-FolderNumberSampleNumber.tdms" at "root folder directory\User Name\Folder Number". The format of the data file is the NI TDMS file format. A white paper details this file format can be found at the link below. Read it for more information if necessary.

https:/www.ni.com/en-us/support/documentation/supplemental/06/the-ni-tdms-fileformat.html

Scout TDMS Editor is a useful software to view TDMS files. The lite version is free to use and can be downloaded at the link below.

https://sine.ni.com/nips/cds/view/p/lang/en/nid/211879.

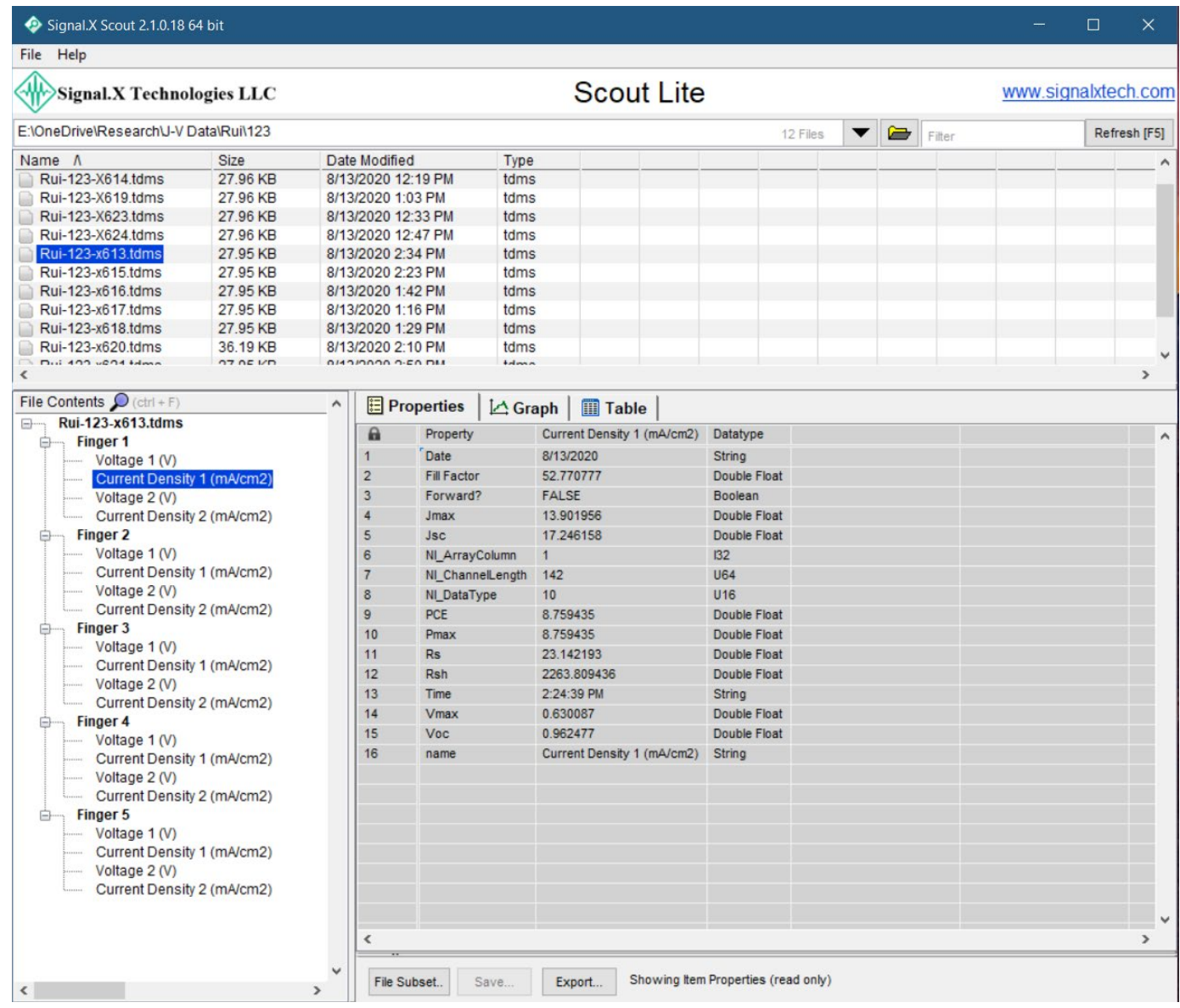

Figure A8 Data file opened in Scout TDMS editor. 
A TDMS file has three levels of hierarchy - file, group, and channel. Each level has its own properties and search-ready data files. Figure A8 shows a data file opened in Scout. The name of each group is the finger number of the fabricated device. Measurements of the same finger are saved in the same group. For every measurement, the voltage and current density are saved in two separate channels. For example, Voltage 1 and Current Density 1 in Finger 1 store the voltage and current density data obtained in the first measurement of Finger 1. Voltage 2 and Current Density 2 in Finger 1 store the voltage and current density data obtained in the second measurement of Finger 1 . The performance metrics calculated by "Solar NXG 5.exe" are stored as the properties of the current density channel, as shown in Figure A8.

The TDMS file can be imported into Origin Pro. For more information about importing TDMS file into Origin Pro, refer to the link below. https://www.originlab.com/doc/X-Function/ref/impNITDM 
VITA

\section{RUI GUO}

Born, Urumqi, China

2008-2012

B.S., Physics

Tsinghua University

Beijing, China

2012-2014

Biochemistry

Florida International University

Miami, Florida

2014-2018

M.S., Physics

Florida International University

Miami, Florida

2015-2016

Visiting scholar University of Houston

Houston, Texas

$2018-2020$

Ph.D. Candidate

Florida International University

Miami, Florida

\section{PUBLICATIONS AND PRESENTATIONS}

Guo, R.; Zhu, Z.; Boulesbaa, A.; Hao, F.; Puretzky, A.; Xiao, K.; Bao, J.; Yao, Y.; Li, W., Synthesis and photoluminescence properties of 2D phenethylammonium lead bromide perovskite nanocrystals. Small Methods, 2017, 1 (10), 1700245.

Guo, R.; Li, W., Perovskite Nanomaterials for solar cells. iScience Notes, 2019, 2.

Yang, M.; Guo, R.; Kadel, K.; Liu, Y.; O'Shea, K.; Bone, R.; Wang, X.; He, J.; Li, W., Improved charge transport of $\mathrm{Nb}$-doped $\mathrm{TiO}_{2}$ nanorods in methylammonium lead iodide bromide perovskite solar cells. J. Mater. Chem. A, 2014, 2, 19616-19622.

Rong, Y.; Venkatesan, S; Guo, R.; Wang, Y.; Bao, J.; Li, W.; Fan, F; Yao, Y., Critical kinetic control of non-stoichiometric intermediate phase transformation for efficient perovskite solar cells. Nanoscale, 2016, 8, 12892-12899.

Thapa, A.; Neupane, S.; Guo, R.; Jungjohann, K.; Pete, D.; Li, W., Direct growth of vertically aligned carbon nanotubes on stainless steel by plasma enhanced chemical vapor deposition. Diamond and Related Materials, 2018, 90, 144-153. 
Thapa, A.; Raj Poudel, Y.; Guo, R.; Jungjohann, K.; Wang, X..; Li, W., Direct synthesis of vertically aligned carbon nanotubes on stainless-steel and their excellent firld emission properties. Carbon, 2021, 171, 188-200.

Zhu, Z.; Hadjiev, V.; Rong, Y.; Guo, R.; Cao, B.; Tang, Z.; Qin, F.; Li, Y.; Wang, Y.; Hao, F.; Venkatesan, S.; Li, W.; Baldelli, S.; Guloy, A.; Fang, H.; Hu, Y.; Yao, Y.; Wang, Z.; Bao, J., Interaction of organic cation with water molecule in perovskite MAPbI3: from dynamic orientation disorder to hydrogen bonding. Chem. Mater., 2016, 28 (20), 7385-7393.

2020 Material Research Society, Spring Meeting and Exhibit, Apr.13-17, 2020, Phoenix, AZ, USA. Presentation: Ambient Processed (110) Preferred MAPbI 3 Thin Films for Highly Efficient Perovskite Solar Cells. Canceled due to COVID-19.

2017 American Physical Society, March Meeting, Mar.13 - 17, 2017, New Orleans, LA, USA. Presentation: Synthesis and photoluminescence properties of $2 \mathrm{D}$ phenethylammonium lead bromide perovskite nanocrystals. 